\title{
Maintaining the stemness of satellite cells during long- term culture
}

Citation for published version (APA):

Ding, S. (2019). Maintaining the stemness of satellite cells during long-term culture. [Doctoral Thesis, Maastricht University]. ProefschriftMaken Maastricht. https://doi.org/10.26481/dis.20190327sd

Document status and date:

Published: 01/01/2019

DOI:

10.26481/dis.20190327sd

Document Version:

Publisher's PDF, also known as Version of record

\section{Please check the document version of this publication:}

- A submitted manuscript is the version of the article upon submission and before peer-review. There can be important differences between the submitted version and the official published version of record.

People interested in the research are advised to contact the author for the final version of the publication, or visit the DOI to the publisher's website.

- The final author version and the galley proof are versions of the publication after peer review.

- The final published version features the final layout of the paper including the volume, issue and page numbers.

Link to publication

\footnotetext{
General rights rights.

- You may freely distribute the URL identifying the publication in the public portal. please follow below link for the End User Agreement:

www.umlib.nl/taverne-license

Take down policy

If you believe that this document breaches copyright please contact us at:

repository@maastrichtuniversity.nl

providing details and we will investigate your claim.
}

Copyright and moral rights for the publications made accessible in the public portal are retained by the authors and/or other copyright owners and it is a condition of accessing publications that users recognise and abide by the legal requirements associated with these

- Users may download and print one copy of any publication from the public portal for the purpose of private study or research.

- You may not further distribute the material or use it for any profit-making activity or commercial gain

If the publication is distributed under the terms of Article $25 \mathrm{fa}$ of the Dutch Copyright Act, indicated by the "Taverne" license above, 


\section{Maintaining the stemness of satellite cells during long-term culture}

Shijie Ding 
(C) Shijie Ding, Maastricht, 2019

Cover picture: www.photophoto.cn

Lay-out: Bianca Gorski-Feenstra

Printing: ProefschriftMaken / www.proefschriftmaken.nl

ISBN: 978-94-6380-268-0 


\title{
Maintaining the stemness of satellite cells during long-term culture
}

\author{
PROEFSCHRIFT \\ Ter verkrijging van de graad van doctor \\ aan de universiteit Maastricht, \\ op gezag van de Rector Magnificus, Prof. dr. Rianne M. Letschert, \\ volgens het besluit van het College van Decanen, \\ in het openbaar te verdedigen op \\ woensdag 27 maart 2019 om 16:00
}

door

Shijie Ding 


\section{Promotoren}

Prof. dr. M.J. Post

Prof. dr. G.H. Zhou

\section{Beoordelingscommissie}

Prof. dr. E.C.M. Mariman, Humane Biologie, FHML (chair)

Prof. dr. M.C. Harmsen, UMCG

Prof. dr. C. Reutelingsperger, Biochemie, FHML

Dr. C. Neuhoff, University of Bonn

Dr. R.Langen, Pulmonology, FHML

The research presented in this dissertation was sponsored by grants from National Center of Meat Quality and Safety Control, Ping's lab, China Scholarship Council, Royal Netherlands Academy of Arts and Sciences and Mosa Meat.

Additional financial support for the publication of this thesis from Mosa Meat is gratefully acknowledged. 


\section{Contents}

Chapter $1 \quad$ General introduction

Chapter 2 Characterization and isolation of highly purified porcine satellite cells

Chapter $3 \quad$ Maintaining bovine satellite cells stemness through p38 pathway

Chapter $4 \quad$ Regulation of STAT3 signal in differentiation and longterm culturing of bovine muscle stem cells

Chapter $5 \quad$ Loss of stemness in satellite cells during subculturing 109 is distinct from loss of stemness by differentiation

Chapter $6 \quad$ Proteomics of bovine muscle stem cell aging

Chapter $7 \quad$ General discussion, future perspectives and conclusion

Summary/samenvatting

Valorization

Acknowledgement

Curriculum Vitae

193

Publications and grants 



\title{
Chapter 1
}

\author{
General introduction
}



Meat is one of the most important dietary components in the evolution of man. Animal source foods are suggested to help the evolving man achieve their unusually large and complex brain while simultaneously continuing their evolutionary trajectory as large, active and highly social primates ${ }^{1}$. The macronutrients (including different proteins, fatty acids, carbohydrates) and micronutrients (including heme iron, vitamins) in the meat and meat products can provide some key elements in the diet of $\operatorname{man}^{2-4}$. On the other hand, processed meat and red meat were recently found to have a positive association with several cancers ${ }^{5}$. Notwithstanding, meat is still important for a balanced human food system².

However, the traditional animal agriculture has a substantial contribution to climate change and air pollution, to land, soil and water degradation and to the reduction of biodiversity ${ }^{6}$. Several credible alternatives to livestock meat have been developed. Among them is cultured meat, which should be efficiently produced and should mimic all of meat's physical sensations ${ }^{7}$.

Cultured meat is produced by muscle specific stem cells obtained from a donor animal. Outside of the body, these cells can multiply and form muscle and fat tissue through the process of tissue engineering. It is a technology with the potential ability to solve traditional animal agriculture problems ${ }^{8}$. Even though it still requires time and effort to present cultured meat on the plate of consumers, the technology is available as shown by a proof of concept ${ }^{8,9}$.

Satellite cells (muscle stem cells) are one of the promising cell sources for cultured meat production ${ }^{7,9,10}$. Purified satellite cells can proliferate and differentiate into myotubes during in vitro culture ${ }^{11-14}$ and finally form 3D muscle tissue in vitro ${ }^{9,15,16}$. However, muscle stem cells will gradually lose proliferation and differentiation ability during in vitro culture ${ }^{13,14,17}$. Understanding the biological process during cultivation of muscle stem cells and looking for a strategy to maintain the proliferation and differentiation abilities is the major goal of the work presented in this PhD thesis.

\section{The challenges of traditional livestock}

According to the United Nations, the global population has reached 7.6 billion in 2017 and will reach 9.8 billion in $2050^{18}$. The overall world meat production already reached 317 million tons in $2016^{19}$ and may reach 465 million tons in $2050^{20}$, an increase of $45 \%$. This is mostly caused by the rapidly rising incomes and urbanization, combined with underlying population growth in many developing countries ${ }^{21}$. For example, China's total production of raw meat has increased at an annual average rate of $5.8 \%$ from 1990-2009. In 2009, China was the world's largest producer of meat with 78.21 million tons ${ }^{22}$. The predicted increase in demand for meat and other animal products is becoming a big issue for the environment. 
Expansion of livestock production causes deforestation and land degradation ${ }^{20}$. Overgrazing already causes land degradation to some extent in about $20 \%$ of the world's pastures and rangelands ${ }^{20}$. The livestock is also responsible for $18 \%$ of greenhouse gas emissions ${ }^{20}$. Livestock farming accounts for about $9 \%$ of man-made carbon dioxide, $37 \%$ of methane, $65 \%$ of nitrous oxide and about two-thirds of ammonia emissions, respectively ${ }^{20}$. The livestock sector also accounts for over $8 \%$ of global fresh water use $^{20}$. The unprecedented threat to biodiversity is also partly induced by the expanding livestock sector ${ }^{20}$. Altogether, the current livestock sector is not environmentally sustainable and would be even less so in the future.

The increasing concern about animal welfare is another problem in livestock. Because of the gap between the meat production and consumption, animal farmers paid more attention to economics and yield per animal, then to animal welfare and animal behavior ${ }^{7,23}$. However, welfare-friendly products are more popular and consumers are willing to pay more (e.g.: free range vs caged egg) ${ }^{23}$. Thus, public concern about animal welfare may change the animal production practices in the future ${ }^{7,23}$.

Human and livestock health is also a common concern in the livestock sector. On one hand, livestock provide a full complement of nutrients in human diets; on the other hand, processed meat and red meat are found to have a positive association with several cancers, coronary heart disease and type 2 diabetes ${ }^{2,4}$. The overuse of veterinary drugs and antibiotics also threaten human health through the rise of antibiotic-resistant strains of micro-organisms ${ }^{6}$. In addition, the frequent eruptions of animal diseases can reduce production and productivity, disrupt local and national economies, threaten human health and exacerbate poverty ${ }^{21,24}$.

The imbalance between a growing livestock meat demand and limited natural resources drives the action towards far-reaching change. One of the actions is to look for efficiency gains in resource use, promoting industrialization of livestock production ${ }^{20}$ and reducing waste of food ${ }^{25}$. Another way is to reduce meat calories by using alternative sources of protein ${ }^{7,19}$, such as plant and insect protein ${ }^{7,26-28}$. Cultured meat is a potential technology, which can partially solve major upcoming problems by traditional livestock $k^{7,8,29}$.

\section{The history of cultured meat}

Winston Churchill wrote in his book Thoughts and Adventures (1932) "...Fifty years hence, we shall escape the absurdity of growing a whole chicken in order to eat the breast or wing, by growing these parts separately under a suitable medium..." ${ }^{\prime 30}$. With the development of knowledge in muscle development ${ }^{31,32}$, tissue engineering ${ }^{33-35}$ and stem cell biology ${ }^{11,36-38}$, cultured meat has been proven as a concept in $2013^{9}$. Table 1 lists the events in cultured meat history. 
Table 1. Events in cultured meat history

\begin{tabular}{|c|c|}
\hline Time & Event \\
\hline 1930s & $\begin{array}{l}\text { Winston Churchill suggest growing chicken meat under a suitable } \\
\text { medium. }{ }^{30}\end{array}$ \\
\hline 1960s & $\begin{array}{l}\text { Description of muscle development }{ }^{39} \text {. Embryonic muscle cells can } \\
\text { proliferate and differentiate in vitro. }\end{array}$ \\
\hline 2000 & $\begin{array}{l}\text { Bio-artificial muscles (BAMs) produced from the skeletal muscle } \\
\text { resident stem cells for medical usage }{ }^{33} \text {. }\end{array}$ \\
\hline 2002 & $\begin{array}{l}\text { America National Aeronautics and Space Administration (NASA) } \\
\text { supported research on cultured gold fish for space missions }{ }^{40} \text {. }\end{array}$ \\
\hline 2001-2007 & $\begin{array}{l}\text { The Dutch government supported cultured meat research at } \\
\text { Amsterdam University, Utrecht University and the Eindhoven } \\
\text { University of Technology }{ }^{41} \text {. }\end{array}$ \\
\hline 2004 & $\begin{array}{l}\text { New Harvest is established in } 2004 \text {, aimed at building the field of } \\
\text { cellular agriculture including cultured meat. }\end{array}$ \\
\hline 2008 & The first "In vitro Meat Symposium" in 2008 , held in Norway. \\
\hline 2013.08 & $\begin{array}{l}\text { Professor Mark Post presented the first cultured beef hamburger } \\
\text { in London, 2013. It is the proof of concept that cultured meat } \\
\text { could work'. }\end{array}$ \\
\hline 2015.10 & $\begin{array}{l}\text { Mark Post and Peter founded the cultured meat company } \\
\text { MosaMeat B.V. in the Netherlands. }\end{array}$ \\
\hline 2015 & $\begin{array}{l}\text { Uma Valeti and Nicholas Genovese founded the cultured meat } \\
\text { company Memphis Meats in } 2015 \text { in America. }\end{array}$ \\
\hline 2016 until now & $\begin{array}{l}\text { More than } 30 \text { companies already founded to start cultured meat } \\
\text { research. }\end{array}$ \\
\hline
\end{tabular}

\section{The basic structure, composition, quality of meat}

After slaughtering, the carcass contains muscle tissue, fat tissue, connective tissue and bone. About $50-60 \%$ is muscle tissue and this is the most important part for raw meat and meat processing ${ }^{42}$. Skeletal muscle tissue consists of approximately $90 \%$ muscle fibers and $10 \%$ connective and $\mathrm{fat}^{43}$. The basic structure of muscle tissue has been clearly characterized ${ }^{44}$. The general structure of muscle is separated by three basic membranes. The endomysium separates the individual muscle fibers, the perimysium delineated fascicles within the muscle and the epimysium encases the entire muscle ${ }^{45}$. The blood vessels, major nerves and extracellular matrix support muscle function by providing oxygen, energy, contraction stimuli and mechanical support. The general 
composition of muscle is $75 \%$ water, $19 \%$ protein, $3.5 \%$ of soluble, nonprotein, substances including inorganic compounds, and $2.5 \%$ of fat ${ }^{46}$. The proteins can be divided into the sarcoplasmic proteins, the myofibrillar proteins, the proteins of the connective tissue and other structures ${ }^{46}$. Fat tissue is another important tissue in the carcass. Depending on species and anatomical location of the muscle, adipose tissue accounts for about 3\%-45\% of the carcass, and intermuscular fat content generally ranges from $1 \%$ to $11 \%{ }^{4,47}$. Connective tissue accounts for about $10 \%$ to $20 \%$ of the carcass and intramuscular connective tissue accounts for about $10 \%$ of skeletal muscle $\mathrm{e}^{46,48}$. It is mainly composed of collagen, elastin and reticular protein.

The sensory quality of meat during eating is determined by color, tenderness, flavor, water-holding capacity, juiciness and taste. Meat quality is strongly affected by muscle composition such as protein, fat and connective tissue. The sarcoplasmic protein myoglobin is the heme containing molecule that is responsible for meat color ${ }^{49}$. For instance, tenderness of meat is determined by intramuscular proteins such as structural and non-structural proteins, proteins in connective tissue, but also by the amount of intramuscular fat ${ }^{50}$. The peptides and amino acid content, free fatty acids as well as nucleotides are contributing to the overall flavor and are appreciably modified during cooking and meat processing ${ }^{51}$. The degradation of thiamine (vitamin B1), glycogen, sugars, and organic acids during heating also affects meat flavor ${ }^{51}$. Water-holding capacity is related to the structural and sarcoplasmic proteins in the muscle, but also to the fat content and strongly determines juiciness ${ }^{52}$. For cultured meat to be a credible mimic of conventional meat, these specific qualities should be considered.

\section{The potential production way for cultured meat industry}

As the producer of the world's first cultured beef item, Mark Post described the process to make the burger ${ }^{9}$. They took a biopsy from a cow and retrieved the satellite cells. The cells were expanded in a traditional cell culture system requiring culture medium and serum, until a sufficient number of cells $\left(>10^{10}\right)$ was obtained. In packages of about 1.5 million, cells were then taken up in a collagen/Matrige ${ }^{\mathrm{TM}}$ gel that was deposited in a culture dish around a central column of agarose gel. In this environment, the cells self-organized into a donut-shaped muscle fiber of $1 \mathrm{~mm}$ thick and matured towards a protein-rich muscle fiber as a result of contraction, compaction and the development of tension. After 3 weeks this maturation process was complete and the muscle fibers were harvested. For the $85 \mathrm{~g}$ of the world first cultured hamburger, they used 10,000 of these muscle strips ${ }^{9}$.

Van der Weele $\mathrm{C}$ and her colleagues summarized the potential flow chart of cultured meat industry production ${ }^{53}$. 
Figure 1. A potential production process for cultured meat

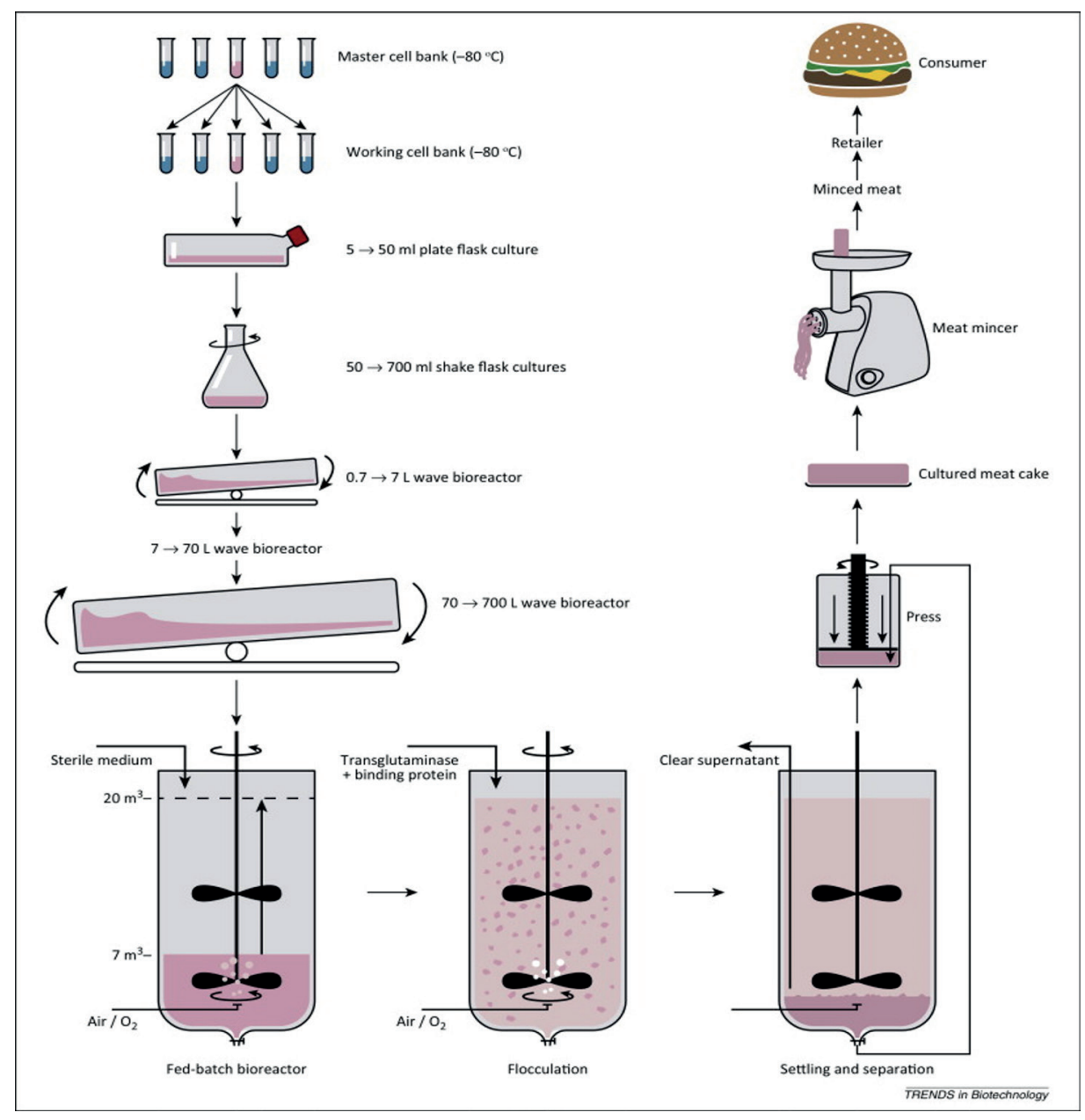

\section{Cell sources for cultured meat}

In the field of biomedicine, the isolation and expansion of muscle stem cells ${ }^{11,13,14}$, and differentiation in three-dimensional condition $s^{54,55}$ are now feasible at laboratory scale. However, turning cultured meat into a commercial product still requires additional technical efforts to improve and complement the product and make it scalable, efficient and cost-effective ${ }^{8}$.

Cultured meat is based on cell culture. There are several requisites for good cell 
candidates. The cells should be easy to harvest and have substantial expansion and differentiation capacity in vitro. The serum-free/chemically defined medium needs to be available for this cell type or one should be able to develop this. The differentiation ability to myotubes should be relatively high for those cells. They should be genetically stable after multiple divisions.

\subsection{Other cell sources and their advantages and disadvantages}

Several cell types have the potential to form myotubes and muscle fibers and are therefore candidates for cultured meat production. Embryonic stem Cells (ES) or induced pluripotent stem cells (iPS) have the ability to differentiate into any cell type and can propagate seemingly interminable ${ }^{56-59}$. In addition, there are reported methods to culture these cells under xeno-free and chemically defined conditions ${ }^{60}$. However, the method to induce ES/iPS to myoblasts or myotubes is still complicated and not very efficient ${ }^{59,60,61}$ and protocols for livestock animals are still rare ${ }^{62}$.

Mesenchymal stem cells (MSC) can be extensively expanded and they are multipotent, i.e. capable of differentiating into various lineages, notably fat, bone and cartilage ${ }^{63,64}$. MSCs can also expand in commercially available xeno-free and chemically defined medium ${ }^{63,65}$. However, the myogenic differentiation of MSC is relatively low ${ }^{64}$. It remains to be determined if this is species and origin dependent.

A host of other cells have reportedly potential to form myotube, such as myoendothelial cells, stem cell biomarker CD133+ cells, cell stress mediator PW1 positive interstitial cells (PICs), muscle-derived stem cells, Twist $2^{+}$progenitor cells, and muscle side population cells. However, All of myoendothelial cells, CD133+ cells, PICs, muscle-derived stem cells and muscle side population cells contain the satellite cell population ${ }^{66-71}$. Even though the TWIST2 ${ }^{+}$cells are distinct from PAX7 $7^{+}$satellite cells in vivo, they quickly upregulate PAX7 and MYOD expression after culturing in vitro, which suggesting TWIST2 ${ }^{+}$cells are the progenitor cell of myoblast ${ }^{72}$. These results suggest that the myogenesis ability of these cells are from the satellite cells or myoblast cells when cultured in vitro ${ }^{69,71}$.

\subsection{Satellite cells as the cultured meat cell source}

The muscle stem cells (MuSCs; also known as satellite cells) are a heterogeneous population of adult stem cells located in skeletal muscles ${ }^{11,73-75}$. They were first identified by Mauro in $1961^{38}$. These cells reside between the muscle sarcolemma and the basal lamina of muscle fibers and remain quiescent under normal conditions ${ }^{11,73,76,77}$. Upon injury, quiescent satellite cells are activated to repair muscle injury while a subset of the activated satellite cells return to the quiescent status after self-renewal ${ }^{11,73,78}$. Satellite cells are essential for muscle regeneration and mice lacking satellite cells display severe muscle regeneration defects ${ }^{79,80,81}$. Satellite cell impairment occurs in muscular diseases such as Duchenne muscular dystrophy (DMD) $)^{82}$ and in aged muscles ${ }^{83}$. 
Satellite cells are an ideal cell source to produce cultured meat. However, it is very important to define and purify the satellite cells since most other cells in culture grow faster than satellite cells, so that the latter will eventually be outnumbered ${ }^{14,84-86}$. Satellite cells are specific mononuclear cells in muscle by expression of the canonical satellite cell regulator, paired box protein 7 (PAX7) ${ }^{73,87}$. The majority of quiescent satellite cells express myogenic factor 5 (MYF5) mRNA but the translation seems to be inhibited $^{74,88,89}$. Both myogenic determination protein (MyoD) mRNA and protein are not detected in quiescent satellite cells ${ }^{90}$. During activation, these cells start to express MYOD and MYF5, and are subsequently called activated satellite cells or myoblasts ${ }^{74,91-93}$. Other transcription factor markers are used to distinguish between activated satellite cells and myoblasts. Activated satellite cells still express PAX7 protein ${ }^{94}$ while myoblast consist of both $\mathrm{PAX7}{ }^{+} \mathrm{MYOD}^{+}$or $\mathrm{PAX7} \mathrm{MYOD}^{+}$cell populations ${ }^{95}$. Further differentiation is regulated by the downregulation of PAX7 and de novo expression of MYOGENIN (also known as MYOG) $)^{73,96,97}$. These cells are then called myocytes ${ }^{94,95}$ (Figure 2). The next stage in differentiation is the terminally differentiated myotube that expresses myosin heavy chain (MyHC) and muscle specific creatin kinase (MCK $)^{97}$.

Figure 2. Regulator markers for quiescent satellite cells, activated satellite cells, myoblasts and myocytes. Adapted from Norio Motohashi and Atsushi Asakura ${ }^{94}$.

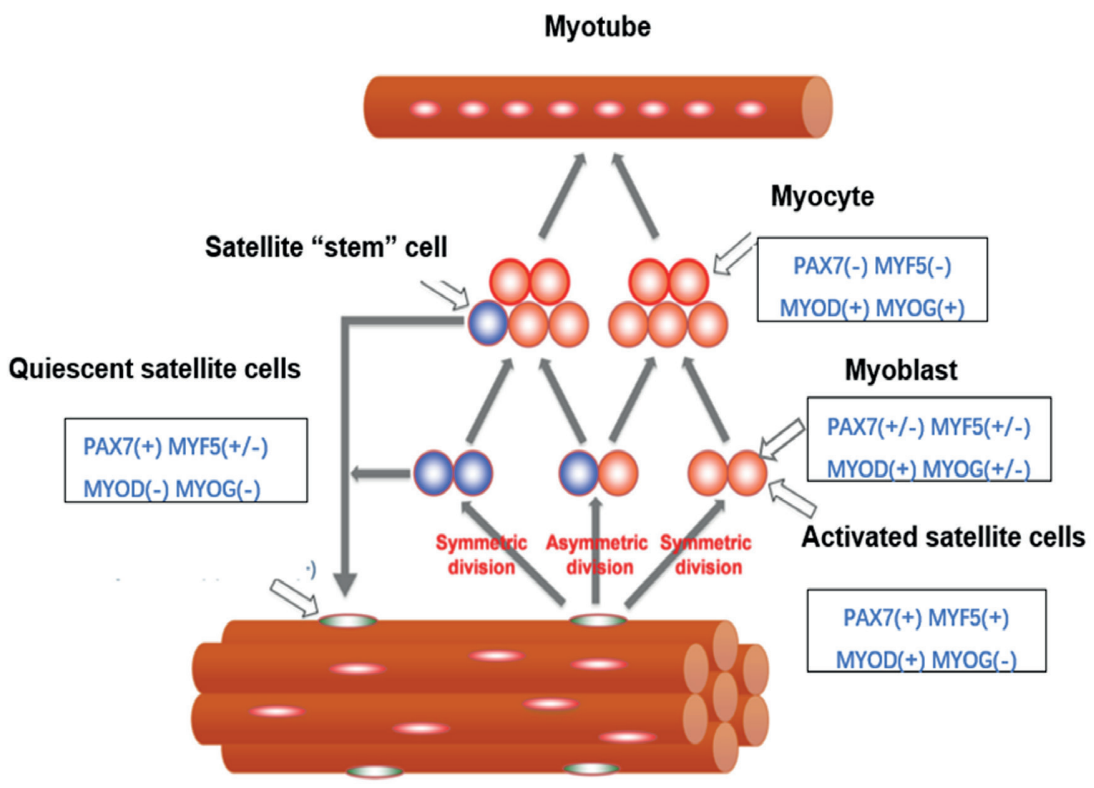


Several surface markers are identified for satellite cells in mice and human. Mice satellite cells express vascular cell adhesion molecule 1 (VCAM1), C-X-C chemokine receptor type 4 (CXCR4), $\beta 1$-integrin, CD34 and $\alpha 7$-integrin ${ }^{85}$. They do not express CD31, CD11b, CD45 and Sca1 ${ }^{11,85}$. Human satellite cells are positive for CD56, CD29 and epidermal growth factor receptor (EGFR). They don't express CD31, CD45 or mouse satellite cell marker CD34 ${ }^{14,98}$. Highly purified mouse and human satellite cell population can be obtained by FACS sorting and this protocol is well described ${ }^{11,14,85,99}$. However, for most livestock species, the method to FACS purify satellite cells is not well established. Thus, it is necessary to develop a robust method to obtain and define highly purified satellite cells.

\section{Maintaining the stemness of satellite cells}

It has been reported that long term cultivation of mouse ${ }^{13,100}, \operatorname{dog}^{101}$, or human ${ }^{14}$ satellite cells in vitro results in loss of most of the regenerative potential after transplantation back into mouse. The differentiation abilities in vitro also show defects after longterm culture ${ }^{102-104}$. Several intracellular signaling pathways have been implicated in maintaining stemness or conversely, move the cells towards a differentiated lineage or senescence.

\section{1 p38 MAPK signal pathway}

Further maintenance of satellite cell stemness can depend on cell signaling during proliferation. p38, a subgroup of the Mitogen-activated protein kinase (MAPKs), that can be activated by stress signals, inflammatory cytokines, and many other stimuli has been implicated in cell proliferation, senescence, apoptosis and other cellular processes ${ }^{105,106}$. The $p 38 \alpha / \beta$ MAPK signaling pathway regulates asymmetric division of satellite cells ${ }^{107}$. One daughter cell activates $\mathrm{p} 38 \alpha / \beta$ MAPK, induces $M y o D$ expression and generates a proliferating myoblast ${ }^{107}$. In the other daughter cell $p 38 \alpha / \beta$ MAPK signaling is not activated, $M y o D$ is not induced, and the fate of the cell is directed towards a quiescent satellite cell that maintains the stem cell pool ${ }^{107}$.

Previous studies have noted that p38-MAPK signaling plays an important role in the loss of stemness in satellite cells ${ }^{14,106,108,109}$. Acute injury in p38 $\alpha$-deficient mice resulted in a prolonged satellite cell response and an increased stem cell pool ${ }^{109}$. Conversely, elevated activity of $\mathrm{p} 38 \alpha / \beta$ MAPK signaling induced regenerative defects in older satellite cells compared with younger ones ${ }^{108}$. In the same model, inhibition of $p 38 \alpha / \beta$ MAPK signaling and culture on soft hydrogel substrates rejuvenated older satellite cells' potential for regeneration ${ }^{108}$. The $\mathrm{p} 38$-MAPK may play an important for long-term cultured myoblast cells. 


\subsection{JAK2-STAT3 signal pathway}

Janus kinase (JAK)-signal transducer and activator of transcription (STAT) pathway is known to have a critical role in cell growth, proliferation and differentiation in many cell types ${ }^{110-112}$, In mammals, the JAK family kinases include four members (JAK1, JAK2, JAK3 and TYK2 (tyrosine kinase 2)), whereas the STAT family have seven (STAT1, STAT2, STAT3, STAT4, STAT5A, STAT5B and STAT6) ${ }^{113,114}$.

The JAK-STAT pathway is not only important in regulating skeletal muscle mass, repair, aging and diseases in vivo ${ }^{114}$, but also can positively regulate the differentiation of satellite cells and myoblasts in vitro ${ }^{115}$. Following acute muscle damage, IL-6-induced activation of STAT3 signaling is essential for satellite cell activation and muscle regeneration ${ }^{116,117}$. Two recent studies reported that JAK2-STAT3 signaling in muscle stem cells induce myogenic differentiation to the detriment of their expansion ${ }^{118-120}$. Knockdown of STAT3 in satellite cells decreased the expression of both MyoD and Myog ${ }^{120,121}$, thus demonstrating the pivotal role of STAT3 in satellite cell myogenic progression. In myoblasts, JAK1-STAT1-STAT3 plays a notable role in proliferation, whereas JAK2-STAT3 and JAK3 function mainly in differentiation ${ }^{112,115,122}$. In summary, the JAK2-STAT3 signaling has double-edged effects in muscle regeneration and satellite cell function. Its role in long-term cultured myoblast still needs further research.

\subsection{Loss of stemness is due to differentiation?}

Several signals are up-regulated during satellite cell activation, such as p38 MAPK ${ }^{69,123,124}$ and JAK-STAT signals ${ }^{112,115,122}$, which make the satellite cells generate more differentiated PAX7-${ }^{-M_{Y O G}+}$ daughter cells, aka myoblasts ${ }^{95,108,125}$. The MYOG expression leads to the down-regulation of genes involved in cell cycle progression and promotes differentiation and fusion ${ }^{126}$. While functional in tissue repair in vivo, this differentiation prevents further cell expansion in culture.

In the long-term passage conditions, the cells were cultured to less than $60 \%$ confluency and with enough nutrition. Even in those conditions there is a gradual loss of proliferation and differentiation abilities during long-term culture similar to the changes occurring during aging ${ }^{95,127}$. Whether the differentiation impaired long-term cultured myoblast cells is discussed.

\subsection{Stem cells function loss is due to stem cell aging?}

Loss of stemness in muscle satellite cells is also related to aging and senescence. Aging is associated with a decline in the regenerative capacity of multiple tissues and organs in vivo $^{128,129}$. The number and the functionality of muscle stem cells decline with aging and this is accompanied by increased fibrosis and fatty degeneration, as a result of changes in niche function and intrinsic properties of $\mathrm{SCs}^{128,130,131}$. Several intracellular processes and signaling pathways have been described as being dysregulated in association with ageing of satellite cells in vivo such as mitochondrial dysfunction ${ }^{132,133}$, FGF2 and FGF 
receptor 1 function ${ }^{95}$, protein homeostasis (proteostasis) ${ }^{134}$, p38 ${ }^{95,108}$, STAT3 $^{119,120}$, p16 ${ }^{135}$, canonical Wnt ${ }^{136}$ and Notch signaling ${ }^{137}$, as well as epigenetic status ${ }^{128,138}$.

The long-term culture induced limited replicative life-span of human fibroblast was firstly described in 1961 and was further designated as the replicative senescence ${ }^{139-141}$. It is also called in vitro aging cells since replicative senescence showed similarities with in vivo aging ${ }^{129}$. Long-term culture of satellite cells not only showed proliferation arrest $^{13,14,103,127}$, but also impaired differentiation ability ${ }^{134,102}$. One of the features of cells subject to extensive subculturing is a gradual impairment of the glucose and lipid metabolism ${ }^{103,127}$. However, more information on aging satellite cells in vitro is still needed ${ }^{103,127}$.

\section{Aims of this study}

Cultured meat has been suggested to use approximately 7-45\% lower energy use, 78-96\% lower GHG emissions, 99\% lower land use, and 82-96\% lower water use than conventionally produced European meat according to the life cycle assessment (LCA) research ${ }^{142}$. This study mainly focuses on characterization and isolation of highly purified porcine and bovine satellite cells as cell sources for cultured meat. Since satellite cells lose proliferation and differentiation ability during in vitro culture, the reasons and solutions are also assessed.

1. To characterize satellite cells in porcine and cattle. Satellite cells have been well studied in human and mice for clinical usage. Less information is available in pig and bovine satellite cells. According to the information from mouse and human, pig and bovine satellite cells are characterized by transcription factors and surface markers that are reported as being important.

2. To isolate high purity satellite cells in porcine and bovine muscle by FACS. It has been a major focus to isolate a purified stem cell population to study stem cell biology. In the past few years, several groups have described the protocols to isolate satellite cells from the muscles tissue of mice and human by FACS. Using the identified surface markers, highly purified porcine and bovine satellite cells were isolated by FACS.

3. To monitor the satellite cells features during long-term culture. Large scale culture of functional satellite cells is a major issue in clinical field and cultured meat project. Loss of stemness has been found in mouse, dog and human satellite cells after culturing in vitro. Bovine and porcine satellite cells from different passages were collected and analyzed for stemness gene expression and differentiation ability.

4. To explore some differentiation and aging pathway effects in long-term cultured satellite cells. The differentiation process is accompanied by cell cycle withdrawal. 
During aging, intrinsic and extrinsic stimuli drive functional decline of muscle stem cells. Several differentiation and aging related signal pathways were checked during long-term culture.

5. To systematic investigate the reason for function loss of long-term cultured satellite cells. The biological changes of long-term cultured satellite cells were analyzed by high throughput label-free quantitative proteomics.

6. To maintain the stemness of long-term cultured satellite cells. Both amount and function of satellite cells are important for clinical and cultured meat purposes. Several biological process and signal pathways were studied and intervened in. The approach to maintain the stemness and differentiation abilities by interfering those signals was evaluated.

\section{Overview of the thesis}

In chapter 2 we cloned the full-length cDNA sequence of porcine PAX7 and characterized the numbers of satellite cells located in various pieces of skeletal muscle. The satellite cell frequency in variant pieces of porcine skeletal muscles were characterized. Then we established a FACS sorting method to isolate porcine satellite cells based on the surface markers. We further demonstrate that similar to satellite cells in other species, porcine satellite cells lose their stem cell identity and differentiation potential after long-term in vitro culturing.

Chapter 3 describes a fluorescence-activated cell sorting strategy to enrich bovine satellite cells. We find that p38-MAPK signaling is activated and PAX7 expression is gradually lost during satellite cell proliferation. The $p 38 \alpha / \beta$ inhibitor SB203580 inhibits the differentiation of bovine satellite cells in short-term experiments while long-term cultivation with p38i helps maintain the stemness and differentiation abilities.

In chapter 4 we show that the STAT3 signal was activated in cultured bovine satellite cells. The JAK2-STAT3 signal is required for bovine myoblast differentiation. Inhibition of JAK2-STAT3 signal impaired the differentiation process. However, JAK2-STAT3 inhibition does not help maintain the stemness gene, proliferation or long-term passage. Further proteomics and western blots results indicate that the JAK2-STAT3 signal was not the reason for the long-term culture defects in bovine satellite cells.

Chapter 5 describes several changes in signal pathways during differentiation and longterm culture process by Western blot. The two processes show similar up-regulation expression profiles in p38-MAPK signal. The JAK2-STAT3 signal pathway is up-regulated during differentiation but remains stable in long-term culture. Both ERK and Akt signal are down-regulated when the cells are confluent and then increased during 
differentiation. However, ERK signal keeps decreasing while Akt signal increases during long-term culture.

In chapter 6 we used proteomic analysis to identify the pathways increased and decreased during long-term passage. Biological pathway analysis shows that the proteins up-regulated in late passage are involved in cell-cell adhesion, muscle contraction, mitochondrial electron transport, NADH to ubiquinone, cell redox homeostasis. Early passages on the other hand show high expression of proteins involved in DNA replication, protein folding, translational initiation, DNA repair, fibroblast growth factor receptor signaling pathway, p53 regulation, proteasome- ubiquitin-dependent proteolysis, telomere maintenance via recombination and somatic stem cell population maintenance. 


\section{References}

1 Milton, K. The critical role played by animal source foods in human (Homo) evolution. J Nutr 133, 3886S-3892S, doi:10.1093/jn/133.11.3886S (2003).

2 De Smet, S. \& Vossen, E. Meat: The balance between nutrition and health. A review. Meat science 120, 145-156, doi:10.1016/j.meatsci.2016.04.008 (2016).

3 Wyness, L. The role of red meat in the diet: nutrition and health benefits. The Proceedings of the Nutrition Society 75, 227-232, doi:10.1017/S0029665115004267 (2016).

4 Wood, J. D. et al. Fat deposition, fatty acid composition and meat quality: A review. Meat science 78, 343-358, doi:10.1016/j.meatsci.2007.07.019 (2008).

5 Bouvard, V. et al. Carcinogenicity of consumption of red and processed meat. Lancet Oncol 16, 15991600, doi:10.1016/S1470-2045(15)00444-1 (2015).

6 Steinfeld, H., Gerber, P., Wassenaar, T., Castel, V. \& De Haan, C. Livestock's long shadow: environmental issues and options. (Food \& Agriculture Org., 2006).

7 Post, M. J. Cultured meat from stem cells: challenges and prospects. Meat science 92, 297-301, doi:10.1016/j.meatsci.2012.04.008 (2012).

8 Post, M. J. \& Hocquette, J. F. in New Aspects of Meat Quality (ed Peter P. Purslow) 425-441 (Woodhead Publishing, 2017).

9 Post, M. J. Cultured beef: medical technology to produce food. J Sci Food Agric 94, 1039-1041, doi:10.1002/jsfa.6474 (2014).

10 Kadim, I. T., Mahgoub, O., Baqir, S., Faye, B. \& Purchas, R. Cultured meat from muscle stem cells: A review of challenges and prospects. J Integr Agr 14, 222-233, doi:Doi 10.1016/S2095-3119(14)608819 (2015).

11 Sacco, A., Doyonnas, R., Kraft, P., Vitorovic, S. \& Blau, H. M. Self-renewal and expansion of single transplanted muscle stem cells. Nature 456, 502-506, doi:10.1038/nature07384 (2008).

12 Gilbert, P. M. et al. Substrate Elasticity Regulates Skeletal Muscle Stem Cell Self-Renewal in Culture. Science 329, 1078-1081, doi:10.1126/science.1191035 (2010).

$13 \mathrm{Fu}, \mathrm{X}$. et al. Combination of inflammation-related cytokines promotes long-term muscle stem cell expansion. Cell Res 25, 655-673, doi:10.1038/cr.2015.58 (2015).

14 Charville, G. W. et al. Ex Vivo Expansion and In Vivo Self-Renewal of Human Muscle Stem Cells. Stem Cell Rep 5, 621-632, doi:10.1016/j.stemcr.2015.08.004 (2015).

15 Madden, L., Juhas, M., Kraus, W. E., Truskey, G. A. \& Bursac, N. Bioengineered human myobundles mimic clinical responses of skeletal muscle to drugs. Elife 4, e04885, doi:10.7554/eLife.04885 (2015).

16 Pruller, J., Mannhardt, I., Eschenhagen, T., Zammit, P. S. \& Figeac, N. Satellite cells delivered in their niche efficiently generate functional myotubes in three-dimensional cell culture. Plos One 13, doi:ARTN e0202574 10.1371/journal.pone.0202574 (2018).

17 Gilbert, P. M. et al. Substrate elasticity regulates skeletal muscle stem cell self-renewal in culture. Science 329, 1078-1081, doi:10.1126/science.1191035 (2010).

18 Nations, U. World Population Prospects: The 2017 Revision. (2017).

19 OECD/FAO. OECD-FAO Agricultural Outlook 2017-2026. (OECD Publishing).

20 FAO. Livestock's long shadow. (2011).

21 FAO. The state of food and agriculture. Livestock in the balance[R]. Rome: FAO. ( 2009).

22 Zhou, G. H., Zhang, W. G. \& Xu, X. L. China's meat industry revolution: Challenges and opportunities for the future. Meat science 92, 188-196, doi:10.1016/j.meatsci.2012.04.016 (2012). 
23 Koknaroglu, H. \& Akunal, T. Animal welfare: An animal science approach. Meat science 95, 821-827, doi:10.1016/j.meatsci.2013.04.030 (2013).

24 Jones, B. A. et al. Zoonosis emergence linked to agricultural intensification and environmental change. Proceedings of the National Academy of Sciences of the United States of America 110, 8399-8404, doi:10.1073/pnas.1208059110 (2013).

25 Poyatos-Racionero, E., Ros-Lis, J. V., Vivancos, J. L. \& Martinez-Manez, R. Recent advances on intelligent packaging as tools to reduce food waste. J Clean Prod 172, 3398-3409, doi:10.1016/j. jclepro.2017.11.075 (2018).

26 Kristensen, L., Stoier, S., Wurtz, J. \& Hinrichsen, L. Trends in meat science and technology: The future looks bright, but the journey will be long. Meat science 98, 322-329 (2014).

27 Van Huis, A. et al. Edible insects: future prospects for food and feed security. (Food and Agriculture Organization of the United Nations, 2013).

28 Kumar, P. et al. Meat analogues: Health promising sustainable meat substitutes. Crit Rev Food Sci 57, 923-932 (2017).

29 Hocquette, J. F. Is in vitro meat the solution for the future? Meat science 120, 167-176, doi:10.1016/j. meatsci.2016.04.036 (2016).

30 Churchill, W. Fifty Years Hence. The Strand Magazine (1931).

31 Christ, B. \& Ordahl, C. P. Early stages of chick somite development. Anat Embryol (Berl) 191, 381-396 (1995).

32 Cossu, G. \& Biressi, S. Satellite cells, myoblasts and other occasional myogenic progenitors: possible origin, phenotypic features and role in muscle regeneration. Seminars in cell \& developmental biology 16, 623-631, doi:10.1016/j.semcdb.2005.07.003 (2005).

33 Dennis, R. G. \& Kosnik, P. E., 2nd. Excitability and isometric contractile properties of mammalian skeletal muscle constructs engineered in vitro. In vitro cellular \& developmental biology. Animal 36, 327-335, doi:10.1290/1071-2690(2000)036<0327:EAICPO>2.0.CO;2 (2000).

34 Hinds, S., Bian, W., Dennis, R. G. \& Bursac, N. The role of extracellular matrix composition in structure and function of bioengineered skeletal muscle. Biomaterials 32, 3575-3583, doi:10.1016/j. biomaterials.2011.01.062 (2011).

35 Qazi, T. H., Mooney, D. J., Pumberger, M., Geissler, S. \& Duda, G. N. Biomaterials based strategies for skeletal muscle tissue engineering: existing technologies and future trends. Biomaterials 53, 502-521, doi:10.1016/j.biomaterials.2015.02.110 (2015).

36 Konigsberg, I. R. Cellular differentiation in colonies derived from single cells platings of freshly isolated chick embryo muscle cells. Proceedings of the National Academy of Sciences of the United States of America 47, 1868-1872 (1961).

37 Jones, N. C., Fedorov, Y. V., Rosenthal, R. S. \& Olwin, B. B. ERK1/2 is required for myoblast proliferation but is dispensable for muscle gene expression and cell fusion. J Cell Physiol 186, 104-115, doi:10.1002/1097-4652(200101)186:1<104::AID-JCP1015>3.0.CO;2-0 (2001).

38 Mauro, A. Satellite cell of skeletal muscle fibers. J Biophys Biochem Cytol 9, 493-495 (1961).

39 Stockdale, F. E. \& Holtzer, H. DNA synthesis and myogenesis. Exp Cell Res 24, 508-520 (1961).

40 Benjaminson, M. A., Gilchriest, J. A. \& Lorenz, M. In vitro edible muscle protein production system (mpps): stage 1, fish. Acta Astronautica 51, 879-889 (2002).

41 Van Eelen, W. F., Van Kooten, W. J., Westerhof, W. \& Mummery, C. INDUSTRIAL PRODUCTION OF MEAT FROM IN VITRO CELL CULTURES. (2003). 
42 Purslow, P. P. in Lawrie's Meat Science (Eighth Edition) (ed Fidel Toldra') 49-97 (Woodhead Publishing, 2017).

43 Listrat, A. et al. How Muscle Structure and Composition Influence Meat and Flesh Quality. TheScientificWorldJournal 2016, 3182746, doi:10.1155/2016/3182746 (2016).

44 Frontera, W. R. \& Ochala, J. Skeletal muscle: a brief review of structure and function. Calcified tissue international 96, 183-195, doi:10.1007/s00223-014-9915-y (2015).

45 Purslow, P. P. The structure and functional significance of variations in the connective tissue within muscle. Comparative Biochemistry and Physiology a-Molecular and Integrative Physiology 133, 947966 (2002).

46 López-Bote, C. in Lawrie's Meat Science (Eighth Edition) (ed Fidel Toldra') 99-158 (Woodhead Publishing, 2017).

47 Hocquette, J. F. et al. Intramuscular fat content in meat-producing animals: development, genetic and nutritional control, and identification of putative markers. Animal An International Journal of Animal Bioscience 4, 303-319 (2010).

48 Kjaer, M. Role of extracellular matrix in adaptation of tendon and skeletal muscle to mechanical loading. Physiological reviews 84, 649-698, doi:10.1152/physrev.00031.2003 (2004).

49 Faustman, C. \& Suman, S. P. in Lawrie's Meat Science (Eighth Edition) (ed Fidel Toldra') 329-356 (Woodhead Publishing, 2017).

50 Hopkins, D. L. in Lawrie's Meat Science (Eighth Edition) (ed Fidel Toldra') 357-381 (Woodhead Publishing, 2017).

51 Flores, M. in Lawrie's Meat Science (Eighth Edition) (ed Fidel Toldra') 383-417 (Woodhead Publishing, 2017).

52 Warner, R. D. in Lawrie's Meat Science (Eighth Edition) (ed Fidel Toldra') 419-459 (Woodhead Publishing, 2017).

53 van der Weele, C. \& Tramper, J. Cultured meat: every village its own factory? Trends in biotechnology 32, 294-296, doi:10.1016/j.tibtech.2014.04.009 (2014).

54 Kang, H. W. et al. A 3D bioprinting system to produce human-scale tissue constructs with structural integrity. Nat Biotechnol 34, 312-319, doi:10.1038/nbt.3413 (2016).

55 Ostrovidov, S. et al. Skeletal muscle tissue engineering: methods to form skeletal myotubes and their applications. Tissue engineering. Part B, Reviews 20, 403-436, doi:10.1089/ten.TEB.2013.0534 (2014).

56 White, J. \& Dalton, S. Cell cycle control of embryonic stem cells. Stem Cell Rev 1, 131-138, doi:10.1385/ SCR:1:2:131 (2005).

57 Becker, K. A., Stein, J. L., Lian, J. B., van Wijnen, A. J. \& Stein, G. S. Establishment of histone gene regulation and cell cycle checkpoint control in human embryonic stem cells. J Cell Physio/ 210, 517-526, doi:10.1002/jcp.20903 (2007).

58 Chal, J. et al. Differentiation of pluripotent stem cells to muscle fiber to model Duchenne muscular dystrophy. Nat Biotechnol 33, 962-969, doi:10.1038/nbt.3297 (2015).

59 Loh, K. M. et al. Mapping the Pairwise Choices Leading from Pluripotency to Human Bone, Heart, and Other Mesoderm Cell Types. Cell 166, 451-467, doi:10.1016/j.cell.2016.06.011 (2016).

60 Simonson, O. E., Domogatskaya, A., Volchkov, P. \& Rodin, S. The safety of human pluripotent stem cells in clinical treatment. Annals of medicine 47, 370-380, doi:10.3109/07853890.2015.1051579 (2015).

$61 \mathrm{Kim}$, J. et al. Expansion and Purification Are Critical for the Therapeutic Application of Pluripotent Stem Cell-Derived Myogenic Progenitors. Stem Cell Rep, doi:10.1016/j.stemcr.2017.04.022 (2017). 
62 Genovese, N. J., Domeier, T. L., Telugu, B. P. \& Roberts, R. M. Enhanced Development of Skeletal Myotubes from Porcine Induced Pluripotent Stem Cells. Sci Rep 7, 41833, doi:10.1038/srep41833 (2017).

63 Cimino, M., Goncalves, R. M., Barrias, C. C. \& Martins, M. C. L. Xeno-Free Strategies for Safe Human Mesenchymal Stem/Stromal Cell Expansion: Supplements and Coatings. Stem Cells Int 2017, 6597815, doi:10.1155/2017/6597815 (2017).

$64 \mathrm{Xu}, \mathrm{Y}$. Y. et al. Regulating myogenic differentiation of mesenchymal stem cells using thermosensitive hydrogels. Acta Biomaterialia 26, 23-33, doi:10.1016/j.actbio.2015.08.010 (2015).

65 Oikonomopoulos, A. et al. Optimization of human mesenchymal stem cell manufacturing: the effects of animal/xeno-free media. Sci Rep 5, 16570, doi:10.1038/srep16570 (2015).

66 Seale, P., Ishibashi, J., Holterman, C. \& Rudnicki, M. A. Muscle satellite cell-specific genes identified by genetic profiling of MyoD-deficient myogenic cell. Dev Biol 275, 287-300, doi:DOI 10.1016/ jydbio.2004.07.034 (2004).

67 Torrente, Y. et al. Human circulating AC133(+) stem cells restore dystrophin expression and ameliorate function in dystrophic skeletal muscle. J Clin Invest 114, 182-195, doi:10.1172/JCI20325 (2004).

68 Zheng, B. et al. Prospective identification of myogenic endothelial cells in human skeletal muscle. Nat Biotechnol 25, 1025-1034, doi:10.1038/nbt1334 (2007).

69 Yin, H., Price, F. \& Rudnicki, M. A. Satellite cells and the muscle stem cell niche. Physiological reviews 93, 23-67, doi:10.1152/physrev.00043.2011 (2013).

70 Meng, J., Muntoni, F. \& Morgan, J. CD133+ cells derived from skeletal muscles of Duchenne muscular dystrophy patients have a compromised myogenic and muscle regenerative capability. Stem Cell Res 30, 43-52, doi:10.1016/j.scr.2018.05.004 (2018).

71 Wosczyna, M. N. \& Rando, T. A. A Muscle Stem Cell Support Group: Coordinated Cellular Responses in Muscle Regeneration. Dev Cell 46, 135-143, doi:10.1016/j.devcel.2018.06.018 (2018).

$72 \mathrm{Liu}$, N. et al. A Twist2-dependent progenitor cell contributes to adult skeletal muscle. Nat Cell Biol 19, 202-213, doi:10.1038/ncb3477 (2017).

73 Almada, A. E. \& Wagers, A. J. Molecular circuitry of stem cell fate in skeletal muscle regeneration, ageing and disease. Nature reviews. Molecular cell biology 17, 267-279, doi:10.1038/nrm.2016.7 (2016).

74 Kuang, S., Kuroda, K., Le Grand, F. \& Rudnicki, M. A. Asymmetric self-renewal and commitment of satellite stem cells in muscle. Cell 129, 999-1010, doi:10.1016/j.cell.2007.03.044 (2007).

75 Collins, C. A. et al. Stem cell function, self-renewal, and behavioral heterogeneity of cells from the adult muscle satellite cell niche. Cell 122, 289-301, doi:10.1016/j.cell.2005.05.010 (2005).

76 Quarta, M. et al. An artificial niche preserves the quiescence of muscle stem cells and enhances their therapeutic efficacy. Nat Biotechnol 34, 752-759, doi:10.1038/nbt.3576 (2016).

77 Cheung, T. H. \& Rando, T. A. Molecular regulation of stem cell quiescence. Nat Rev Mol Cell Bio 14, 329340, doi:10.1038/nrm3591 (2013).

78 Zammit, P. S. et al. Muscle satellite cells adopt divergent fates: a mechanism for self-renewal? J Cell Biol 166, 347-357, doi:10.1083/jcb.200312007 (2004).

79 Relaix, F. \& Zammit, P. S. Satellite cells are essential for skeletal muscle regeneration: the cell on the edge returns centre stage. Development 139, 2845-2856, doi:10.1242/dev.069088 (2012).

80 Sambasivan, R. et al. Pax7-expressing satellite cells are indispensable for adult skeletal muscle regeneration. Development 138, 3647-3656, doi:10.1242/dev.067587 (2011). 
81 Lepper, C., Partridge, T. A. \& Fan, C. M. An absolute requirement for Pax7-positive satellite cells in acute injury-induced skeletal muscle regeneration. Development 138, 3639-3646, doi:10.1242/ dev.067595 (2011).

82 Dumont, N. A. et al. Dystrophin expression in muscle stem cells regulates their polarity and asymmetric division. Nat Med 21, 1455-+, doi:10.1038/nm.3990 (2015).

83 Fry, C. S. et al. Inducible depletion of satellite cells in adult, sedentary mice impairs muscle regenerative capacity without affecting sarcopenia. Nat Med 21, 76-80, doi:10.1038/nm.3710 (2015).

84 Pasut, A., Oleynik, P. \& Rudnicki, M. A. Isolation of muscle stem cells by fluorescence activated cell sorting cytometry. Methods in molecular biology 798, 53-64, doi:10.1007/978-1-61779-343-1_3 (2012).

85 Liu, L., Cheung, T. H., Charville, G. W. \& Rando, T. A. Isolation of skeletal muscle stem cells by fluorescence-activated cell sorting. Nat Protoc 10, 1612-1624, doi:10.1038/nprot.2015.110 (2015).

86 Ding, S. et al. Characterization and isolation of highly purified porcine satellite cells. Cell Death Discov 3, 17003, doi:10.1038/cddiscovery.2017.3 (2017).

87 Seale, P. et al. Pax7 is required for the specification of myogenic satellite cells. Cell 102, 777-786, doi:Doi 10.1016/S0092-8674(00)00066-0 (2000).

88 Baroffio, A. et al. Identification of self-renewing myoblasts in the progeny of single human muscle satellite cells. Differentiation 60, 47-57, doi:10.1046/j.1432-0436.1996.6010047.x (1996).

89 Crist, C. G., Montarras, D. \& Buckingham, M. Muscle satellite cells are primed for myogenesis but maintain quiescence with sequestration of Myf5 mRNA targeted by microRNA-31 in mRNP granules. Cell stem cell 11, 118-126, doi:10.1016/j.stem.2012.03.011 (2012).

90 Cornelison, D. D. W., Olwin, B. B., Rudnicki, M. A. \& Wold, B. J. MyoD(-/-) satellite cells in single-fiber culture are differentiation defective and MRF4 deficient. Dev Biol 224, 122-137, doi:10.1006/ dbio.2000.9682 (2000).

91 Megeney, L. A., Kablar, B., Garrett, K., Anderson, J. E. \& Rudnicki, M. A. MyoD is required for myogenic stem cell function in adult skeletal muscle. Gene Dev 10, 1173-1183, doi:DOI 10.1101/gad.10.10.1173 (1996).

92 Tajbakhsh, S. \& Cossu, G. Establishing myogenic identity during somitogenesis. Curr Opin Genet Dev 7, 634-641, doi:Doi 10.1016/S0959-437x(97)80011-1 (1997).

93 Cooper, R. N. et al. In vivo satellite cell activation via Myf5 and MyoD in regenerating mouse skeletal muscle. J Cell Sci 112, 2895-2901 (1999).

94 Motohashi, N. \& Asakura, A. Muscle satellite cell heterogeneity and self-renewal. Front Cell Dev Bio/ 2, 1, doi:10.3389/fcell.2014.00001 (2014).

95 Bernet, J. D. et al. p38 MAPK signaling underlies a cell-autonomous loss of stem cell self-renewal in skeletal muscle of aged mice. Nat Med 20, 265-271, doi:10.1038/nm.3465 (2014).

96 Faralli, H. \& Dilworth, F. J. Turning on myogenin in muscle: a paradigm for understanding mechanisms of tissue-specific gene expression. Comp Funct Genomics 2012, 836374, doi:10.1155/2012/836374 (2012).

97 Hindi, S. M., Tajrishi, M. M. \& Kumar, A. Signaling Mechanisms in Mammalian Myoblast Fusion. Sci Signal 6 (2013).

98 Pisani, D. F. et al. Isolation of a Highly Myogenic CD34-Negative Subset of Human Skeletal Muscle Cells Free of Adipogenic Potential. Stem Cells 28, 753-764, doi:10.1002/stem.317 (2010).

$99 \mathrm{Xu}, \mathrm{X}$. et al. Human Satellite Cell Transplantation and Regeneration from Diverse Skeletal Muscles. Stem Cell Rep 5, 419-434, doi:10.1016/j.stemcr.2015.07.016 (2015). 
100 Montarras, D. et al. Direct isolation of satellite cells for skeletal muscle regeneration. Science 309, 2064-2067, doi:10.1126/science.1114758 (2005).

101 Parker, M. H. et al. Activation of Notch Signaling During Ex Vivo Expansion Maintains Donor Muscle Cell Engraftment. Stem Cells 30, 2212-2220, doi:10.1002/stem.1181 (2012).

102 Bigot, A. et al. Replicative aging down-regulates the myogenic regulatory factors in human myoblasts. Biol Cell 100, 189-199, doi:10.1042/Bc20070085 (2008).

103 Nehlin, J. O., Just, M., Rustan, A. C. \& Gaster, M. Human myotubes from myoblast cultures undergoing senescence exhibit defects in glucose and lipid metabolism. Biogerontology 12, 349-365, doi:10.1007/ s10522-011-9336-5 (2011).

104 Sharples, A. P., Al-Shanti, N., Lewis, M. P. \& Stewart, C. E. Reduction of Myoblast Differentiation Following Multiple Population Doublings in Mouse C2C12 Cells: A Model to Investigate Ageing? J Cell Biochem 112, 3773-3785, doi:10.1002/jcb.23308 (2011).

105 Igea, A. \& Nebreda, A. R. The Stress Kinase p38 alpha as a Target for Cancer Therapy. Cancer Res 75, 3997-4002 (2015).

106 Segales, J., Perdiguero, E. \& Munoz-Canoves, P. Regulation of Muscle Stem Cell Functions: A Focus on the p38 MAPK Signaling Pathway. Front Cell Dev Biol 4, 91, doi:10.3389/fcell.2016.00091 (2016).

107 Troy, A. et al. Coordination of satellite cell activation and self-renewal by Par-complex-dependent asymmetric activation of p38alpha/beta MAPK. Cell stem cell 11, 541-553, doi:10.1016/j. stem.2012.05.025 (2012).

108 Cosgrove, B. D. et al. Rejuvenation of the muscle stem cell population restores strength to injured aged muscles. Nat Med 20, 255-264, doi:10.1038/nm.3464 (2014).

109 Brien, P., Pugazhendhi, D., Woodhouse, S., Oxley, D. \& Pell, J. M. p38alpha MAPK regulates adult muscle stem cell fate by restricting progenitor proliferation during postnatal growth and repair. Stem Cells $\mathbf{3 1}$, 1597-1610, doi:10.1002/stem.1399 (2013).

110 Morales, J. K., Falanga, Y. T., Depcrynski, A., Fernando, J. \& Ryan, J. J. Mast cell homeostasis and the JAK-STAT pathway. Genes and immunity 11, 599-608, doi:10.1038/gene.2010.35 (2010).

111 Rawlings, J. S., Rosler, K. M. \& Harrison, D. A. The JAK/STAT signaling pathway. J Cell Sci 117, 1281-1283, doi:10.1242/jcs.00963 (2004).

112 Trenerry, M. K., Della Gatta, P. A. \& Cameron-Smith, D. JAK/STAT signaling and human in vitro myogenesis. BMC physiology 11, 6, doi:10.1186/1472-6793-11-6 (2011).

113 Kataoka, Y. et al. Reciprocal inhibition between MyoD and STAT3 in the regulation of growth and differentiation of myoblasts. J Biol Chem 278, 44178-44187, doi:10.1074/jbc.M304884200 (2003).

114 Guadagnin, E., Mazala, D. \& Chen, Y. W. STAT3 in Skeletal Muscle Function and Disorders. Int J Mol Sci 19, doi:10.3390/ijms19082265 (2018).

115 Jang, Y. N. \& Baik, E. J. JAK-STAT pathway and myogenic differentiation. Jak-Stat 2, e23282, doi:10.4161/ jkst.23282 (2013).

116 Zhang, C. et al. Interleukin-6/signal transducer and activator of transcription 3 (STAT3) pathway is essential for macrophage infiltration and myoblast proliferation during muscle regeneration. $J$ Biol Chem 288, 1489-1499, doi:10.1074/jbc.M112.419788 (2013).

117 Toth, K. G. et al. IL-6 Induced STAT3 Signalling Is Associated with the Proliferation of Human Muscle Satellite Cells Following Acute Muscle Damage. Plos One 6, doi:ARTN e17392 10.1371/journal. pone.0017392 (2011).

118 Chazaud, B. \& Mouchiroud, G. Inflamm-aging: STAT3 signaling pushes muscle stem cells off balance. Cell stem cell 15, 401-402, doi:10.1016/j.stem.2014.09.010 (2014). 
119 Price, F. D. et al. Inhibition of JAK-STAT signaling stimulates adult satellite cell function. Nat Med 20, 1174-1181, doi:10.1038/nm.3655 (2014).

120 Tierney, M. T. et al. STAT3 signaling controls satellite cell expansion and skeletal muscle repair. Nat Med 20, 1182-1186 (2014).

121 Yang, Y. et al. STAT3 induces muscle stem cell differentiation by interaction with myoD. Cytokine 46, 137-141, doi:10.1016/j.cyto.2008.12.015 (2009).

122 Jang, Y. N., Lee, I. J., Park, M. C. \& Baik, E. J. Role of JAK3 in myogenic differentiation. Cell Signal 24, 742-749, doi:10.1016/j.cellsig.2011.11.009 (2012).

123 Keren, A., Tamir, Y. \& Bengal, E. The p38 MAPK signaling pathway: a major regulator of skeletal muscle development. Mol Cell Endocrinol 252, 224-230, doi:10.1016/j.mce.2006.03.017 (2006).

124 Segales, J. et al. Chromatin-wide and transcriptome profiling integration uncovers p38alpha MAPK as a global regulator of skeletal muscle differentiation. Skelet Muscle 6, 9, doi:10.1186/s13395-016-0074-x (2016).

125 Yennek, S., Burute, M., Thery, M. \& Tajbakhsh, S. Cell adhesion geometry regulates non-random DNA segregation and asymmetric cell fates in mouse skeletal muscle stem cells. Cell Rep 7, 961-970, doi:10.1016/j.celrep.2014.04.016 (2014).

$126 \mathrm{Liu}, \mathrm{Q}$. C. et al. Comparative expression profiling identifies differential roles for Myogenin and p38alpha MAPK signaling in myogenesis. J Mol Cell Biol 4, 386-397, doi:10.1093/jmcb/mjs045 (2012).

127 Baraibar, M. A. et al. Impaired energy metabolism of senescent muscle satellite cells is associated with oxidative modifications of glycolytic enzymes. Aging 8, 3375-3389, doi:10.18632/aging.101126 (2016).

128 Ermolaeva, M., Neri, F., Ori, A. \& Rudolph, K. L. Cellular and epigenetic drivers of stem cell ageing. Nature reviews. Molecular cell biology, doi:10.1038/s41580-018-0020-3 (2018).

129 Hohn, A. et al. Happily (n)ever after: Aging in the context of oxidative stress, proteostasis loss and cellular senescence. Redox Biol 11, 482-501, doi:10.1016/j.redox.2016.12.001 (2017).

130 Dumon, N. A., Wang, Y. X. \& Rudnicki, M. A. Intrinsic and extrinsic mechanisms regulating satellite cell function. Development 142, 1572-1581, doi:10.1242/dev.114223 (2015).

131 Blau, H. M., Cosgrove, B. D. \& Ho, A. T. V. The central role of muscle stem cells in regenerative failure with aging. Nat Med 21, 854-862 (2015).

132 Zhang, H. et al. $N A D(+)$ repletion improves mitochondrial and stem cell function and enhances life span in mice. Science 352, 1436-1443, doi:10.1126/science.aaf2693 (2016).

133 Baumann, K. Ageing: The yin and yang of mitochondrial dysfunction. Nature reviews. Molecular cell biology 17, 331, doi:10.1038/nrm.2016.71 (2016).

134 Garcia-Prat, L. et al. Autophagy maintains stemness by preventing senescence. Nature 529, 37-42, doi:10.1038/nature16187 (2016).

135 Sousa-Victor, P. et al. Geriatric muscle stem cells switch reversible quiescence into senescence. Nature 506, 316-+, doi:10.1038/nature13013 (2014).

136 Brack, A. S. et al. Increased Wnt signaling during aging alters muscle stem cell fate and increases fibrosis. Science 317, 807-810 (2007).

137 Conboy, I. M., Conboy, M. J., Smythe, G. M. \& Rando, T. A. Notch-mediated restoration of regenerative potential to aged muscle. Science 302, 1575-1577, doi:DOI 10.1126/science.1087573 (2003).

138 Liu, L. et al. Chromatin Modifications as Determinants of Muscle Stem Cell Quiescence and Chronological Aging. Cell Rep 4, 189-204, doi:10.1016/j.celrep.2013.05.043 (2013).

139 Goldstein, S. Replicative senescence: the human fibroblast comes of age. Science 249, 1129-1133 (1990). 
Chapter 1

140 Hayflick, L. \& Moorhead, P. S. The serial cultivation of human diploid cell strains. Exp Cell Res 25, 585621 (1961).

141 DiLoreto, R. \& Murphy, C. T. The cell biology of aging. Mol Biol Cell 26, 4524-4531, doi:10.1091/mbc. E14-06-1084 (2015).

142 Tuomisto, H. L. \& de Mattos, M. J. T. Environmental Impacts of Cultured Meat Production. Environ Sci Technol 45, 6117-6123, doi:Doi 10.1021/Es200130u (2011). 




\section{Chapter 2}

\section{Characterization and isolation of highly purified porcine satellite cells}




\begin{abstract}
Pork is an important food source and the pig is an excellent animal model for human diseases. Careful characterization of the swine skeletal muscle stem cells (satellite cells) will shed a light on the generation of a swine skeletal muscle disease model and on efficient production of porcine meat for the food industry. PAX7 is a highly conserved transcription factor shared by satellite cells from various species. However, the sequence of PAX7 has not been characterized in pig. The lack of a method to isolate highly purified satellite cells hinders the thorough characterization of swine satellite cells. Here we found molecular markers for swine satellite cells and revealed that porcine satellite cells were heterogeneous in various pieces of skeletal muscle. We further developed a method to isolate highly purified satellite cells directly from porcine muscles using fluorescence-activated cell sorting (FACS). We next characterized the proliferation and differentiation abilities of isolated satellite cells in vitro and found that long-term culturing of satellite cells in vitro led to loss of stemness.
\end{abstract}




\section{Introduction}

Satellite cells are a heterogeneous population of adult stem cells located in skeletal muscles ${ }^{1,2,3,4}$. These cells reside between the muscle sarcolemma and the basal lamina of muscle fibers and remain quiescent under normal conditions $s^{1,2,5,6}$. Upon injury, quiescent satellite cells are activated to repair muscle injury while a subset of the activated satellite cells return to quiescent status after self-renewal $\left.\right|^{1,2,7}$. Satellite cells are essential for muscle regeneration and mice lacking satellite cells display severe muscle regeneration defects $s^{8,9,10}$. Satellite cell impairment occurs in muscular diseases such as Duchenne muscular dystrophy (DMD) ${ }^{11}$ and in aged muscles ${ }^{12}$.

Pigs have many advantages in modeling human diseases due to their similar anatomic and physiological features to human beings ${ }^{13,14}$. For example, the swine DMD model recapitulates human symptoms better than the mouse model. The severe progressive dystrophic changes of skeletal muscles, impaired mobility, muscle weakness and a much shorter life span are common symptoms in human DMD patients ${ }^{15}$. These symptoms can only be recapitulated in the pig DMD model ${ }^{16}$, but not in the mouse DMD model ${ }^{17}$, supporting the notion that pigs can model human diseases better than rodents. Characterization of satellite cells in pig will be a valuable addition to our understanding of the porcine model system.

PAX7 has been shown to be the critical regulator of satellite cell maintenance and proliferation in several species ${ }^{18,19,20}$. PAX7 is a highly conserved protein present in many mammalian species such as human, mouse, and cattle. In mice, PAX7 can directly regulate $M y o D$ and $M y f 5$ to modulate satellite cell maintenance and proliferation ${ }^{21,22,23,24}$. The full length CDS of Pax7 has been found in the mouse (Accession \#: NM_011039) and the human (Accession \#: NM_001135254) database. For PAX7 in pig, however, there are currently only three short partial sequences in the database.

The frequency of satellite cells and their functions are heterogeneous in both mouse and human skeletal muscles ${ }^{4,25,26}$. Mouse Soleus and diaphragm muscles have more satellite cells per $\mathrm{mm}^{3}$ compared to other muscles ${ }^{25}$. In humans, the Temporalis muscle has estimated higher satellite cell numbers, whereas other body and limb muscles show lower satellite cell numbers ${ }^{26}$. Little is known about the satellite cell frequency heterogeneity in pig muscles.

Highly purified mouse satellite cell populations can be obtained by FACS sorting but the method to purify porcine satellite cells is not well established. Several approaches have been reported to isolate the myogenic lineage cells from porcine muscle tissues, including Percoll gradient centrifugation and preplating $27,28,29,30,31$. However, the cell identity of the myogenic lineage population obtained by the above methods has not been carefully characterized yet. The purification efficiency of Percoll gradient centrifugation shows big variation as reported by different groups ${ }^{27,32}$. Furthermore, in cells obtained by Percoll gradient centrifugation, only a portion $(<60 \%)$ of them stain 
positive for neural cell adhesion molecule ( $\mathrm{N}$-Cam), which is considered to be a porcine satellite cell marker ${ }^{28}$. Consistently, only $65 \%$ of the cells obtained by this method are able to fuse and form myotubes ${ }^{33}$. Another widely used approach to isolate porcine myogenic lineage cells is the preplating method ${ }^{29,34,35}$. PAX7 immunofluorescent staining indicates that satellite cells only account for $20 \%-50 \%$ of the cell population obtained by this method ${ }^{29,35}$. Thus, it is necessary to develop a more efficient method to obtain highly purified satellite cells.

Previous studies in mice have suggested that highly purified satellite cells can be obtained by FACS sorting ${ }^{2,36,37}$. The cell surface markers for FACS sorting have been well characterized in murine muscle tissues. The most commonly used cell surface markers in murine are CD34 and $\alpha 7$-integrin ${ }^{2,36,38}$. The cell surface markers to specify pig satellite cells are not well characterized. It has been reported that CD56 was expressed in a myogenic cell population residing in human ${ }^{26,39}$ and swine skeletal muscles ${ }^{40}$. Further analysis in human muscles showed that the cells expressing CD56 can be further divided into two populations based on CD34 expression. $C D 56^{+} \mathrm{CD} 34^{-}$cells isolated from skeletal muscles displayed only myogenic potency, whereas $\mathrm{CD} 56^{+} \mathrm{CD} 34^{+}$cells showed both adipogenic and myogenic potentials ${ }^{40}$, though the scenario in pigs has not been well characterized. CD29 ( $\beta 1$-integrin) is a member of the integrin family that can form heterodimers to link the extracellular matrix to the actin cytoskeleton within cells ${ }^{41}$. CD29-deficient embryonic myoblasts displayed impaired fusion ability in vitro $^{42}$. Satellite cells lacking CD29 fail to maintain a quiescent state and cannot sustain the expansion and self-renewal of this stem cell pool during regeneration ${ }^{43}$. In mice, more than $95 \%$ of satellite cells are CD29 and PAX7 double positive ${ }^{44}$; in human, $96 \%$ of satellite cells are CD29 and PAX7 double positive ${ }^{26}$. These observations suggest that CD29 could be a surface marker to specify satellite cells together with other markers.

It has been reported that long-term cultivation of satellite cells in vitro resulted in loss of most of the regenerative potential in vivo after transplantation in mouse ${ }^{36,45}$, canine $^{46}$, and human ${ }^{47}$. Scattered reports have shown that the progenitor cells derived from swine skeletal muscles display multilineage differentiation capacities after being cultured in vitro for 3 month $^{48}$, but the identity of these cells has not been characterized. Whether the lack of ability to be expanded in vitro is also true in pig satellite cells is not known yet.

Here we characterize the satellite cell frequency in variant pieces of porcine skeletal muscles. The cell surface markers specific for porcine satellite cells have been identified, and a FACS sorting method to isolate porcine satellite cells based on the surface markers has been established. We further demonstrate that similar to satellite cells in other species, porcine satellite cells lose their stem cell identities and differentiation potentials after long-term in vitro culturing. 


\section{Results}

\section{Clone of the full length porcine $P A X 7$ gene}

PAX7 is an important regulator of muscle satellite cells ${ }^{18,19,20}$. We set out to compare the similarity of the PAX7 peptide sequence between pig and other species. However, we could not find the full length $P A X 7$ sequence in the NCBI database. There are only several partial porcine PAX7 cDNA sequences in NCBI nucleotide database (Accession \#: AY653213, XM_013992407, XM_013991732). These translated peptide sequences were aligned with PAX7 peptide sequences from several species (Figure 1a). Peptide sequence (Accession \#: AAT72072) translated from AY653213 displayed $100 \%$ identity to PAX7 peptide sequences from multiple species (Figure 1a and Supplementary Figure S1). PAX3 belongs to the same family as PAX7 and is very similar to PAX7. Sequence comparison indicated differences between two key amino acids in the peptide sequence derived from AY653213 and the PAX3 amino acid sequence from various species (Supplementary Figure S1), suggesting that AY653213 could be a partial sequence of porcine PAX7.

To identify the complete cDNA sequence of $P A X 7$ in pig, we performed $5^{\prime}$ and $3^{\prime}$ rapid amplification of cDNA ends (RACE) using AY653213 as the seed sequence with total RNA extracted from porcine myoblasts (Supplementary Figure S2a). A 400bp fragment was generated by the 5' RACE; and a 5000bp fragment was generated by the 3' RACE (Supplementary Figure S2b). The 2 fragments could be assembled into a $1512 \mathrm{bp}$ CDS (Accession \#: KX815346), which encoded a 503 amino acid polypeptide (Figure 1b). The assembled nucleic acid sequence showed $93 \%$ identity to human $P A X 7$ and $90 \%$ identity to mouse PAX7 (Supplementary Figure S3a). The translated polypeptide displayed $99 \%$ identity to human PAX7 and $98 \%$ identity to mouse PAX7 protein (Supplementary Figure S3b). Paired box domain (PAX), homeobox domain (Homeobox) and Paired box protein 7 (Pax7) domain, the three highly conserved domains of PAX7 from various species, were all found in the amino acid sequence translated from the full-length pig PAX7 CDS (Figure 1b). 
Figure 1. Cloning of the full length porcine PAX7 CDS

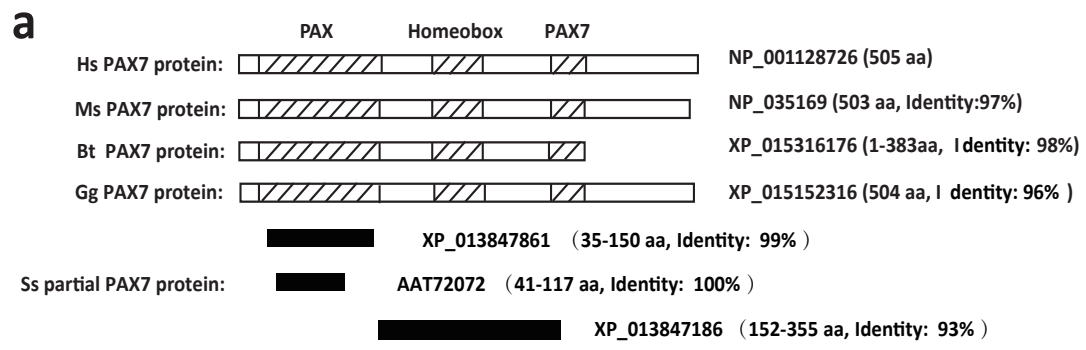

b

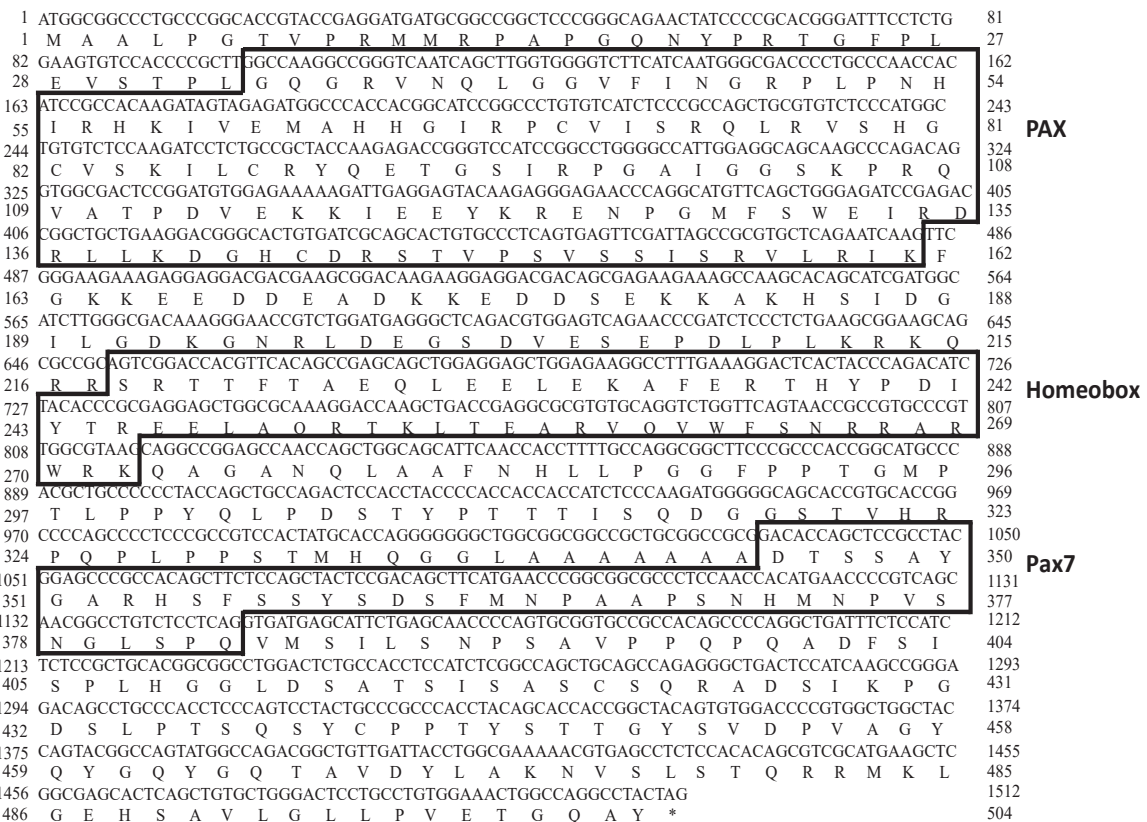

(a) Schematic representation of the PAX7 protein sequences from different species. Hatched segments indicate conserved domains. Mouse (Mus musculus, Ms), cattle (Bos taurus, Bt), chick (Gallus gallus, Gg) PAX7 proteins and partial pig (Sus scrofa, Ss) PAX7 peptide sequences were aligned with human (Homo sapiens, $H s$ ) PAX7 protein. Black indicates the partial porcine $P A X 7$ CDNA sequences. (b) Nucleotide sequence of pig PAX7 and the predicted protein sequence. The conserved Paired Box (PAX), Homeobox (Homeobox) and Paired box protein 7 (Pax7) are boxed. 


\section{The satellite cell number varied at different age and location}

We tested several antibodies and found the antibody recognizing porcine PAX7 protein. This antibody was utilized to detect the endogenous porcine satellite cells. Consistent with observations in mouse ${ }^{18}$ and human ${ }^{26}$, PAX7 positive satellite cells were detected underneath the basal membrane as indicated by Laminin immunofluorescent staining in both postnatal and adult pigs (Figure $2 a$ and $b$ ).

The satellite cell number is important for skeletal muscle homeostasis maintenance. It has been reported that the satellite cell number decreased in adult when compared to neonatal mice ${ }^{49}$. The number of satellite cells also differed between various pieces of skeletal muscles in the same individual ${ }^{25}$. We next checked the satellite cell number in Semitendinosus from 1- and 25-week old pigs by PAX7 immunofluorescent staining. The number of satellite cells decreased in adult skeletal muscle (25-week old) compared to neonatal (1-week old) muscles in pig (Figure $2 \mathrm{~b}$ and c). To compare the satellite cell numbers in different muscle pieces, we analyzed 9 types of adult pig skeletal muscle from different locations. Peroneus Tertius, Psoas Major, and Extensor carpi radialis had high numbers of satellite cells, whereas Intercostal muscle and Biceps femoris had low amounts of satellite cells (Figure $2 \mathrm{~d}$ and e). These results suggest that the distribution of satellite cells in different types of skeletal muscle is different.

\section{Identification the satellite cell specific cell surface markers}

In order to set up a FACS sorting method to isolate porcine satellite cells, we next characterized the specificity of the surface markers for porcine satellite cells. CD56 and CD29 have been reported to mark satellite cells in human. We performed immunofluorescent staining assays to verify whether these surface markers were also applicable to porcine satellite cells. Both CD56 and CD29 co-localized in the same cell with PAX7 in porcine skeletal muscles (Figure 3a), suggesting that they could be used as cell surface marker for isolation of satellite cells from pig skeletal muscles. Antibodies against CD31 (an endothelial cell marker ${ }^{50}$ ) and CD45 (a hematopoietic cell marker ${ }^{48}$ ) were utilized to distinguish the endothelial and hematopoietic cells present in the mononuclear cells isolated from porcine skeletal muscles. Based on these results, we isolated $\mathrm{CD} 31^{-} \mathrm{CD} 45^{-} \mathrm{CD} 56^{+} \mathrm{CD} 29^{+}$cells from mononuclear cell population obtained from porcine skeletal muscles by FACS sorting (Figure 3b). The PAX7 and MYF5 mRNA level in this cell population was compared with that in $\mathrm{CD} 31^{+} \mathrm{CD} 45^{+}$and $\mathrm{CD} 31^{-} \mathrm{CD} 45^{-}$ CD56 ${ }^{-}{ }^{-} 29^{+}$populations by RT-qPCR. PAX7 and MYF5 are enriched in the CD31-CD45$\mathrm{CD} 56^{+} \mathrm{CD} 29^{+}$population (Figure $3 \mathrm{C}$ and Supplementary Figure S4a). Immunofluorescent staining assays revealed that $94 \%$ of $\mathrm{CD} 31^{-} \mathrm{CD} 45^{-} \mathrm{CD} 56^{+} \mathrm{CD} 29^{+}$cells express PAX7 (Figure $3 d, 3 e$ and Supplementary Figure S4b), suggesting specific enrichment of PAX7 ${ }^{+}$cells in CD31 ${ }^{-C D} 45^{-} \mathrm{CD}^{2} 6^{+} \mathrm{CD} 29^{+}$cell population isolated from porcine skeletal muscles. Taken together, satellite cells can be isolated from pig skeletal muscles by FACS sorting using CD31 and CD45 negative selection followed by CD56 and CD29 positive selection. 
Figure 2. The number of satellite cells varied at different age and location

a
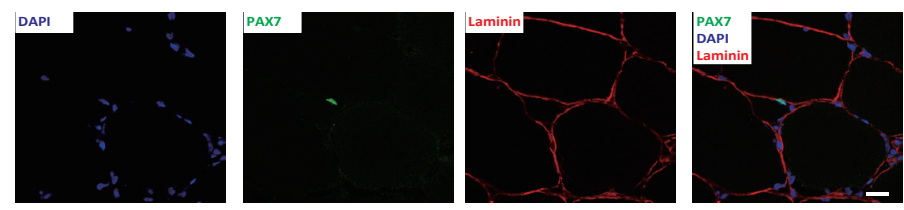

b

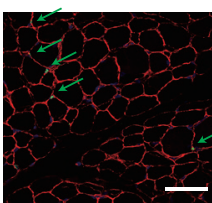

1-week old

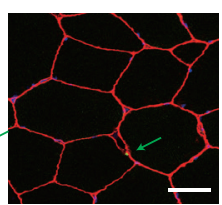

25-week old

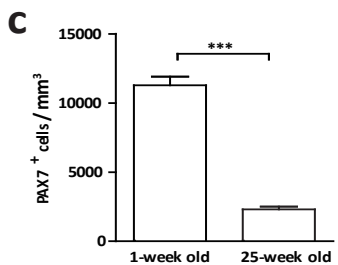

d

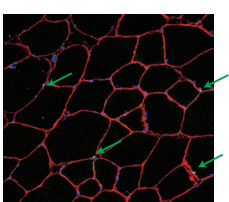

Biceps femoris

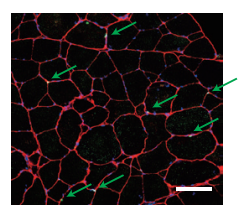

Extensor carpi radialis

e

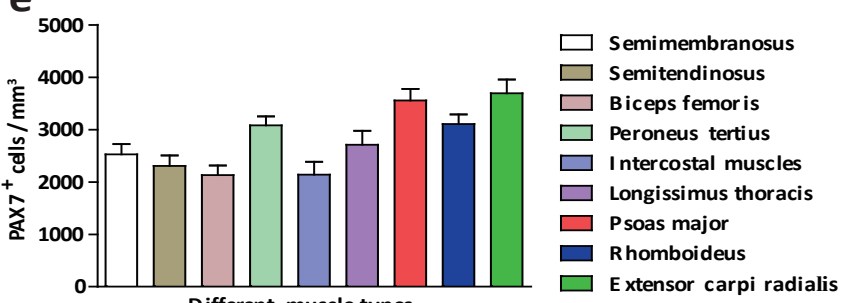

Different muscle types

(a) Immunofluorescent staining of the Semitendinosus muscle section from 25-week old pig using PAX7 and Laminin antibodies. Green: PAX7; Red: Laminin; Blue: DAPI. Scale bars: $20 \mu \mathrm{m}$. (b) Representative images of immunofluorescent staining of PAX7 (satellite cells) and Laminin on pig Semitendinosus cross sections obtained from 1-week or 25-week old pigs. Green: PAX7; Red: Laminin; Blue: DAPI. The green arrows indicate the satellite cells. Scale bars: $50 \mu \mathrm{m}$. (c) Quantifications of the satellite cell numbers in mice at different ages. Error bars represent S.E.M. and were based on 4 independent experiments. Significance was analyzed by student's t-test, $* * *$ indicates $\mathrm{P}<0.001$. (d) Representative images of immunofluorescent staining of pig satellite cells on tissue sections derived from different muscle types in 25-week old pigs. Green: PAX7; Red: Laminin; Blue: DAPI. The green arrows indicate the satellite cells. Scale bars: $100 \mu \mathrm{m}$. (e) Quantifications of satellite cell number in different pieces of skeletal muscles. Error bars represent mean \pm S.E.M. and are based on 4 independent experiments. 
Figure 3. Identification the satellite cell specific cell surface markers

a
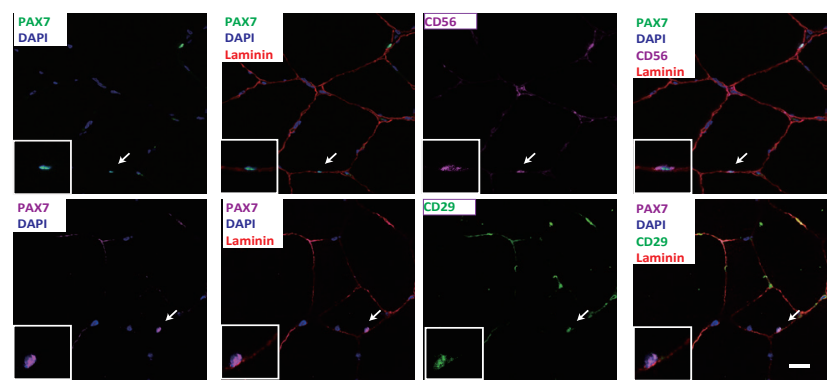

b

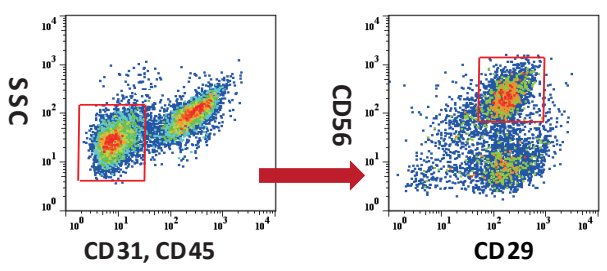

C

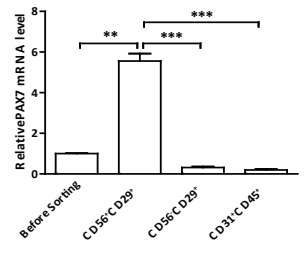

d

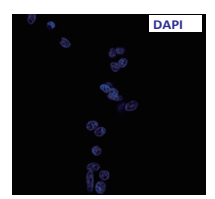

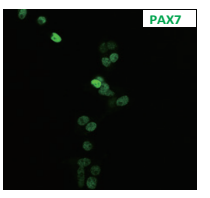

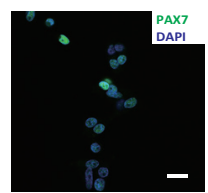

e

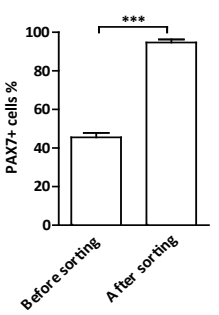

(a) Immunofluorescent staining of PAX7, CD56 (a, top), CD29 (a, bottom), and Laminin on cross sections of Semitendinosus muscle from 25-week old pig. Green: PAX7 (a, top) or CD29 (a, bottom); Purple: CD56 (a, top) or PAX7 (a, bottom); Blue: DAPI; Red: Laminin. Arrows indicate satellite cells expressing all three markers. Scale bars: $20 \mu \mathrm{m}$. (b) FACS analysis of mononuclear cells from Semitendinosus obtained from 1-week old pig. Cells were gated by forward scatter and side scatter (not shown) prior to gating for CD45/31, CD56, and CD29. Red gates indicate sub-populations containing pig satellite cells. (c) qRT-PCR analysis of PAX7 mRNA levels in freshly isolated pig satellite cells and other cell populations were shown. (d) Immunofluorescent staining of PAX7 in pig satellite cells cultured 4d in vitro. Blue: DAPI; Green: PAX7. Scale bars: $20 \mu \mathrm{m}$. (e) Quantification of PAX7 immunofluorescent staining of sorted $\mathrm{CD} 566^{+} \mathrm{CD} 29^{+}$cells and unsorted cells cultured $4 d$ in vitro from 1-week old pig. Data represent mean \pm S.E.M. and are based on 3 (figure 3e) or 4 (figure 3c) independent experiments. Significance was analyzed by student's t-test, $* *$ indicates $p<0.01, * * *$ indicates $p<0.001$. 
To analyze the proliferation abilities of porcine satellite cells in vitro, we cultured the satellite cells for several days in vitro. After being cultured in vitro for 4 days, the cell size started to increase and the cell shape became more spindle-like (Figure $4 a, b$ and $c$ and Supplementary Figure S5a). Previous reports have shown that the cell size increased when satellite cells are being activated and start differentiating to myoblasts ${ }^{51}$. To further characterize the identity of the cells isolated from pig skeletal muscles by FACS sorting, we performed immunofluorescent staining of MyoD and PAX7. In the round satellite cells, which were cultured in vitro for less than 6 h, PAX7 protein was detected and MyoD protein level was relatively low (Figure $4 \mathrm{c}$ ). Cells being cultured for $4 \mathrm{~d}$ were bigger, and PAX7 positive (Figure 4c). MyoD protein displayed punctuated distribution and was mostly located in nuclei (Figure 4c). The PAX7 mRNA level was decreased during in vitro culturing (Figure $4 \mathrm{~d}$ ). These results suggest that, consistent with the circumstance in mouse ${ }^{5,51}$, porcine satellite cells being cultured in vitro for over $4 \mathrm{~d}$ were activated and started to differentiate to myoblasts.

We next assayed the differentiation potential of porcine satellite cells in vitro. Porcine satellite cells were differentiated in either $2 \%$ horse serum (HS) or $0.4 \%$ Ultroser G (UG) (Figure $4 \mathrm{e}$ and $4 \mathrm{f})$. The myosin heavy chain $(\mathrm{MyHC}$ ) expression level was dramatically higher in UG-induced differentiation (Figure 4f). The differentiation efficiency was also enhanced by UG induction (Figure 4f).

We next examined whether cell density would affect pig satellite cell differentiation. We seeded $2 \times 10^{4}, 1 \times 10^{5}$, and $5 \times 10^{5}$ pig satellite cells in a $3.5 \mathrm{~cm}$ dish for 2 days (Supplementary Figure S5b) and induced differentiation with UG, respectively. When the density of the seeded pig satellite cells was low, the differentiation efficiency decreased; when the cell density reached the threshold, the differentiation efficiency plateaued (Figure $4 \mathrm{~g}$ and $\mathrm{h}$ ). Higher seeding cell density yielded myotubes with elevated $\mathrm{MyHC}$ expression levels and a higher percentage myotube nuclei ( $\geq 3$ nuclei) of total nuclei (Figure $4 i$ and $j$ ). Together, these results suggest that high cell density facilitates pig satellite cell differentiation. We further examined the contractility of the differentiated myotubes. After being cultured in medium containing UG and $\mathrm{Ca}^{2+}$ for 6 days, myotubes differentiated from swine satellite cells were able to contract. These results suggest that swine satellite cells were able to generate functional myotubes. 
Figure 4. Proliferation and differentiation abilities of pig satellite cells in vitro

a

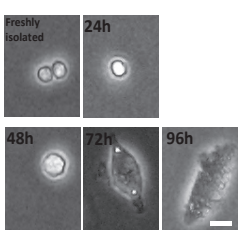

b

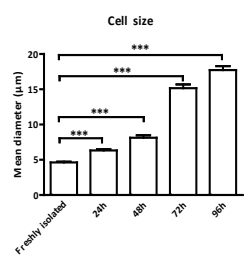

C

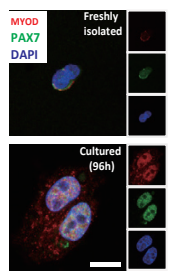

d

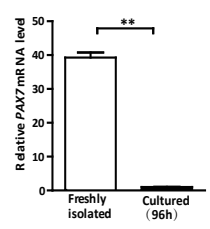

e

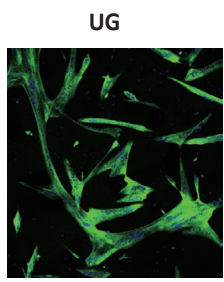

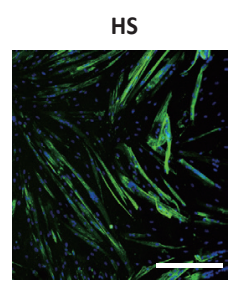

f
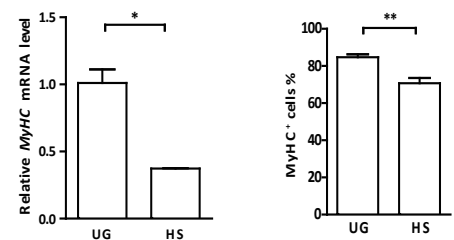

g

$2 \times 10^{4}$

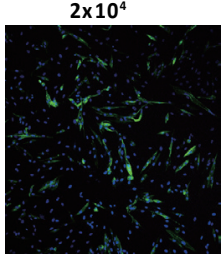

$1 \times 10^{5}$

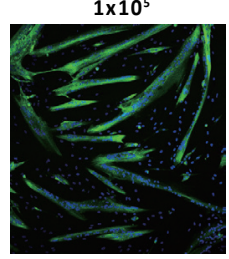

$5 \times 10^{5}$
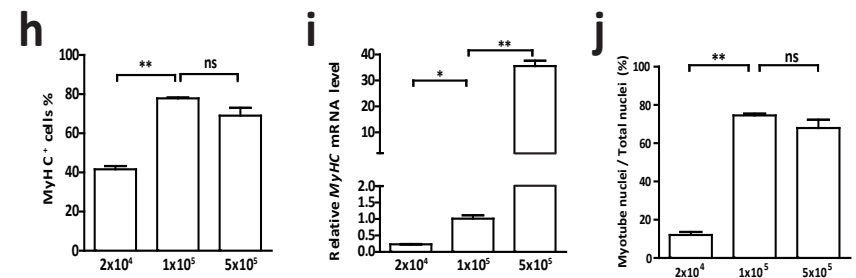

Figure legend on next page 
(a) Representative phase contrast images of pig satellite cells cultured in F-10 medium for various hours. Scale bars: $10 \mu \mathrm{m}$. (b) Quantification of the cell size with different culturing time. (c) Representative immunofluorescent staining images of pig freshly isolated satellite cells or cultured in vitro for $96 \mathrm{~h}$. In the inserts, Red: MyoD; Green: PAX7; Blue: DAPI. Scale bars: $10 \mu \mathrm{m}$. (d) qRT-PCR analysis of PAX7 mRNA levels in freshly isolated pig satellite cells and satellite cells cultured for 4d. (e) Representative immunofluorescent staining images of MyHC of differentiated satellite cells at passage 1 with $0.4 \%$ UG and $2 \% \mathrm{HS}$. Green: MyHC; Blue: DAPI. Scale bars: $50 \mu \mathrm{m}$. (f) qRT-PCR analysis of $\mathrm{MyHC}$ mRNA levels with cells differentiated in $0.4 \%$ UG and $2 \% \mathrm{HS}$ conditions ( $\mathrm{f}$, left). Quantification of the number of $\mathrm{MyHC}^{+}$cell numbers with cells differentiated in $0.4 \%$ UG and $2 \%$ HS conditions (f, right). (g) Representative immunofluorescent staining images of MyHC with different amount of seed cells at passage 3. Cells were cultured with $2 \times 10^{4}$ (left), $1 \times 10^{5}$ (middle), $5 \times 10^{5}$ (right) cells for 2 days, then induced to differentiate in 0.4\% UG. Green: MyHC; Blue: DAPI. Scale bars: $50 \mu \mathrm{m}$. (h) Quantification of the number of $\mathrm{MyHC}^{+}$cells in cells differentiated from different amount of seed cells, (i) qRT-PCR analysis of MyHC mRNA levels in cells differentiated from different amount of seed cells. (j) Quantification of the percentage of nuclei in myotubes differentiated from different amount of seed cells. Bars represent mean \pm S.E.M. and are based on 3 independent experiments. Significance was analyzed by student's t-test or one-way ANOVA. * indicates $p<0.05,{ }^{* *}$ indicates $p<0.01{ }^{* * *}$ indicates $p<0.001$. NS: Non-significant.

\section{Porcine satellite cells lost their stemness after long-term in vitro expansion}

Both mouse and human satellite cells have been reported to suffer loss of their ability to repair muscle injury in vivo after days of in vitro culturing $5,36,45,47,52$. We therefore examined whether porcine satellite cells have the same feature. As described above, the cell size of porcine satellite cells increased and the cell shape became more spindle-like after $4 d$ of in vitro culturing (Figure $4 a$ ), suggesting these cells to be in a more differentiated status. The morphology of porcine satellite cells remained to be spindle-like after serial expansion in vitro (Figure $5 a$ ). These cells could be propagated logarithmically in vitro (Figure 5b). To further characterize the identity of the cells being serially expanded in vitro, CD56 and CD29 expression was analyzed by FACS. The expression level of both CD56 and CD29 decreased after passage 4 (Figure 5c), suggesting a gradual loss of satellite cell character. Consistently, the percentage of PAX $7^{+}$ cells also decreased dramatically after passage 4 and 5 (Figure $4 \mathrm{~d}$ ). The expression level of PAX7 echoed the morphology changes observed above. After $4 \mathrm{~d}$ of in vitro culturing, the $P A X 7$ mRNA level dropped more than 30 -fold (Figure 5e). Serial expansion in vitro of these cells further drove the PAX7 mRNA level and the percentage of PAX7 ${ }^{+}$cells down (Figure $5 \mathrm{~d}$ and e). After passage 4 and 5 , the PAX7 expression level decreased to a very low level (Figure 5e), suggesting that these cells had lost their satellite cell features. Consistently, the cells expanded in vitro for over 5 passages displayed significant lower differentiation potentials (Figure $5 f$ and $g$ ). Taken together, these results suggest that pig satellite cells quickly lose their stem cell features in vitro. 
Figure 5. Porcine satellite cells lost their stemness after long term expansion in vitro

a

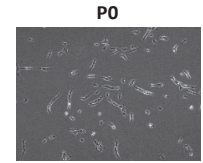

b

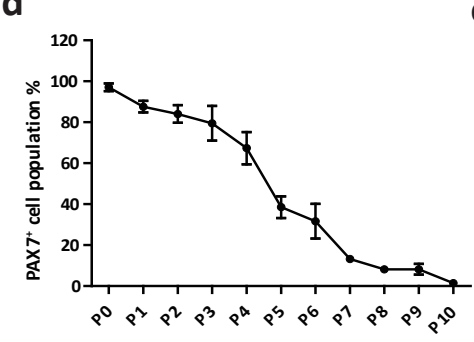

$\mathbf{f}$

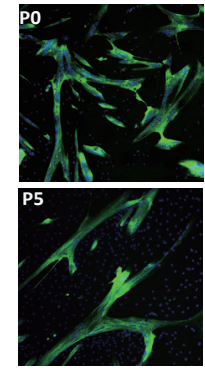

P2

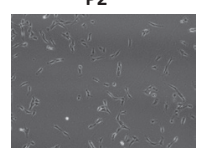

C

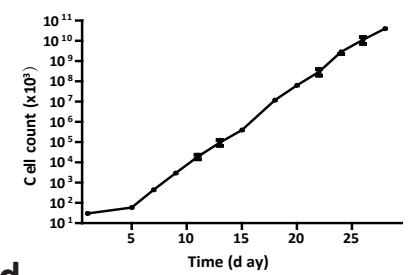

d

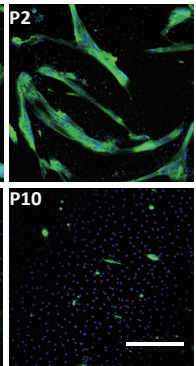

P5
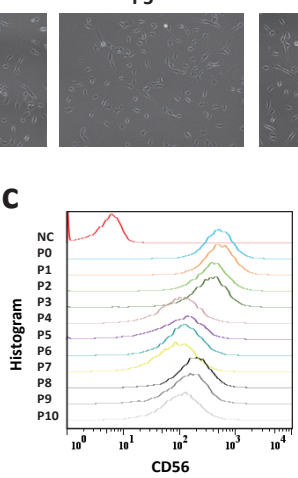

e

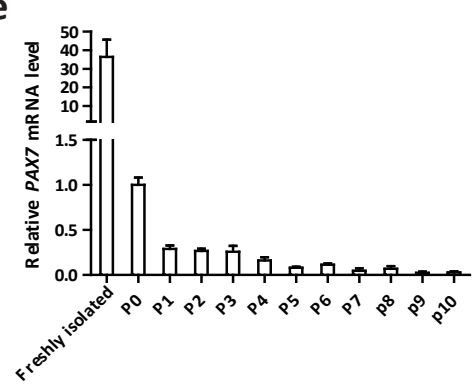

g

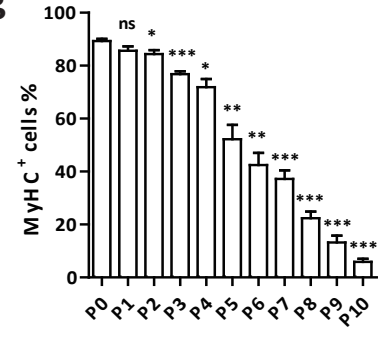

(a) Representative phase contrast images of pig satellite cells cultured in F10 medium for different passages. Scale bars: $200 \mu \mathrm{m}$. (b) Growth curves of pig satellite cells isolated from 1-week old pig. Cells were serially expanded and counted at each passage. (c) FACS analysis of CD56 and CD29 expression from different passages of pig satellite cells cultured in F-10 medium. (d) Quantification of the number of PAX7 $7^{+}$cells from different passages. (e) qRT-PCR analysis of $P A X 7 \mathrm{mRNA}$ levels from cells being expanded for different passages. (f) Representative immunofluorescent staining images of $\mathrm{MyHC}$ staining of myotubes differentiated from $\mathrm{PO}$, P2, P5 and P10 satellite cells. Green: MyHC; Blue: DAPI. Scale bars: $50 \mu \mathrm{m}$. (g) Quantification of MyHC ${ }^{+}$cell numbers differentiated from satellite cells being serially expanded in vitro. Bars represent mean \pm S.E.M. and were based on 3 independent experiments. Significance was analyzed by student's t-test or one-way ANOVA. * indicates $p<0.05, * *$ indicates $p<0.01, * * *$ indicates $p<0.001$. NS indicates no significant difference. 
We further examined the ability of pig satellite cells to repair muscle injury in vivo by cell transplantation. Satellite cells were isolated from 1-week old piglets by FACS sorting. Tibialis Anterior (TA) muscle injury in immunodeficient recipient mice (NOD. $\mathrm{Cg}-P r k d c^{\text {scid }} / / 2 r g^{t m 1 w_{j l}} / \mathrm{SzJ}$ ) was induced by cardiotoxin injection. Various numbers of pig satellite cells were transplanted to the recipient mice. Four weeks after transplantation, TA muscles from recipient mice were harvested to make cryo-sections and stained with antibody specifically recognizing pig LAMIN A/C. Pig LAMIN A/C could be detected in TA muscles of the recipient mice (Figure 6a and Supplementary Figure S6a). One week after transplantation, the porcine LAMIN A/C could also be detected in newly formed myofibers (indicated by MYH3 staining) (Figure 6b), suggesting that the transplanted pig satellite cells were able to engraft and contribute to muscle regeneration in recipient mice. We further examined whether the transplanted swine satellite cells were capable of homing to the right niche. PAX7 expressing satellite cells were detected in TA muscles of the recipient mice four weeks after transplantation (Supplementary Figure S6b). The PAX7 expressing satellite cells of pig origin (indicated by LAMIN A/C staining) were detected at the similar location where the endogenous satellite cells resided (Supplementary Figure S6c). These results suggest that the transplanted swine satellite cells were capable of homing to the niche.

We next investigated whether in vitro expansion of porcine satellite cells affects their engraftment efficiency. The same number of freshly isolated pig satellite cells and porcine satellite cells expanded in vitro for different periods were transplanted to immunodeficient recipient mice, respectively. The antibody specifically recognizing porcine LAMIN A/C was used to perform immunofluorescent staining with muscle tissue sections 4 weeks after transplantation. The pig satellite cells expanded in vitro for 2 passages displayed similar engraftment efficiency as the freshly isolated pig satellite cells. However, few myofibers generated from pig satellite cells could be detected when these cells were expanded in vitro for 5 passages (Figure $6 c$ and d), suggesting that pig satellite cells lost their stemness and ability to repair muscle injury in vivo after prolonged in vitro expansion. These results were also consistent with the morphology and differentiation potential changes described above (Figure 4 and 5), suggesting that pig satellite cells lost their stem cell features after being expanded in vitro for 5 passages. Taken together, these results suggest that pig satellite cells lose their stemness and differentiation abilities after in vitro expansion, a feature shared by both mouse and human satellite cells. 
Figure 6. Pig satellite cells participated in the muscle regeneration in recipient mice and lose the engraftment efficiency after long-term expansion in vitro

a
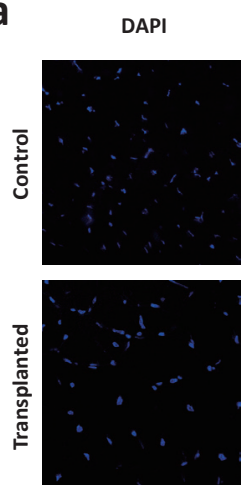

b

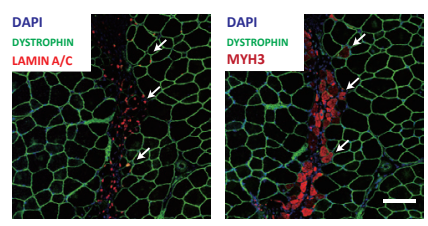

c

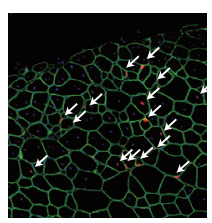

Freshly isolated
LAMIN A/C
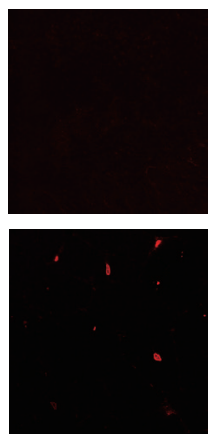

DYSTROPHIN
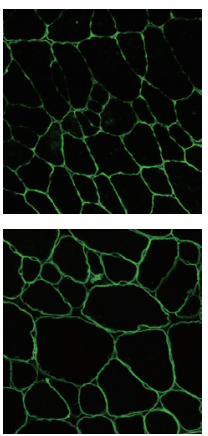

MERGE
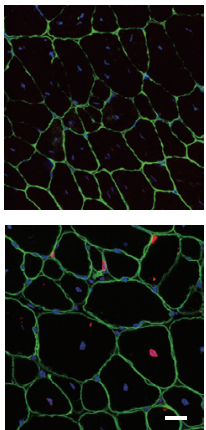

d

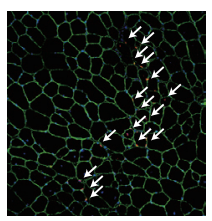

P2

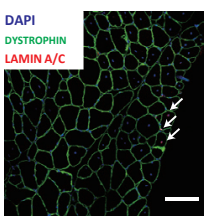

P5

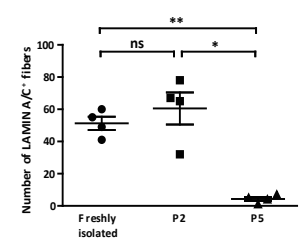

(a) Four weeks after transplantation, engraftment efficiency of freshly isolated pig satellite cells was determined by DYSTROPHIN and LAMIN A/C immunofluorescent staining with muscle sections derived from recipient mice. PBS was injected as negative control. Blue: DAPI; Red: LAMIN A/C; Green: DYSTROPHIN. Scale bars: $20 \mu \mathrm{m}$. (b) LAMIN A/C, MYH3 immunofluorescent staining with series muscle sections derived from recipient mice 7 days after transplantation. Blue indicated DAPI; red indicated LAMIN A/C (b, left) or MYH3 (b, right). Green: DYSTROPHIN. Scale bars: $100 \mu \mathrm{m}$. (c) Representative immunofluorescent staining images of DYSTROPHIN and LAMIN A/C on mouse sections from mice injected with freshly isolated (c, left), P2 (c, middle) and P5 (c, right) satellite cells. Blue: DAPI; Red: LAMIN A/C; Green: DYSTROPHIN. Scale bars: $100 \mu \mathrm{m}$. (d) Quantification of the number of LAMIN A/C fibers in each TA 4 weeks after transplantation. Significance was analyzed by one-way ANOVA. * indicates $p<0.05, * *$ indicates $p<0.01$. NS indicates no significant difference. 


\section{Discussion}

Here we characterized pig muscle satellite cells and provided basic information for further utilization of these cells. We cloned the full-length cDNA sequence of porcine PAX7 and characterized the numbers of satellite cells located at various piece of skeletal muscles. A FACS sorting based method was established to isolate highly purified pig satellite cells. Using this method, we isolated pig satellite cells and found that they lost their stem cell morphology, differentiation potential, and ability to repair muscle injury in vivo after prolonged in vitro culturing.

Neonatal mice have high numbers of satellite cells, while the number decreased in the adult (reviewed by Fu $\mathrm{X}$ et $\mathrm{al}^{53}$ ). A similar phenomenon has been observed in pigs. The number of satellite cells was much higher in 1-week old pigs compared to that in 25 -week old pig. The number of satellite cells varied at different locations. In mouse, extraocular and diaphragm have high number of satellite cells, Gastrocnemius and Tibialis Anterior have low number of satellite cells ${ }^{25}$. In human muscles, it is indicated that under normal homeostatic conditions, most adult human skeletal muscles contain a relatively homogeneous frequency of PAX7 satellite cells per fiber ${ }^{26}$. Since pig and human have larger fibers than mouse, whether pig fibers contain the relatively constant frequency of satellite cells still needs more studies.

The loss of ability to repair muscle injury in vivo of satellite cells after being cultured in vitro (empty amplification) is a common problem shared by mouse and human satellite cells $5^{5,36,47,52}$. This problem hampers the application of satellite cell in the clinic. Our results revealed that pig satellite cells have the same problem. It suggests that the factors required for stemness maintenance are lacking in the in vitro culturing system. Recently, Fu et al found that cytokines secreted by activated $\mathrm{T}$ cells during the acute inflammation after muscle injury can help maintain the stemness of mouse satellite cells in vitro for over 2 months ${ }^{36}$. Charville et al. showed that inhibition of p38 signaling is important to maintain the quiescent stage and stemness of human satellite cells ${ }^{47}$. Whether these factors also work to maintain stemness of pig satellite cells is an interesting question to pursue. 


\section{Materials and Methods}

\section{Animals and pig muscle tissues}

All animal procedures were performed according to institutional and national guidelines and approved by the Shanghai Institute of Biochemistry and Cell Biology, Chinese Academy of Sciences in this study. Pig muscle tissues were collected from commercial pig "large white" killed at euthanized (asphyxiated by $\mathrm{CO}_{2}$ of 1 week old, or stunned electrically and then killed by cutting the jugular vein of 25-week-old). The NOD.CgPrkdc scid $\| / 2 r^{t m 1}{ }^{\text {wjl }} / \mathrm{SzJ}$ (NSG) mice were purchased from Jackson Laboratories.

\section{Pig satellite cells isolation}

Pig satellite cells were isolated from 1 or 25 week old male pigs as previously described and adapted to pig tissues ${ }^{26,47}$. Briefly, freshly harvested pig muscle was either immediately digested or kept in DMEM (Gibco) at $4^{\circ} \mathrm{C}$. The tissues were dissected and dissociated with collagenase $\mathrm{D}$ (Roche $2 \mathrm{mg} / \mathrm{ml}$ ) and dispase II (Roche $1.07 \mathrm{U} / \mathrm{ml}$ ) in DMEM supplement with $1 \%$ penicillin-streptomycin (P.S.) at $37^{\circ} \mathrm{C}$ for $1.5 \mathrm{~h}$. The mixture was triturated with pipette once per 15-20 min. After digestion, the muscle was aspirated and ejected in and out of the syringe 10 times with a 20-ml syringe and a 20-gauge needle. After centrifuging at $100 \mathrm{~g}$ for $5 \mathrm{~min}$, the supernatant was collected and centrifuged at $1000 \mathrm{~g}$ for $5 \mathrm{~min}$ at $4^{\circ} \mathrm{C}$. The cells were washed with $20 \%$ FBS in DMEM and filtered through a $100 \mu \mathrm{m}$ cell strainer followed by a $40 \mu \mathrm{m}$ cell strainer. The cells were then centrifuged at $1000 \mathrm{~g}$ for $5 \mathrm{~min}$ at $4^{\circ} \mathrm{C}$ and incubated with the erythrocyte lysis buffer (ACK) buffer for 5 min on ice. Then the cells were washed with PBS twice and cell pellet was reconstituted with FACS buffer (1\% BSA in PBS) or frozen in FBS supplement with $10 \%$ dimethyl sulphoxide (DMSO).

For freezing cells, the cells were recovered in $37^{\circ} \mathrm{C}$ water bath and washed with PBS twice. The cells were reconstituted with FACS buffer and stained with an antibody cocktail consisting Alexa Fluor 647 anti-pig CD45 (1:20 BIO-RAD Cat\# MCA1222A647), APC-conjugated anti-pig CD31 (1:20 BIO-RAD Cat\# MCA1746APC), Alexa Fluor 488 antihuman CD29 (1:40 BioLegend, Cat\#303016), PE-conjugated anti-human CD56 (1:40 BioLegend, Cat\# 304606) for 30-45min on ice. After antibody incubation, the cells were washed with cold PBS for two times and reconstituted in F-10 with $20 \% \mathrm{FBS}$. The viable CD31 ${ }^{-} \mathrm{CD} 45^{-} \mathrm{CD}^{-} 6^{+} \mathrm{CD} 29^{+}$cells were isolated. Also, the $\mathrm{CD} 31^{+} \mathrm{CD} 45^{+}$cells and $\mathrm{CD} 31^{-} \mathrm{CD} 45^{-}$ CD29+CD56 cells were also isolated to extract RNA. Cell sorting was performed with a BD Influx cell sorter using $488 \mathrm{~nm}, 561 \mathrm{~nm}$, and $640 \mathrm{~nm}$ lasers. Unstained cells were routinely used to define FACS gating parameters.

\section{Satellite cell culture and differentiation}

Dishes (Corning) were coated with $0.05 \%$ collagen type I (Corning). FACS isolated pig satellite cells were cultured on collagen-coated dishes in F10 medium (F10 medium (Gibco) containing 15\% FBS, $5 \mathrm{ng} / \mathrm{ml} \mathrm{FGF} \mathrm{(Invitrogen)} \mathrm{and} \mathrm{1 \%} \mathrm{P.S.).} \mathrm{Freshly} \mathrm{isolated}$ 
satellite cells were collected and plated in collagen coated dish and cultured for less than $6 \mathrm{~h}$ to attach. Cells cultured at various hours were fixed with $4 \%$ paraformaldehyde (PFA) for immunofluorescent staining. For serial expansion, Cells were serially passaged to maintain a density of $<60 \%$ confluence and counted at each passage. Pig satellite cells differentiation were induced with DMEM (Invitrogen) with $2 \%$ horse serum (Hyclone) or $0.4 \%$ Ultroser G (Pall Corporation 15950-017). Differentiation was induced for 4 days. The expanded and differentiated cells were fixed with 4\% PFA for immunofluorescent staining.

To observe the myotube contraction, pig satellite cells were differentiated in DMEM containing 0.4\% Ultroser G (Pall Corporation 15950-017) for 6 days, medium was changed at day 4 .

For preplating method, isolated mononuclear cells were firstly cultured in F10 basal medium for 2 days. Cells were then treated with $0.25 \%$ trypsin for 5 min and stopped with F10 basal medium, centrifuged and re-plated. To separate satellite cells from fibroblast cells, the cells were incubated in an uncoated dish at $37^{\circ} \mathrm{C}$ for $60 \mathrm{~min}$ and then transferred to a new collagen-coated dish. This preplate technical was repeated 3 times to remove residual fibroblast cells. The bright field images were acquired by Olympus DP73 microscope.

\section{Immunofluorescent analysis of cultured cells}

Cultured satellite cells were fixed with ice-cold 4\% PFA (in PBS) for 20 min, rinsed with PBS, and permeabilized in 0.5\% Triton X-100 (in PBS) for 8 min. Fixed and permeabilized cells were blocked and incubated with primary antibodies 1\% BSA (in PBS) overnight at $4^{\circ} \mathrm{C}$. Primary antibodies recognizing PAX7 (1:100, Developmental Studies Hybridoma Bank, Cat\# PAX7), MyoD1 (1:200, abclonal, Cat\# A0671), Myosin heavy chain (1:1000, Upstate, Cat\# 05-716). After washing with PBS, cells were incubated with secondary antibodies for $1 \mathrm{~h}$ at room temperature. Next, the cells were stained with Alexa 488, 561- labeled anti-mouse or -rabbit antibodies (Invitrogen) and then mounted with VECTASHIELD mounting medium with DAPI (Vector Laboratories Cat\# H-1200). All images were acquired by Leica SP8 confocal microscope and processed with Adobe Photoshop CS5 to adjust brightness and contrast for publication.

For the FACS analysis of cultured satellite cells, about $10^{5}$ cells were collected at each passage. The cells were fixed by $2 \%$ PFA for $15 \mathrm{~min}$ and washed $5 \mathrm{~min} 3$ times. The cells were then incubated with Alexa Fluor 488 anti-human CD29 (1:40 BioLegend, Cat\#303016), PE-conjugated anti-human CD56 (1:40 BioLegend, Cat\# 304606) in 1\% BSA in PBS for 30-45 min. After antibody incubation, the cells were washed with PBS for two times and reconstituted in PBS. FACS analysis was performed in LSR II (BD Biosciences) cell analyzer. Unstained cells were routinely used to define FACS gating parameters. 


\section{Pig muscle analysis}

The pig muscle tissues were cut into small pieces and then frozen in liquid nitrogen. Cross sections were cut at $8 \mu \mathrm{m}$ and processed for immunofluorescent staining. The cross sections were fixed with 4\% PFA at room temperature for $10 \mathrm{~min}$, washed in PBS. The sections were permeabilized with $0.5 \%$ Triton X-100 for 6 min and washed with PBS again. Sections were then blocked for $1 \mathrm{~h}$ with $10 \%$ goat serum at room temperature. For PAX7 and Laminin co-staining, sections were incubated at $4{ }^{\circ} \mathrm{C}$ overnight with the following primary antibodies: anti-Laminin antibody (1:50, Sigma, Cat\# L9393) or rat anti-Laminin (1:1000, Abcam, Cat\# 11576), mouse anti-PAX7 (1:25, Developmental Studies Hybridoma Bank, Cat\# PAX7). After PBS wash for 5 min 3 times, the sections were stained with Alexa 488-, 561- or 647-labeled anti-mouse or -rabbit or-rat antibodies (Invitrogen) and then mounted with VECTASHIELD mounting medium with DAPI (Vector Laboratories Cat\# H-1200).

For sections co-stained with PAX7, Laminin and CD56/CD29, PAX7 and Laminin costaining were firstly performed. After incubation with the secondary antibody above, sections were washed with PBS for 5 min 3 times and incubated with the Alexa Fluor 488 anti-human CD29 (1:25, BioLegend, Cat\# 303016), APC anti-human CD56 (1:25, BioLegend, Cat\# 304610) for 2-4h at room temperature. After washing with PBS for 3 times, sections were mounted with VECTASHIELD mounting medium with DAPI (Vector Laboratories Cat\# H-1200). All images were acquired by Leica SP8 confocal microscope and processed with Adobe Photoshop CS5 to adjust brightness and contrast for publication.

\section{Pig satellite cells transplantation}

NSG mice were pretreated with 18 gamma (Gy) 1 days before transplantation limited to the hindlimb. Muscle injury was induced by the injection of CTX (Sigma) to TA muscle. Briefly, $15 \mu \mathrm{l}$ of $10 \mu \mathrm{M}$ CTX was injected at each TA muscle using 28-gauge needles. After $24 \mathrm{~h}$, freshly isolated and cultured pig satellite cells (treated by trypsin) at passage 2 and 5 were counted, centrifuged, and resuspended in $15 \mu \mathrm{lPBS}$ with $10^{5}$ cells. Cells were injected into the TA muscle using 28-gauge needles. Recipient mice were treated with daily drinking water supplement with neomycin sulfate $(0.25 \mathrm{mg} / \mathrm{mg})$ for 2 weeks. The transplanted TA muscles were harvested 1 week, 4 weeks after transplantation in liquid nitrogen. Serial $10 \mu \mathrm{m}$ transverse sections of the TA muscle were stored in $-80^{\circ} \mathrm{C}$ fridge.

All glass slides were removed from $-80^{\circ} \mathrm{C}$ and warmed at room temperature for $10 \mathrm{~min}$. Sections were rehydrated with PBS and fixed in 4\% PFA for $10 \mathrm{~min}$ at room temperature. After washed with PBS for 5 min 3 times, the sections were permeabilized with $0.5 \%$ Triton X-100 for 6 min and again washed with PBS. Then Sections were blocked for $1 \mathrm{~h}$ in $10 \%$ goat serum (in PBS) with mouse-on-mouse blocking reagent (Vector Laboratories). After blocking, sections were washed with PBS and incubated overnight with primary antibodies at $4^{\circ} \mathrm{C}$. Next day, sections were then washed with PBS for 5 min 3 times 
and incubated with secondary antibodies $1 \mathrm{~h}$ at room temperature. Finally, sections were washed with PBS and mounted with VECTASHIELD mounting medium with DAPI (H-1200 Vector Laboratories, Burlingame, CA). Antibodies used in the staining were mouse anti-PAX7 (1:20, Developmental Studies Hybridoma Bank, Cat\# PAX7), mouse anti-MYH3 (1:100, Developmental Studies Hybridoma Bank), mouse anti-LAMIN A/C (1:50, Santa Cruz Biotechnology, Cat\# sc-7292), rabbit anti-DYSTROPHIN antibody (1:50, abcam, Cat\# ab15277). The sections were next stained with Alexa 488-, 561- labeled anti-mouse or -rabbit antibodies (Invitrogen). All images were acquired by Leica SP8 confocal microscope and processed with Adobe Photoshop CS5 to adjust brightness and contrast for publication.

\section{Gene expression analysis}

RNA was extracted from cells using the RNAprep pure cell/bacteria kit including DNase treatment (TIANGEN) according to the manufacturer's instruction. One $\mu \mathrm{g}$ of total RNA from each sample was reverse transcribed to CDNA using M-MLV transcriptase (Promega) according to the manufacturer's instruction. Relative gene expression was determined was performed in triplicate using a SYBR Green PCR master mix on an ABI 7500 Fast Real-Time PCR system.

The primers used in these assays were the followings:

PAX7-F, 5' - GGTGGGGTCTTCATCAATGG -3',

PAX7-R, 5'- GTCTCTTGGTAGCGGCAGAG -3',

MYF5-F, 5'- AGAAGGTCAACCAGGCGTTT -3',

MYF5-R, 5'- GTAGCGGATGGCATTCCTGA -3',

GAPDH-F, 5' - CAAGGAGTAAGAGCCCCTGG -3',

GAPDH-R, 5' - AGTCAGGAGATGCTCGGTGT -3'.

\section{5' and 3' rapid amplification of cDNA ends}

RNA was isolated from primary pig myoblasts by preplate method. The original sequence was based on the published partial pig PAX7 cDNA sequence (Accession \#: AY653213). We designed 4 pairs of gene specific primers: P1, P2, P3, P4 for 5 '-RACE, P5, P6, P7, P8 for 3'-RACE. RACE experiments were performed with SMARTer RACE 5'/3' Kit (Clontech) following the manufacturers' protocols. Finally, we cloned the result cDNA into the pUC19-based vector and sequenced. The peptide and nucleotide sequences were aligned by the NCBI online Basic Local Alignment Search Tool.

The primers used were:

P1, 5'-GGTGGGGTTTTCATCAATGGGCGACC -3',

P2, 5'-CCACATCCGCCACAAGATAGTAGAG -3',

P3, 5'-TGCCCAACCACATCCGCCACAAGATAG -3',

P4, 5'-AGTAGAGATGGCCCACCACGGCATCCG -3',

P5, 5'-GTCTCTTGGTAGCGGCAGAGGAT -3', 
P6, 5'-AGGCCGGATGGACCCGGTCTCTTGG -3',

P7, 5'-TGTCTGGGCTTGCTGCCTCCAATGG -3',

P8, 5'-TCCACATCCGGAGTCGCCACCTGTCTG -3'.

\section{Cell size, $\mathrm{PAX7}^{+}$cells population, differentiation and engraftment efficiency measurement}

The cell sizes were measured by Image J software (NIH). Bright field images of satellite cells cultured at different time points were acquired using Olympus DP73 microscope. Immediately after isolation, freshly isolated satellite cells were firstly plated and allowed to adhere for less than $6 \mathrm{~h}$ at $37^{\circ} \mathrm{C}$.

$\mathrm{PAX7}^{+}$cells population was expressed as the number of nuclei co-stained with DAPI and PAX7 divided by the total number of nuclei in the same field. More than 400 nuclei from 5 randomly chosen fields were analyzed.

$\mathrm{MyHC}^{+}$cells population was expressed as the number of nuclei co-stained with $\mathrm{MyHC}^{+}$ and DAPI divided by the total number of nuclei in the same field. More than $\mathbf{3 0 0 0}$ nuclei from 4 randomly chosen fields were analyzed.

The percentage of myotube nuclei in total nuclei was expressed as the nuclei inside myotube (at least 3 nuclei) divided by total nuclei in the same field. More than $\mathbf{3 0 0 0}$ nuclei from 4 randomly chosen fields were analyzed.

\section{Statistics}

Statistical analyses were performed using GraphPad Prism 5 (GraphPad Software). For comparisons of two treatment groups, a Student's t-test was used. For more than two groups, one-way ANOVA was used. Results are means \pm S.E.M. unless stated. $P<0.05$ is considered significant.

\section{Acknowledgements}

We thank the flow cytometry services and the confocal microscopy services in National Protein Science Center and SIBCB. This work was sponsored by grants from the Ministry of Science and Technology of China (2014CB964700 to P.H.), the CAS-CISTRO Cooperative Research Program (GJHZ1504 to P. H.), the National Natural Science Foundation of China (31671536 and 91649104 to P. H.), and the Key Research Program of the Chinese Academy of Sciences (KJZD-EW-L13 to P. H.). 


\section{References}

1. Almada AE, Wagers AJ. Molecular circuitry of stem cell fate in skeletal muscle regeneration, ageing and disease. Nature reviews Molecular cell biology 2016; 17: 267-279.

2. Sacco A, Doyonnas R, Kraft P, Vitorovic S, Blau HM. Self-renewal and expansion of single transplanted muscle stem cells. Nature 2008; 456: 502-506.

3. Kuang S, Kuroda K, Le Grand F, Rudnicki MA. Asymmetric self-renewal and commitment of satellite stem cells in muscle. Cell 2007; 129: 999-1010.

4. Collins CA, Olsen I, Zammit PS, Heslop L, Petrie A, Partridge TA, et al. Stem cell function, self-renewal, and behavioral heterogeneity of cells from the adult muscle satellite cell niche. Cell 2005; 122: 289301.

5. Quarta M, Brett JO, DiMarco R, De Morree A, Boutet SC, Chacon R, et al. An artificial niche preserves the quiescence of muscle stem cells and enhances their therapeutic efficacy. Nat Biotechnol 2016; 34: 752-759.

6. Cheung TH, Rando TA. Molecular regulation of stem cell quiescence. Nat Rev Mol Cell Bio 2013; 14: 329-340.

7. Zammit PS, Golding JP, Nagata Y, Hudon V, Partridge TA, Beauchamp JR. Muscle satellite cells adopt divergent fates: a mechanism for self-renewal? J Cell Biol 2004; 166: 347-357.

8. Relaix F, Zammit PS. Satellite cells are essential for skeletal muscle regeneration: the cell on the edge returns centre stage. Development 2012; 139: 2845-2856.

9. Sambasivan R, Yao R, Kissenpfennig A, Van Wittenberghe L, Paldi A, Gayraud-Morel B, et al. Pax7expressing satellite cells are indispensable for adult skeletal muscle regeneration. Development 2011; 138: 3647-3656.

10. Lepper C, Partridge TA, Fan CM. An absolute requirement for Pax7-positive satellite cells in acute injury-induced skeletal muscle regeneration. Development 2011; 138: 3639-3646.

11. Dumont NA, Wang YX, von Maltzahn J, Pasut A, Bentzinger CF, Brun CE, et al. Dystrophin expression in muscle stem cells regulates their polarity and asymmetric division. Nat Med 2015; 21: 1455-+.

12. Fry CS, Lee JD, Mula J, Kirby TJ, Jackson JR, Liu F, et al. Inducible depletion of satellite cells in adult, sedentary mice impairs muscle regenerative capacity without affecting sarcopenia. Nat Med 2015; 21: 76-80.

13. Douglas WR. Pigs and Men and Research - Review of Applications and Analogies of Pig, Sus Scrofa, in Human Medical-Research. Space Life Sci 1972; 3: 226-\&.

14. Groenen MAM, Archibald AL, Uenishi H, Tuggle CK, Takeuchi Y, Rothschild MF, et al. Analyses of pig genomes provide insight into porcine demography and evolution. Nature 2012; 491: 393-398.

15. Moser H. Duchenne muscular dystrophy: pathogenetic aspects and genetic prevention. Hum Genet 1984; 66: 17-40.

16. Klymiuk N, Blutke A, Graf A, Krause S, Burkhardt K, Wuensch A, et al. Dystrophin-deficient pigs provide new insights into the hierarchy of physiological derangements of dystrophic muscle. Hum Mol Genet 2013; 22: 4368-4382.

17. Nakamura A, Takeda S. Mammalian models of Duchenne Muscular Dystrophy: pathological characteristics and therapeutic applications. J Biomed Biotechnol 2011; 2011: 184393.

18. Seale P, Sabourin LA, Girgis-Gabardo A, Mansouri A, Gruss P, Rudnicki MA. Pax7 is required for the specification of myogenic satellite cells. Cell 2000; 102: 777-786. 
19. Sambasivan R, Gayraud-Morel B, Dumas G, Cimper C, Paisant S, Kelly R, et al. Distinct Regulatory Cascades Govern Extraocular and Pharyngeal Arch Muscle Progenitor Cell Fates. Dev Cell 2009; 16: 810-821.

20. Relaix F, Montarras D, Zaffran S, Gayraud-Morel B, Rocancourt D, Tajbakhsh S, et al. Pax3 and Pax7 have distinct and overlapping functions in adult muscle progenitor cells. J Cell Biol 2006; 172: 91-102.

21. Wen Y, Bi P, Liu W, Asakura A, Keller C, Kuang S. Constitutive Notch activation upregulates Pax7 and promotes the self-renewal of skeletal muscle satellite cells. Mol Cell Biol 2012; 32: 2300-2311.

22. Olguin HC, Yang Z, Tapscott SJ, Olwin BB. Reciprocal inhibition between Pax7 and muscle regulatory factors modulates myogenic cell fate determination. J Cell Biol 2007; 177: 769-779.

23. Kawabe YI, Wang YX, McKinnell IW, Bedford MT, Rudnicki MA. Carm1 Regulates Pax7 Transcriptional Activity through MLL1/2 Recruitment during Asymmetric Satellite Stem Cell Divisions. Cell stem cell 2012; 11: 333-345.

24. Hu P, Geles KG, Paik JH, DePinho RA, Tjian R. Codependent activators direct myoblast-specific MyoD transcription. Dev Cell 2008; 15: 534-546.

25. Keefe AC, Lawson JA, Flygare SD, Fox ZD, Colasanto MP, Mathew SJ, et al. Muscle stem cells contribute to myofibres in sedentary adult mice. Nat Commun 2015; 6.

26. Xu X, Wilschut KJ, Kouklis G, Tian H, Hesse R, Garland C, et al. Human Satellite Cell Transplantation and Regeneration from Diverse Skeletal Muscles. Stem Cell Rep 2015; 5: 419-434.

27. Mau M, Oksbjerg N, Rehfeldt C. Establishment and conditions for growth and differentiation of a myoblast cell line derived from the semimembranosus muscle of newborn piglets. In Vitro Cell Dev-An 2008; 44: 1-5.

28. Mesires NT, Doumit ME. Satellite cell proliferation and differentiation during postnatal growth of porcine skeletal muscle. Am J Physiol-Cell Ph 2002; 282: C899-C906.

29. Wilschut KJ, Haagsman HP, Roelen BAJ. Extracellular matrix components direct porcine muscle stem cell behavior. Exp Cell Res 2010; 316: 341-352.

30. Wilschut KJ, van Tol HTA, Arkesteijn GJA, Haagsman HP, Roelen BAJ. Alpha 6 integrin is important for myogenic stem cell differentiation. Stem Cell Res 2011; 7: 112-123.

31. Wilschut KJ, Tjin EPM, Haagsman HP, Roelen BAJ. Approaches to isolate porcine skeletal muscle stem and progenitor cells. Protocol Exchange 2010.

32. Ortenblad N, Young JF, Oksbjerg N, Nielsen JH, Lambert IH. Reactive oxygen species are important mediators of taurine release from skeletal muscle cells. Am J Physiol-Cell Ph 2003; 284: C1362-C1373.

33. Perruchot $\mathrm{MH}$, Ecolan $\mathrm{P}$, Sorensen IL, Oksbjerg N, Lefaucheur L. In vitro characterization of proliferation and differentiation of pig satellite cells. Differentiation 2012; 84: 322-329.

34. Qin LL, Xu J, Wu ZF, Zhang Z, Li JQ, Wang C, et al. Notch1-mediated signaling regulates proliferation of porcine satellite cells (PSCs). Cell Signal 2013; 25: 561-569.

35. Patruno M, Caliaro F, Martinello T, Mascarello F. Expression of the paired box domain Pax7 protein in myogenic cells isolated from the porcine semitendinosus muscle after birth. Tissue Cell 2008; 40: 1-6.

36. Fu X, Xiao J, Wei YN, Li S, Liu Y, Yin J, et al. Combination of inflammation-related cytokines promotes long-term muscle stem cell expansion. Cell Res 2015; 25: 655-673.

37. Liu L, Cheung TH, Charville GW, Rando TA. Isolation of skeletal muscle stem cells by fluorescenceactivated cell sorting. Nat Protoc 2015; 10: 1612-1624.

38. Pasut A, Oleynik $P$, Rudnicki MA. Isolation of muscle stem cells by fluorescence activated cell sorting cytometry. Methods in molecular biology 2012; 798: 53-64. 
39. Pisani DF, Dechesne CA, Sacconi S, Delplace S, Belmonte N, Cochet O, et al. Isolation of a Highly Myogenic CD34-Negative Subset of Human Skeletal Muscle Cells Free of Adipogenic Potential. Stem Cells 2010; 28: 753-764.

40. Perruchot MH, Lefaucheur L, Barreau C, Casteilla L, Louveau I. Age-related changes in the features of porcine adult stem cells isolated from adipose tissue and skeletal muscle. Am J Physiol-Cell Ph 2013; 305: C728-C738.

41. Hynes RO. Integrins: bidirectional, allosteric signaling machines. Cell 2002; 110: 673-687.

42. Schwander M, Leu M, Stumm M, Dorchies OM, Ruegg UT, Schittny J, et al. beta 1 integrins regulate myoblast fusion and sarcomere assembly. Dev Cell 2003; 4: 673-685.

43. Rozo M, Li L, Fan CM. Targeting beta1-integrin signaling enhances regeneration in aged and dystrophic muscle in mice. Nat Med 2016; 22: 889-896.

44. Bosnakovski D, Xu ZH, Li W, Thet S, Cleaver O, Perlingeiro RCR, et al. Prospective Isolation of Skeletal Muscle Stem Cells with a Pax7 Reporter. Stem Cells 2008; 26: 3194-3204.

45. Montarras D, Morgan J, Collins C, Relaix F, Zaffran S, Cumano A, et al. Direct isolation of satellite cells for skeletal muscle regeneration. Science 2005; 309: 2064-2067.

46. Parker MH, Loretz C, Tyler AE, Duddy WJ, Hall JK, Olwin BB, et al. Activation of Notch Signaling During Ex Vivo Expansion Maintains Donor Muscle Cell Engraftment. Stem Cells 2012; 30: 2212-2220.

47. Charville GW, Cheung TH, Yoo B, Santos PJ, Lee GK, Shrager JB, et al. Ex Vivo Expansion and In Vivo SelfRenewal of Human Muscle Stem Cells. Stem Cell Rep 2015; 5: 621-632.

48. Wilschut KJ, Jaksani S, Van Den Dolder J, Haagsman HP, Roelen BAJ. Isolation and Characterization of Porcine Adult Muscle-Derived Progenitor Cells. J Cell Biochem 2008; 105: 1228-1239.

49. Allbrook DB, Han MF, Hellmuth AE. Population of muscle satellite cells in relation to age and mitotic activity. Pathology 1971; 3: 223-243.

50. Li MY, Sibbons PD, Hornick P, Ansari T. The use of commercially available antibodies in the study of vascular disease using a porcine model. Comparative Clinical Pathology 2006; 16: 15-23.

51. Rodgers JT, King KY, Brett JO, Cromie MJ, Charville GW, Maguire KK, et al. mTORC1 controls the adaptive transition of quiescent stem cells from G(0) to G(Alert). Nature 2014; 510: 393-+.

52. Gilbert PM, Havenstrite KL, Magnusson KEG, Sacco A, Leonardi NA, Kraft P, et al. Substrate Elasticity Regulates Skeletal Muscle Stem Cell Self-Renewal in Culture. Science 2010; 329: 1078-1081.

53. Fu X, Wang HT, Hu P. Stem cell activation in skeletal muscle regeneration. Cell Mol Life Sci 2015; 72: 1663-1677. 


\section{Supplementary information}

Figure S1. Comparison of the partial peptide sequences of PAX3 and PAX7 in cattle, human, mouse and pig. Related to Figure 1

$\begin{array}{lrll}\text { PAX3 (Bt) } & 1 & \text { GGVFINGRPLPNHIRHKIVEMAHHGIRPCVISRQLRVSHGCV } & 42 \\ \text { PAX3 (Hs) } & 1 & \text { GGVFINGRPLPNHIRHKIVEMAHHGIRPCVISRQLRVSHGCV } & 42 \\ \text { PAX3 (Ms) } & 1 & \text { GGVFINGRPLPNHIRHKIVEMAHHGIRPCVISRQLRVSHGCV } & 42 \\ \text { PAX3 (Ss) } & 1 & \text { GGVFINGRPLPNHIRHKIVEMAHHGIRPCVISRQLRVSHGCV } & 42 \\ \text { PAX7 (Bt) } & 1 & \text { GGVFINGRPLPNHIRHKIVEMAHHGIRPCVISRQLRVSHGCV } & 42 \\ \text { PAX7 (Hs) } & 1 & \text { GGVFINGRPLPNHIRHKIVEMAHHGIRPCVISRQLRVSHGCV } & 42 \\ \text { PAX7 (Ms) } & 1 & \text { GGVINGRPLPNHIRHKIVEMAHHGIRPCVISRQLRVSHGCV } & 42 \\ \text { PAX7 (Ss: AAT72072 ) } & 1 & \text { GGVFINGRPLPNHIRHKIVEMAHHGIRPCVISRQLRVSHGCV } & 42 \\ \text { Consensus } & 1 & \text { GGVINGRPLPNHIRHKIVEMAHHGIRPCVISRQLRVSHGCV } & 42 \\ \text { PAX3 (Bt) } & 43 & \text { SKILCRYQETGSIRPGAIGGSKPKQVTTPDVEKK 76 } & \\ \text { PAX3 (Hs) } & 43 & \text { SKILCRYQETGSIRPGAIGGSKPK-VTTPDVEKK 76 } & \\ \text { PAX3 (Ms) } & 43 & \text { SKILCRYQETGSIRPGAIGGSKPKQVTTPDVEKK 76 } & \\ \text { PAX3 (Ss) } & 43 & \text { SKILCRYQETGSIRPGAIGGSKPKQVTTPDVEKK 76 } & \\ \text { PAX7 (Bt) } & 43 & \text { SKILCRYQETGSIRPGAIGGSKPR-VATPDVEKK 76 } & \\ \text { PAX7 (Hs) } & 43 & \text { SKILCRYQETGSIRPGAIGGSKPRQVATPDVEKK 76 } & \\ \text { PAX7 (Ms) } & 43 & \text { SKILCRYQETGSIRPGAIGGSKPRQVATPDVEKK 76 } & \\ \text { PAX7 (Ss: AAT72072 } & 43 & \text { SKILCRYQETGSIRPGAIGGSKPRQVATPDVEKK 76 } & \\ \text { Consensus } & 43 & \text { SKILCRYQETGSIRPGAIGGSKP QV TPDVEKK 76 } & \\ & & & \end{array}$

The comparison of partial predicted peptide sequences of PAX3 and PAX7 in cattle, human, mouse and pig. The green and blue background indicates differences on two key amino acids between PAX3 and PAX7 peptide sequence. 
Figure S2. Identification of the completed CDNA sequence of pig PAX7 by RACE. Related to Figure 1

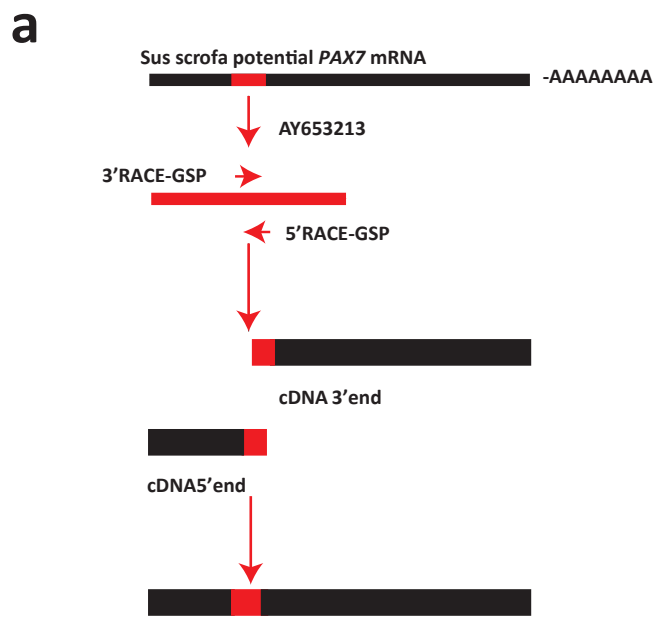

Sus scrofa PAX7 cDNA

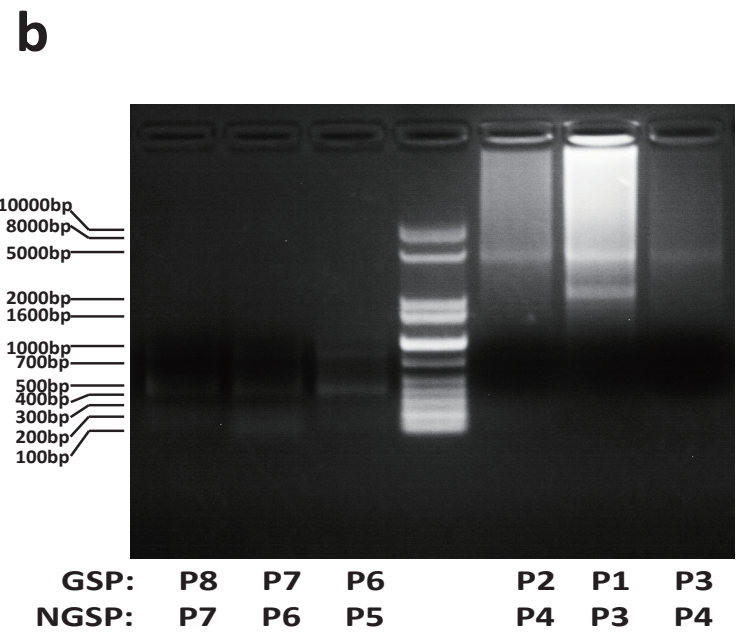

(a) The strategy to generate full-length pig PAX7 cDNA sequence by RACE. The red band indicates the seed sequence for RACE. (b) The 5' and 3' cDNA fragments generated by 5' and 3' RACE reactions. GSP indicates gene specific primer, NGSP indicates nested gene specific primer. The band generated by 5 ' RACE was about $400 \mathrm{bp}$ ( $\mathrm{b}$ left) and a $5 \mathrm{~kb}$ fragment was generated by the 3'RACE (b right). 
Figure S3. Alignment of pig PAX7 polypeptide sequence from different species. Related to Figure 1

\section{a}

\begin{tabular}{|c|c|c|c|}
\hline & PAX & Homeobox & Pax7 \\
\hline Ss PAX7 CDS: & 01777771 & $\sqrt{771}$ & $\sqrt{7}$ \\
\hline Hs PAX7 CDS: & 口1777777 & 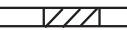 & $\bar{L}$ \\
\hline
\end{tabular}

NM_001135254 (1518 bp, Identity: 93\%)

NM_011039 (1512 bp Identity: 90\%)

b

\begin{tabular}{|c|c|c|c|c|}
\hline & PAX & Homeobox & Pax7 & \\
\hline Ss PAX7 protein: & $\square / 7 / 17 / 1$ & $\mathrm{~V} / \mathrm{C}$ & $\mathrm{V}$ & \\
\hline Hs PAX7 protein: & 口17777771 & $D 77$ & $D A$ & NP_001128726 (505 aa, Identity: 99\%) \\
\hline Ms PAX7 protein: & पZZZZZA & DZA & DA & NP_035169 (503 aa, Identity: 98\%) \\
\hline
\end{tabular}

(a) Alignment of the full-length pig PAX7 CDS with human and mouse Pax7. Hatched indicates the conserved domains. Human (Homo sapiens, Hs) and mouse (Mus musculus, Ms) PAX7 cDNA sequences were aligned with assembled pig PAX7 cDNA sequence. (b) The human and mouse PAX7 polypeptide sequences were aligned with a pig PAX7 polypeptide sequence derived from full length CDS. 
Chapter 2

Figure S4. Identification of the cell surface marker for swine satellite cells. Related to Figure 3

a

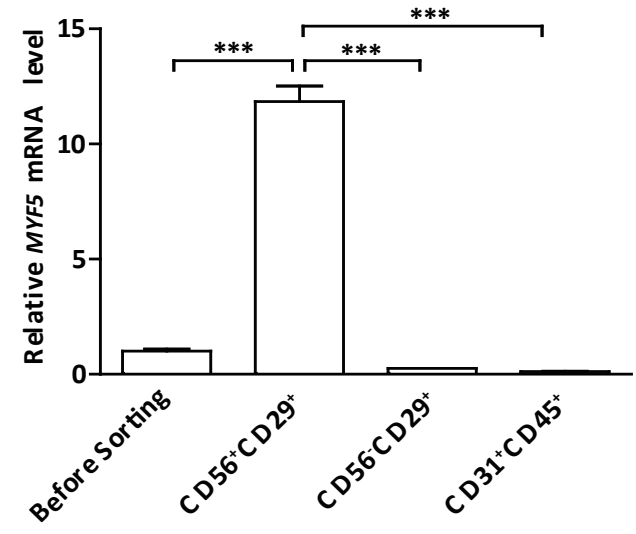

b
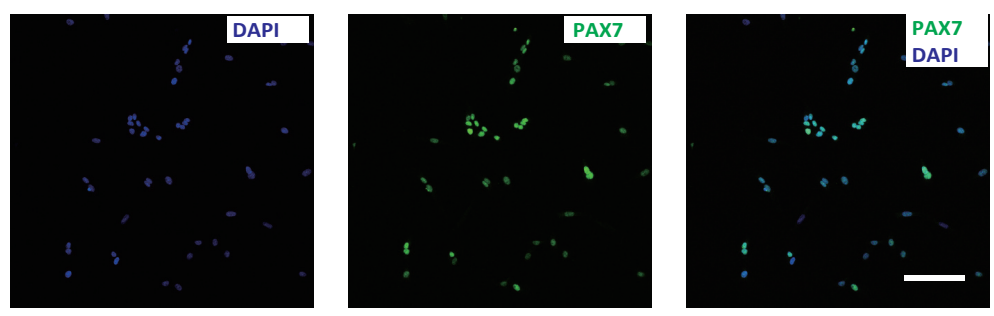

(a) RT-qPCR analysis of MYF5 mRNA levels in freshly isolated pig satellite cells and other cell populations. Error bars represented S.E.M. and were based on 4 independent experiments. Significance was analyzed by student's t-test, $* * *$ indicates $p<0.001$. (b) Immunofluorescent staining of PAX7 in pig satellite cells cultured 4 days in vitro. Cells were stained with antibodies against PAX7 and with DAPI to identify nuclei. Blue: DAPI; Green: PAX7. Scale bars: $50 \mu \mathrm{m}$. 
Figure S5. Related to Figure 4. In vitro proliferation and differentiation features of pig satellite cells. Related to Figure 4
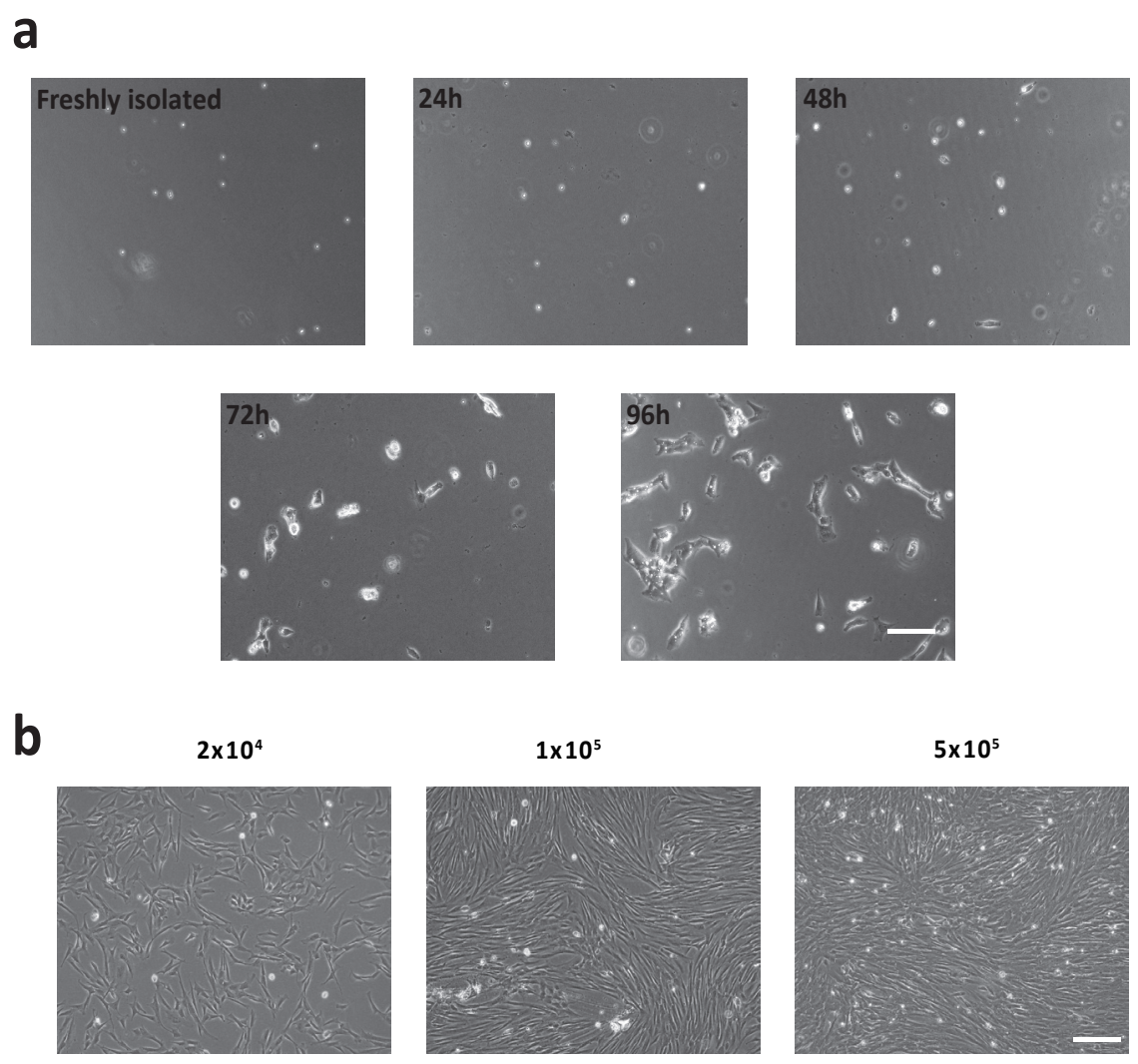

(a) Representative phase contrast images of pig satellite cells cultured in F-10 medium for various hours. Scale bars: $100 \mu \mathrm{m}$. (b) Representative phase-contrast pictures of $2 \times 10^{4}, 1 \times 10^{5}, 5 \times 10^{5}$ cells cultured in F10 medium in $3.5 \mathrm{~cm}$ dish for 2 days. Scale bars: $200 \mu \mathrm{m}$. 
Chapter 2

Figure S6. Swine satellite cells contributed to muscle regeneration in recipient mice. Related to Figure 6

a
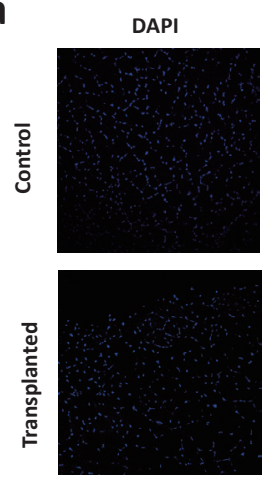

b
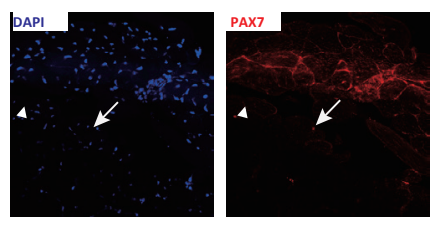

C
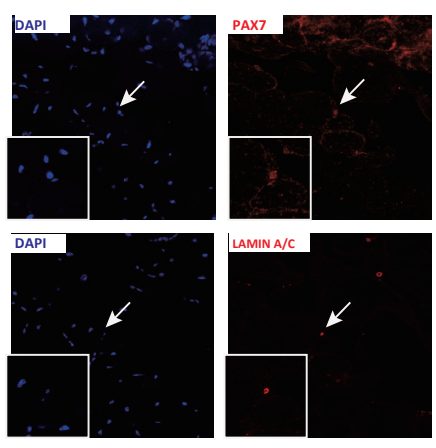

LAMIN A/C
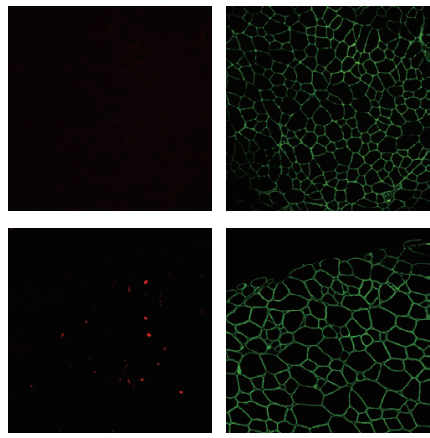

MERGE
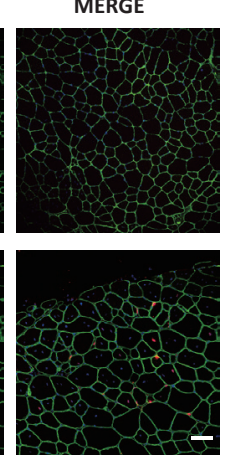
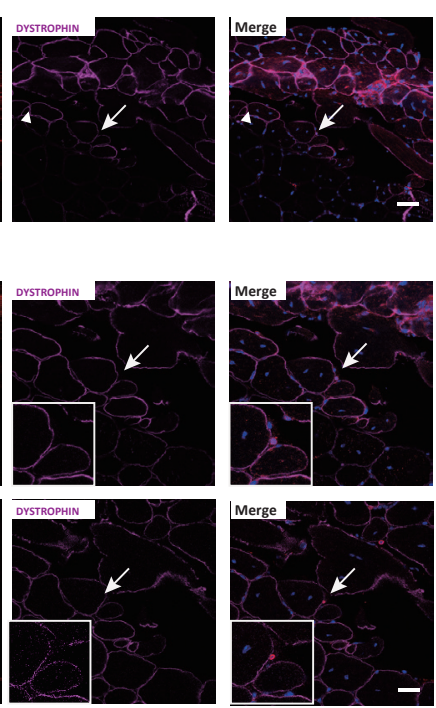

(a) Four weeks after transplantation, engraftment efficiency of freshly isolated pig satellite cells was determined by DYSTROPHIN and LAMIN A/C immunofluorescent staining with muscle sections derived from recipient mice. PBS was injected as negative control. Blue: DAPI; Red: LAMIN A/C; Green: DYSTROPHIN. Scale bars: $100 \mu \mathrm{m}$. (b) PAX7, immunofluorescent staining with muscle sections derived from recipient mice four weeks after transplantation. Blue: DAPI; Red: PAX7; Purple: DYSTROPHIN. Arrow and arrowhead indicate PAX7 expressing satellite cells. Scale bars: 100 $\mu \mathrm{m}$. (c) Pax7, LAMIN A/C immunofluorescent staining with series muscle sections derived from recipient mice four weeks after transplantation. Blue: DAPI; Red: PAX7 (c, top) or LAMIN A/C (c, bottom); Purple: DYSTROPHIN. Scale bars: $20 \mu \mathrm{m}$. 


Chapter 3

\section{Maintaining bovine satellite cells stemness through $p 38$ pathway}

Shijie Ding, Swennen GNM, Tobias Messmer, Mick Gagliardi, Daniël G. M. Molin, Chunbao Li, Guanghong Zhou, Mark J. Post

Sci Rep-UK 8, 2018. DOI Artn 10808 10.1038/S41598-018-28746-7. 


\begin{abstract}
Isolating and maintaining the appropriate stem cell for large scale cell culture is essential in tissue engineering or food production. For bovine satellite cells an optimized isolation and purification protocol is lacking and there is also no detailed understanding on the factors that maintain stemness of these cells. Here, we set up a fluorescence-activated cell sorting strategy to enrich bovine satellite cells. We found that p38-MAPK signaling is activated and PAX7 expression is gradually lost during satellite cell proliferation. The p38 inhibitor (SB203580) treatment maintained PAX7 expression but inhibited the fusion of satellite cells in a concentration-dependent way in short-term incubation. The mechanism of p38 inhibition was confirmed by inhibiting canonical p38 signaling, i.e. HSP27. Long-term culture with an appropriate concentration of $\mathrm{p} 38 \mathrm{i}$ enhanced the proliferation and PAX7 expression, while the differentiation capacity recovered and was enhanced compared to vehicle control. These studies indicate that bovine satellite cells maintenance depends on cell purity and p38 MAPK signaling. Inhibition of p38 MAPK signaling is a promising strategy to facilitate large scale cell expansion of primary cells for tissue engineering and cultured meat purposes.
\end{abstract}




\section{Introduction}

Satellite cells, initially identified by Mauro ${ }^{1}$ in 1961 , are the bona fide muscle stem cells. These cells are located beneath the sarcolemma and the basal membrane and originate from the dermomyotome cell population ${ }^{2}$. During peri- and postnatal development, satellite cells contribute new nuclei to growing muscle fibers by fusing with the adjacent fiber $^{3,4}$. Subsequently, they enter a quiescent stage and are activated in injured muscle or for further muscle growth ${ }^{3,5,6}$. Understanding the biology of satellite cells will help understand skeletal muscle regeneration, ageing , disease ${ }^{5}$ as well as the emerging field of culturing meat. Culturing meat for consumption uses stem cells to culture muscle tissue for future meat consumption with potential benefits for the environment, animal welfare and food security 7,8 . This technology depends heavily on the ability of satellite cells to expand to high numbers of cells, for instance by maintaining their stemness while providing fast-growing myoblast colonies ${ }^{7,9}$.

Maintaining or improving stemness, requires a highly purified satellite cell population. Bovine satellite cells are usually isolated by the preplating method ${ }^{10,11}$, which in the absence of further purification leads to a purity of $31 \%$ based on fusion index or $95 \%$ by DESMIN staining ${ }^{11,12}$. Satellite cells can be further purified using cell surface markers, but these are mostly characterized for mice and humans ${ }^{13-15}$ as well as for pigs ${ }^{16}$, not for cattle. Highly purified mouse ${ }^{17}$, human ${ }^{15,18}$ and pig $^{16}$ satellite cell populations can be obtained by fluorescence-activated cell sorting (FACS) using CD34, $\beta 7$-integrin, CD56 or $\mathrm{CD} 29^{15-17,19}$. Expression of these markers is species specific. For instance, mouse satellite cells express CD34, whereas human satellite cells do not ${ }^{17,18,20}$. Bovine satellite cell marker expression is not well characterized. We therefore first set out to purify the initial population of bovine satellite cells, based on marker expression.

Further maintenance of satellite cell stemness can depend on cell signaling during proliferation. p38, a subgroup of the Mitogen Activated Protein Kinases (MAPKs), can be activated by stress signals, inflammatory cytokines, and many other stimuli and has been implicated in cell proliferation, senescence, apoptosis and other cellular processes ${ }^{21,22}$. The $p 38 \alpha / \beta$ MAPK signaling pathway regulates asymmetric division of satellite cells ${ }^{23}$. One daughter cell activates $\mathrm{p} 38 \alpha / \beta$ MAPK, induces $M y o D$ expression and generates a proliferating myoblast ${ }^{23}$. In the other daughter cell $p 38 \alpha / \beta$ MAPK signaling is not activated and $M y O D$ is not induced, thus renewing the quiescent satellite cell to maintain the stem cell pool ${ }^{23}$.

Previous studies have noted that p38-MAPK signaling plays an important role in the loss of stemness in satellite cells ${ }^{18,22,24,25}$. Acute injury in p38 $\alpha$-deficient mice resulted in a prolonged satellite cell response and an increased stem cell pool ${ }^{25}$. Conversely, elevated activity of $\mathrm{p} 38 \alpha / \beta$ MAPK signaling induced regenerative defects in older satellite cells compared with younger ones ${ }^{24}$. In the same model, inhibition of $p 38 \alpha / \beta$ MAPK signaling and culture on soft hydrogel substrates rejuvenated older satellite cells' potential for regeneration ${ }^{24}$. 
In a purified bovine satellite cell population, we investigated if bovine satellite cells showed up-regulated p38 MAPK signaling accompanied by a loss of differentiation ability during long-term culturing in vitro and if p38 inhibition could rescue stemness of satellite cells. Specifically, we found that the $p 38 \alpha / \beta$ inhibitor SB203580 inhibited the differentiation of bovine satellite cells in short-term experiments while long-term cultivation with p38i helped maintain the stemness and differentiation abilities.

\section{Results}

\section{FACS purification of bovine satellite cells}

To isolate bovine satellite cells by FACS method, we firstly analyzed PAX7, CD56 and CD29 protein expression in mature bovine muscle fibers (Figure 1a). PAX7 is the most specific marker of satellite cells ${ }^{26,27}$ and bovine satellite cells were recognized by PAX7 nuclear staining. Both CD56 and CD29 co-stained with PAX7 in bovine skeletal muscle fibers (Figure 1a). This suggests that these two proteins might serve as positive markers for bovine satellite cells in FACS method. CD31 and CD45, two antibodies against endothelial cells and hematopoietic cells were utilized as negative markers for sorting satellite cells ${ }^{16-18}$. After isolating the mononuclear cell population obtained from bovine skeletal muscles, Hoechst was used to distinguish cells and tissue debris (Figure 1b, left). Then the $\mathrm{CD} 31^{-} \mathrm{CD} 45^{-} \mathrm{CD} 56^{+} \mathrm{CD} 29^{+}$cells were isolated as bovine satellite cells (Figure $1 \mathrm{~b}$ middle, right). PAX7, PAX3 and MYF5 mRNA were highly expressed in sorted satellite cells compared with unsorted cells or satellite cell depleted populations (Figure 1c, Supplementary Figure S1a, b). Immunofluorescent staining for PAX7 further confirmed the satellite cell identity (Figure $1 \mathrm{~d}$ ). About $92 \%$ sorted satellite cells were co-stained with DAPI and PAX7 protein (Figure 1d and 1e). We also checked other surface markers and transcriptional factors of sorted satellite cells (Supplementary Figure S1c-g), such as MYOD $^{28}(98.48 \pm 1.81 \%)$, DESMIN $^{29}(98.57 \pm 2.13 \%)$, M-Cadherin ${ }^{28,30}(97.64 \pm 0.89 \%)$, MYF5 $^{17}(97.01 \pm 2.73 \%), I T G A 7^{17}(98.27 \pm 3.03 \%)$. These results indicate that bovine satellite cells can be isolated from muscles tissue and purified by FACS sorting using CD31 and CD45 negative selection followed by CD56 and CD29 positive selection. 
Figure 1. Isolation bovine satellite cells by specific cell surface markers

a
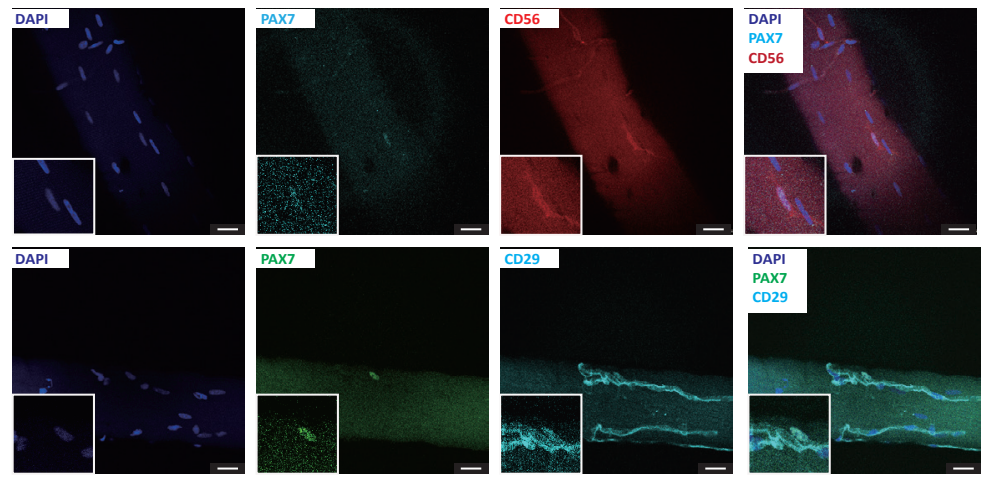

b
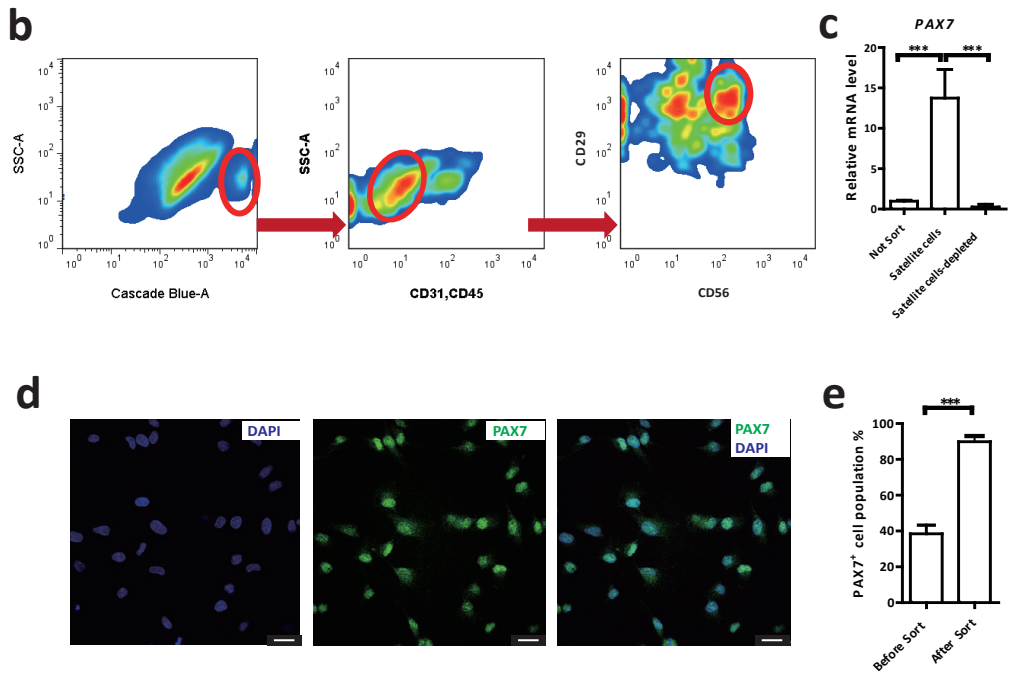

(a) Representative Immunofluorescent staining of DAPI, PAX7, CD56 (a, top), CD29 (a, bottom) on an adult bovine muscle fiber. Scale bars: $25 \mu \mathrm{m}$. (b) FACS analysis of mononuclear cells from biceps femoris obtained from adult cow. Cells were gated by forward scatter and side scatter (not shown) prior to gating for Hoechst, CD45/31, CD56/29. Red gates (ovals) indicate sub-populations containing bovine satellite cells. (c) qRT-PCR analysis of PAX7 mRNA levels in total cells (not sorted), sorted satellite cells and satellite cells depleted populations after a period of 4 days in culture. $(n=3)$. (d) Representative Immunofluorescent staining of PAX7 in sorted bovine satellite cells cultured for 4 days. Scale bars: $25 \mu \mathrm{m}$. (e) Quantification of PAX7 immunofluorescent staining of sorted $\mathrm{CD} 56^{+} \mathrm{CD} 29^{+}$cells and unsorted cells cultured for 4 days $(n=3)$. Data are represented as mean \pm SEM. Significance was analyzed by Student's t-test for 2 groups, One-way ANOVA with Bonferroni's Multiple Comparison Test for more than 2 groups. Asterisks: *** indicates $P<0.001$. 
p38 inhibition maintains PAX7 expression in bovine satellite cells

To investigate if phosphorylated (activated) p38 (p-p38) is up-regulated during culturing of bovine satellite cells, we stained the p-p38 together with PAX7 in muscle fiber and cultured bovine satellite cells (Figure $2 \mathrm{a}$ ). In muscle fibers, only $4.6 \%$ of total PAX7 ${ }^{+}$ cells $(n=44)$ is $p-p 38^{+}$as opposed to cultured satellite cells, where $95.7 \%$ of PAX7 $7^{+}$ cells $(n=140)$ are $p-p 38^{+}$. Phosphorylated-p38 was absent from quiescent satellite cells in bovine muscle fibers (Figure 2a, top); it was activated during cell culture and expansion (Figure 2a, bottom). Inhibition of p38 (p38i) MAPK signaling by SB203580 concentration-dependently increased the expression of PAX7 mRNA (Figure 2b), whereas the solvent had no effect. Up to a concentration of $10 \mu \mathrm{M}$, the p38 inhibitor had no effect on cell proliferation measured by EdU incorporation (Figure 2c). Effective p38 inhibition by SB203580 was shown by significantly reduced phosphorylation of the p38 substrate HSP27 (Ser82) ${ }^{18,24}$ (Figure 2d, 2e and Supplementary Figure S2a, 2b). However, in confluent cell culture, the $p-p 38 / p 38$ ratio was only slightly decreased by p38i treatment (Figure $2 \mathrm{~d}, 2 \mathrm{e}$ ). These results show that p38 MAPK signaling is activated in bovine satellite cells during culture and that short-term inhibition of p38 MAPK signaling maintains the $P A X 7$ expression suggesting that stemness is preserved.

\section{p38 inhibition reversibly interferes with myoblast differentiation}

In order to establish p38i effects on the ability of bovine myoblasts to differentiate into myocytes, we cultured bovine satellite cells with different concentrations of the p38 inhibitor. Similar to human ${ }^{18}$, bovine satellite cells automatically fused to form myotubes upon reaching confluency (Figure 3a, left top, 3d). However, myotube formation was inhibited in p38i treatment groups (Figure 3a, 3d). At $10 \mu \mathrm{M}$ and $20 \mu \mathrm{M}$, SB203580 strongly inhibited myotube formation (Figure 3a, 3d). MYOGENIN (MYOG) and Myosin Heavy Chain (MyHC), both markers of myocyte differentiation, were also inhibited by $\mathrm{p} 38 \mathrm{i}$ in a concentration-dependent manner (Figure 3b, 3c). The proliferative potential of bovine satellite cells as undifferentiated cells was maintained in p38i treatment group (Supplementary Figure S3a, 3b). Immunofluorescent staining for Pax 7 showed that the percentage of Pax7 positive cells was also higher in p38i treatment group (Supplementary Figure S3a, 3b). Cell lysates of 6 days cultured satellite cells accumulate more $\mathrm{p}-\mathrm{HSP} 27, \mathrm{MyHC}$ proteins in the control group than in p38i treatment group (Figure $3 \mathrm{e}-\mathrm{g}$ ). However, the p-p38/p38 ratio showed only a slightly increase. To test whether the inhibition was reversible, we cultured cells with $10 \mu \mathrm{M}$ p38i for 4 days until confluency and then induced differentiation with differentiation medium in the absence of p38i. Prior p38i treated satellite cells fused into myotubes to the same degree as in the control group (Supplementary Figure S3e) suggesting that the effect on differentiation is reversible. Taken together, p38i reversibly inhibits bovine satellite cells differentiation in a concentration-dependent way. 
Figure 2. p38 inhibition maintains PAX7 expression in bovine satellite cells

a
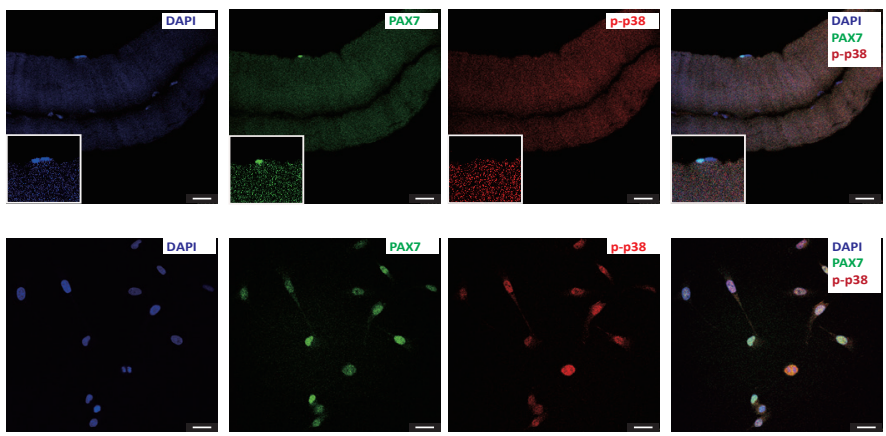

b

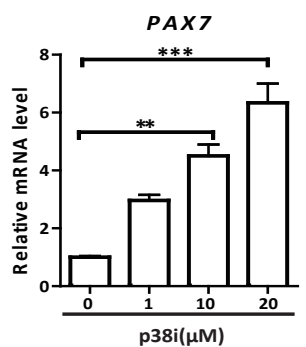

C

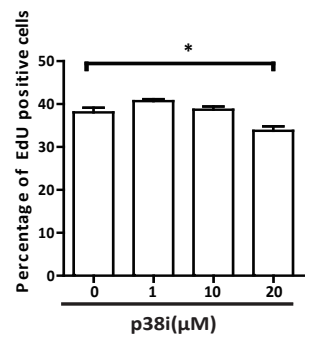

d

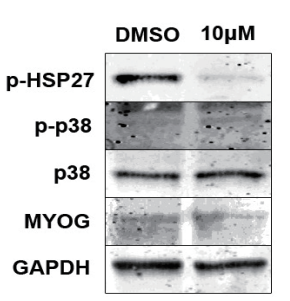

e

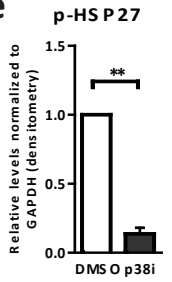

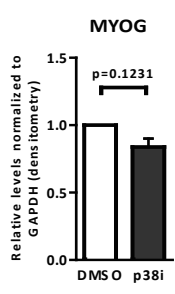

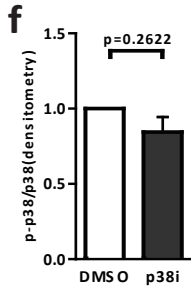

(a) Representative immunofluorescent staining of DAPI, PAX7 and p-p38 in quiescent bovine satellite cells (freshly isolated fiber, top) and activated satellite cells in culture (bottom). Scale bars: $25 \mu \mathrm{m}$. (b) qRTPCR: concentration-dependent inhibition of PAX7 expression in 2 days cultured satellite cells (passage 2) by p38i inhibitor SB203580. ( $n=3$ ). (c) Relative percentage of $1.5 \mathrm{hr}$ window EdU incorporation at given concentrations of $\mathrm{p} 38 \mathrm{i}$ for satellite cells at passage 2 after 2 days culturing. $(n=4)$. (d) Representative images of immunoblotting against p-HSP27, p-p38, p38, and GAPDH from cell lysates of cells cultured 4 days to $90 \%$ confluent in the presence or absence of $10 \mu \mathrm{M}$ p38i. Full-length blots are presented in Supplementary Figure S5. (e) Relative levels of p-HSP27 normalized to GAPDH are indicated from (d). (n=3). (f) Relative levels of $p$-p38 normalized to p38 from (d). $(n=3)$. Data are represented as mean \pm SEM. Significance was analyzed by Student's t-test for 2 groups, One-way ANOVA with Bonferroni's Multiple Comparison Test for more than 2 groups. Asterisks: * indicates $P<0.05, * *$ indicates $\mathrm{P}<0.01, * * *$ indicates $P<0.001$. 
Chapter 3

Figure 3. $p 38$ inhibition interferes with myoblast differentiation

a
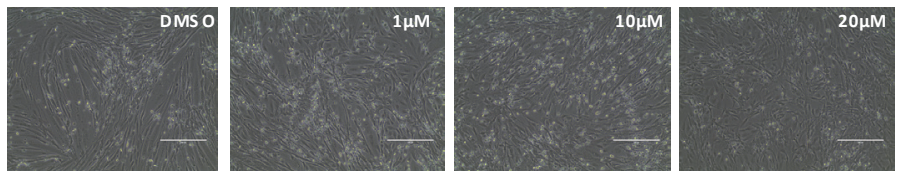

b

C

d
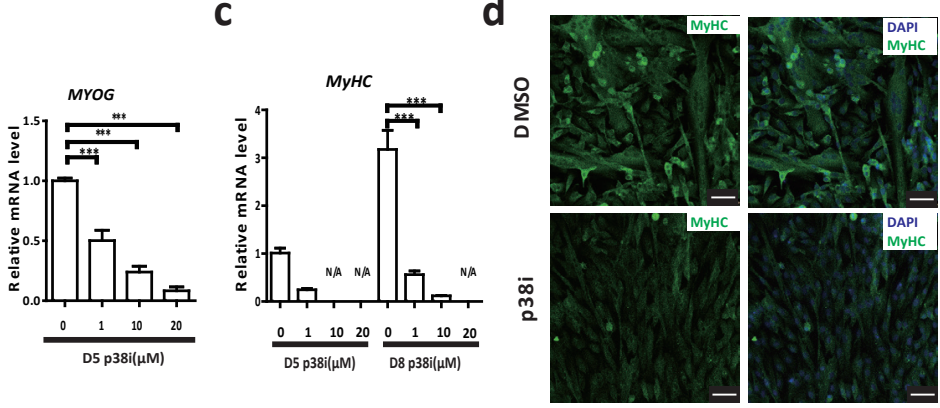

e

\section{f}
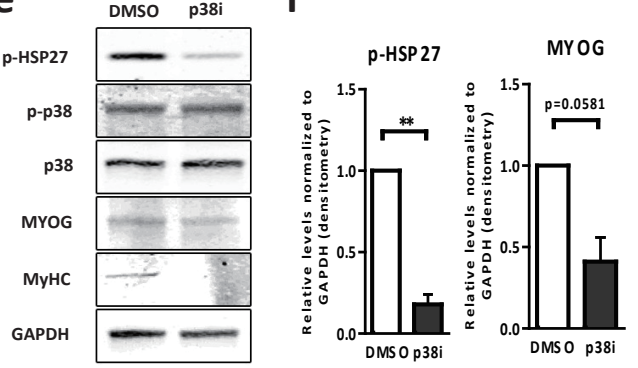

g

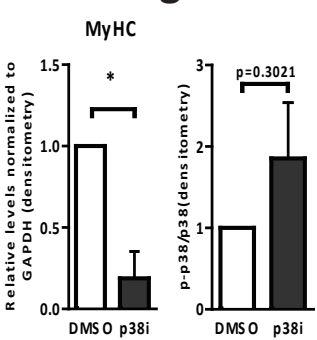

(a) Representative phase contrast images of passage 2 bovine satellite cells cultured for 6 days at given concentrations of p38i (SB203580). Scale bars: $200 \mu \mathrm{m}$.(b) MYOG expression after 5 days of culture at given concentrations of p38i. ( $n=3$ ) (c) MyHC expression after 5 and 8 days of culture at given concentrations of p38i. ( $n=3$ ). (d) Representative immunofluorescent staining of DAPI and MyHC after 6 days of culture in the presence or absence of p38i. Scale bars: $50 \mu \mathrm{m}$. (e) Representative images of immunoblotting against p-HSP27, p-p38, p38, MyHC and GAPDH from cell lysates of cells cultured 6 days in the presence or absence of $10 \mu \mathrm{M}$ p38i. Full-length blots are presented in Supplementary Figure S5. (f) Relative levels of p-HSP27 and MyHC normalized to GAPDH are indicated from (d). (n=3). (g) Relative levels of p-p38 normalized to p38 from (d). $(n=3)$. Data are represented as mean \pm SEM. Significance was analyzed by Student's t-test for 2 groups, One-way ANOVA with Bonferroni's Multiple Comparison Test for more than 2 groups. Asterisks: ${ }^{*}$ indicates $P$ $<0.05,{ }^{*}$ indicates $P<0.01, * * *$ indicates $P<0.001$. N/A: not available. 
Long-term p38 inhibition delays loss in stemness of bovine satellite cells As p38i can short-term maintain bovine satellite cells stemness in an undifferentiated state, we next checked the long-term effects of p38i on cultured bovine satellite cells. Firstly, we checked the protein expression of p-HSP27, p-p38, p38 in different passage cells. During long-term culturing in vitro, bovine satellite cells showed an upregulated p-HSP27 expression (Supplementary Figure S4a). Cells could be propagated logarithmically while long-term exposure to p38 inhibition supported bovine satellite cell proliferation (Figure 4a, 2-way ANOVA with time and treatment as independent variables: $P<0.0001$ for time effect, $P<0.0001$ for $p 38$ i treatment effect, $P<0.0001$ for interaction effect). CD56 and CD29 expression were also analyzed by FACS. Inhibition of p38 maintained CD56 expression compared with the control group (Figure 4b). The expression of PAX7 mRNA decreased in both groups during passages (Figure 4c). However, p38i resulted in higher PAX7 expression levels compared to controls (Figure 4c, 2-way ANOVA with passage and treatment as independent variables: $P<0.0001$ for passage effect, $P<0.0001$ for p38i treatment effect, $P<0.0001$ for interaction effect). We further ascertained PAX7 positivity of cells in each passage (Supplementary Figure S4b). Consistently, the percentage of $\mathrm{PAX7}^{+}$cells also decreased during passages whereas p38 inhibition continued to show a larger population of PAX7-positive cells (Figure 4d, 2-way ANOVA with passage and treatment as independent variables: $P<0.0001$ for passage effect, $P<0.0001$ for p38i treatment effect, $P=0.0469$ for interaction effect). To analyze the differentiation ability of myoblasts upon passaging, we induced differentiation when cells were $90 \%$ confluence at each passage. After 10 passages, cultured myoblasts lost their capacity to differentiate into myocytes, whereas myoblasts exposed to p38 inhibition maintained this capacity (Figure 5a, b, 2-way ANOVA with passage and treatment as independent variables: $P<0.0001$ for passage effect, $P<0.0001$ for $p 38$ i treatment effect, $P<0.0001$ for interaction effect). Taking together, p38 inhibition during long-term culture maintains stemness and the ability to differentiate of bovine satellite cells. 
Figure 4. Long-term p38 inhibition maintains bovine satellite cells proliferation and PAX7 expression

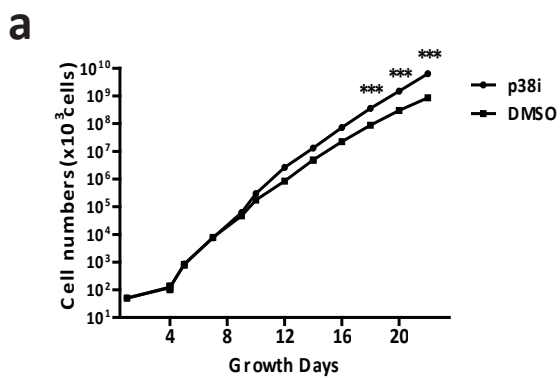

b
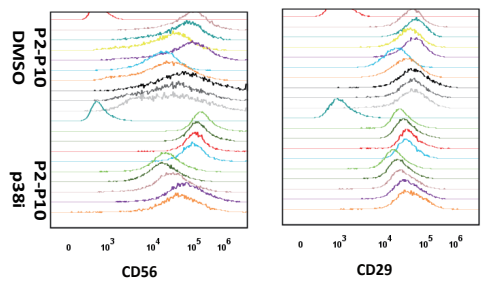

C
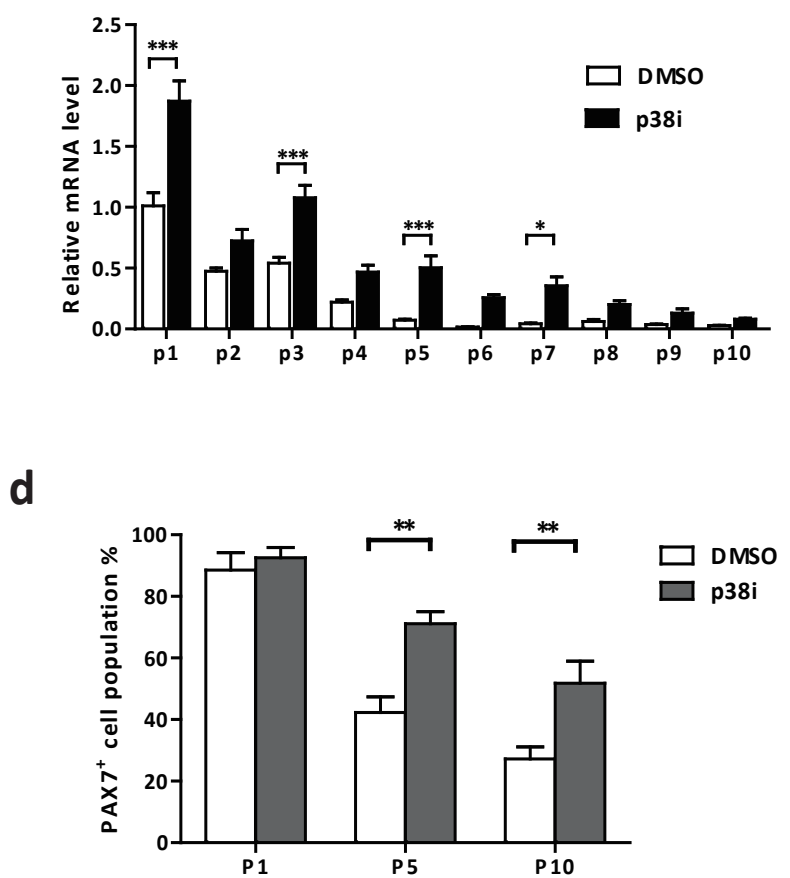

(a) Growth curves of bovine satellite cells in absence and presence of p38i. (n=3). (b) FACS analysis of CD56 (left) and CD29 (right) expression from different passages (P2-P10) of bovine satellite cells with DMSO (top 9 lines) and p38i treatment (bottom 9 lines). (c) PAX7 mRNA levels at different passages $(n=3)$. (d) Quantification of PAX7 immunofluorescent staining of different passages. $(n=3)$. Data are represented as mean \pm SEM. Significance was analyzed by 2-way ANOVA and Bonferroni post-tests were used to compare treatment in different passages. Asterisks: * indicates $P<0.05, * *$ indicated $P<0.01$. *** indicates $P<0.001$. 
Figure 5. Long-term p38 inhibition delays loss in differentiation of bovine satellite cells

a
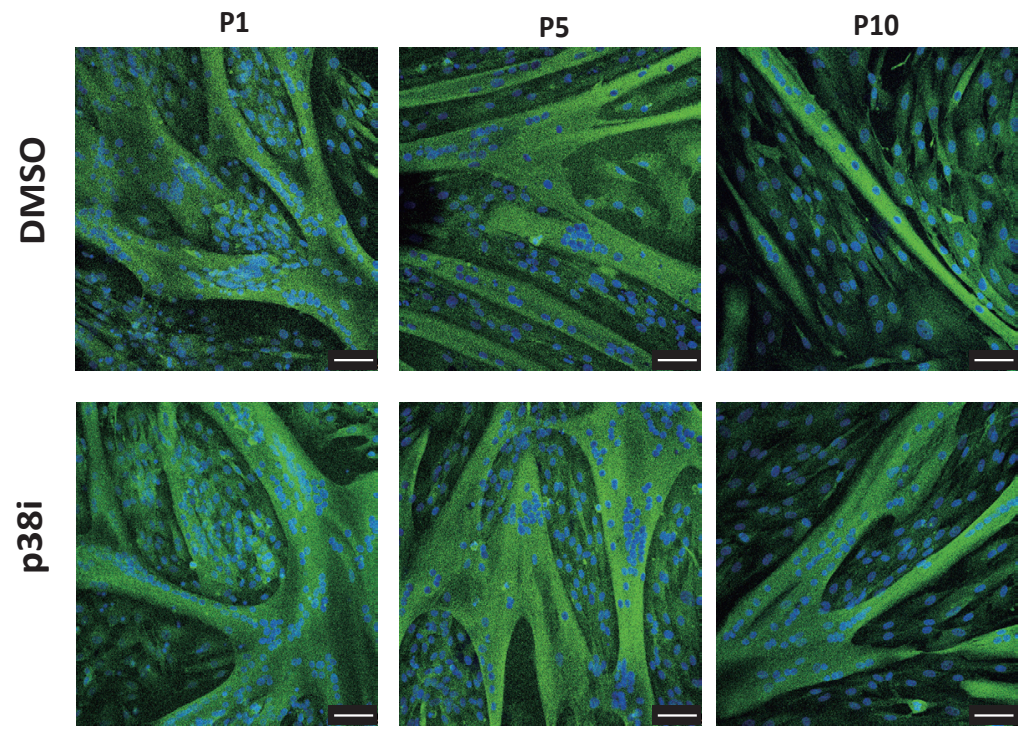

b

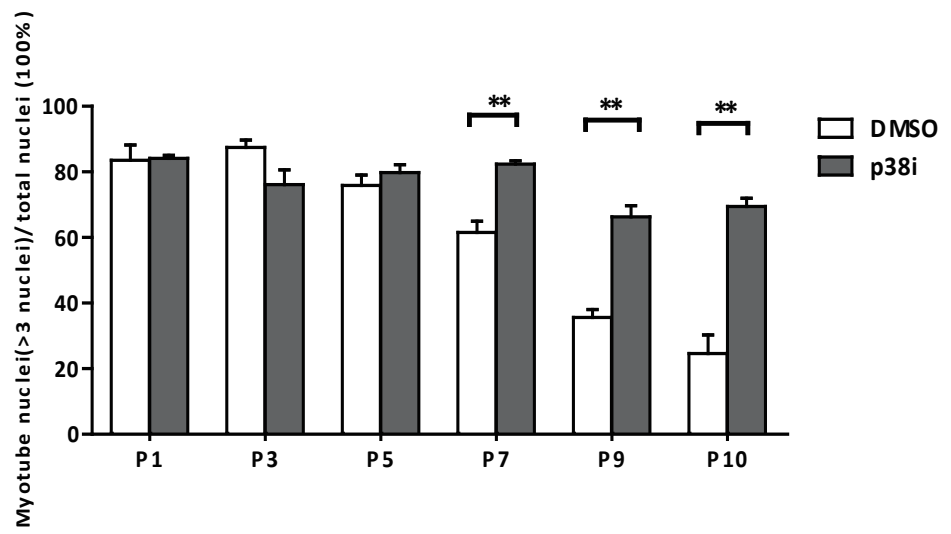

(a) Representative immunofluorescent images (Myosin Heavy Chain staining) of myotubes differentiated from P1, P5 and P10 satellite cells. Green indicates MYHC; blue indicates DAPI (nuclei). Scale bars, $75 \mu \mathrm{m}$. (g) Percentage of nuclei in myotubes differentiated from satellite cells depending of passage (P1, P3, P5, P7, P9, $P 10)$. $(n=3)$. Data are represented as mean \pm SEM. Significance was analyzed by 2 -way ANOVA and Bonferroni post-tests were used to compare treatment in different passages. Asterisks: ${ }^{* *}$ indicates $\mathrm{P}<0.01$. 


\section{Discussion}

Maintenance of stemness in a stem cell population is of considerable scientific and societal importance. Recently tissue engineering endeavors, mostly for medical, but even more so for food applications, rely on high expansion numbers of undifferentiated cells that at the same time retain their differentiation capacity ${ }^{18,19,31-33}$. A prerequisite for maintaining stemness is to start with a highly purified stem cell population, since most other cells in culture grow faster than the stem cells, so that the latter will eventually be outnumbered ${ }^{16,18,34,35}$. Even in a highly purified stem cell population, the more differentiated off-spring from asymmetric division, such as myoblasts from satellite cells, will overgrow the stem cells ${ }^{16,18,36}$.

Here, we firstly improved the purity of bovine satellite cells by FACS and established that a combination of negative selection for CD31 and CD45 with a positive selection for CD29 and CD56 results in a high purity satellite cells population as judged by their degree of PAX7 positivity. In this highly purified population, we observed that inhibition of p38 phosphorylation kept the stem cell profile of bovine satellite cells for more passages, while they retained the ability to differentiate into myocytes.

p38 $\alpha / \beta$ MAPKs is required for satellite cells activation and can function as a molecular switch for satellite cell activation even before $M y o D$ up-regulation ${ }^{37}$. Because of serum and growth factor stimulation, $p 38 \alpha / \beta$ signaling will continually be activated. Activated $p 38 \alpha / \beta$ targets the SWI-SNF chromatin-remodeling complex to $M y o g$ loci $^{38}$, which makes the satellite cells generate more differentiated $\mathrm{Pax}^{-} \mathrm{MYOG}^{+}$daughter cell ${ }^{24,39,40}$. The MYOG expression leads to down-regulation of genes involved in cell cycle progression and promotes differentiation and fusion ${ }^{41}$. This can be seen as a first step towards myoblast differentiation. At the same time, $p 38 \alpha$ represses $P A X 7$ through interaction between the transcription repressors YY1 and Polycomb Repressive Complex (PRC2) $)^{42,43}$, further leading to loss of satellite cell stemness. Modest inhibition of p38 $\alpha$ will maintain PAX7 expression (Figure. $2 b)^{18,24,40}$ and therefore the stemness of satellite cells ${ }^{44-46}$. Total inhibition of $\mathrm{p} 38 \alpha / \beta$ by SB203580 at $20 \mu \mathrm{M}$ also inhibited satellite cells proliferation (Figure $2 \mathrm{c}$ ) and this is consistent with previous studies ${ }^{18,37}$. At lower concentrations however, and in the presence of FGF-2, p38 inhibition slightly increased proliferation of satellite cells in long-term culture (Figure 4a), most likely due to maintenance of stemness as Pax7 expression is preserved and MYOG, as a marker of differentiation, is decreased. MYOG downregulation by SB203580 has been observed in other studies and in different cell culture models as well ${ }^{24,38,40}$. Together the data show that p38 inhibition keeps satellite cells in an undifferentiated and proliferative state.

Although PAX7 decrease is delayed by p38 inhibition, long-term cultivation of bovine satellite cells still leads to loss of PAX7 expression and also loss of differentiation abilities. (Figure 4,5). Other interventions may be required to further improve the replicative capacity of satellite cells. In mouse muscle stem cells for instance, the stiffness of the 
substrate elasticity helped maintaining the stemness of muscle stem cells ${ }^{24,47-49}$. The suitable stiffness for bovine muscle stem cells still needs to be investigated. Another optimal way for keeping the stemness of bovine satellite cells is to culture the bovine satellite cells in hypoxia conditions ${ }^{50-52}$. Hypoxia (1\% oxygen) stimulates the proliferation and differentiation of bovine myoblasts ${ }^{51}$. Similar results have been shown in mouse satellite cells: Hypoxia ( $1 \%$ oxygen) conditions favor quiescence of primary mouse myoblasts by upregulating $P A X 7^{52}$.

We noticed progressive loss of stemness (PAX7 positivity) during passaging, but also loss of differentiation capacity. Loss of differentiation capacity into myocytes suggests de-differentiation of satellite cells that progresses further than just losing stemness. It is currently unknown what is responsible for this de-differentiation. One option is that the cells transdifferentiate into another lineage. For instance, satellite cells can generate brown fat cells during long-term cultivation ${ }^{53-55}$. The Prdm16 gene controls a brown fat and skeletal muscle switch ${ }^{53,54}$. Whether this switch or other factors are responsible for the general decrease in differentiation capacity of satellite cells and myoblasts in culture, requires further studies.

We conclude that FACS purification of bovine satellite cells using CD29 and CD56 as positive markers increase the stem cell population and that in long-term culture p38 inhibition preserves stemness, proliferation and differentiation of bovine muscle precursors. This might bring large scale bovine muscle cell culture for cultured beef applications closer to reality.

\section{Materials and Methods}

\section{Bovine muscle tissues}

The bovine satellite cells in this study were derived from fresh (within 30 min of euthanasia) muscle samples obtained at a local slaughterhouse.

\section{Bovine satellite cells isolation}

Bovine satellite cells were isolated from 1-2 year old male cattle as previously described and adapted to bovine tissues ${ }^{15,16,18}$. Briefly, freshly harvest bovine muscle was immediately transferred to the lab on ice and washed with $75 \%$ ethanol for $1 \mathrm{~min}$, followed by PBS for 2 times. Then, the tissues were mechanically dissected and dissociated with collagenase II (Worthington, CLS-2, 0.2\%) in DMEM (Invitrogen, Cat\# 41966-29) supplemented with $1 \%$ penicillin-streptomycin (P.S. Lonza, Cat\# 17-745E) at $37^{\circ} \mathrm{C}$ for $1.5 \mathrm{~h}$. The mixture was mixed by vertexing or triturated with pipette once per 10 min. After digestion, 20\% FBS in DMEM was added and mixed well with pipette. The muscle fragments were centrifuged at $80 \mathrm{~g}$ for $3 \mathrm{~min}$ and the supernatant was collected as mononuclear cell suspension. The precipitated debris was again triturated 
with a 20-gauge needle in PBS and centrifugated at $80 \mathrm{~g}$ for $3 \mathrm{~min}$. The supernatant was collected again and mixed with former mononuclear cell suspensions. After centrifugation at 1,000 g for $5 \mathrm{~min}$, the cells were washed twice with PBS followed by DMEM with $20 \%$ FBS. After that, the cells were filtered through a $100 \mu \mathrm{m}$ cell strainer followed by a $40 \mu \mathrm{m}$ cell strainer. The cells were then centrifuged at 1,000g for $5 \mathrm{~min}$ at $4^{\circ} \mathrm{C}$ and incubated with the erythrocyte lysis buffer (ACK) buffer for 5 min on ice. Then the cells were washed twice with PBS and cell pellet was reconstituted with FACS buffer (1 \% BSA in PBS) or frozen in FBS supplement with $10 \%$ dimethyl sulphoxide (DMSO, sigma).

The frozen cells were first recovered in a $37^{\circ} \mathrm{C}$ water bath and washed with PBS twice. The cells were resuspended in FACS buffer and stained with APC anti-human CD29 Antibody (1:10, BioLegend, Cat\# 303008), PE-Cy ${ }^{\mathrm{TM}} 7$ anti-human CD56 (1:10, BD, Cat\# 335826), FITC anti-sheep CD31 (1:10, BIO-RAD, Cat\# MCA1097F), FITC anti-sheep CD45 (1:10, BIO-RAD, Cat\# MCA2220F) for 30-45min on ice. After antibody incubation, the cells were washed twice with cold PBS and reconstituted in F-10 with $20 \%$ FBS. The viable $\mathrm{CD} 31^{-} \mathrm{CD} 45^{-} \mathrm{CD} 56^{+} \mathrm{CD} 29^{+}$cells were isolated by cell sorting. The negative cells were also isolated to extract RNA. Cell sorting was performed with a BD FACSAria cell sorter using 405, 488nm and $640 \mathrm{~nm}$ lasers. Unstained cells were routinely used to define FACS gating parameters.

\section{Satellite cell culture and differentiation}

Dishes (Corning) were coated with 0.05\% bovine collagen type I (Sigma, Cat\# C4243). FACS isolated bovine satellite cells and unsorted cells were cultured on collagencoated dishes in F10 medium (Gibco, Cat\# 31550-023) containing 20\% fetal bovine serum (FBS, Gibco, Cat\# 10500-06), 5 ng/mL bFGF (R\&D, Cat\# 233-FB-025) and 1\% P.S. Where indicated, medium was supplemented with p38i (SB203580, Selleck, Cat\# S1076) and DMSO (Sigma, Cat\# D8418). For serial expansion, cells were passaged to maintain a density of $<60 \%$ confluence and counted at each passage. Bovine satellite cells differentiation was induced at $90 \%$ confluency with DMEM (Invitrogen, Cat\# 41966-29) with $2 \%$ FBS. The expanded and differentiated cells were fixed with 4\% PFA for immunofluorescent staining. The bright field images were acquired by AMG-EVOS microscope.

\section{Immunofluorescent analysis of cultured cells}

Cultured satellite cells were fixed with ice-cold 4\% PFA (in PBS) for 20 min, rinsed with PBS, and permeabilized in 0.5\% Triton X-100 (in PBS) for 15 min. Permeabilized cells were blocked and incubated with primary antibodies in 1\% BSA (in PBS) overnight at $4^{\circ} \mathrm{C}$. Primary antibodies recognizing mouse Pax7 (1:10, Developmental Studies Hybridoma Bank, Cat\# Pax7), mouse myosin heavy chain (1:100, Sigma, Cat\# M4276), mouse MyoD (1:200, ABclonal, CAT\# A0671), mouse Desmin (1:100, sigma, Cat\# D1033), mouse M-cadherin (1:200, BD, Cat\# 611100), Rabbit Myf5 (1:50, Santa Cruz, 
Cat\# SC-302), Rabbit ITGA7 (1:100, LifeSpan BioSciences, Cat\# LS-C313325), Rabbit p-p38 (1:100, Cell Signaling, Cat\#9211). After washing with PBS, cells were incubated with Alexa 488 labeled anti-mouse (1:600, Invitrogen, Cat \#A-11001) antibodies for $1 \mathrm{~h}$ at room temperature and mounted with VECTASHIELD mounting medium with DAPI (Vector Laboratories Cat\# H-1500).

EdU detection was carried-out using a Click-It EdU detection kit (Life Technologies, Cat\# C10337) according to the manufacturer's instructions.

For the FACS analysis of cultured satellite cells, about $10^{5}$ cells were collected at each passage. The cells were fixed with 4\% PFA for $15 \mathrm{~min}$ and washed two times for $5 \mathrm{~min}$ with PBS. The cells were then incubated with Alexa Fluor 488 anti-human CD29 (1:10, BioLegend, Cat\#303016), PE-conjugated anti-human CD56 (1:10, BioLegend, Cat\# $304606)$ in $1 \%$ BSA in PBS for 30-45 min. After antibody incubation, the cells were washed with PBS for two times and reconstituted in PBS. FACS analysis was performed with the Cytomics FC500 Flow Cytometer (Beckman Coulter) cell analyzer. Unstained cells were routinely used to define FACS gating parameters.

\section{Western blots analysis of cultured cells}

Western blots were either performed from total cell lysates obtained by lysing cells directly with RIPA buffer complemented with PMSF, protease inhibitor cocktail and sodium orthovanadate (Santa Cruz, CAT\# sc-24948). Proteins concentration was determined using BCA protein assay kit (Thermo). SDS-PAGE electrophoresis was carried out in $7.5 \%$ pre-cast polyacrylamide gels (Bio-Rad, CAT\# 5671023). After transfer onto nitrocellulose, membranes were blocked for 30 min with Odyssey Blocking Buffer in PBS (Part Number: 927-40000, LI-COR Biosciences) and probed overnight with primary antibody: p-HSP27(Ser 82) (1:500, Cell Signaling, CAT\# 9709), p-p38 (1:1000, Cell Signaling, CAT\# 9211), p38 (1:1000, Cell Signaling, CAT\# 8690), MyHC (1:500, Millipore, CAT\# 05-716), GAPDH (1:500, Millipore, CAT\# MAB374). After that, IRDye700-conjugated or IRDye800-conjugated secondary antibodies were used and visualized with the Odyssey infrared detector (LI-COR Biosciences, Westburg, Leusden, the Netherlands). For Protein quantification a, we used the background correction option in the software of the supplier (Image Studio ${ }^{\text {TM }}$ Software for the Odyssey CLx-LICOR Biosciences) and scanned the corresponding band of the protein of interest.

\section{Bovine muscle fiber isolation and analysis}

The bovine muscle fiber was isolated as previously described and adapted to bovine tissues ${ }^{15}$. After procurement, part of the specimen was immediately fixed in $4 \%$ paraformaldehyde (PFA) at room temperature for $20 \mathrm{~min}$ and washed with PBS. The sample was then embedded in $30 \%$ glycerol in PBS overnight at $4^{\circ} \mathrm{C}$, then $50 \%$ glycerol in PBS overnight at $4^{\circ} \mathrm{C}$, then $80 \%$ glycerol in PBS overnight at $4^{\circ} \mathrm{C}$ and finally $100 \%$ glycerol. The fibers were stored in $100 \%$ glycerol at $4^{\circ} \mathrm{C}$ until dissection. 
Single fibers were dissected using fine forceps under a dissecting microscope. Single fibers were washed in PBS for $15 \mathrm{~min}$ at room temperature, then permeabilized with $0.5 \%$ Triton X-100 (Sigma-Aldrich, Cat\#X-100) for $10 \mathrm{~min}$, and washed twice with PBS for $8 \mathrm{~min}$. Single fibers were then blocked with $3 \%$ goat serum in PBS for $1 \mathrm{~h}$ at room temperature and incubated overnight at $4^{\circ} \mathrm{C}$ with the following primary antibodies: mouse monoclonal anti-Pax7 (1:10 Developmental Studies Hybridoma Bank, Cat\#Pax7), p-p38 (1:100, Cell Signaling, Cat\#9211), The next day, after PBS wash at room temperature for $15 \mathrm{~min}$, fibers were incubated with Alexa 488 labeled anti-mouse (1:600, Invitrogen, Cat\#A-11001), Alexa 594 labeled anti-rabbit (1:600, Invitrogen, Cat\#:A-21207) antibodies for $1 \mathrm{~h}$ at room temperature. Then mounted with VECTASHIELD mounting medium with DAPI (Vector Laboratories Cat\# H-1500). All images were acquired by Leica SP6 confocal microscope and processed with Adobe Photoshop CS5 to adjust brightness and contrast for publication.

For fibers co-stained with Pax7 and CD56/CD29, Pax7 staining was firstly performed. After incubation with the secondary antibody (Alexa 488 labeled anti-mouse for Pax7 and CD29 co-staining, Alexa 647 labeled anti-mouse (1:600, Invitrogen, Cat\#:A-31571) for Pax7 and CD56 co-staining ) above, sections were washed twice with PBS for 8 min and incubated with the APC anti-human CD29 (1:10, BioLegend, Cat\# 303016) or PE anti-human CD56 (1:10, BioLegend, Cat\# 304606) antibody for $2 \mathrm{~h}$ at room temperature. After washing with PBS for 3 times, fibers were mounted with VECTASHIELD mounting medium with DAPI (Vector Laboratories, Cat\# H-1500). All images were acquired by Leica SP6 confocal microscope and processed with Adobe Photoshop CS5 to adjust brightness and contrast for publication.

\section{Gene expression analysis}

RNA was extracted from cells using the RNeasy Micro Kit (QIAGEN, Cat\#74004) including RNase-Free DNase Set (QIAGEN, Cat\# 79254) according to the manufacturer's instruction. $500 \mathrm{ng}$ of total RNA from each sample was reverse transcribed to cDNA using iScript cDNA Synthesis Kit (Bio-Rad, Cat\#1708891) according to the manufacturer's instruction. Relative gene expression was performed in triplicate using a SYBR Green PCR master mix on an CFX 96 Real Time PCR system (Bio-Rad).

The primers used in these assays were the followings:

PAX7-F, 5' - CTCCCTCTGAAGCGTAAGCA -3', PAX7-R, 5'- GGGTAGTGGGTCCTCTCGAA -3'; PAX3-F, 5' - CAAAGCTTACAGAGGCCCGA -3', PAX3-R, 5'- GGTCTCTGACAGCTGGTACG -3' MYF5-F, 5' - TCTATCTCTCTGCTGTCCAGGC -3', MYF5-R, 5' - AACTCGTCCCCGAACTCAC -3'; MYOG-F, 5' - GCGCAGACTCAAGAAGGTGA -3', MYOG-R, 5'- TGCAGGCGCTCTATGTACTG $-3^{\prime}$;

MyHC-F, 5'-AGAGCAGCAAGTGGATGACCTTGA-3', MyHC-R,5'- TGGACTCTTGGGCCAACTTGAGAT -3';

GAPDH-F, 5' - CACCCTCAAGATTGTCAGC -3', GAPDH-R, 5' - TAAGTCCCTCCACGATGC -3'. 


\section{$\mathrm{Pax}^{+}$cells population, differentiation efficiency, EdU and pHSP27 percentage measurement}

$\mathrm{Pax}^{+}$cell populations were expressed as the number of nuclei co-stained with DAPI and Pax7 divided by the total number of nuclei in the same field. More than 300 nuclei from 5 or more randomly chosen fields were analyzed.

The percentage of myotube nuclei per condition was expressed as the nuclei inside myotube (at least 3 nuclei) divided by total nuclei in the same field. More than 1000 nuclei from 4 randomly chosen fields were analyzed.

For EdU detection, cells cultured in BD Falcon 96 wells HTS Imaging microplates were imaged using a High-Content Analyzer (BD Pathway 855 ) with a $4 \times$ objective. In total 16 images were taken for each condition and individual cell segmentation and analysis was performed using the BD Attovision software (BD Biosciences, version 1.6). Hoechst positive cells were segmented and counted, then the same was done for EdU positive cells. The numerical data were further analyzed with Kaluza software (version 1.3; Beckman Coulter), where the EdU positive percentage was determined for more than 6000 nuclei from 16 randomly chosen fields.

For pHSP27(Ser82) detection, cells cultured in 96-well plate were imaged using a HighContent Imager (BD Pathway 855) with a 20x objective. Together 16 images were taken for each condition. Using AttoVision-software, the entire cell was segmented by fluorescence intensity and the pHSP27 (Ser82) positive speckles were counted in each cell. The average speckles were defined between different groups. More than 700 nuclei from 16 randomly chosen fields were analysed.

\section{Statistics}

Statistical analyses were performed using GraphPad Prism 5 (GraphPad Software). For comparisons of two treatment groups, a Student's t-test was used. For more than two groups, One-way ANOVA with Bonferroni's Multiple Comparison Test was used. For long-term culture experiments, 2-way ANOVA was used to distinguish the p38i treatment and passages effects. Results were means \pm S.E.M. unless otherwise stated. $P<0.05$ was considered significant.

\section{Acknowledgements}

We thank the flow cytometry services in Maastricht University Medical Centre by Mat Rousch and the confocal microscopy services in Maastricht University. This work was sponsored by Royal Netherlands Academy of Arts and Sciences and China Scholarship Council. 


\section{References}

1 Mauro, A. Satellite cell of skeletal muscle fibers. J Biophys Biochem Cytol 9, 493-495 (1961).

2 Gros, J., Manceau, M., Thome, V. \& Marcelle, C. A common somitic origin for embryonic muscle progenitors and satellite cells. Nature 435, 954-958, doi:10.1038/nature03572 (2005).

3 Biressi, S., Molinaro, M. \& Cossu, G. Cellular heterogeneity during vertebrate skeletal muscle development. Dev Biol 308, 281-293, doi:10.1016/j.ydbio.2007.06.006 (2007).

4 Relaix, F., Rocancourt, D., Mansouri, A. \& Buckingham, M. A Pax3/Pax7-dependent population of skeletal muscle progenitor cells. Nature 435, 948-953, doi:10.1038/nature03594 (2005).

5 Almada, A. E. \& Wagers, A. J. Molecular circuitry of stem cell fate in skeletal muscle regeneration, ageing and disease. Nature reviews. Molecular cell biology 17, 267-279, doi:10.1038/nrm.2016.7 (2016).

$6 \mathrm{Fu}, \mathrm{X}$. , Wang, H. T. \& Hu, P. Stem cell activation in skeletal muscle regeneration. Cell Mol Life Sci 72, 1663-1677, doi:10.1007/s00018-014-1819-5 (2015).

7 Post, M. J. Cultured meat from stem cells: challenges and prospects. Meat science 92, 297-301, doi:10.1016/j.meatsci.2012.04.008 (2012).

8 Tuomisto, H. L. \& de Mattos, M. J. T. Environmental Impacts of Cultured Meat Production. Environ Sci Technol 45, 6117-6123, doi:Doi 10.1021/Es200130u (2011).

9 Post, M. J. Cultured beef: medical technology to produce food. J Sci Food Agric 94, 1039-1041, doi:10.1002/jsfa.6474 (2014).

$10 \mathrm{Li}$, J. et al. Evidence of heterogeneity within bovine satellite cells isolated from young and adult animals. J Anim Sci 89, 1751-1757 (2011).

11 Will, K., Schering, L., Albrecht, E., Kalbe, C. \& Maak, S. Differentiation of bovine satellite cell-derived myoblasts under different culture conditions. In vitro cellular \& developmental biology. Animal 51, 885889, doi:10.1007/s11626-015-9916-9 (2015).

12 Coles, C. A. et al. Proliferation Rates of Bovine Primary Muscle Cells Relate to Liveweight and Carcase Weight in Cattle. Plos One 10 (2015).

13 Quarta, M. et al. An artificial niche preserves the quiescence of muscle stem cells and enhances their therapeutic efficacy. Nat Biotechnol 34, 752-759, doi:10.1038/nbt.3576 (2016).

14 Rozo, M., Li, L. \& Fan, C. M. Targeting beta1-integrin signaling enhances regeneration in aged and dystrophic muscle in mice. Nat Med 22, 889-896, doi:10.1038/nm.4116 (2016).

$15 \mathrm{Xu}, \mathrm{X}$. et al. Human Satellite Cell Transplantation and Regeneration from Diverse Skeletal Muscles. Stem Cell Rep 5, 419-434, doi:10.1016/j.stemcr.2015.07.016 (2015).

16 Ding, S. et al. Characterization and isolation of highly purified porcine satellite cells. Cell Death Discov 3, 17003, doi:10.1038/cddiscovery.2017.3 (2017).

17 Sacco, A., Doyonnas, R., Kraft, P., Vitorovic, S. \& Blau, H. M. Self-renewal and expansion of single transplanted muscle stem cells. Nature 456, 502-506, doi:10.1038/nature07384 (2008).

18 Charville, G. W. et al. Ex Vivo Expansion and In Vivo Self-Renewal of Human Muscle Stem Cells. Stem Cell Rep 5, 621-632, doi:10.1016/j.stemcr.2015.08.004 (2015).

$19 \mathrm{Fu}, \mathrm{X}$. et al. Combination of inflammation-related cytokines promotes long-term muscle stem cell expansion. Cell Res 25, 655-673, doi:10.1038/cr.2015.58 (2015).

20 Pisani, D. F. et al. Isolation of a Highly Myogenic CD34-Negative Subset of Human Skeletal Muscle Cells Free of Adipogenic Potential. Stem Cells 28, 753-764, doi:10.1002/stem.317 (2010). 
21 Igea, A. \& Nebreda, A. R. The Stress Kinase p38 alpha as a Target for Cancer Therapy. Cancer Res 75, 3997-4002 (2015).

22 Segales, J., Perdiguero, E. \& Munoz-Canoves, P. Regulation of Muscle Stem Cell Functions: A Focus on the p38 MAPK Signaling Pathway. Front Cell Dev Biol 4, 91, doi:10.3389/fcell.2016.00091 (2016).

23 Troy, A. et al. Coordination of satellite cell activation and self-renewal by Par-complex-dependent asymmetric activation of p38alpha/beta MAPK. Cell stem cell 11, 541-553, doi:10.1016/j. stem.2012.05.025 (2012).

24 Cosgrove, B. D. et al. Rejuvenation of the muscle stem cell population restores strength to injured aged muscles. Nat Med 20, 255-264, doi:10.1038/nm.3464 (2014).

25 Brien, P., Pugazhendhi, D., Woodhouse, S., Oxley, D. \& Pell, J. M. p38alpha MAPK regulates adult muscle stem cell fate by restricting progenitor proliferation during postnatal growth and repair. Stem Cells 31, 1597-1610, doi:10.1002/stem.1399 (2013).

26 Seale, P. et al. Pax7 is required for the specification of myogenic satellite cells. Cell 102, 777-786, doi:Doi 10.1016/S0092-8674(00)00066-0 (2000).

27 Relaix, F. et al. Pax3 and Pax7 have distinct and overlapping functions in adult muscle progenitor cells. J Cell Biol 172, 91-102, doi:10.1083/jcb.200508044 (2006).

28 Bosnakovski, D. et al. Prospective Isolation of Skeletal Muscle Stem Cells with a Pax7 Reporter. Stem Cells 26, 3194-3204, doi:10.1634/stemcells.2007-1017 (2008).

29 Collins, C. A. et al. Stem cell function, self-renewal, and behavioral heterogeneity of cells from the adult muscle satellite cell niche. Cell 122, 289-301, doi:10.1016/j.cell.2005.05.010 (2005).

30 Sajko, S. et al. Frequency of M-cadherin-stained satellite cells declines in human muscles during aging. J Histochem Cytochem 52, 179-185, doi:10.1177/002215540405200205 (2004).

31 Badenes, S. M., Fernandes, T. G., Rodrigues, C. A., Diogo, M. M. \& Cabral, J. M. Microcarrier-based platforms for in vitro expansion and differentiation of human pluripotent stem cells in bioreactor culture systems. J Biotechnol, doi:10.1016/j.jbiotec.2016.07.023 (2016).

32 Mizukami, A. et al. Stirred tank bioreactor culture combined with serum-/xenogeneic-free culture medium enables an efficient expansion of umbilical cord-derived mesenchymal stem/stromal cells. Biotechnol J 11, 1048-1059, doi:10.1002/biot.201500532 (2016).

33 Moritz, M. S. M., Verbruggen, S. E. L. \& Post, M. J. Alternatives for large-scale production of cultured beef: A review. J Integr Agr 14, 208-216, doi:10.1016/S2095-3119(14)60889-3 (2015).

34 Pasut, A., Oleynik, P. \& Rudnicki, M. A. Isolation of muscle stem cells by fluorescence activated cell sorting cytometry. Methods in molecular biology 798, 53-64, doi:10.1007/978-1-61779-343-1_3 (2012).

35 Liu, L., Cheung, T. H., Charville, G. W. \& Rando, T. A. Isolation of skeletal muscle stem cells by fluorescence-activated cell sorting. Nat Protoc 10, 1612-1624, doi:10.1038/nprot.2015.110 (2015).

36 Montarras, D. et al. Direct isolation of satellite cells for skeletal muscle regeneration. Science 309, 2064-2067, doi:10.1126/science.1114758 (2005).

37 Jones, N. C. et al. The p38 alpha/beta MAPK functions as a molecular switch to activate the quiescent satellite cell. J Cell Biol 169, 105-116 (2005).

38 Simone, C. et al. p38 pathway targets SWI-SNF chromatin-remodeling complex to muscle-specific loci. Nat Genet 36, 738-743, doi:10.1038/ng1378 (2004).

39 Yennek, S., Burute, M., Thery, M. \& Tajbakhsh, S. Cell adhesion geometry regulates non-random DNA segregation and asymmetric cell fates in mouse skeletal muscle stem cells. Cell Rep 7, 961-970, doi:10.1016/j.celrep.2014.04.016 (2014). 
40 Bernet, J. D. et al. p38 MAPK signaling underlies a cell-autonomous loss of stem cell self-renewal in skeletal muscle of aged mice. Nat Med 20, 265-271, doi:10.1038/nm.3465 (2014).

41 Liu, Q. C. et al. Comparative expression profiling identifies differential roles for Myogenin and p38alpha MAPK signaling in myogenesis. J Mol Cell Biol 4, 386-397, doi:10.1093/jmcb/mjs045 (2012).

42 Mozzetta, C. et al. Selective control of Pax7 expression by TNF-activated p38alpha/polycomb repressive complex 2 (PRC2) signaling during muscle satellite cell differentiation. Cell Cycle 10, 191-198, doi:10.4161/cc.10.2.14570 (2011).

43 Palacios, D. et al. TNF/p38alpha/polycomb signaling to Pax7 locus in satellite cells links inflammation to the epigenetic control of muscle regeneration. Cell stem cell 7, 455-469, doi:10.1016/j. stem.2010.08.013 (2010).

44 Rocheteau, P., Gayraud-Morel, B., Siegl-Cachedenier, I., Blasco, M. A. \& Tajbakhsh, S. A Subpopulation of Adult Skeletal Muscle Stem Cells Retains All Template DNA Strands after Cell Division. Cell 148, 112125 (2012).

45 Olguin, H. C. \& Olwin, B. B. Pax-7 up-regulation inhibits myogenesis and cell cycle progression in satellite cells: a potential mechanism for self-renewal. Dev Biol 275, 375-388, doi:10.1016/j. ydbio.2004.08.015 (2004).

46 von Maltzahn, J., Jones, A. E., Parks, R. J. \& Rudnicki, M. A. Pax7 is critical for the normal function of satellite cells in adult skeletal muscle. Proceedings of the National Academy of Sciences of the United States of America 110, 16474-16479, doi:10.1073/pnas.1307680110 (2013).

47 Gilbert, P. M. et al. Substrate elasticity regulates skeletal muscle stem cell self-renewal in culture. Science 329, 1078-1081, doi:10.1126/science.1191035 (2010).

48 Urciuolo, A. et al. Collagen VI regulates satellite cell self-renewal and muscle regeneration. Nat Commun 4, doi:Artn 1964 10.1038/Ncomms2964 (2013).

49 Boonen, K. J., Rosaria-Chak, K. Y., Baaijens, F. P., van der Schaft, D. W. \& Post, M. J. Essential environmental cues from the satellite cell niche: optimizing proliferation and differentiation. American journal of physiology. Cell physiology 296, C1338-1345, doi:10.1152/ajpcell.00015.2009 (2009).

50 Chaillou, T. \& Lanner, J. T. Regulation of myogenesis and skeletal muscle regeneration: effects of oxygen levels on satellite cell activity. Faseb J 30, 3929-3941, doi:10.1096/fj.201600757R (2016).

51 Kook, S. H. et al. Hypoxia affects positively the proliferation of bovine satellite cells and their myogenic differentiation through up-regulation of MyoD. Cell biology international 32, 871-878, doi:10.1016/j. cellbi.2008.03.017 (2008).

52 Liu, W. et al. Hypoxia promotes satellite cell self-renewal and enhances the efficiency of myoblast transplantation. Development 139, 2857-2865, doi:10.1242/dev.079665 (2012).

53 Pasut, A. et al. Notch Signaling Rescues Loss of Satellite Cells Lacking Pax7 and Promotes Brown Adipogenic Differentiation. Cell Rep 16, 333-343, doi:10.1016/j.celrep.2016.06.001 (2016).

54 Seale, P. et al. PRDM16 controls a brown fat/skeletal muscle switch. Nature 454, 961-967, doi:10.1038/ nature07182 (2008).

55 Shefer, G., Wleklinski-Lee, M. \& Yablonka-Reuveni, Z. Skeletal muscle satellite cells can spontaneously enter an alternative mesenchymal pathway. J Cell Sci 117, 5393-5404, doi:10.1242/jcs.01419 (2004). 


\section{Supplementary information}

Figure S1. Characterization of sorted bovine satellite cells. Related to Figure 1
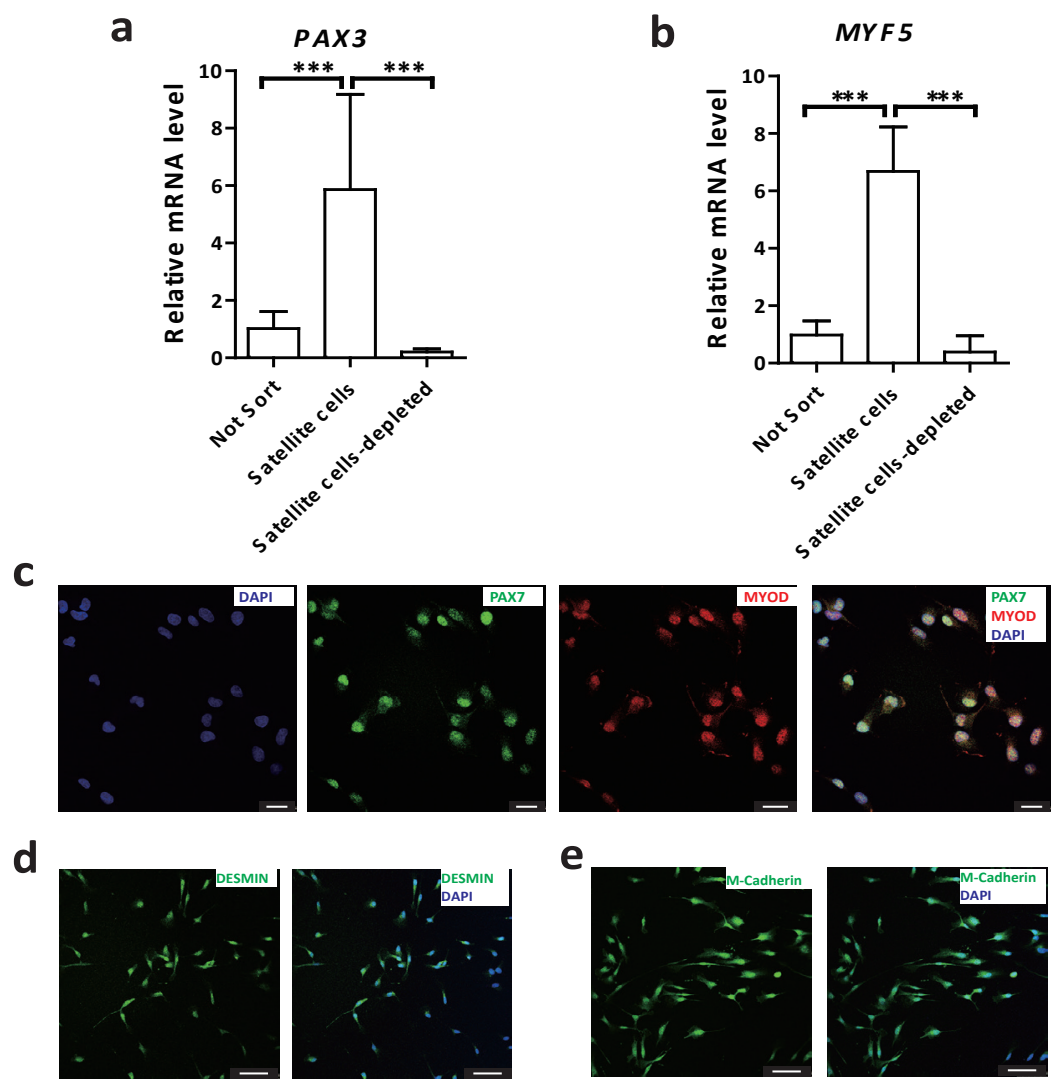

f

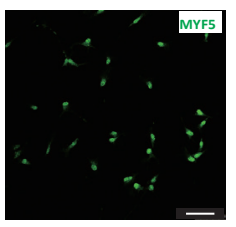

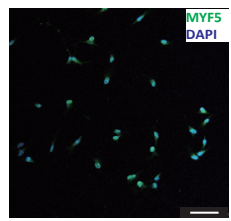

g

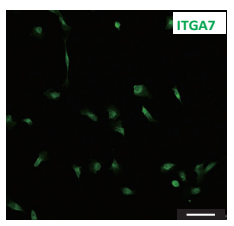

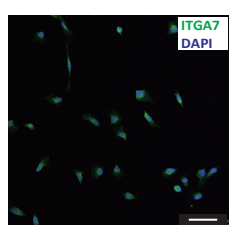

(a) qRT-PCR analysis of PAX3, MYF5 mRNA levels in total cells (not sorted), sorted satellite cells and satellite cells depleted populations after a period of 4 days in culture $(n=3)$. (b) Immunofluorescent staining of Pax 7 and MYOD in sorted bovine satellite cells cultured for 4 days. Scale bars: $25 \mu \mathrm{m}$. (c) Immunofluorescent staining of DESMIN, M-Cadherin, MYF5, ITGA7 in sorted bovine satellite cells cultured for 4 days. Scale bars: $75 \mu \mathrm{m}$. Data are represented as mean \pm SEM. Significance was analyzed by One-way ANOVA with Bonferroni's Multiple Comparison Test. Asterisks: ${ }^{* * *}$ indicates $P<0.001$. 
Figure S2. p38i treatment repressed phosphorylation of the p38 substrate HSP27 (Ser82). Related to Figure 2

a

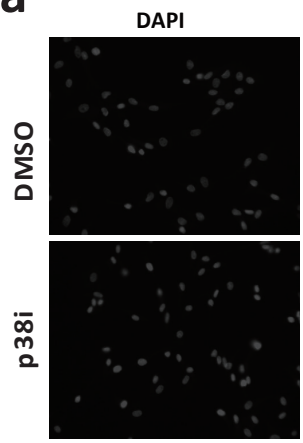

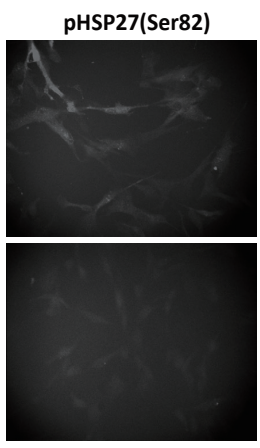

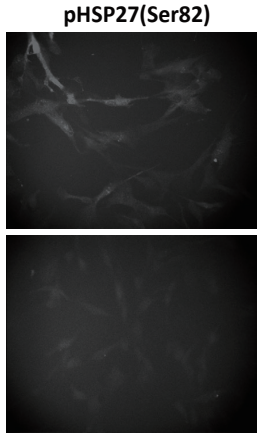

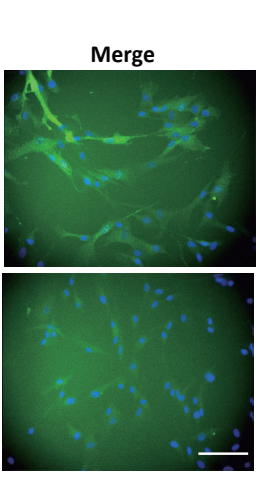

b

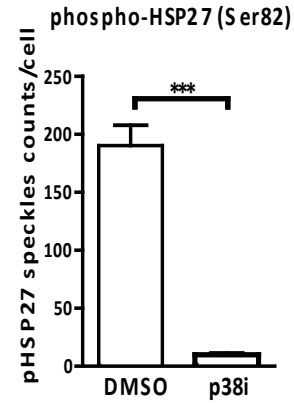

(a) Representative IF analysis of phospho-HSP27 (Ser82) in passage 2 bovine cells cultured for 2 days in the presence or absence of p38i. Scale bar: $100 \mu \mathrm{m}$ (b) Quantification of IF for phospho-HSP27 (Ser82) per cell from $(a)$. $(n=3)$. Data are represented as mean \pm SEM. Significance was analyzed by Student's t-test. Asterisks: *** indicates $P<0.001$. 
Figure S3. p38i treatment maintains the proliferation and Pax7 population of satellite cells. Related to Figure 3

a
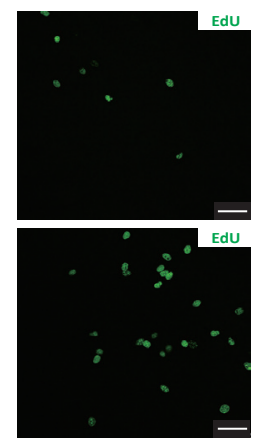

C
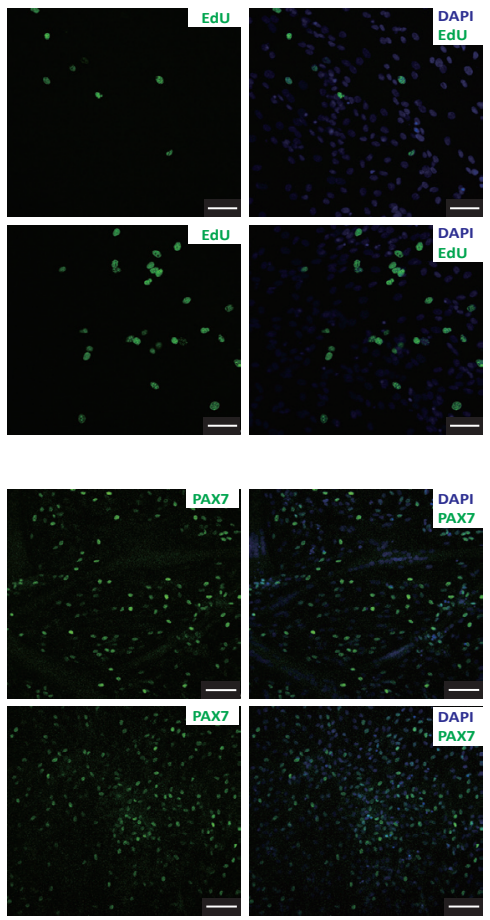

e

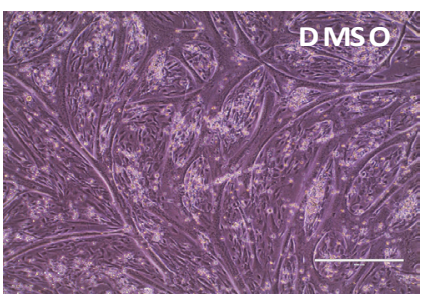

b

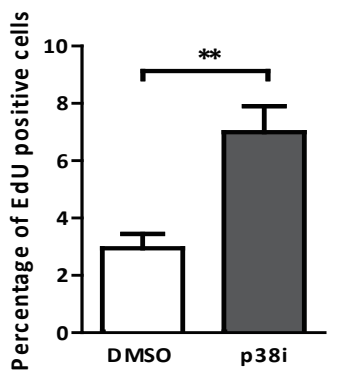

d

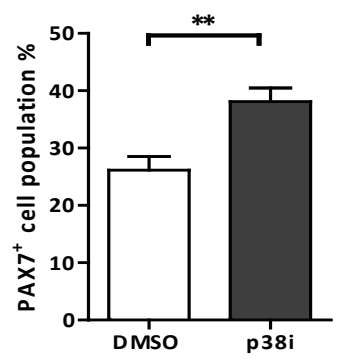

(a) Representative DAPI and EdU immunofluorescent staining of $1 \mathrm{~h}$ window EdU incorporation after 6 days of culture in the absence (top panels) or presence (bottom panels) or of p38i. Scale bars: 50 $\mu$ m. (b) Relative percentage of EdU from (a). (c) Representative immunofluorescent staining of DAPI and Pax7 after 6 days of culture in the absence (top panels) or presence (bottom panels) of p38i. Scale bars: $75 \mu \mathrm{m}$. (d) Quantification of Pax7 immunofluorescent staining from (c). (e) Representative phase contrast images of differentiated bovine satellite cells. Passage 2 satellite cells are originally cultured in F-10 medium with DMSO or $10 \mu \mathrm{M} \mathrm{p38i}$ for 4 days before differentiation. Scale bars: $400 \mu \mathrm{m}$. Data are represented as mean $\pm \mathrm{SEM}$. Significance was analyzed by Student's t-test. Asterisks: ** indicates $\mathrm{P}<0.01$. 
Figure S4. p38-MAPK signal is up-regulated during long-term culturing and p38i treatment maintains PAX7 population. Related to Figure 4

a

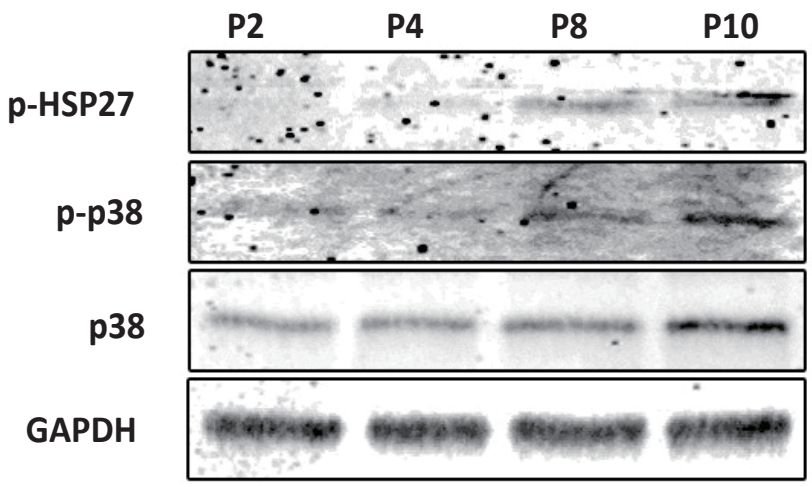

b

DMSO
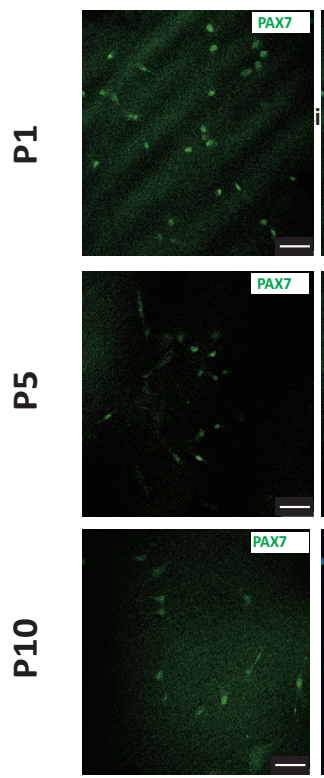
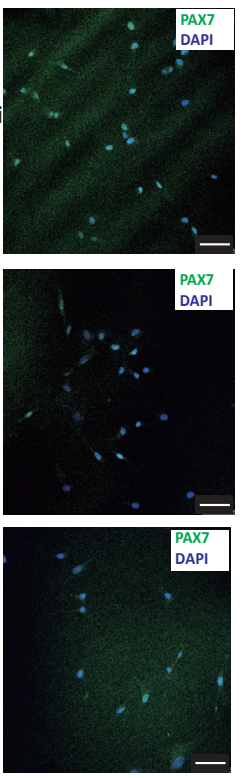

p38i
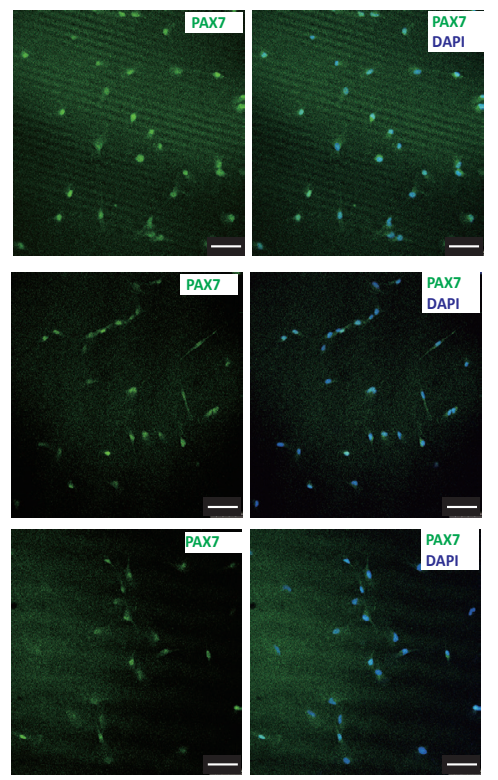

(a) Representative images of immunoblotting against p-HSP27, p-p38, p38 and GAPDH of myoblast cells from P2, P4, P8, P10 cultured in F-10 medium. Full-length blots are presented in Supplementary Figure S5. (b) Representative Immunofluorescent staining of PAX7 in different passage myoblast cells cultured in the presence or absence of p38i. Scale bars: $75 \mu \mathrm{m}$. 
Figure S5. Full-length western blots. Related to Figure 2, Figure3, Figure S4

a

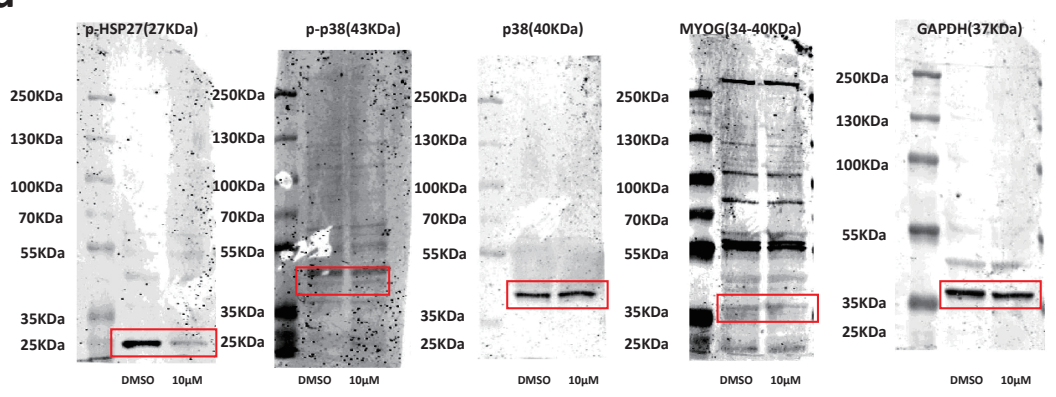

b
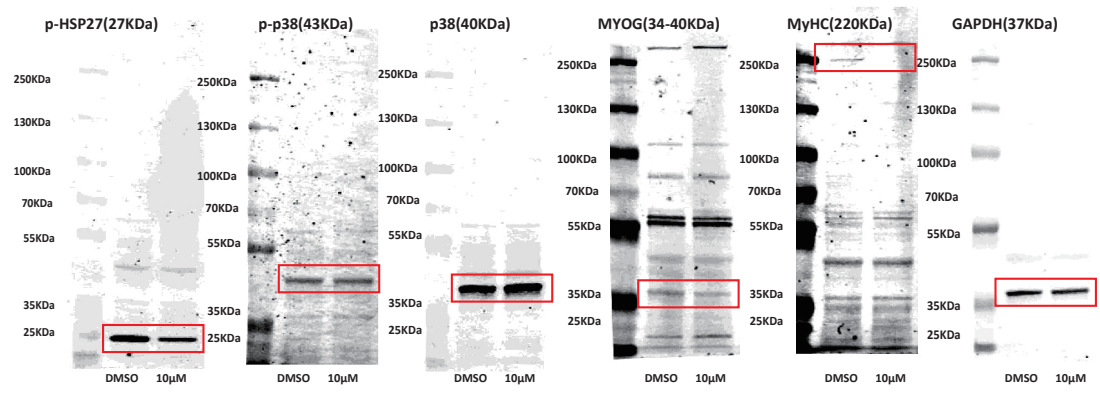

C
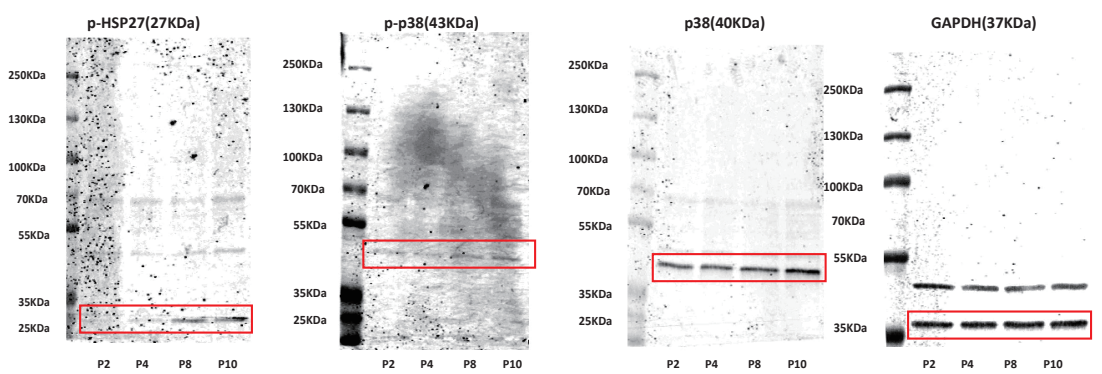

(a) Representative full-length immunoblotting blots against p-HSP27, p-p38, p38 and GAPDH from cell lysates of cells cultured 4 days to $90 \%$ confluent in the presence or absence of $10 \mu \mathrm{M} \mathrm{p38i}$. (b) Representative full-length immunoblotting blots against p-HSP27, p-p38, p38, MyHC and GAPDH from cell lysates of cells cultured 6 days in the presence or absence of $10 \mu \mathrm{M} \mathrm{p38i.} \mathrm{(c)} \mathrm{Representative} \mathrm{full-length} \mathrm{immunoblotting} \mathrm{blots}$ against p-HSP27, p-p38, p38 and GAPDH of myoblast cells from P2, P4, P8, P10 cultured in F-10 medium. 



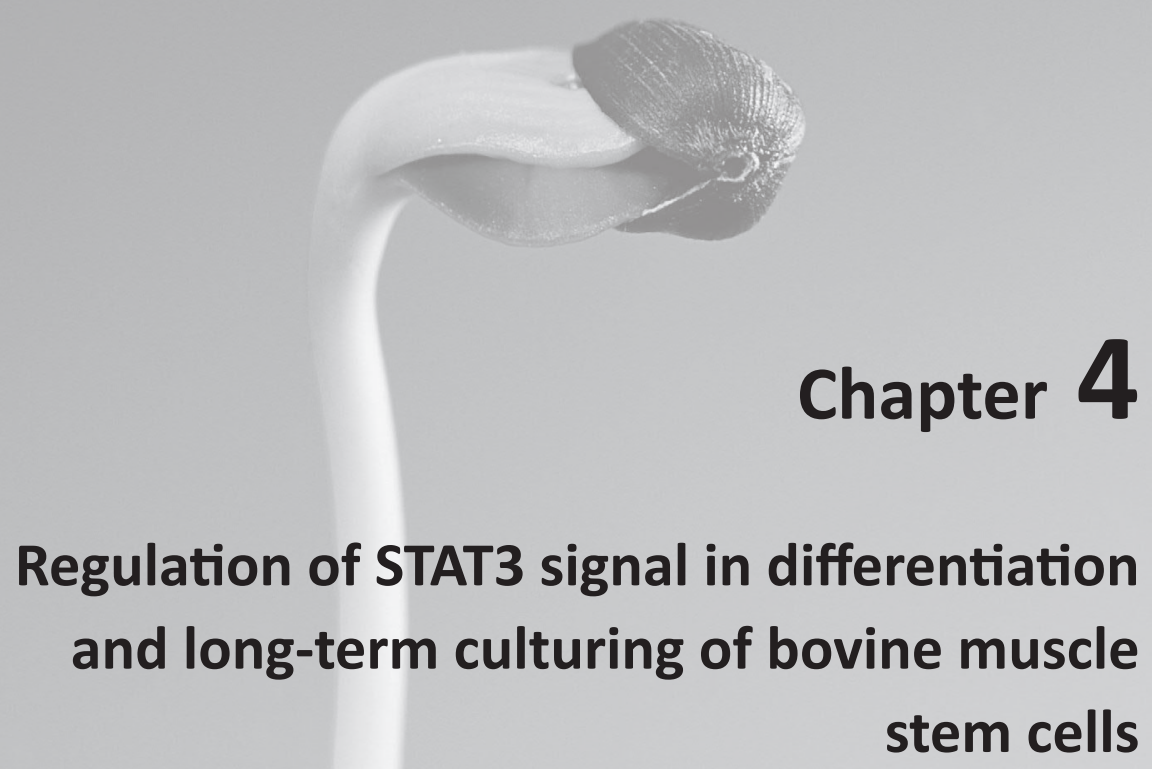

Shijie Ding, Lea Melzener, Anon van Essen, Mick Gagliardi, Guanghong Zhou, Mark J. Post 


\begin{abstract}
In muscle biology, the activator of transcription 3 (STAT3) pathway is not only important in regulating skeletal muscle mass, repair, aging and diseases in vivo, but also can regulate the in vitro proliferation and differentiation of myoblasts. However, some groups reported conflicting data on the function of STAT3 in the stemness of satellite cells. We show that STAT3 signal was activated in cultured bovine myoblast cells. The JAK2-STAT3 signal was required for bovine myoblast differentiation. Inhibition of JAK2STAT3 signal impaired the differentiation process. However, JAK2-STAT3 inhibition did not maintain satellite stemness or proliferation or long-term passaging of myoblasts. Western blots results indicated that the JAK2-STAT3 signal was not the reason for the long-term culture defects in bovine myoblasts.
\end{abstract}




\section{Introduction}

Janus kinase (JAK)-signal transducer and activator of transcription (STAT) pathway is known to have a critical role in cell growth, proliferation and differentiation in many cell types ${ }^{1-3}$. In mammals, the JAK family kinases include four members (JAK1, JAK2, JAK3 and TYK2 i.e. Tyrosine kinase 2), whereas the STAT family has seven (STAT1, STAT2, STAT3, STAT4, STAT5A, STAT5B and STAT6) $)^{4,5}$. The JAK-STAT family is activated by cytokines or growth factors, e.g. leukemia inhibitory factor (LIF) and basic fibroblast growth factor (bFGF or FGF-2) 2,6,7. Activated JAKs lead to phosphorylation of their selective STATs, which dissociate from the receptor, dimerize and translocate into the nucleus to regulate expression of target genes ${ }^{2,6}$.

The JAK-STAT pathway is not only important in regulating skeletal muscle mass, repair, aging and diseases in vivo ${ }^{5}$, but can also regulate the differentiation of satellite cells or myoblast cells in vitro ${ }^{8}$. Following acute muscle damage, IL-6-induced activation of STAT3 signaling is essential for satellite cell activation and muscle regeneration ${ }^{9,10}$. Two recent studies reported that JAK2-STAT3 signaling in muscle stem cells induce myogenic differentiation to the detriment of their expansion ${ }^{11-13}$. In accordance, knockdown of STAT3 in satellite cells decreased the expression of both MYOD and Myogenin (MYOG) ${ }^{13,14}$, thus demonstrating the pivotal role of STAT3 in satellite cell myogenic progression. In myoblasts, JAK1-STAT1-STAT3 plays a notable role in proliferation, whereas JAK2-STAT3 and JAK3 mainly mediate differentiation ${ }^{3,8,15}$. In summary, the JAK2-STAT3 signaling has complex effects in muscle regeneration and satellite cell function.

STAT3 signalling is also involved in aging of muscle. Aged muscle shows an up-regulated IL-6/STAT3 signal ${ }^{13,16}$ and pharmacological inhibition of STAT3 activity promoted satellite cell expansion and enhanced tissue repair from aged muscle ${ }^{13}$. Long-term culture of cells may serve as an vitro model of aged cells ${ }^{17}$. In this study we investigated the function of STAT3 signalling in bovine myoblast cell proliferation, differentiation, and long-term culture. We found that JAK2-STAT3 signal is essential for myoblast cells culture and differentiation. However, the JAK2-STAT3 signal is not the reason for the long-term culture defects in bovine myoblast cells.

\section{Results}

\section{p-STAT3 is activated in bovine myoblasts during culturing}

Under physiological conditions, quiescent satellite cells do not do express p-STAT3. However, activated satellite cells start to express p-STAT3 during muscle injury ${ }^{13}$. Since the STAT3 signal pathway is up-regulated in mouse satellite cells activation ${ }^{5,18,19}$, we checked the expression of p-STAT3 in cultured bovine satellite cells. Immunofluorescent staining showed that the p-STAT3 was expressed in cultured bovine satellite cells (Figure 1). 
Figure 1. $p$-STAT3 is activated in bovine myoblasts during culturing

a

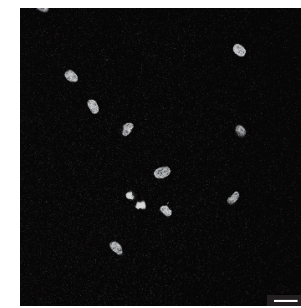

MYOD

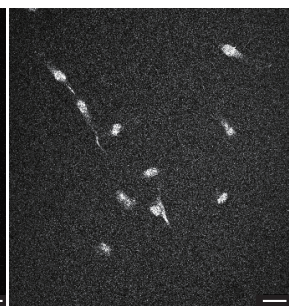

P-STAT3

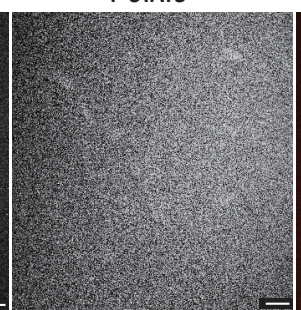

Merge

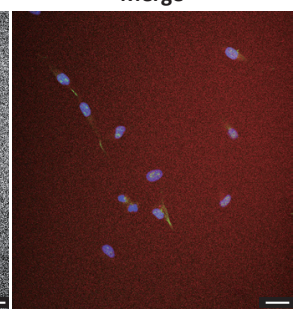

(a) Representative Immunofluorescent staining of DAPI, MYOD, p-STAT3 on bovine muscle stem cells cultured for 4 days. Scale bars: $25 \mu \mathrm{m}$.

JAK2-STAT3 is important for myoblast proliferation but does not maintain the stemness gene $P A X 7$

In mouse satellite cells, pharmacological inhibition of JAK2 or STAT3 maintains the $\mathrm{Pax}^{+}$satellite cells per fiber in single muscle fiber culture ${ }^{19}$ and supports satellite cell proliferation in vitro ${ }^{13}$. To investigate pharmacological inhibition of JAK2 or STAT3 in bovine myoblast cells culturing in vitro, we cultured bovine myoblast cells with STAT3i (Stattic) and JAK2i (AG490). EdU incorporation results showed that up to $4 \mu \mathrm{M}$, STAT3i and JAK2 $i$ had no effect on bovine myoblast cells proliferation (Figure $2 a, 2 b$ ). Higher concentrations of STAT3i $(4 \mu \mathrm{M})$ and JAK2i $(\geq 4 \mu \mathrm{M})$ inhibited myoblast cells proliferation (Figure $2 \mathrm{a}, 2 \mathrm{~b}$ ). The $P A X 7$ expression in passage 2 was not affected by the different concentrations of STAT3i and JAK2i (Figure2c, 2d). It has been reported that MYOD is regulated by STAT3 ${ }^{13,14}$. We also checked the MYOD expression with the STAT3i and JAK2 $i$ treatment. High concentration of STAT3i $(4 \mu \mathrm{M})$ showed MYOD repression whereas JAK2i treatment didn't affect MYOD expression in mRNA level (Figure 2e, 2f). 
Figure 2. JAK2-STAT3 is important for myoblast proliferation but does not maintain the stemness gene PAX7

a

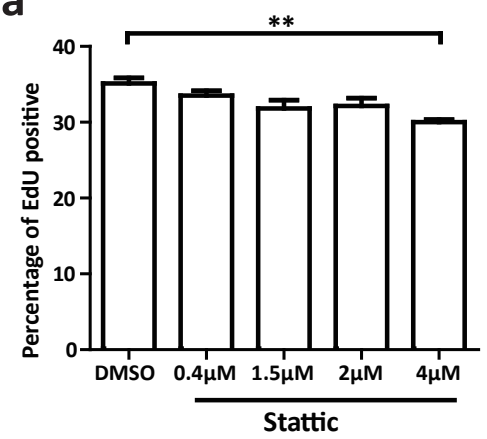

C

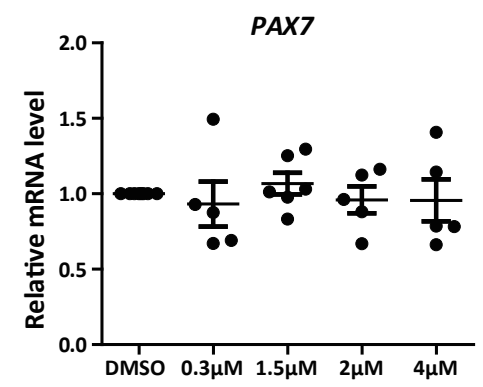

e

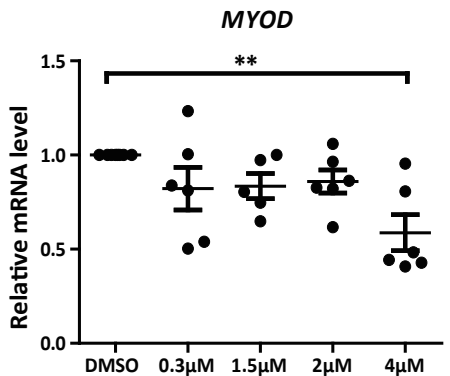

b

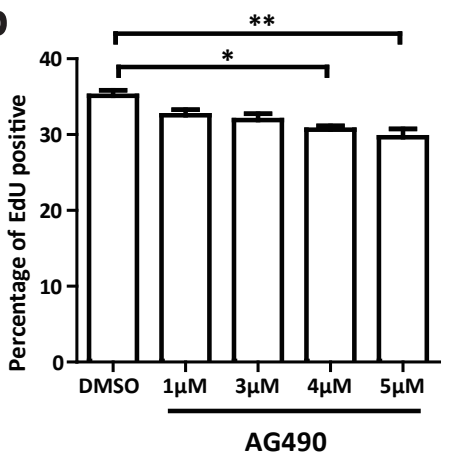

d

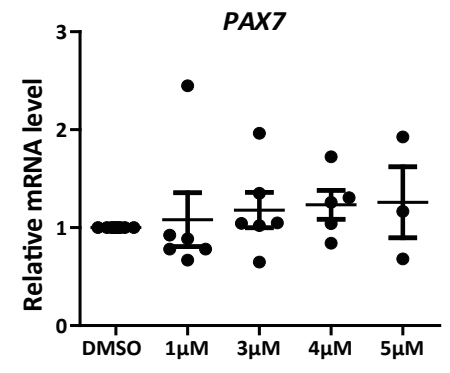

(a) Relative percentage of $1 \mathrm{hr}$ window EdU incorporation at given concentrations of STAT3i for myoblast cells at passage 2 after overnight culture. $(n=4)(b)$ Quantification of the percentage of EdU ${ }^{+}$cells at different concentrations of JAK2 $i$ for myoblast cells at passage 2 after overnight culture. ( $n=4)$. (c, d) PAX7 relative expression at different concentrations of STAT3i (c) or JAK2i (d) by qRT-PCR. ( $n=3-6)$. (e, f) MYOD relative expression at different concentrations of STAT3i (e) or JAK2i ( $f$ ) by qRT-PCR. $(n=6)$. Data are represented as mean \pm SEM. Significance was analyzed by One-way ANOVA with Bonferroni's Multiple Comparison Test. Asterisks: * indicates $P<0.05, * *$ indicates $P<0.01$. 


\section{JAK2-STAT3 signal is essential for bovine myoblast cell differentiation}

In mouse and human myoblasts, JAK2-STAT3 signal is up-regulated during myoblast fusion ${ }^{3,14,20}$. We investigated if the JAK2-STAT3 signal is also increased in bovine myoblast differentiation. We induced bovine myoblast differentiation by lowering the serum to $2 \%$. Bovine myoblasts showed nice myotubes formation after 3 days of differentiation (Figure 3a, left). The STAT3 downstream proteins SOCS3, p-JAK2, p-STAT3 were upregulated during differentiation (Figure $3 \mathrm{~b}$ ). The addition of STAT3i and JAK2 $i$ decreased the myotube size (Figure 3a, middle and right) and associated MYHC expression (Figure 3c, 3d). We also cultured bovine myoblast cells for 8 days in growth medium. Under these conditions, bovine myoblast cells automatically fuse to form nascent myotubes upon reaching $100 \%$ confluency (Figure 4a). However, JAK2i and STAT3i treatment inhibited the myotube formation ability compared with control groups. The Myogenin (MYOG) and $M y H C$, both markers of myocyte differentiation, were also inhibited by JAK2i and STAT3i (Figure 4b, 4c). Altogether, JAK2-STAT3 signal is up-regulated during bovine myoblast differentiation. Addition of JAK2 $i$ and STAT3 $i$ inhibits the differentiation process, indicating that JAK2 and STAT3 signalling is required during differentiation. 
Figure 3. JAK2-STAT3 signal is essential for bovine myoblast cell differentiation

a
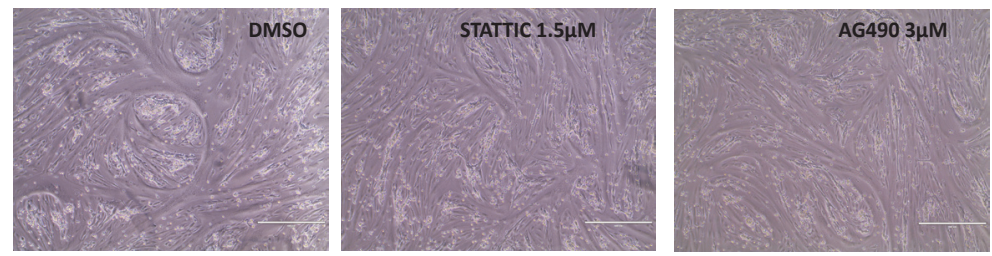

b

Myoblast Confluent Differentiation

C

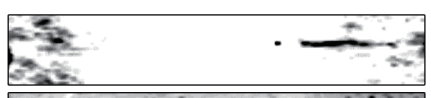

SOCs3

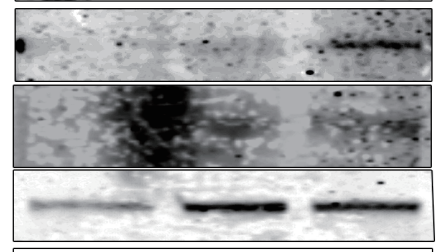

p-JAK2

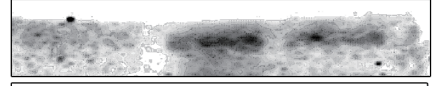

JAK2

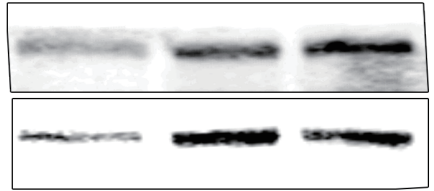

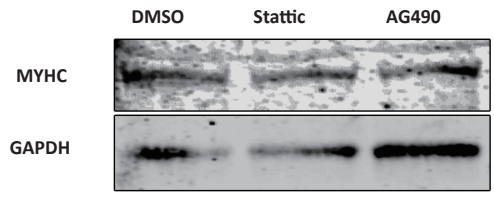

d

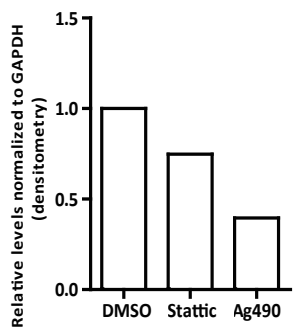

(a) Representative phase contrast images of passage 2 bovine myoblast cells differentiated with control (left), STAT3i (middle), JAK2i (right). Cell were cultured to 95\% confluency and then switched to differentiation medium. Scale bars: $400 \mu \mathrm{m}$. (b) Representative images of immunoblotting against MYHC, SOCS3, p-STAT3, STAT3, p-JAK2, JAK2 and GAPDH from cell lysates of myoblast, 95\% confluency and differentiation stage. (c) Representative images of immunoblotting against MYHC and GAPDH from cell lysates of passage 2 bovine myoblast cells differentiated with control, JAK2i, STAT3i. (d) Relative levels of MyHC normalized to GAPDH from (c). $(n=1)$. Data are represented as mean. 
Figure 4. JAK2 and STAT3 inhibition interferes with myoblast differentiation
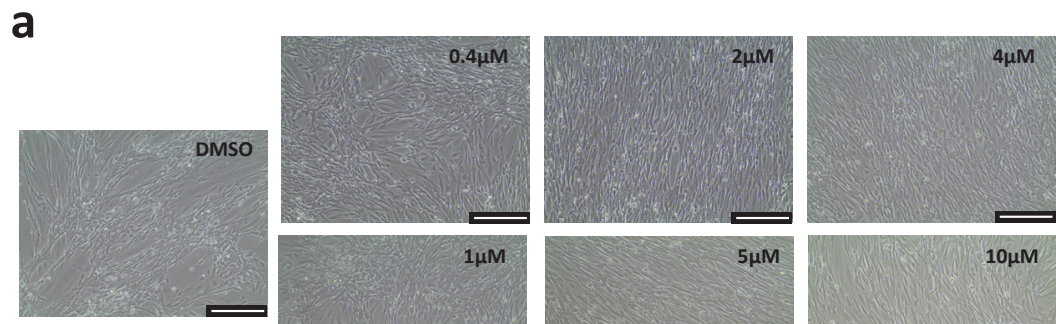

Stattic
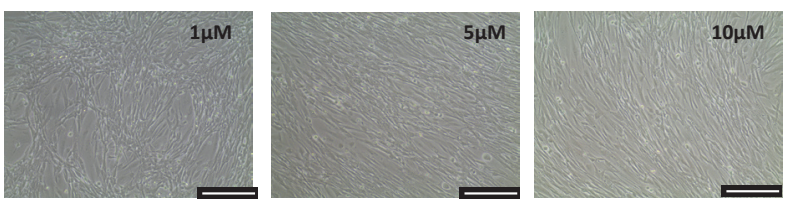

AG490

b

MYOG

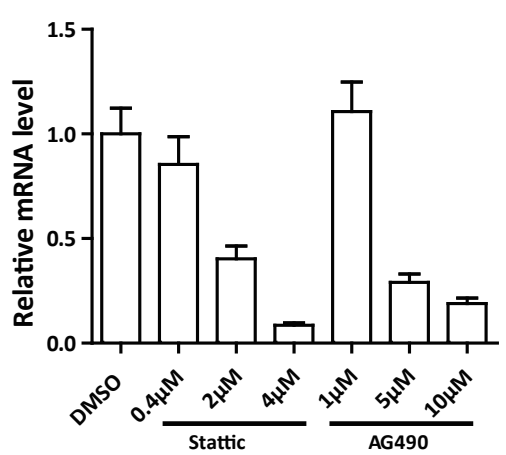

C

MyHC

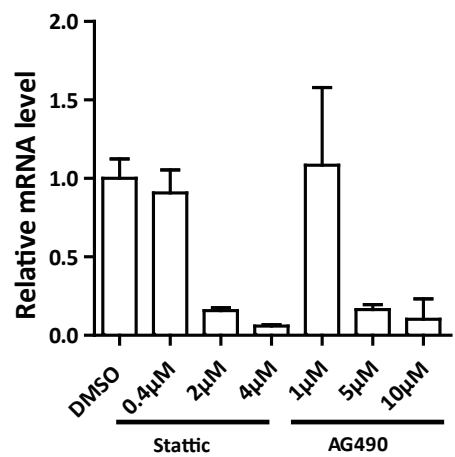

(a) Representative phase contrast images of passage 2 bovine myoblast cells cultured for 8 days in growth medium with control, JAK2i, STAT3i. Scale bars: $400 \mu \mathrm{m}$. (b) MYOG expression after 7 days of culture in growth medium with control, JAK2i and STAT3i. $(n=1)$. (c) MyHC expression after 7 days of culture in growth medium with control, JAK2i and STAT3i. $(n=1)$. Data are represented as mean \pm SD.

In long-term culture, STAT3i and JAK2i have no effect on proliferation, stemness gene expression and differentiation of long-term culture of bovine myoblasts

Eventhough JAK2i and STAT3i doesn't affect the stemness gene PAX7 in short term treatment, they inhibit the differentiation of bovine myoblast cells. We checked longterm culture of bovine myoblast cells with JAK2i and STAT3i. Both of the inhibitors didn't affect the proliferation of bovine myoblast cells in long-term culture (Figure 5a). The PAX7 and MYOD expression were also not affected by STAT3i treatment in P6, P8 or JAK2 $\mathrm{i}$ in $\mathrm{P} 10$ (Figure $5 \mathrm{~b}, \mathrm{c}$ ). Passage 9 myoblasts in different treatment groups showed similar differentiation abilities (Figure $5 \mathrm{~d}$ ). Altogether, JAK2i or STAT3i doesn't affect proliferation, stemness gene expression or differentiation in long-term passage. 
Figure 5. STAT3i and JAK2i have no effect on proliferation, stemness gene expression and differentiation of long-term culture of bovine myoblasts

a

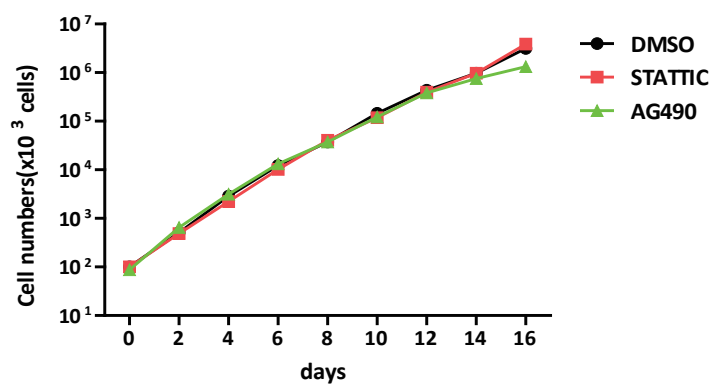

b

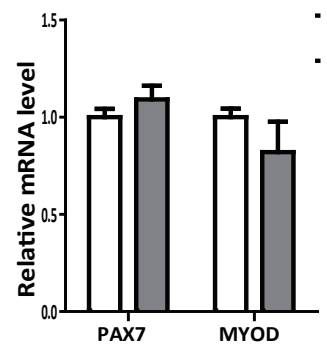

P6

d

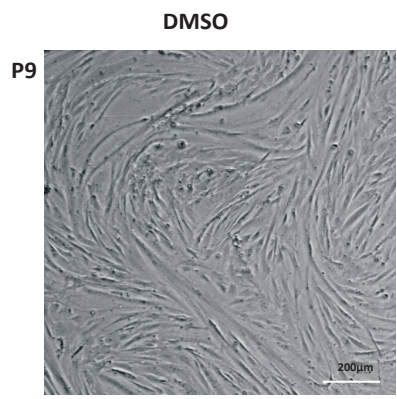

C
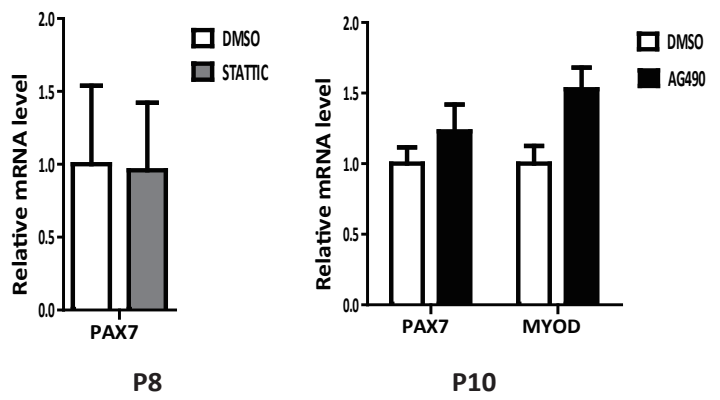

STATTIC
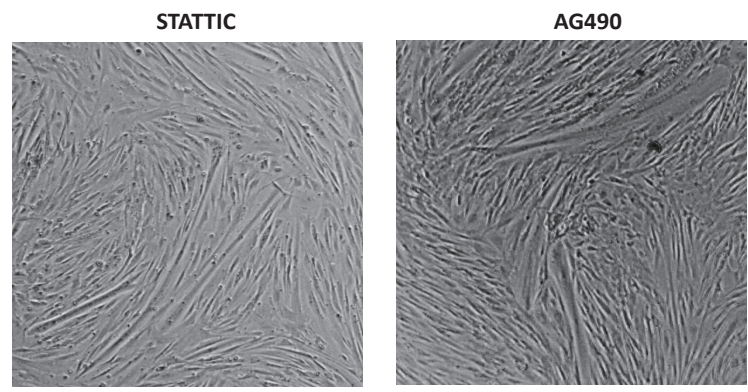

Cells were serially passaged to maintain a density of $<60 \%$ confluency and were counted at each passage. (a) Growth curve of bovine myoblast cells cultured with STAT3i, JAK2i or control. ( $n=3$ for STAT3i, $n=2$ for JAK2i). (b) PAX7 and MYOD mRNA levels at passage 6 and 8 during long-term passage with or without STAT3i. $(n=1)$. (c) PAX7 and MYOD mRNA levels at passage 10 during long-term passage with or without JAK2i. $(n=1)$. (d) Representative phase contrast images of passage 9 myoblast cells from control (left), STAT3i (middle), JAK2i (right) were induced differentiation with the same differentiation medium. Data are represented as mean \pm SEM. For the growth curve, significance was analyzed by 2-way ANOVA and Bonferroni post-tests were used to compare treatment in different passages. 


\section{JAK2-STAT3 signal is stable during long-term passage}

Since the expression of p-JAK2 and p-STAT3 is very weak by Western Blot in myoblast, we analysed the total STAT3, JAK2 and downstream SOCS3 in different passages. Those proteins did not show obvious changes (Figure 6a, b). Taking together, long-term passage doesn't affect the JAK2-STAT3 signal pathway.

Figure 6. JAK2-STAT3 signal is stable during long-term passage

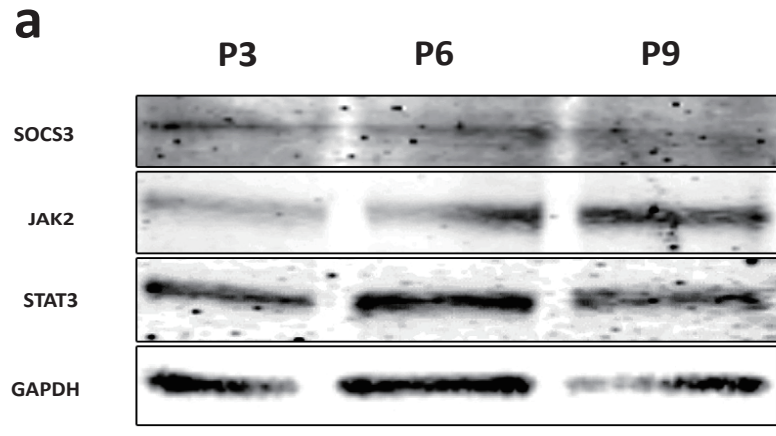

b

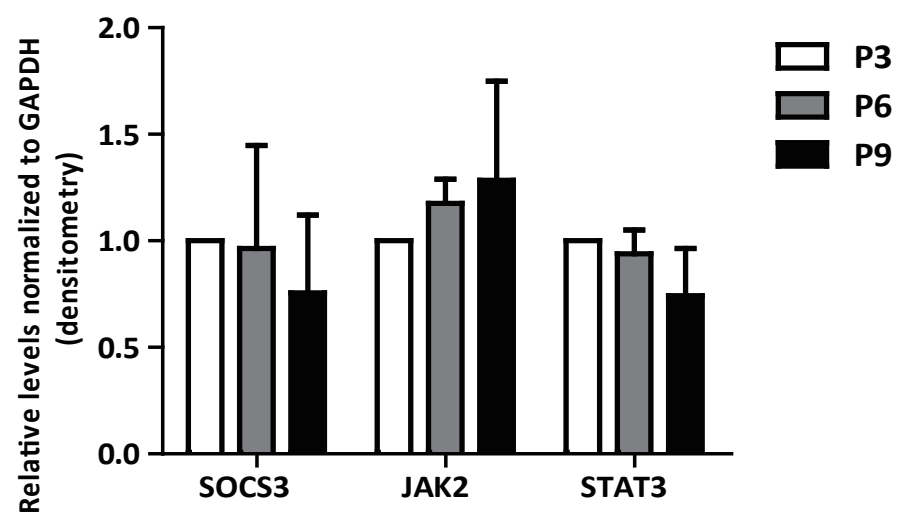

(a) Representative images of immunoblotting against SOCS3, STAT3, JAK2 and GAPDH from cell lysates of different passage myoblast cells during serial expansion. (b) Relative levels of SOCS3, JAK2, STAT3 proteins normalized to GAPDH from (a). Data are represented as mean \pm SEM ( $n=3)$. Significance was analyzed by Oneway ANOVA with Bonferroni's Multiple Comparison Test. 


\section{Discussion}

In our results, we observed STAT3 activation during short term cultured of bovine myoblast cells. High concentration (more than $4 \mu \mathrm{M}$ ) of JAK2i or STAT3i treatment inhibited myoblast cells proliferation. JAK2 $i$ and STAT3i did not affect stemness gene PAX7 expression of bovine myoblast cells but inhibited the differentiation process. Pharmacological inhibition of JAK2 and STAT3 also did not affect proliferation or differentiation abilities of the bovine myoblast cells in long-term culture (Figure 6), Further protein analysis through western blotting indicates that JAK2-STAT3 signaling does not seem to determine the long-term culture defects in bovine myoblast cells.

\section{STAT3 in proliferation}

STAT3 signaling is important in myoblasts proliferation in vitro. Activated STAT3 ( $p$-STAT3) is not expressed or in a low level in satellite cells under physiological conditions ${ }^{13,21}$. After culturing in vitro, the p-STAT3 is expressed in satellite cells ${ }^{13}$ (Figure 1). However, the role of STAT3 in satellite cell proliferation is controversial. On one hand, LIF-induced STAT3 and STAT1 activation results in myoblast proliferation in $\mathrm{C} 2 \mathrm{C} 12$ that is inhibited by knockdown of STAT3 ${ }^{22}$. The STAT3 conditional KO satellite cells are defective in cell proliferation ${ }^{23}$. On the other hand, others have shown that pharmacological or shRNA inhibition of STAT3 supported mouse and human satellite cells proliferation, mainly by inhibition of MYOD and MYOG expression ${ }^{13}$. In our hands, both JAK2 $i$ and STAT3i inhibited myoblast proliferation at high dose, suggesting that STAT3 and JAK2 activation during proliferation indeed have a small stimulatory effect in bovine myoblast cells (Figure 2a, 2b).

\section{STAT3 in differentiation}

Unlike the proliferation and in vivo data, JAK2-STAT3 signaling in differentiation is clear. During myoblast differentiation, both activated JAK2 ( $p$-JAK) and STAT3 ( $p$-STAT3) are up-regulated ${ }^{24}$. JAK2 is critical for the MYOD and MEF2 expression and transactivation function $^{25}$ STAT3 phosphorylation increases during myoblast differentiation and activates SOCS-3 transcription ${ }^{26}$. As a feedback, SOCS3 inhibits the IGF1-induced STAT3 activation $^{27,28}$. The myogenic differentiation was inhibited by knockdown of JAK2 or STAT3 ${ }^{24,25}$. Likewise, pharmacological JAK2i and STAT3i treatment inhibited muscle differentiation ${ }^{13,29}$. In our results, bovine myoblast cells differentiation was inhibited by JAK2 $i$ and STAT3i both in growth medium ( $20 \%$ serum) and differentiation medium ( $2 \%$ serum) (Figure 4 and 5). However, optimized JAK2i and STAT3i didn't affect the differentiation ability during long-term passaging (Figure 5). STAT3 is required for muscle differentiation, but inhibition does not preclude future differentiation. 


\section{In vivo, the role of STAT3 is more complex}

It is evident that JAK2-STAT3 signal is important in muscle stem cells in vivo. Damage by overloading muscle causes increased p-STAT3 positive satellite cells ${ }^{21}$. Likewise, loss of muscle mass in disease conditions is also due to activated STAT3 (p-STAT3), which means that $\mathrm{p}$-STAT3 initiates muscle wasting ${ }^{5,30,31}$. In what seems to be a contrast, however, the IL-6/STAT3 axis is also critical in satellite cell proliferation-mediated hypertrophic muscle growth ${ }^{32}$.

A similar dichotomy is observed in muscle injury models. Injury induced IL-6-activated STAT3 signaling results in defective regeneration. Transient STAT3 inhibition by STAT3 inhibitors promotes satellite cell expansion and enhances tissue repair in both young, aged and dystrophic muscle ${ }^{12,13}$. It should be noted that the chemical inhibitors used in the studies above may have off-target effects ${ }^{5,23}$. Conditional ablation of STAT3 signal in satellite cells results in their increased expansion during regeneration ${ }^{13}$. Similarly, STAT3 conditional KO in satellite cells by another group show opposite results in that the satellite cells decrease after muscle injury ${ }^{23}$. In fact, the former group only finds the increased expansion of satellite cells in 2-month old but not in 3-month old MuSCspecific STAT3 knockout mice ${ }^{13}$. Irrespective of the age effect, both groups showed that MuSC-specific STAT3 knockout mice showed impaired regeneration. Those results confirm a complex effect of STAT3 signal in satellite cells in vivo, which needs more research to clarify.

\section{STAT3 signal in aging}

In transcriptome profiles higher expression of JAK2-STAT3 signaling in aging muscle stem cell has been established ${ }^{12,33}$. Inhibition of JAK2-STAT3 signaling rescues the proliferation and engraftment defect of satellite cells from the muscle of older adult mice $^{12}$. The reason for up-regulation of JAK2-STAT3 signal in aging satellite cells could be increased inflammation as indicated by a higher IL-6 signal ${ }^{16,30}$. Likewise, in elder muscle, increased IL-6 activated STAT3, SOCS3 protein expression ${ }^{30,34-36}$. Subculture of cells may be viewed as an aging model ${ }^{17}$ and long-term cultured satellite cells show some similarities with aging satellite cells in vivo ${ }^{37,38}$. In subculture of TIG3 human fibroblasts, aged cells (later passages) showed higher p-STAT3 signaling than younger cells $^{39}$. However, in two other reports, it was found that the p-STAT3 expression was high in young passages as well ${ }^{40,41}$. In our long-term cultured myoblast cells, we didn't observe an up-regulation of STAT3 during passaging.

Therefore, our results show that JAK2-STAT3 signal is important in bovine myoblast cells proliferation and differentiation. However, the JAK2-STAT3 signal is not the reason for the long-term culture defects in bovine myoblast cells. 


\section{Materials and Methods}

\section{Bovine muscle tissues}

The bovine satellite cells in this study were derived from fresh muscle samples obtained at a local slaughterhouse. The transport time is about $30 \mathrm{~min}$.

\section{Bovine satellite cells isolation}

Bovine satellite cells were isolated from 4-6 year old male cattle as previously described and adapted to bovine tissues ${ }^{42-44}$. The detailed method for isolation mononuclear cells from muscle tissue was described in Chapter 2.

The frozen cells were first recovered in growth medium $(\mathrm{F} 10+20 \%$ fetal calf serum + $5 \mathrm{ng} / \mathrm{ml} \mathrm{bFGF)} \mathrm{for} 2$ days. The floating debris were washed away and the adherent cells were collected by trypsin dissociation. These cells were resuspended in FACS buffer and stained with APC anti-human CD29 Antibody (1:10, BioLegend, Cat\# 303008), PE-Cy ${ }^{\mathrm{TM}} 7$ anti-human CD56 (1:10, BD, Cat\# 335826), FITC anti-sheep CD31 (1:10, BIORAD, Cat\# MCA1097F), FITC anti-sheep CD45 (1:10, BIO-RAD, Cat\# MCA2220F) for 30$45 \mathrm{~min}$ on ice. After antibody incubation, the cells were washed twice with cold PBS and reconstituted in growth medium. The viable $\mathrm{CD} 31^{-} \mathrm{CD} 45^{-} \mathrm{CD} 56^{+} \mathrm{CD} 29^{+}$cells were isolated by cell sorting. Cell sorting was performed with a BD FACSAriall cell sorter using $405,488 \mathrm{~nm}$ and $640 \mathrm{~nm}$ lasers. Unstained cells were routinely used to define FACS gating parameters.

\section{Satellite cell culture and differentiation}

Dishes (Corning) were coated with $0.05 \%$ bovine collagen type I (Sigma, Cat\# C4243). FACS isolated bovine satellite cells and unsorted cells were cultured on collagencoated dishes in F10 medium (Gibco, Cat\# 31550-023) containing 20\% fetal bovine serum (FBS, Gibco, Cat\# 10500-06), 5 ng/mL bFGF (R\&D, Cat\# 233-FB-025) and 1\% P.S. Where indicated, medium was supplemented with STATTIC (Sigma, Cat\# S7947), AG490 (InvivoGene, Cat\# tIrl-ag4) and DMSO (Sigma, Cat\# D8418). For serial expansion, cells were passaged to maintain a density of $<60 \%$ confluence and counted at each passage. Bovine myoblast cells differentiation was induced at $95 \%$ confluency with DMEM (Invitrogen, Cat\# 41966-29) with 2\% FBS. The expanded and differentiated cells were fixed with 4\% PFA for immunofluorescent staining. The bright field images were acquired by AMG-EVOS microscope.

\section{Immunofluorescent analysis of cultured cells}

Cultured satellite cells were fixed with ice-cold 4\% PFA (in PBS) for $20 \mathrm{~min}$, rinsed with PBS, and permeabilized in 0.5\% Triton X-100 (in PBS) for 15 min. Permeabilized cells were blocked and incubated with primary antibodies in 1\% BSA (in PBS) overnight at $4^{\circ} \mathrm{C}$. Primary antibodies recognizing rabbit MYOD (1:200, ABclonal, CAT\# A0671), 
mouse STAT3 (1:50, cell signaling technology, CAT\# 9139). After washing with PBS, cells were incubated with Alexa 488 labeled anti-rabbit (1:600, Invitrogen, Cat \# A-11034), 594 labeled anti-mouse (1:600, invitrogen, Cat \# A-11032) antibodies for $1 \mathrm{~h}$ at room temperature and mounted with VECTASHIELD mounting medium with DAPI (Vector Laboratories Cat\# H-1500).

EdU detection was carried-out using a Click-It EdU detection kit (Life Technologies, Cat\# C10337) according to the manufacturer's instructions.

\section{Western blots analysis of cultured cells}

Western blots were either performed from total cell lysates obtained by lysing cells directly with RIPA buffer complemented with PMSF, protease inhibitor cocktail and sodium orthovanadate (Santa Cruz, CAT\# sc-24948). Proteins concentration was determined using BCA protein assay kit (Thermo). SDS-PAGE electrophoresis was carried out in $7.5 \%$ pre-cast polyacrylamide gels (Bio-Rad, CAT\# 5671023). After transfer onto nitrocellulose, membranes were blocked for 30 min with Odyssey Blocking Buffer in PBS (Part Number: 927-40000, LI-COR Biosciences) and probed overnight with primary antibody: p-STAT3 (1:250, Cell Signaling, CAT\# 9138S), STAT3 (1:500, Cell Signaling, CAT\# 9139S), p-JAK2 (1:250, Cell Signaling, CAT\# 3776S), JAK2 (1:500, Cell Signaling, CAT\# 3230S), SOCS3 (1:500, Cell Signaling, CAT\# 2932S), MyHC (1:500, Millipore, CAT\# 05-716), GAPDH (1:500, Millipore, CAT\# MAB374). After that, IRDye700-conjugated or IRDye800-conjugated secondary antibodies were used and visualized with the Odyssey infrared detector (LI-COR Biosciences, Westburg, Leusden, the Netherlands). For Protein quantification a, we used the background correction option in the software of the supplier (Image Studio ${ }^{\text {TM }}$ Software for the Odyssey CLx-LI-COR Biosciences) and scanned the corresponding band of the protein of interest.

\section{Gene expression analysis}

RNA was extracted from cells using the RNeasy Micro Kit (QIAGEN, Cat\#74004) including RNase-Free DNase Set (QIAGEN, Cat\# 79254) according to the manufacturer's instruction. 500 ng of total RNA from each sample was reverse transcribed to cDNA using iScript cDNA Synthesis Kit (Bio-Rad, Cat\#1708891) according to the manufacturer's instruction. Relative gene expression was performed in triplicate using a SYBR Green PCR master mix on an CFX 96 Real Time PCR system (Bio-Rad).

The primers used in these assays were the followings:

PAX7-F, 5' - CTCCCTCTGAAGCGTAAGCA -3', PAX7-R, 5' - GGGTAGTGGGTCCTCTCGAA -3'; MYOD-F, 5' - CGACGGCATGATGGACTACA-3', MYOD-R, 5' - GTAAGTGCGGTCGTAGCAGT -3' MYOG-F, 5'- GCGCAGACTCAAGAAGGTGA -3', MYOG-R, 5'- TGCAGGCGCTCTATGTACTG -3 ;

MyHC2-F, 5'-AGAGCAGCAAGTGGATGACCTTGA-3', MyHC-R, 5' - TGGACTCTTGGGCCAACTTGAGAT -3'; 
GAPDH-F, 5' - CACCCTCAAGATTGTCAGC -3', GAPDH-R, 5' - TAAGTCCCTCCACGATGC -3'. EdU percentage measurement

For EdU detection, cells cultured in BD Falcon 96 wells HTS Imaging microplates were imaged using a High-Content Analyzer (BD Pathway 855) with a 10x objective. In total 16 images were taken for each condition and individual cell segmentation and analysis was performed using the BD Attovision software (BD Biosciences, version 1.6). Hoechst positive cells were segmented and counted, then the same was done for EdU positive cells. The numerical data were further analyzed with Kaluza software (version 1.3; Beckman Coulter), where the EdU positive percentage was determined for more than 1000 nuclei from 16 randomly chosen fields.

\section{Statistics}

Statistical analyses were performed using GraphPad Prism 5 (GraphPad Software). For comparisons of two treatment groups, a Student's t-test was used. For more than two groups, One-way ANOVA with Bonferroni's Multiple Comparison Test was used. Results were means \pm S.E.M. unless otherwise stated. $P<0.05$ was considered significant.

\section{Acknowledgements}

This work was supported by the Core Facility Flow Cytometry, a core facility of the Interdisciplinary Center for Clinical Research (IZKF) Aachen within the Faculty of Medicine at RWTH Aachen University. We thank the confocal microscopy services in Maastricht University. This work was sponsored by Royal Netherlands Academy of Arts and Sciences and China Scholarship Council. 


\section{References}

1 Morales, J. K., Falanga, Y. T., Depcrynski, A., Fernando, J. \& Ryan, J. J. Mast cell homeostasis and the JAK-STAT pathway. Genes and immunity 11, 599-608, doi:10.1038/gene.2010.35 (2010).

2 Rawlings, J. S., Rosler, K. M. \& Harrison, D. A. The JAK/STAT signaling pathway. J Cell Sci 117, 1281-1283, doi:10.1242/jcs.00963 (2004).

3 Trenerry, M. K., Della Gatta, P. A. \& Cameron-Smith, D. JAK/STAT signaling and human in vitro myogenesis. BMC physiology 11, 6, doi:10.1186/1472-6793-11-6 (2011).

4 Kataoka, Y. et al. Reciprocal inhibition between MyoD and STAT3 in the regulation of growth and differentiation of myoblasts. J Biol Chem 278, 44178-44187, doi:10.1074/jbc.M304884200 (2003).

5 Guadagnin, E., Mazala, D. \& Chen, Y. W. STAT3 in Skeletal Muscle Function and Disorders. Int J Mol Sci 19, doi:10.3390/ijms19082265 (2018).

6 O’Sullivan, L. A., Liongue, C., Lewis, R. S., Stephenson, S. E. M. \& Ward, A. C. Cytokine receptor signaling through the Jak-Stat-Socs pathway in disease. Mol Immunol 44, 2497-2506, doi:10.1016/j. molimm.2006.11.025 (2007).

7 Megeney, L. A., Perry, R. L., LeCouter, J. E. \& Rudnicki, M. A. bFGF and LIF signaling activates STAT3 in proliferating myoblasts. Developmental genetics 19, 139-145, doi:10.1002/(SICI)15206408(1996)19:2<139::AID-DVG5>3.0.CO;2-A (1996).

8 Jang, Y. N. \& Baik, E. J. JAK-STAT pathway and myogenic differentiation. Jak-Stat 2, e23282, doi:10.4161/ jkst.23282 (2013).

9 Zhang, C. et al. Interleukin-6/signal transducer and activator of transcription 3 (STAT3) pathway is essential for macrophage infiltration and myoblast proliferation during muscle regeneration. $J$ Biol Chem 288, 1489-1499, doi:10.1074/jbc.M112.419788 (2013).

10 Toth, K. G. et al. IL-6 Induced STAT3 Signalling Is Associated with the Proliferation of Human Muscle Satellite Cells Following Acute Muscle Damage. Plos One 6, doi:ARTN e17392 10.1371/journal. pone.0017392 (2011).

11 Chazaud, B. \& Mouchiroud, G. Inflamm-aging: STAT3 signaling pushes muscle stem cells off balance. Cell stem cell 15, 401-402, doi:10.1016/j.stem.2014.09.010 (2014).

12 Price, F. D. et al. Inhibition of JAK-STAT signaling stimulates adult satellite cell function. Nat Med 20, 1174-1181, doi:10.1038/nm.3655 (2014).

13 Tierney, M. T. et al. STAT3 signaling controls satellite cell expansion and skeletal muscle repair. Nat Med 20, 1182-1186 (2014).

14 Yang, Y. et al. STAT3 induces muscle stem cell differentiation by interaction with myoD. Cytokine 46, 137-141, doi:10.1016/j.cyto.2008.12.015 (2009).

15 Jang, Y. N., Lee, I. J., Park, M. C. \& Baik, E. J. Role of JAK3 in myogenic differentiation. Cell Signal 24, 742-749, doi:10.1016/j.cellsig.2011.11.009 (2012).

16 McKay, B. R. et al. Elevated SOCS3 and altered IL-6 signaling is associated with age-related human muscle stem cell dysfunction. Am J Physiol-Cell Ph 304, C717-C728, doi:10.1152/ ajpcell.00305.2012 (2013).

17 Hohn, A. et al. Happily (n)ever after: Aging in the context of oxidative stress, proteostasis loss and cellular senescence. Redox Biol 11, 482-501, doi:10.1016/j.redox.2016.12.001 (2017).

18 Pietrosemoli, N. et al. Comparison of multiple transcriptomes exposes unified and divergent features of quiescent and activated skeletal muscle stem cells. Skelet Muscle 7, 28, doi:10.1186/s13395-0170144-8 (2017). 
Price, F. D. et al. Inhibition of JAK-STAT signaling stimulates adult satellite cell function. Nat Med 20, 1174-1181 (2014).

20 Wang, K., Wang, C., Xiao, F., Wang, H. \& Wu, Z. JAK2/STAT2/STAT3 are required for myogenic differentiation. J Biol Chem 283, 34029-34036, doi:10.1074/jbc.M803012200 (2008).

21 Toth, K. G. et al. IL-6 induced STAT3 signalling is associated with the proliferation of human muscle satellite cells following acute muscle damage. Plos One 6, e17392, doi:10.1371/journal.pone.0017392 (2011).

22 Sun, L. G. et al. JAK1-STAT1-STAT3, a key pathway promoting proliferation and preventing premature differentiation of myoblasts. J Cell Biol 179, 129-138, doi:10.1083/jcb.200703184 (2007).

23 Zhu, H. et al. STAT3 Regulates Self-Renewal of Adult Muscle Satellite Cells during Injury-Induced Muscle Regeneration. Cell Rep 16, 2102-2115, doi:10.1016/j.celrep.2016.07.041 (2016).

24 Diao, Y. R., Wang, X. \& Wu, Z. G. SOCS1, SOCS3, and PIAS1 Promote Myogenic Differentiation by Inhibiting the Leukemia Inhibitory Factor-Induced JAK1/STAT1/STAT3 Pathway. Mol Cell Biol 29, $5084-$ 5093, doi:10.1128/Mcb.00267-09 (2009).

25 Wang, K. P., Wang, C. H., Xiao, F., Wang, H. X. \& Wu, Z. G. JAK2/STAT2/STAT3 Are Required for Myogenic Differentiation. J Biol Chem 283, 34029-34036, doi:10.1074/jbc.M803012200 (2008).

26 Spangenburg, E. E. SOCS-3 induces myoblast differentiation. J Biol Chem 280, 10749-10758, doi:10.1074/jbc.M410604200 (2005).

27 Zong, C. S. et al. Mechanism of STAT3 activation by insulin-like growth factor I receptor. J Biol Chem 275, 15099-15105, doi:10.1074/jbc.M000089200 (2000).

28 Heinrich, P. C. et al. Principles of interleukin (IL)-6-type cytokine signalling and its regulation. Biochem J 374, 1-20, doi:10.1042/BJ20030407 (2003).

29 Miyake, T. et al. Cardiotrophin-1 Maintains the Undifferentiated State in Skeletal Myoblasts. J Biol Chem 284, 19679-19693, doi:10.1074/jbc.M109.017319 (2009).

30 Munoz-Canoves, P., Scheele, C., Pedersen, B. K. \& Serrano, A. L. Interleukin-6 myokine signaling in skeletal muscle: a double-edged sword? Febs J 280, 4131-4148, doi:10.1111/febs.12338 (2013).

31 Zhang, L. P. et al. Stat3 Activation Links a C/EBP delta to Myostatin Pathway to Stimulate Loss of Muscle Mass. Cell Metabolism 18, 368-379, doi:10.1016/j.cmet.2013.07.012 (2013).

32 Serrano, A. L., Baeza-Raja, B., Perdiguero, E., Jardi, M. \& Munoz-Cinoves, P. Interleukin-6 is an essential regulator of satellite cell-mediated skeletal muscle hypertrophy. Cell Metabolism 7, 33-44, doi:10.1016/j.cmet.2007.11.011 (2008).

33 Zhang, H. et al. $\mathrm{NAD}(+)$ repletion improves mitochondrial and stem cell function and enhances life span in mice. Science 352, 1436-1443, doi:10.1126/science.aaf2693 (2016).

34 Accardi, G. \& Caruso, C. Immune-inflammatory responses in the elderly: an update. Immun Ageing 15, doi:ARTN 11 10.1186/s12979-018-0117-8 (2018).

35 Barbieri, M. et al. Chronic inflammation and the effect of IGF-I on muscle strength and power in older persons. Am J Physiol Endocrinol Metab 284, E481-487, doi:10.1152/ajpendo.00319.2002 (2003).

36 Haddad, F., Zaldivar, F., Cooper, D. M. \& Adams, G. R. IL-6-induced skeletal muscle atrophy. J App/ Physiol (1985) 98, 911-917, doi:10.1152/japplphysiol.01026.2004 (2005).

37 Bigot, A. et al. Replicative aging down-regulates the myogenic regulatory factors in human myoblasts Biol Cell 100, 189-199, doi:10.1042/Bc20070085 (2008).

38 Sharples, A. P., Al-Shanti, N., Lewis, M. P. \& Stewart, C. E. Reduction of Myoblast Differentiation Following Multiple Population Doublings in Mouse C2C12 Cells: A Model to Investigate Ageing? J Cell Biochem 112, 3773-3785, doi:10.1002/jcb.23308 (2011). 
Chapter 4

39 Kojima, H., Kunimoto, H., Inoue, T. \& Nakajima, K. The STAT3-IGFBP5 axis is critical for IL-6/gp130induced premature senescence in human fibroblasts. Cell Cycle 11, 730-739, doi:10.4161/ cc.11.4.19172 (2012).

40 Sakellaropoulos, T. et al. Qualitative modeling of signaling networks in replicative senescence by selecting optimal node and arc sets. bioRxiv, doi:10.1101/389692 (2018).

41 Wang, X. D. et al. [Changes of STAT3 in cell replicative senescence and effects of angiotensin II on STAT3]. Zhonghua Yi Xue Za Zhi 83, 324-327 (2003).

42 Charville, G. W. et al. Ex Vivo Expansion and In Vivo Self-Renewal of Human Muscle Stem Cells. Stem Cell Rep 5, 621-632, doi:10.1016/j.stemcr.2015.08.004 (2015).

$43 \mathrm{Xu}, \mathrm{X}$. et al. Human Satellite Cell Transplantation and Regeneration from Diverse Skeletal Muscles. Stem Cell Rep 5, 419-434, doi:10.1016/j.stemcr.2015.07.016 (2015).

44 Ding, S. et al. Characterization and isolation of highly purified porcine satellite cells. Cell Death Discov 3, 17003, doi:10.1038/cddiscovery.2017.3 (2017). 




\section{Chapter 5}

\section{Loss of stemness in satellite cells during subculturing is distinct from loss of stemness by differentiation}




\begin{abstract}
Satellite cells are quiescent in uninjured muscle tissue and can quickly enter the cell cycle following muscle injury or culturing in vitro. On one hand, satellite cells easily start myogenic differentiation with irreversibly withdrawal from the cell cycle when cultured in vitro. On the other hand, satellite cells also lose their capability to multiply when they are serially subcultured in the absence of differentiation. Both of these two processes lead to loss of stemness of satellite cells. Whether differentiation is the main reason for the subculture defects is discussed here. Here we compare several proteins in crucial signaling pathways during differentiation and long-term culture. Differentiation and long-term culture showed a similar up-regulation of the p38-MAPK signal. In contrast, the JAK2-STAT3 signal pathway was up-regulated during differentiation but remained stable during long-term culture. Both ERK and Akt signals were down-regulated when the cells reached confluency to subsequently increase during differentiation. During long-term subculturing ERK signaling kept decreasing whereas Akt signal continued to increase. Our results show that differentiation and long-term passaging are two different biological processes at the level of major signaling pathways. Preventing cell differentiation in early stage myocytes or myoblasts is not sufficient to maintain the stemness of satellite cells during long-term passaging.
\end{abstract}




\section{Introduction}

Satellite cells are a population of small mononucleated muscle stem cells ${ }^{1,2}$. They are about $2-10 \%$ of the total amount of myonuclei ${ }^{3,4}$. In physiological conditions, satellite cells are quiescent and are characterized by the expression of the paired box protein 7 (PAX7) ${ }^{1}$. They are activated upon injury and start asymmetric division to generate the myogenic progenitors needed for muscle regeneration ${ }^{1,5}$. The other daughter cells from asymmetric division do not commit to differentiation, and can undergo self-renew to replenish the muscle stem cell pool ${ }^{5}$.

Satellite cells have been successfully isolated and cultured in vitro ${ }^{6-8}$. Even though the activated satellite cells in vivo show different gene expression profiles compared with satellite cells activated after cell culture ${ }^{9,10}$, they still share the myogenic process. The satellite cell is activated in part by the induced expression of MYOD and MYF5, 5 ,11-15. During activation, satellite cells (or myoblasts) start to express myogenic determination protein (MYOD) and myogenic factor 5 (MYF5) ${ }^{11,16-18}$. Further differentiation is regulated

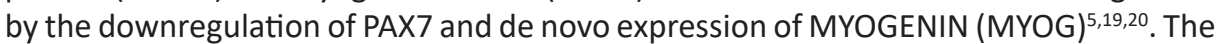
terminally differentiated myotube expresses myosin heavy chain $(\mathrm{MyHC})$ and muscle specific creatin kinase $(\mathrm{MCK})^{20}$.

Several signals are up-regulated during activation, such as p38 MAPK $^{10,21,22}$ and JAKSTAT signals ${ }^{23-25}$, which mediate the transition of satellite cells to more differentiated $\mathrm{PAX7}^{-} \mathrm{MYOG}^{+}$daughter cells, aka myoblasts ${ }^{26-28}$. The MYOG expression leads to downregulation of genes involved in cell cycle progression and promotes differentiation and fusion ${ }^{29}$. The subsequent automatic differentiation impairs the expansion of satellite cells or myoblasts in vitro ${ }^{30-32}$.

Subculturing of stem cells decreases the proliferation and differentiation abilities, especially in mesenchymal stem cells ${ }^{33-36}$. The defects after serial cultivation have also been observed in myoblast cells ${ }^{37-39}$. Whether the automatic differentiation is the main reason for subculture defects is still unclear in satellite cells.

Here we present data to show that subculturing and differentiation are two different biological processes. They share up-regulation of the p38-MAPK signal. However, the JAK2-STAT3, ERK and Akt signals were differently expressed in long-term culture compared with the differentiation process. Preventing the cell to differentiate in early stage myocytes/myoblasts is not sufficient to maintain the stemness of satellite cells during long-term passaging. 


\section{Results}

\section{Differentiation and long-term culture of bovine myoblasts}

Bovine myoblast cells were cultured to confluency and induced to differentiate by $2 \%$ fetal bovine serum. These cells formed multinuclear myotubes (Figure 1a). Myosin heavy chain protein increased in differentiated myotubes, which confirmed the differentiation process (Figure 1b, 1c). The long-term passage cells showed larger cell size during passaging (Figure $1 \mathrm{~d}$ ). The MYOD protein was up-regulated during passaging and maintained stable in later passages (Figure 1e, 1f).

\section{p38 MAPK signaling}

It has been reported that p38-MAPK signaling is up-regulated during differentiation and aging $27,28,40-43$. We compared the p38-MAPK signal in these two conditions at the protein level. Differentiation resulted in an up-regulated phosphorylation of the specific p38 downstream target protein HSP27 (Figure $2 a, 2 b)^{44,45}$. Phosphorylation of p38 however did not change (Figure 2a, 2b). The long-term passage also showed up-regulation of HSP27 phosphorylation (Figure 2c, 2d). The phosphorylation of p38 showed a slight upward trend with increasing passage number. Total p38 level did not change (Figure $2 c, 2 d)$. Both differentiation and longterm passage showed up-regulation of the p38MAPK signal (Figure 2e-g). 
Figure 1. Differentiation and long-term culture of bovine myoblasts

a
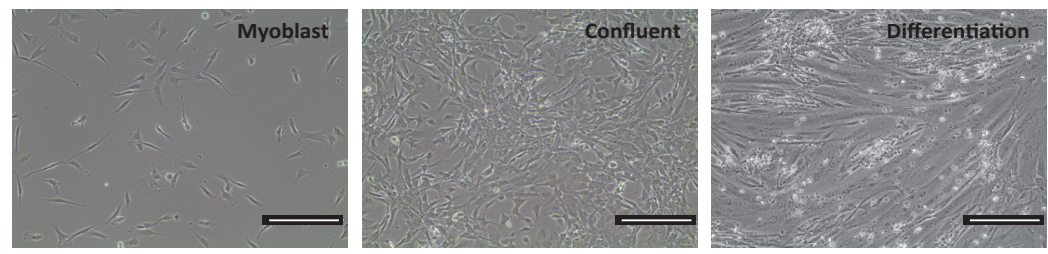

b

Myoblast Confluent Differentiation

MYHC

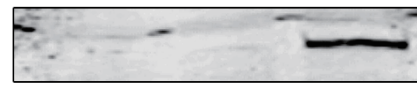

GAPDH

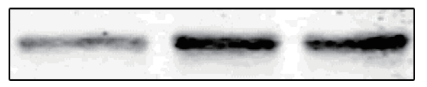

C

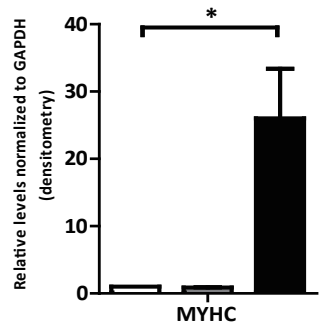

d
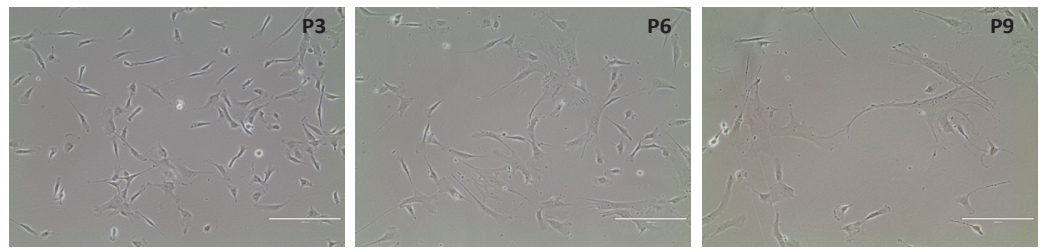

e
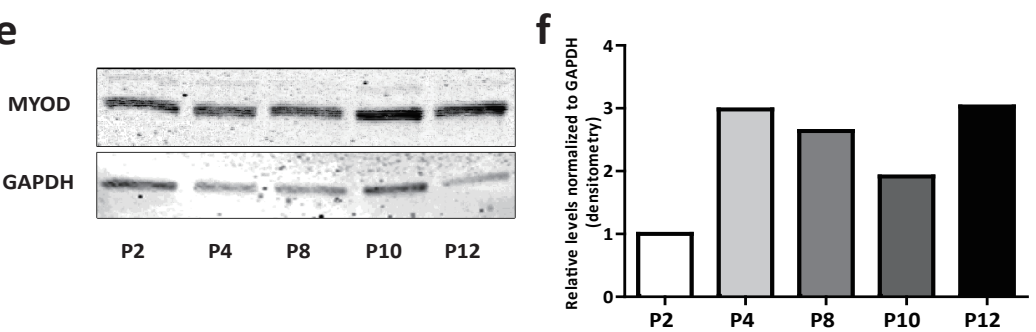

(a) Representative phase contrast images of P3 bovine myoblast cells at proliferation ( $50 \%$ confluency), predifferentiation (95\% confluency) and differentiation stage. Scale bars: $200 \mu \mathrm{m}$. (b) Representative images of immunoblotting against MyHC and GAPDH from cell lysates of myoblast, 95\% confluency and differentiation stage. (c) Relative levels of MyHC normalized to GAPDH are indicated from (b). ( $n=3)$. Data are represented as mean \pm SEM. Significance was analyzed by One-way ANOVA with Bonferroni's Multiple Comparison Test. Asterisks: * indicates $P<0.05$. (d) Representative phase contrast images of P3, P6, P9 bovine myoblast cells. Scale bars: $200 \mu \mathrm{m}$. (e) Representative images of immunoblotting against MYOD and GAPDH from cell lysates of myoblast at passage 2, 4, 8, 10, 12. (f) Relative levels of MYOD normalized to GAPDH are indicated from (b). $(n=1)$. 
Figure 2. p38 MAPK signaling in differentiation and subculturing processes

a

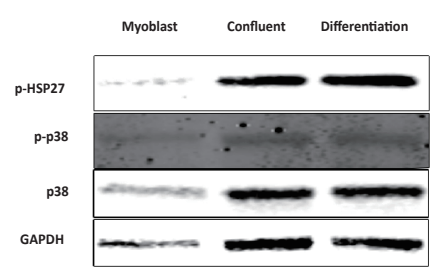

C

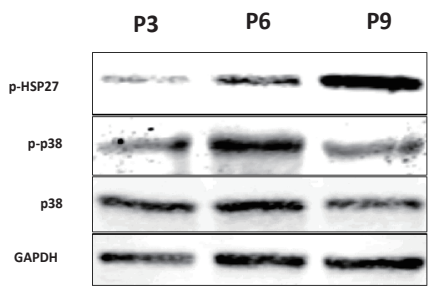

e

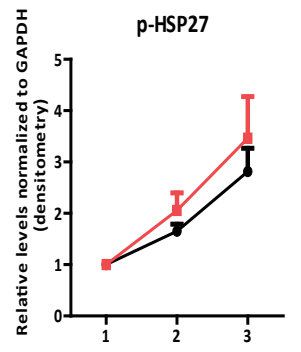

b

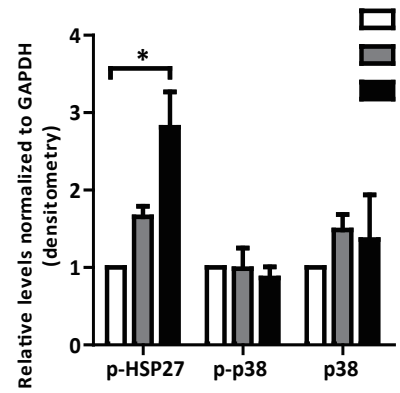

d

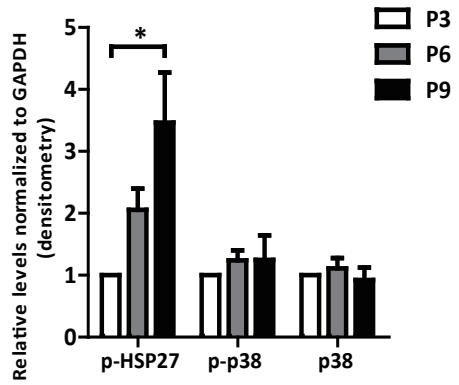

g

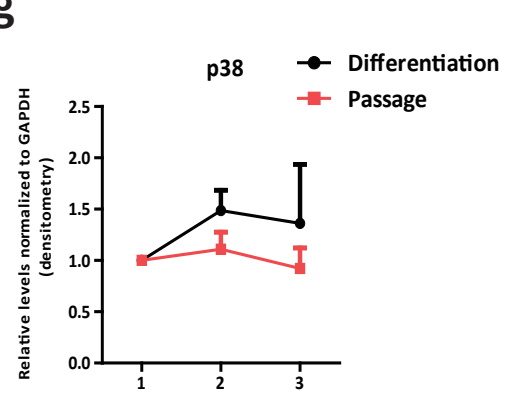

(a) Representative images of immunoblotting against p-HSP27, p-p38, p38 and GAPDH from cell lysates of myoblast, 95\% confluency and differentiation stage. (b) Relative levels of p-HSP27, p-p38, p38 normalized to GAPDH are indicated from (a). $(n=3)$. (c) Representative images of immunoblotting against p-HSP27, p-p38, p38 and GAPDH from cell lysates of myoblast at passage 3, 6, 9. (d) Relative levels of p-HSP27, p-p38, p38 normalized to GAPDH are indicated from $(c) .(n=3)$. $(e, f, g)$ The combination results from (b) and (d) for p-HSP27 (e), p-p38 (f), p38 (g). Data are represented as mean \pm SEM. Significance was analyzed by One-way ANOVA with Bonferroni's Multiple Comparison Test. Asterisks: * indicates $P<0.05$. 


\section{JAK2-STAT3 signaling}

The JAK2-STAT3 signal is up-regulated during myoblast fusion ${ }^{23,46,47}$. Aged satellite cells also show up-regulated JAK2-STAT3 signal ${ }^{48}$. In accordance, the levels of p-JAK2 and p-STAT3 up-regulated during differentiation (Figure 3a, 3b, chapter 4). SOCS3 is downstream of STAT3 signaling and can create a negative feedback to prevent the induction of gp130 signaling ${ }^{49-51}$. SOCS3 gradually increased during differentiation ${ }^{50}$. Our results also showed a higher expression of SOCS3 during differentiation (Figure 3a, 3b). However, SOCS3 expression did not change during long-term passaging (Figure 3c, 3d). Since the expression of p-JAK2 and p-STAT3 is very weak, we checked total JAK2 and STAT3 proteins and they were not affected by passage number either (Figure 3c, 3d). Thus, differentiation and long-term passaging are associated with different expression patterns of SOCS3, JAK2 and STAT3 signaling (Figure 3e-3f).

\section{Akt signaling}

Akt signaling can regulate the balance between protein synthesis and degradation in muscle mass and is also involved in cell survival ${ }^{52,53}$. When primary bovine myoblasts reach confluence, the p-Akt showed a lower expression level compared with nonconfluent myoblasts (Figure 4a, 4b). However, Akt phosphorylation was up-regulated again when cell fusion started as the initial step towards muscle differentiation (Figure $4 a, 4 b)$. Similar results were also presented in $\mathrm{C} 2 \mathrm{C} 12$ cell lines that moved from myoblast to final differentiation ${ }^{24,46,54}$. Total Akt showed a slight up-regulation during differentiation (Figure 4a, 4b). However, the long-term passage cells showed a different p-Akt expression profile. $p$-Akt was increased during long-term passaging while total Akt didn't change (Figure 4c, 4d). Thus, the expression of Akt is different between differentiation and long-term passage (Figure 4e, 4f). 
Figure 3. JAK2-STAT3 signaling in differentiation and subculturing processes

a

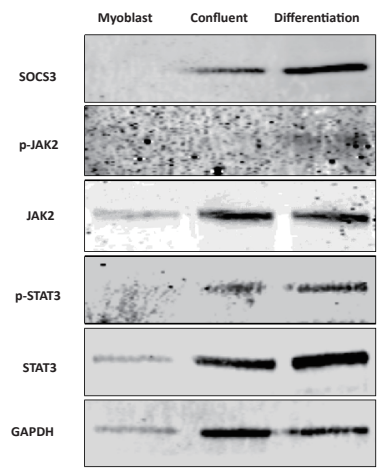

C

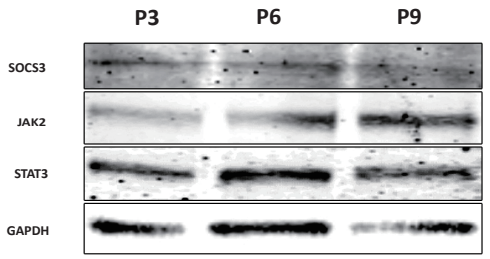

e

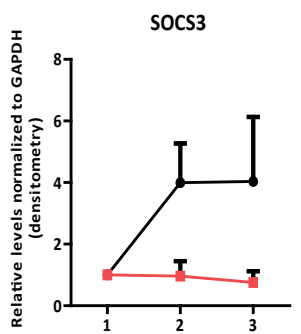

b

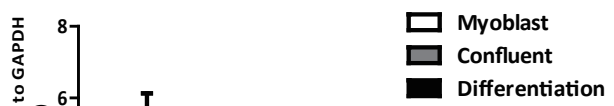

d

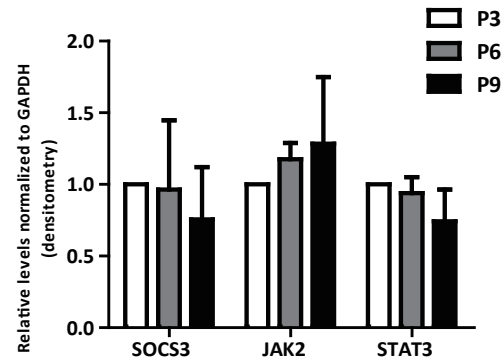

g

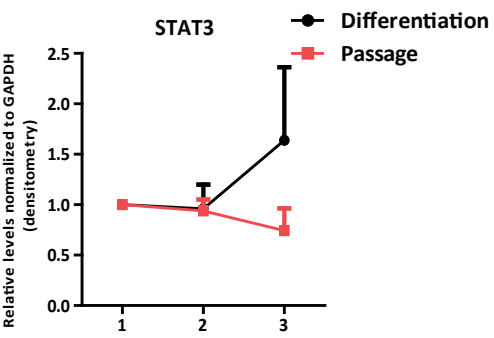

(a) Representative images of immunoblotting against SOCS3, p-JAK2, JAK2, p-STAT3, STAT3 and GAPDH from cell lysates of myoblast, 95\% confluency and differentiation stage. (b) Relative levels of SOCS3, p-JAK2, JAK2, p-STAT3, STAT3 normalized to GAPDH are indicated from (a). ( $n=3)$. (c) Representative images of immunoblotting against SOCS3, JAK2, STAT3 and GAPDH from cell lysates of myoblast at passage 3, 6, 9. (d) Relative levels of SOCS3, JAK2, STAT3 normalized to GAPDH are indicated from (c). ( $n=3)$. (e, f, g) The combination results from (b) and (d) for SOCS3 (e), JAK2 ( $f$ ), STAT3 (g). Data are represented as mean \pm SEM. Significance was analyzed by One-way ANOVA with Bonferroni's Multiple Comparison Test (differences were non-significant). 
Figure 4. Akt signaling in differentiation and subculturing processes

a

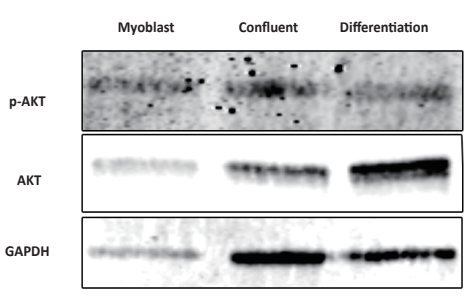

C

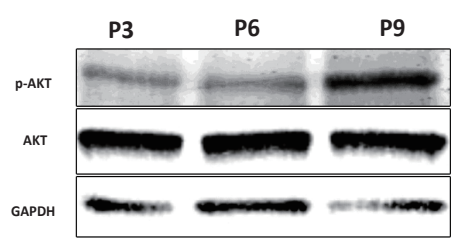

e

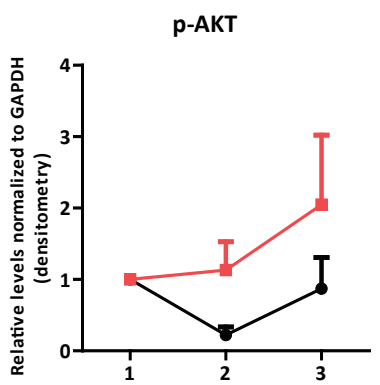

b

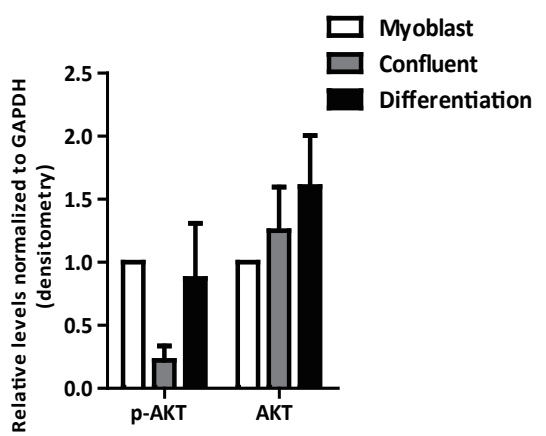

d

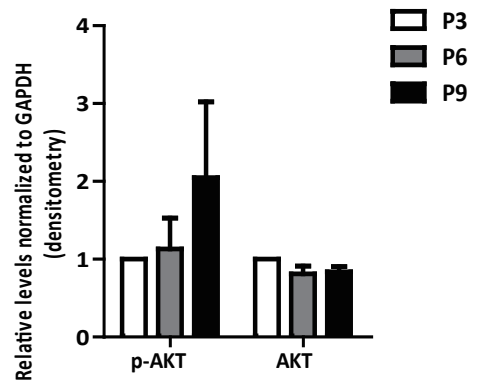

f

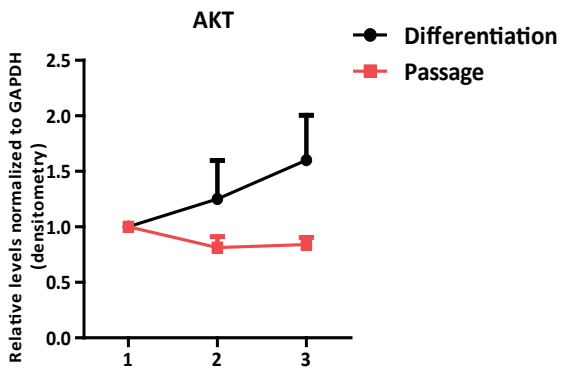

(a) Representative images of immunoblotting against p-Akt, Akt and GAPDH from cell lysates of myoblast, 95\% confluency and differentiation stage. (b) Relative levels of p-Akt, Akt normalized to GAPDH are indicated from (a). ( $n=3)$. (c) Representative images of immunoblotting against p-Akt, Akt and GAPDH from cell lysates of myoblast at passage 3, 6, 9. (d) Relative levels of p-Akt, Akt normalized to GAPDH are indicated from (c). $(n=3)$. (e, f) The combination results from (b) and (d) for p-Akt (e), Akt (f). Data are represented as mean \pm SEM. Significance was analyzed by One-way ANOVA with Bonferroni's Multiple Comparison Test (differences were non-significant). 


\section{ERK signaling}

ERK activation has been reported to mediate myoblast proliferation ${ }^{55}$. In accordance with a previous report ${ }^{56}$, p-ERK was down-regulated when the primary bovine myoblasts reached confluence and then increased in late differentiation (Figure 5a, 5b). Total ERK remained unchanged (Figure $5 a, 5 b$ ). During long-term passaging, $p$-ERK decreased with passage number whereas total ERK increased (Figure $5 c, 5 d$ ). The ERK signal is different expressed between differentiation and long-term passage (Figure 5e, 5f).

\section{Other relevant signaling pathways}

Leukemia inhibitory factor (LIF) is known to stimulate myoblast proliferation and inhibit its differentiation ${ }^{50,57-59}$. However, LIF did not support the proliferation of bovine myoblast cells in long-term culture (Figre 6a-c).

The canonical Wnt/ $\beta$-catenin signal is important in myoblast differentiation ${ }^{30,60}$. Inhibition of canonical Wnt/ $\beta$-catenin induces defects in myoblast fusion ${ }^{30,60}$. Inhibition of Setd7 by PFI-2, which cause failure of $\beta$-catenin to accumulate in the nucleus upon Wnt stimulation allows the in vitro expansion of myogenic stem cells with improved therapeutic potential ${ }^{30}$. However, our results showed that PFI-2 failed to support longterm bovine myoblast culture (Figure $6 \mathrm{~d}$ ). Non-canonical WNT signaling by WNT7A promotes symmetric cell divisions in vivo and cultured fibers ${ }^{61,62}$ and should therefore maintain stemness of satellite cells. WNT7A has also been reported to induce longlasting effects on cell migration of myoblasts leading to in vitro hypertrophy ${ }^{62-64}$. In our conditions, in primary bovine myoblasts, WNT7A did not support long-term passaging (Figure 6e).

These divergence of results with LIF and WNT in long-term passaging versus reported positive effects on differentiation, further underscore that failure to be extensively subcultured is likely not a result of differentiation of the myoblasts. 
Figure 5. ERK signaling in differentiation and subculturing processes

a

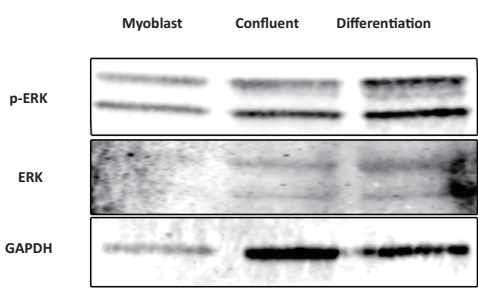

C

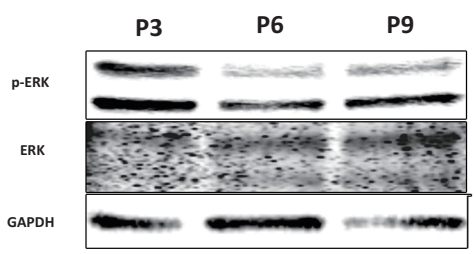

e

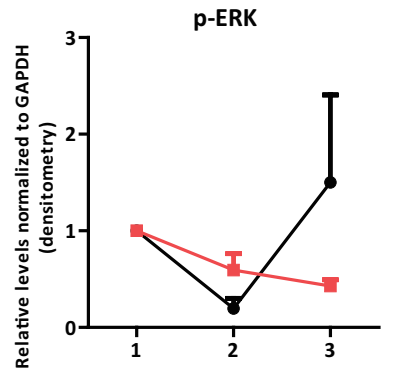

b

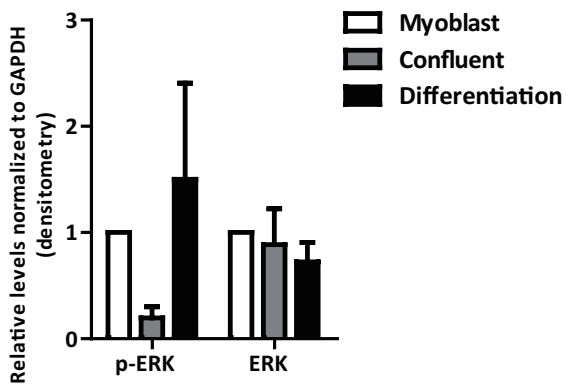

d

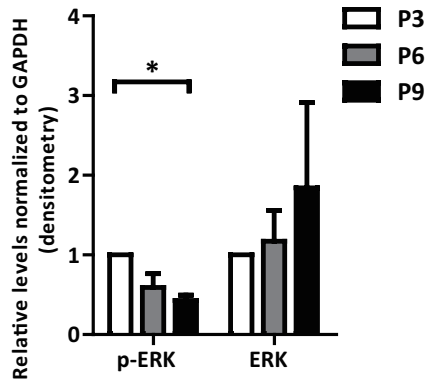

f

ERK

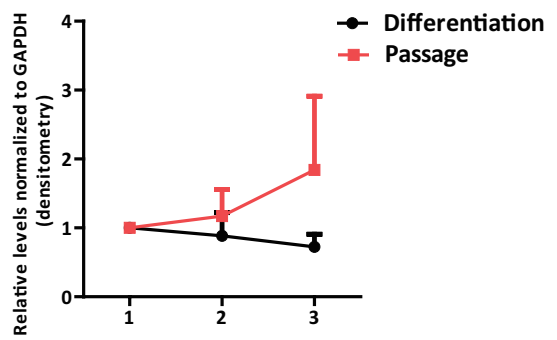

(a) Representative images of immunoblotting against p-ERK, ERK and GAPDH from cell lysates of myoblast, $95 \%$ confluency and differentiation stage. (b) Relative levels of p-ERK, ERK normalized to GAPDH are indicated from (a). ( $n=3)$. (c) Representative images of immunoblotting against $p$-ERK, ERK and GAPDH from cell lysates of myoblast at passage 3, 6, 9. (d) Relative levels of p-ERK, ERK normalized to GAPDH are indicated from (c). $(n=3)$. (e, f) The combination results from (b) and (d) for p-ERK (e), ERK (f). Data are represented as mean \pm SEM. Significance was analyzed by One-way ANOVA with Bonferroni's Multiple Comparison Test. 
Figure 6. Preventing cell differentiation is not sufficient to maintain the stemness during long-term passaging

a

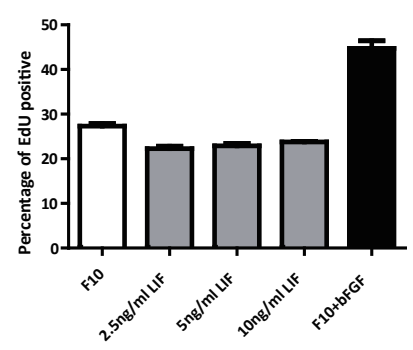

b

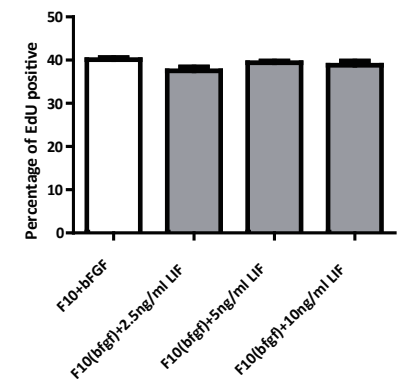

C

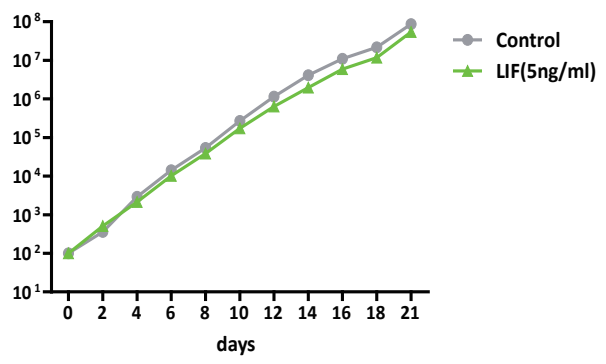

d

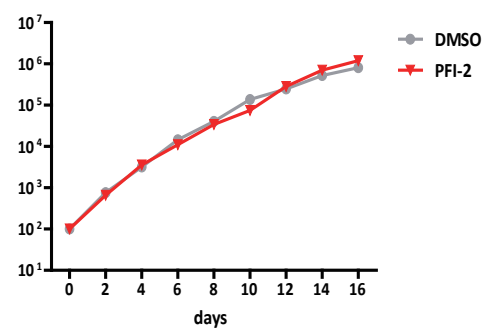

\section{e}

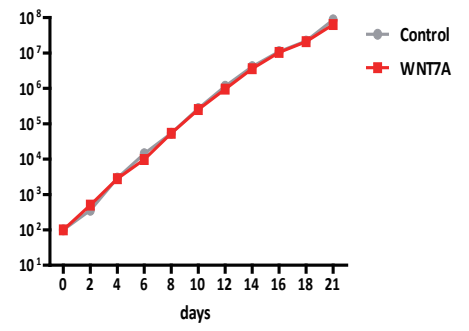

(a) Relative percentage of $1 \mathrm{hr}$ window EdU incorporation at different concentrations of LIF for myoblast cells at passage 2 after overnight culture without bFGF. ( $n=4)$. (b) Relative percentage of 1 hr window EdU incorporation at different concentrations of LIF for myoblast cells at passage 2 after overnight culture with bFGF. (c) Growth curve of bovine myoblast cells cultured with LIF $(5 \mathrm{ng} / \mathrm{ml})$ or control. Cells were serially passaged to maintain a density of $<60 \%$ confluency and were counted at each passage. (d) Growth curve of bovine myoblast cells cultured with PFI- $2(4 \mu \mathrm{M})$ or control. Cells were serially passaged to maintain a density of $<60 \%$ confluency and were counted at each passage. (e) Growth curve of bovine myoblast cells cultured with WNT7A $(50 \mathrm{ng} / \mathrm{ml}$ ) or control. Cells were serially passaged to maintain a density of $<60 \%$ confluency and were counted at each passage. 


\section{Discussion}

Differentiation of myoblasts is stimulated by high cell density and reduction of nutrition, i.e. serum factors ${ }^{65,66}$. In the long-term passage conditions, the cells were cultured at less than $60 \%$ confluence and with sufficient nutrition. Even in those conditions there is a gradual loss of proliferation and differentiation ability during long-term culture similar to the changes occurring during aging ${ }^{27,67}$. Long-term culture of cells may serve as an vitro model of aged cells ${ }^{68}$. Several intracellular processes and signaling pathways have been described in relation to the dysregulated regenerative capacity in aging satellite cells in vivo such as mitochondrial dysfunction ${ }^{69,70}$, bFGF and FGF receptor 1 function ${ }^{27}$, protein homeostasis (proteostasis) ${ }^{71}, \mathrm{p}^{2} 8^{27,28}, \mathrm{STAT}^{32,72}, \mathrm{p} 16^{73}$, canonical $\mathrm{WNT}^{74}$ and Notch signaling ${ }^{75}$, as well as epigenetic status ${ }^{76,77}$. Only a few studies focus on myoblast aging during long-term culture ${ }^{37-39}$.

Here, we showed several signal pathway changes in long-term culturing (as a model for aging) and in differentiation by Western blot. Expression patterns in differentiation and aging were similar in p38-MAPK signaling but different in JAK2-STAT3, ERK and Akt signaling.

\section{1. p38-MAPK signaling}

\section{1 p38-MAPK in differentiation}

p38 signal is very important during differentiation, which was discussed before (Chapter 3).

\section{2 p38-MAPK in aging}

In old animals, satellite cells show a senescent phenotype and an autonomous loss in regeneration, self-renewal and engraftment ability $27,28,71,73,78$. This could be mediated by alterations in $p 38 \alpha / \beta$ MAPK signaling in satellite cells from aged mice ${ }^{27,28}$ as $p 38 \alpha / \beta$ MAPK inhibition rescues proliferation and augments stem cell gene expression in satellite cells from aged mice, thus rejuvenating their potential for regeneration ${ }^{27,28}$. The same result is obtained by pharmacologic inhibition of $p 38 \alpha / \beta$ in young satellite cells in mice and human ${ }^{28}$. Aging results in elevated $p 38 \alpha / \beta$ signaling, possibly from increased cellular stress and inflammatory responses ${ }^{27,68,77}$.

Long-term culture is generally considered an in vitro model of cellular aging ${ }^{68,79,80}$. This has been, at least partly, related to oxidative stress (ROS production) induced senescence in MSC cells ${ }^{68,81-83}$. The elevated ROS levels have been suggested to increase stress signaling, such as p38-MAPK, that leads to loss of stem cell function ${ }^{77,84}$. The impaired phosphorylation activity of p38 MAP kinase (p38 MAPK) in long-term cultured hMSCs led to a compromised immunomodulatory ability through the regulation of COX- 
$2^{85}$. Elevated ROS levels and a senescent phenotype were also found in aged muscle stem cells in vivo ${ }^{71,73}$. Whether aging and differentiation are similar in our long-term cultured bovine myoblast with respect to p38-MAPK signaling still needs to be shown. In accordance with earlier aging studies of satellite cells, in long-term passage, our bovine myoblast cells showed up-regulation of the p38 MAPK signal. At a functional level, p38 MAPK appears to be elevated as the p38 substrate p-HSP27 was increased during passaging (Figure 2), so it is highly likely that in bovine myoblasts p38 signaling also leads to senescence and inhibition of stem cell function. Indeed, we have shown in an earlier study that inhibition of p38 partially protects against loss of satellite stem cell function during long-term passaging (Chapter 3$)^{86}$.

\section{STAT3 signaling}

During myoblast differentiation, both activated JAK2 ( $p$-JAK) and STAT3 ( $p$-STAT3) are up-regulated ${ }^{50}$. STAT3 phosphorylation activates SOCS-3 transcription during myoblast differentiation ${ }^{51}$. The STAT3 signal is also up-regulated during aging in vivo ${ }^{69,72}$. However, conflict data are shown by subculturing process ${ }^{87-89}$. The STAT3 signal in differentiation and aging was discussed before (Chapter 4)

\section{Akt signaling}

\subsection{Akt signaling in differentiation}

$\mathrm{PI3K} /$ Akt is up-regulated during differentiation ${ }^{90,91}$ and induces muscle differentiation by increasing the transcriptional activity of MyoD and MEF2C ${ }^{90,92}$. PI3K/Akt also regulates MYOG expression through p70S6K during differentiation ${ }^{90}$. Conversely, inhibition of PI3K/Akt signaling down-regulates the MYOG expression thus inhibiting differentiation ${ }^{54,90,91}$. In addition, increased Akt signal dominantly inhibits the effects of myostatin, which also leads to the differentiation ${ }^{93,94}$. In contrast with the general opposing patterns in proliferation and differentiation, $\mathrm{p}$-Akt is expressed at higher levels during early passage proliferation than in the first $12 \mathrm{~h}$ (early differentiation stage) of differentiation ${ }^{46}$. Our results showed a similar expression pattern. $p$-Akt expression was high in the myoblast proliferation stage, down-regulated when cells were confluent, but up-regulated again during differentiation (Figure 4).

\subsection{Akt signaling in aging}

Akt signaling pathway has physiological responses fundamental to healthy aging and longevity ${ }^{95,96}$. PI3K/Akt is persistently activated in aging muscle and neuronal tissue in Alzheimer's disease (AD) ${ }^{95,97}$. Reducing, but not obliterating, the IGF-1/PI3-K/Akt signal can extend a healthy lifespan in organisms from yeast to mammals (reviewed in ${ }^{95,96}$ ). This effect is an evolutionarily conserved influence on somatic aging and longevity ${ }^{96}$. During long-term passaging, increased Akt signal is also responsible for the replicative 
senescence in cultured human endothelial cells and vascular smooth muscle cells ${ }^{98,99}$. Akt inactivates the FoxO3a-SOD2 axis and consequently allows ROS production, which elicits senescence through irreparable DNA damage ${ }^{100,101}$. The activated Akt signal is also increased in our long-term passage, but if this is a cause or effect of senescence in bovine myoblast still needs to be established by intervention studies.

\section{ERK signaling}

\subsection{ERK signaling in proliferation and differentiation}

The ERK expression is high during the myoblast (proliferation) stage (Figure 5), especially when bFGF is added to the medium. Blocking ERK1/2 activity through inactivation of the Raf-MKK1/2-ERK1/2 pathway in myoblasts prevents myoblast proliferation ${ }^{55}$. The bFGF stimulated ERK1/2 signaling is required during the G1 phase of the cell cycle and thus important for proliferation but is not required for either repression or promotion of differentiation ${ }^{55}$. However, others found that ERK showed a biphasic activation profile from myoblast to myotube ${ }^{102,103}$ with peaks in ERK1/2 activity in undifferentiated myoblasts as well as in postmitotic myotubes. When the differentiation starts, the activation of ERK1/2 inhibits the differentiation stage ${ }^{102}$. There is a critical time window (16-20h) for bFGF to activate ERK and to repress myogenic gene expression and differentiation ${ }^{104}$. For efficient terminal differentiation of skeletal myoblast cells, a final activation of ERK2 is required ${ }^{103}$. In accordance, our own observations also show biphasic regulation of ERK activity during myogenic differentiation (Figure 5).

\subsection{ERK signaling in aging}

The ERK signal in replicative senescence by long-term passaging has been well studied. ERK signal is decreased during long-term passage ${ }^{105,106}$. The suppression of MEK/ ERK pathway in senescent cells leads to accumulation of damaged mitochondria and reactive oxygen species (ROS $)^{105}$. Dephosphorylation of ERK1/2 leads to p53mediated upregulation of MKP-3, which contributes to the senescent phenotype ${ }^{107}$. The MKP2-mediated inactivation of nuclear ERK2 is also a key event in replicative senescence ${ }^{108}$. Restoration of nuclear ERK activity can extend replicative lifespan ${ }^{108}$. ERK is indispensable for myoblast proliferation ${ }^{55,103}$. In accordance, our results with primary bovine myoblasts showed down-regulation of $p$-ERK in late passages (Figure 5). Whether sustained ERK activation is an achievable and effective target for maintain the long-term culture needs to be confirmed with gain of function experiments.

\section{Other mediators of differentiation}

Two additional pathways that are frequently studied in the setting of muscle differentiation are LIF and WNT. Proteins from the IL- 6 family such as LIF, CT-1, inhibit myogenic differentiation and repress skeletal myogenesis through interference with 
Myogenic regulatory factors (MRF) activity by activation of MEK/ERK signaling 47,109-111. This repression is independent of JAK-STAT signaling. In contrast however, LIF enhances transplantation efficiency of satellite cells suggesting preservation of differentiation capacity $^{112}$. We studied LIF during the proliferation phase of myoblasts and we did not find an effect on proliferation (Figure 6). Differentiation as a function of LIF was not studied but we may expect enhanced differentiation based on other studies.

Canonical WNT activation is shown to drive differentiation of myoblasts. Induction of Canonical WNT signaling by Setd7 enhances in vitro expansion of satellite cells ${ }^{30}$. Likewise, non-canonical WNT signaling by WNT7A promotes myoblast expansion in vivo and in cultured myofibers ${ }^{61,62}$. WNT7A also induces long-lasting effects on cell migration that finally support the myoblast to participate in muscle repair ${ }^{62-64}$. In our in vitro conditions, inhibiting the canonical WNT pathway with PFI-2 (an inhibitor of Setd7) or stimulation of the non-canonical by WNT7A did not affect long-term passaging so in vitro their roles are still unclear (Figure 6).

To conclude, our results showed that subculturing and differentiation are two different biological processes. Although the profiles of p38-MAPK signaling were similar during differentiation and long-term culture, JAK2-STAT3, ERK and Akt signals showed clear differences between the kinase activities during these two processes. Inhibiton of differentiation is not sufficient for maintaining the stemness during long-term passaging. Future work is needed to clarify the biological changes during long-term passaging of bovine myoblasts and to develop interventions that support prolonged cell culture.

\section{Materials and Methods}

\section{Bovine muscle tissues}

The bovine satellite cells in this study were derived from fresh muscle samples obtained at a local slaughterhouse. The transport time is about $30 \mathrm{~min}$.

\section{Bovine satellite cells isolation}

Bovine satellite cells were isolated from 4-6 year old male cattle as previously described and adapted to bovine tissues ${ }^{8,31,113}$. The detailed method for isolation mononuclear cells from muscle tissue was described in Chapter 2.

The frozen cells were first recovered in growth medium (F10 $+20 \%$ fetal calf serum + $5 \mathrm{ng} / \mathrm{ml} \mathrm{bFGF)} \mathrm{for} 2$ days. The floating debris were washed away and the adherent cells were collected by trypsin dissociation. These cells were resuspended in FACS buffer and stained with APC anti-human CD29 Antibody (1:10, Biolegend, Cat\# 303008), PE-Cy ${ }^{\text {TM}} 7$ anti-human CD56 (1:10, BD, Cat\# 335826), FITC anti-sheep CD31 (1:10, BIO- 
RAD, Cat\# MCA1097F), FITC anti-sheep CD45 (1:10, BIO-RAD, Cat\# MCA2220F) for 30$45 \mathrm{~min}$ on ice. After antibody incubation, the cells were washed twice with cold PBS and reconstituted in growth medium. The viable $\mathrm{CD} 31^{-} \mathrm{CD} 45^{-} \mathrm{CD} 56^{+} \mathrm{CD} 29^{+}$cells were isolated by cell sorting. Cell sorting was performed with a BD FACSAriall cell sorter using 405, 488nm and 640nm lasers. Unstained cells were routinely used to define FACS gating parameters.

\section{Satellite cell culture and differentiation}

Dishes (Corning) were coated with $0.05 \%$ bovine collagen type I (Sigma, Cat\# C4243). FACS isolated bovine satellite cells and unsorted cells were cultured on collagencoated dishes in F10 medium (Gibco, Cat\# 31550-023) containing 20\% fetal bovine serum (FBS, Gibco, Cat\# 10500-06), 5 ng/mL bFGF (R\&D, Cat\# 233-FB-025) and 1\% P.S. Where indicated, medium was supplemented with PFI-2 (Sigma, Cat\# SML1408), LIF (R\&D Systems, Cat\# 7734-LF) and DMSO (Sigma, Cat\# D8418). For serial expansion, cells were passaged to maintain a density of $<60 \%$ confluence and counted at each passage. Bovine myoblast cells differentiation was induced at $95 \%$ confluency with DMEM (Invitrogen, Cat\# 41966-29) with 2\% FBS and 1\% P.S. The bright field images were acquired by AMG-EVOS microscope.

\section{Immunofluorescent analysis of cultured cells}

EdU detection was carried-out using a Click-It EdU detection kit (Life Technologies, Cat\# C10337) according to the manufacturer's instructions.

\section{Western blots analysis of cultured cells}

Western blots were either performed from total cell lysates obtained by lysing cells directly with RIPA buffer complemented with PMSF, protease inhibitor cocktail and sodium orthovanadate (Santa Cruz, CAT\# sc-24948). Proteins concentration was determined using BCA protein assay kit (Thermo). SDS-PAGE electrophoresis was carried out in $7.5 \%$ pre-cast polyacrylamide gels (Bio-Rad, CAT\# 5671023). After transfer onto nitrocellulose, membranes were blocked for 30 min with Odyssey Blocking Buffer in PBS (Part Number: 927-40000, LI-COR Biosciences) and probed overnight with primary antibody: mouse MyoD (1:200, ABclonal, CAT\# A0671), Buffer in PBS (Part Number: $927-$ 40000, LI-COR Biosciences) and probed overnight with primary antibody: $\mathrm{p}-\mathrm{HSP} 27$ (Ser 82) (1:500, Cell Signaling, CAT\# 9709), p-p38 (1:1000, Cell Signaling, CAT\# 9211), p38 (1:1000, Cell Signaling, CAT\# 8690), p-STAT3 (1:250, Cell Signaling, CAT\# 9138S), STAT3 (1:500, Cell Signaling, CAT\# 9139S), p-JAK2 (1:250, Cell Signaling, CAT\# 3776S), JAK2 (1:500, Cell Signaling, CAT\# 3230S), SOCS3 (1:500, Cell Signaling, CAT\# 2932S), Erk (1:250, Cell Signaling, CAT\# 9107S), p-Erk (1:1000, Cell Signaling, CAT\# 4370S), Akt (1:500, Cell Signaling, CAT\# 4685S), p-Akt (1:1000, Cell Signaling, CAT\# 4060S), MyHC (1:500, Millipore, CAT\# 05-716), GAPDH (1:500, Millipore, CAT\# MAB374). After that, IRDye700-conjugated or IRDye800-conjugated secondary antibodies were used and 
visualized with the Odyssey infrared detector (LI-COR Biosciences, Westburg, Leusden, the Netherlands). For Protein quantification a, we used the background correction option in the software of the supplier (Image Studio ${ }^{\text {TM }}$ Software for the Odyssey CLx-LICOR Biosciences) and scanned the corresponding band of the protein of interest.

\section{EdU percentage measurement}

For EdU detection, cells cultured in BD Falcon 96 wells HTS Imaging microplates were imaged using a High-Content Analyzer (BD Pathway 855) with a 10x objective. In total 16 images were taken for each condition and individual cell segmentation and analysis was performed using the BD Attovision software (BD Biosciences, version 1.6). Hoechst positive cells were segmented and counted, then the same was done for EdU positive cells. The numerical data were further analyzed with Kaluza software (version 1.3; Beckman Coulter), where the EdU positive percentage was determined for more than 1000 nuclei from 16 randomly chosen fields.

\section{Statistics}

Statistical analyses were performed using GraphPad Prism 5 (GraphPad Software). For more than two groups, One-way ANOVA with Bonferroni's Multiple Comparison Test was used. Results were means \pm S.E.M. unless otherwise stated. $P<0.05$ was considered significant.

\section{Acknowledgements}

This work was supported by the Core Facility Flow Cytometry, a core facility of the Interdisciplinary Center for Clinical Research (IZKF) Aachen within the Faculty of Medicine at RWTH Aachen University. This work was sponsored by Royal Netherlands Academy of Arts and Sciences and China Scholarship Council. 


\section{References}

1 Dumont, N. A., Wang, Y. X. \& Rudnicki, M. A. Intrinsic and extrinsic mechanisms regulating satellite cell function. Development 142, 1572-1581, doi:10.1242/dev.114223 (2015).

2 Blau, H. M., Cosgrove, B. D. \& Ho, A. T. V. The central role of muscle stem cells in regenerative failure with aging. Nat Med 21, 854-862 (2015).

3 Dumon, N. A., Wang, Y. X. \& Rudnicki, M. A. Intrinsic and extrinsic mechanisms regulating satellite cell function. Development 142, 1572-1581, doi:10.1242/dev.114223 (2015).

$4 \mathrm{Fu}, \mathrm{X}$. et al. Combination of inflammation-related cytokines promotes long-term muscle stem cell expansion. Cell Res 25, 655-673, doi:10.1038/cr.2015.58 (2015).

5 Almada, A. E. \& Wagers, A. J. Molecular circuitry of stem cell fate in skeletal muscle regeneration, ageing and disease. Nature reviews. Molecular cell biology 17, 267-279, doi:10.1038/nrm.2016.7 (2016).

6 Bosnakovski, D. et al. Prospective Isolation of Skeletal Muscle Stem Cells with a Pax7 Reporter. Stem Cells 26, 3194-3204, doi:10.1634/stemcells.2007-1017 (2008).

7 Sacco, A., Doyonnas, R., Kraft, P., Vitorovic, S. \& Blau, H. M. Self-renewal and expansion of single transplanted muscle stem cells. Nature 456, 502-506, doi:10.1038/nature07384 (2008).

$8 \mathrm{Xu}, \mathrm{X}$. et al. Human Satellite Cell Transplantation and Regeneration from Diverse Skeletal Muscles. Stem Cell Rep 5, 419-434, doi:10.1016/j.stemcr.2015.07.016 (2015).

9 Pallafacchina, G. et al. An adult tissue-specific stem cell in its niche: a gene profiling analysis of in vivo quiescent and activated muscle satellite cells. Stem Cell Res 4, 77-91, doi:10.1016/j. scr.2009.10.003 (2010).

10 Yin, H., Price, F. \& Rudnicki, M. A. Satellite cells and the muscle stem cell niche. Physiological reviews 93, 23-67, doi:10.1152/physrev.00043.2011 (2013).

11 Kuang, S., Kuroda, K., Le Grand, F. \& Rudnicki, M. A. Asymmetric self-renewal and commitment of satellite stem cells in muscle. Cell 129, 999-1010, doi:10.1016/j.cell.2007.03.044 (2007).

12 Wen, Y. et al. Constitutive Notch activation upregulates Pax7 and promotes the self-renewal of skeletal muscle satellite cells. Mol Cell Biol 32, 2300-2311, doi:10.1128/MCB.06753-11 (2012).

13 Olguin, H. C., Yang, Z., Tapscott, S. J. \& Olwin, B. B. Reciprocal inhibition between Pax7 and muscle regulatory factors modulates myogenic cell fate determination. J Cell Biol 177, 769-779, doi:10.1083/ jcb.200608122 (2007).

14 Kawabe, Y. I., Wang, Y. X., McKinnell, I. W., Bedford, M. T. \& Rudnicki, M. A. Carm1 Regulates Pax7 Transcriptional Activity through MLL1/2 Recruitment during Asymmetric Satellite Stem Cell Divisions Cell stem cell 11, 333-345, doi:10.1016/j.stem.2012.07.001 (2012).

$15 \mathrm{Hu}$, P., Geles, K. G., Paik, J. H., DePinho, R. A. \& Tjian, R. Codependent activators direct myoblastspecific MyoD transcription. Dev Cell 15, 534-546, doi:10.1016/j.devcel.2008.08.018 (2008).

16 Megeney, L. A., Kablar, B., Garrett, K., Anderson, J. E. \& Rudnicki, M. A. MyoD is required for myogenic stem cell function in adult skeletal muscle. Gene Dev 10, 1173-1183, doi:DOI 10.1101/gad.10.10.1173 (1996).

17 Tajbakhsh, S. \& Cossu, G. Establishing myogenic identity during somitogenesis. Curr Opin Genet Dev 7, 634-641, doi:Doi 10.1016/S0959-437x(97)80011-1 (1997).

18 Cooper, R. N. et al. In vivo satellite cell activation via Myf5 and MyoD in regenerating mouse skeletal muscle. J Cell Sci 112, 2895-2901 (1999). 
19 Faralli, H. \& Dilworth, F. J. Turning on myogenin in muscle: a paradigm for understanding mechanisms of tissue-specific gene expression. Comp Funct Genomics 2012, 836374, doi:10.1155/2012/836374 (2012).

20 Hindi, S. M., Tajrishi, M. M. \& Kumar, A. Signaling Mechanisms in Mammalian Myoblast Fusion. Sci Signal 6 (2013).

21 Keren, A., Tamir, Y. \& Bengal, E. The p38 MAPK signaling pathway: a major regulator of skeletal muscle development. Mol Cell Endocrinol 252, 224-230, doi:10.1016/j.mce.2006.03.017 (2006).

22 Segales, J. et al. Chromatin-wide and transcriptome profiling integration uncovers p38alpha MAPK as a global regulator of skeletal muscle differentiation. Skelet Muscle 6, 9, doi:10.1186/s13395-016-0074-x (2016).

23 Trenerry, M. K., Della Gatta, P. A. \& Cameron-Smith, D. JAK/STAT signaling and human in vitro myogenesis. BMC physiology 11, 6, doi:10.1186/1472-6793-11-6 (2011).

24 Jang, Y. N., Lee, I. J., Park, M. C. \& Baik, E. J. Role of JAK3 in myogenic differentiation. Cell Signal 24, 742-749, doi:10.1016/j.cellsig.2011.11.009 (2012).

25 Jang, Y. N. \& Baik, E. J. JAK-STAT pathway and myogenic differentiation. Jak-Stat 2, e23282, doi:10.4161/ jkst.23282 (2013).

26 Yennek, S., Burute, M., Thery, M. \& Tajbakhsh, S. Cell adhesion geometry regulates non-random DNA segregation and asymmetric cell fates in mouse skeletal muscle stem cells. Cell Rep 7, 961-970, doi:10.1016/j.celrep.2014.04.016 (2014).

27 Bernet, J. D. et al. p38 MAPK signaling underlies a cell-autonomous loss of stem cell self-renewal in skeletal muscle of aged mice. Nat Med 20, 265-271, doi:10.1038/nm.3465 (2014).

28 Cosgrove, B. D. et al. Rejuvenation of the muscle stem cell population restores strength to injured aged muscles. Nat Med 20, 255-264, doi:10.1038/nm.3464 (2014).

29 Liu, Q. C. et al. Comparative expression profiling identifies differential roles for Myogenin and p38alpha MAPK signaling in myogenesis. J Mol Cell Biol 4, 386-397, doi:10.1093/jmcb/mjs045 (2012).

30 Judson, R. N. et al. Inhibition of Methyltransferase Setd7 Allows the In Vitro Expansion of Myogenic Stem Cells with Improved Therapeutic Potential. Cell stem cell 22, 177-190 e177, doi:10.1016/j. stem.2017.12.010 (2018).

31 Charville, G. W. et al. Ex Vivo Expansion and In Vivo Self-Renewal of Human Muscle Stem Cells. Stem Cell Rep 5, 621-632, doi:10.1016/j.stemcr.2015.08.004 (2015).

32 Tierney, M. T. et al. STAT3 signaling controls satellite cell expansion and skeletal muscle repair. Nat Med 20, 1182-1186 (2014).

33 Sun, H. J. et al. A proteomic analysis during serial subculture and osteogenic differentiation of human mesenchymal stem cell. Journal of orthopaedic research : official publication of the Orthopaedic Research Society 24, 2059-2071, doi:10.1002/jor.20273 (2006).

34 Bae, S. H. et al. L-ascorbic acid 2-phosphate and fibroblast growth factor-2 treatment maintains differentiation potential in bone marrow-derived mesenchymal stem cells through expression of hepatocyte growth factor. Growth Factors 33, 71-78, doi:10.3109/08977194.2015.1013628 (2015).

35 Yang, Y. K., Ogando, C. R., Wang See, C., Chang, T. Y. \& Barabino, G. A. Changes in phenotype and differentiation potential of human mesenchymal stem cells aging in vitro. Stem Cell Res Ther 9, 131, doi:10.1186/s13287-018-0876-3 (2018).

36 Pradel, W., Mai, R., Gedrange, T. \& Lauer, G. Cell Passage and Composition of Culture Medium Effects Proliferation and Differentiation of Human Osteoblast-Like Cells from Facial Bone. J Physiol Pharmacol 59, 47-58 (2008). 
Loss of stemness in satellite cells during subculturing is distinct from loss of stemness by differentiation

37 Bigot, A. et al. Replicative aging down-regulates the myogenic regulatory factors in human myoblasts. Biol Cell 100, 189-199, doi:10.1042/Bc20070085 (2008).

38 Sharples, A. P., Al-Shanti, N., Lewis, M. P. \& Stewart, C. E. Reduction of Myoblast Differentiation Following Multiple Population Doublings in Mouse C2C12 Cells: A Model to Investigate Ageing? J Cell Biochem 112, 3773-3785, doi:10.1002/jcb.23308 (2011).

39 Nehlin, J. O., Just, M., Rustan, A. C. \& Gaster, M. Human myotubes from myoblast cultures undergoing senescence exhibit defects in glucose and lipid metabolism. Biogerontology 12, 349-365, doi:10.1007/ s10522-011-9336-5 (2011).

40 Cuenda, A. \& Cohen, P. Stress-activated protein kinase-2/p38 and a rapamycin-sensitive pathway are required for C2C12 myogenesis. J Biol Chem 274, 4341-4346 (1999).

41 Simone, C. et al. p38 pathway targets SWI-SNF chromatin-remodeling complex to muscle-specific loci. Nat Genet 36, 738-743, doi:10.1038/ng1378 (2004).

42 Perdiguero, E. et al. Genetic analysis of p38 MAP kinases in myogenesis: fundamental role of p38alpha in abrogating myoblast proliferation. Embo J 26, 1245-1256, doi:10.1038/sj.emboj.7601587 (2007).

43 Rocheteau, P., Gayraud-Morel, B., Siegl-Cachedenier, I., Blasco, M. A. \& Tajbakhsh, S. A Subpopulation of Adult Skeletal Muscle Stem Cells Retains All Template DNA Strands after Cell Division. Cell 148, 112125 (2012).

44 Zarubin, T. \& Han, J. Activation and signaling of the p38 MAP kinase pathway. Cell Res 15, 11-18, doi:10.1038/sj.cr.7290257 (2005).

$45 \mathrm{Xu}$, L., Chen, S. \& Bergan, R. C. MAPKAPK2 and HSP27 are downstream effectors of p38 MAP kinasemediated matrix metalloproteinase type 2 activation and cell invasion in human prostate cancer. Oncogene 25, 2987-2998, doi:10.1038/sj.onc.1209337 (2006).

46 Wang, K., Wang, C., Xiao, F., Wang, H. \& Wu, Z. JAK2/STAT2/STAT3 are required for myogenic differentiation. J Biol Chem 283, 34029-34036, doi:10.1074/jbc.M803012200 (2008).

47 Yang, Y. et al. STAT3 induces muscle stem cell differentiation by interaction with myoD. Cytokine 46, 137-141, doi:10.1016/j.cyto.2008.12.015 (2009).

48 Price, F. D. et al. Inhibition of JAK-STAT signaling stimulates adult satellite cell function. Nat Med 20, 1174-1181 (2014).

49 Gao, S. et al. Acute myotube protein synthesis regulation by IL-6-related cytokines. American journal of physiology. Cell physiology 313, C487-C500, doi:10.1152/ajpcell.00112.2017 (2017).

50 Diao, Y. R., Wang, X. \& Wu, Z. G. SOCS1, SOCS3, and PIAS1 Promote Myogenic Differentiation by Inhibiting the Leukemia Inhibitory Factor-Induced JAK1/STAT1/STAT3 Pathway. Mol Cell Biol 29, 50845093, doi:10.1128/Mcb.00267-09 (2009).

51 Spangenburg, E. E. SOCS-3 induces myoblast differentiation. J Biol Chem 280, 10749-10758, doi:10.1074/jbc.M410604200 (2005).

52 Rodriguez, J. et al. Myostatin and the skeletal muscle atrophy and hypertrophy signaling pathways. Cell Mol Life Sci 71, 4361-4371, doi:10.1007/s00018-014-1689-x (2014).

53 Gordon, B. S., Kelleher, A. R. \& Kimball, S. R. Regulation of Muscle Protein Synthesis and the Effects of Catabolic States. Int J Biochem Cell B 45, 2147-2157 (2013).

54 Gonzalez, I. et al. Akt2, a novel functional link between p38 mitogen-activated protein kinase and phosphatidylinositol 3-kinase pathways in myogenesis. Mol Cell Biol 24, 3607-3622, doi:10.1128/ Mcb.24.9.3607-3622.2004 (2004). 
55 Jones, N. C., Fedorov, Y. V., Rosenthal, R. S. \& Olwin, B. B. ERK1/2 is required for myoblast proliferation but is dispensable for muscle gene expression and cell fusion. J Cell Physiol 186, 104-115, doi:10.1002/1097-4652(200101)186:1<104::AID-JCP1015>3.0.CO;2-0 (2001).

56 Wang, M. X. et al. Identification of Map4k4 as a Novel Suppressor of Skeletal Muscle Differentiation. Mol Cell Biol 33, 678-687, doi:Doi 10.1128/Mcb.00618-12 (2013).

57 Sun, L. et al. JAK1-STAT1-STAT3, a key pathway promoting proliferation and preventing premature differentiation of myoblasts. J Cell Biol 179, 129-138, doi:10.1083/jcb.200703184 (2007).

58 Charge, S. B. \& Rudnicki, M. A. Cellular and molecular regulation of muscle regeneration. Physiological reviews 84, 209-238, doi:10.1152/physrev.00019.2003 (2004).

59 Megeney, L. A., Perry, R. L., LeCouter, J. E. \& Rudnicki, M. A. bFGF and LIF signaling activates STAT3 in proliferating myoblasts. Developmental genetics 19, 139-145, doi:10.1002/(SICI)15206408(1996)19:2<139::AID-DVG5>3.0.CO;2-A (1996).

60 Lacour, F. et al. R-spondin1 Controls Muscle Cell Fusion through Dual Regulation of Antagonistic Wnt Signaling Pathways. Cell Rep 18, 2320-2330, doi:10.1016/j.celrep.2017.02.036 (2017).

61 Le Grand, F., Jones, A. E., Seale, V., Scime, A. \& Rudnicki, M. A. Wnt7a activates the planar cell polarity pathway to drive the symmetric expansion of satellite stem cells. Cell stem cell 4, 535-547, doi:10.1016/j.stem.2009.03.013 (2009).

62 von Maltzahn, J., Zinoviev, R., Chang, N. C., Bentzinger, C. F. \& Rudnicki, M. A. A truncated Wnt7a retains full biological activity in skeletal muscle. Nat Commun 4, doi:Artn 2869 10.1038/Ncomms3869 (2013).

63 von Maltzahn, J., Bentzinger, C. F. \& Rudnicki, M. A. Wnt7a-Fzd7 signalling directly activates the Akt/ mTOR anabolic growth pathway in skeletal muscle. Nat Cell Biol 14, 186-191, doi:10.1038/ncb2404 (2011).

64 Bentzinger, C. F. et al. Wnt7a stimulates myogenic stem cell motility and engraftment resulting in improved muscle strength. J Cell Biol 205, 97-111, doi:10.1083/jcb.201310035 (2014).

65 Abmayr, S. M. \& Pavlath, G. K. Myoblast fusion: lessons from flies and mice. Development 139, 641656, doi:10.1242/dev.068353 (2012).

66 Tanaka, K. et al. Evidence for Cell Density Affecting C2c12 Myogenesis: Possible Regulation of Myogenesis by Cell-Cell Communication. Muscle Nerve 44, 968-977, doi:10.1002/mus.22224 (2011).

67 Baraibar, M. A. et al. Impaired energy metabolism of senescent muscle satellite cells is associated with oxidative modifications of glycolytic enzymes. Aging 8, 3375-3389, doi:10.18632/aging.101126 (2016).

68 Hohn, A. et al. Happily (n)ever after: Aging in the context of oxidative stress, proteostasis loss and cellular senescence. Redox Biol 11, 482-501, doi:10.1016/j.redox.2016.12.001 (2017).

69 Zhang, H. et al. $\mathrm{NAD}(+)$ repletion improves mitochondrial and stem cell function and enhances life span in mice. Science 352, 1436-1443, doi:10.1126/science.aaf2693 (2016).

70 Baumann, K. Ageing: The yin and yang of mitochondrial dysfunction. Nature reviews. Molecular cell biology 17, 331, doi:10.1038/nrm.2016.71 (2016).

71 Garcia-Prat, L. et al. Autophagy maintains stemness by preventing senescence. Nature 529, 37-42, doi:10.1038/nature16187 (2016).

72 Price, F. D. et al. Inhibition of JAK-STAT signaling stimulates adult satellite cell function. Nat Med 20, 1174-1181, doi:10.1038/nm.3655 (2014).

73 Sousa-Victor, P. et al. Geriatric muscle stem cells switch reversible quiescence into senescence. Nature 506, 316-+, doi:10.1038/nature13013 (2014). 
Loss of stemness in satellite cells during subculturing is distinct from loss of stemness by differentiation

74 Brack, A. S. et al. Increased Wnt signaling during aging alters muscle stem cell fate and increases fibrosis. Science 317, 807-810 (2007).

75 Conboy, I. M., Conboy, M. J., Smythe, G. M. \& Rando, T. A. Notch-mediated restoration of regenerative potential to aged muscle. Science 302, 1575-1577, doi:DOI 10.1126/science.1087573 (2003).

76 Liu, L. et al. Chromatin Modifications as Determinants of Muscle Stem Cell Quiescence and Chronological Aging. Cell Rep 4, 189-204, doi:10.1016/j.celrep.2013.05.043 (2013).

77 Ermolaeva, M., Neri, F., Ori, A. \& Rudolph, K. L. Cellular and epigenetic drivers of stem cell ageing. Nature reviews. Molecular cell biology, doi:10.1038/s41580-018-0020-3 (2018).

78 van Deursen, J. M. The role of senescent cells in ageing. Nature 509, 439-446, doi:10.1038/ nature13193 (2014).

79 Hwang, E. S., Yoon, G. \& Kang, H. T. A comparative analysis of the cell biology of senescence and aging. Cell Mol Life Sci 66, 2503-2524, doi:10.1007/s00018-009-0034-2 (2009).

80 Shibata, K. R. et al. Expression of the p161NK4A gene is associated closely with senescence of human mesenchymal stem cells and is potentially silenced by DNA methylation during in vitro expansion. Stem Cells 25, 2371-2382, doi:10.1634/stemcells.2007-0225 (2007).

$81 \mathrm{Gu}, \mathrm{Y}$. et al. Changes in mesenchymal stem cells following long-term culture in vitro. Mol Med Rep 13, 5207-5215, doi:10.3892/mmr.2016.5169 (2016).

82 Geissler, S. et al. Functional comparison of chronological and in vitro aging: differential role of the cytoskeleton and mitochondria in mesenchymal stromal cells. Plos One 7, e52700, doi:10.1371/journal. pone.0052700 (2012).

83 Jeong, S. G. et al. Functional restoration of replicative senescent mesenchymal stem cells by the brown alga Undaria pinnatifida. Anim Cells Syst 21, 108-114, doi:10.1080/19768354.2017.1292951 (2017).

84 Ito, K. et al. Reactive oxygen species act through p38 MAPK to limit the lifespan of hematopoietic stem cells. Nat Med 12, 446-451, doi:10.1038/nm1388 (2006).

$85 \mathrm{Yu}, \mathrm{K}$. R. et al. A p38 MAPK-mediated alteration of COX-2/PGE2 regulates immunomodulatory properties in human mesenchymal stem cell aging. Plos One 9, e102426, doi:10.1371/journal. pone.0102426 (2014).

86 Ding, S. J. et al. Maintaining bovine satellite cells stemness through p38 pathway. Sci Rep-Uk 8, doi:Artn 10808m10.1038/S41598-018-28746-7 (2018).

87 Kojima, H., Kunimoto, H., Inoue, T. \& Nakajima, K. The STAT3-IGFBP5 axis is critical for IL-6/gp130induced premature senescence in human fibroblasts. Cell Cycle 11, 730-739, doi:10.4161/ cc.11.4.19172 (2012).

88 Sakellaropoulos, T. et al. Qualitative modeling of signaling networks in replicative senescence by selecting optimal node and arc sets. bioRxiv, doi:10.1101/389692 (2018).

89 Wang, X. D. et al. [Changes of STAT3 in cell replicative senescence and effects of angiotensin II on STAT3]. Zhonghua Yi Xue Za Zhi 83, 324-327 (2003).

$90 \mathrm{Xu}, \mathrm{Q}$. \& Wu, Z. The insulin-like growth factor-phosphatidylinositol 3-kinase-Akt signaling pathway regulates myogenin expression in normal myogenic cells but not in rhabdomyosarcoma-derived RD cells. J Biol Chem 275, 36750-36757, doi:10.1074/jbc.M005030200 (2000).

91 Tureckova, J., Wilson, E. M., Cappalonga, J. L. \& Rotwein, P. Insulin-like growth factor-mediated muscle differentiation - Collaboration between phosphatidylinositol 3-kinase-Akt-signaling pathways and myogenin. J Biol Chem 276, 39264-39270, doi:DOI 10.1074/jbc.M104991200 (2001). 
92 Serra, C. et al. Functional interdependence at the chromatin level between the MKK6/p38 and IGF1/PI3K/AKT pathways during muscle differentiation. Mol Cell 28, 200-213, doi:10.1016/j. molcel.2007.08.021 (2007).

93 Glass, D. J. PI3 kinase regulation of skeletal muscle hypertrophy and atrophy. Current topics in microbiology and immunology 346, 267-278, doi:10.1007/82_2010_78 (2010).

94 Trendelenburg, A. U. et al. Myostatin reduces Akt/TORC1/p70S6K signaling, inhibiting myoblast differentiation and myotube size. American journal of physiology. Cell physiology 296, C1258-1270, doi:10.1152/ajpcell.00105.2009 (2009).

95 C, O. N. PI3-kinase/Akt/mTOR signaling: impaired on/off switches in aging, cognitive decline and Alzheimer's disease. Exp Gerontol 48, 647-653, doi:10.1016/j.exger.2013.02.025 (2013).

96 Templeman, N. M. \& Murphy, C. T. Regulation of reproduction and longevity by nutrient-sensing pathways. J Cell Biol 217, 93-106, doi:10.1083/jcb.201707168 (2018).

$97 \mathrm{Wu}, \mathrm{M}$. Z. et al. Aging-Associated Dysfunction of Akt/Protein Kinase B: S-Nitrosylation and Acetaminophen Intervention. Plos One 4, doi:ARTN e6430 10.1371/journal.pone.0006430 (2009).

98 Miyauchi, H. et al. Akt negatively regulates the in vitro lifespan of human endothelial cells via a p53/ p21-dependent pathway. Embo J 23, 212-220, doi:10.1038/sj.emboj.7600045 (2004).

99 Tan, P. et al. The PI3K/Akt/mTOR pathway regulates the replicative senescence of human VSMCs. Mol Cell Biochem 422, 1-10, doi:10.1007/s11010-016-2796-9 (2016).

100 Chen, Y. et al. Tumour suppressor SIRT3 deacetylates and activates manganese superoxide dismutase to scavenge ROS. EMBO Rep 12, 534-541, doi:10.1038/embor.2011.65 (2011).

101 Imai, Y. et al. Crosstalk between the Rb Pathway and AKT Signaling Forms a Quiescence-Senescence Switch. Cell Rep 7, 194-207, doi:10.1016/j.celrep.2014.03.006 (2014).

$102 \mathrm{Wu}, \mathrm{Z}$. G. et al. p38 and extracellular signal-regulated kinases regulate the myogenic program at multiple steps. Mol Cell Biol 20, 3951-3964, doi:Doi 10.1128/Mcb.20.11.3951-3964.2000 (2000).

$103 \mathrm{Li}$, J. \& Johnson, S. E. ERK2 is required for efficient terminal differentiation of skeletal myoblasts. Biochem Bioph Res Co 345, 1425-1433, doi:10.1016/j.bbrc.2006.05.051 (2006).

104 Tortorella, L. L., Milasincic, D. J. \& Pilch, P. F. Critical proliferation-independent window for basic fibroblast growth factor repression of myogenesis via the p42/p44 MAPK signaling pathway. J Biol Chem 276, 13709-13717, doi:DOI 10.1074/jbc.M100091200 (2001).

105 Kochetkova, E. Y. et al. Targeted elimination of senescent Ras-transformed cells by suppression of MEK/ ERK pathway. Aging 9, 2352-2375, doi:10.18632/aging.101325 (2017).

106 Eom, Y. W. et al. The role of growth factors in maintenance of stemness in bone marrow-derived mesenchymal stem cells. Biochem Biophys Res Commun 445, 16-22, doi:10.1016/j.bbrc.2014.01.084 (2014).

107 Zhang, H., Chi, Y., Gao, K., Zhang, X. L. \& Yao, J. p53 Protein-mediated Up-regulation of MAP Kinase Phosphatase 3 (MKP-3) Contributes to the Establishment of the Cellular Senescent Phenotype through Dephosphorylation of Extracellular Signal-regulated Kinase 1/2 (ERK1/2). J Biol Chem 290, 1129-1140, doi:10.1074/jbc.M114.590943 (2015).

108 Tresini, M., Lorenzini, A., Torres, C. \& Cristofalo, V. J. Modulation of replicative senescence of diploid human cells by nuclear ERK signaling. J Biol Chem 282, 4136-4151, doi:10.1074/jbc.M604955200 (2007).

$109 \mathrm{Jo}$, C. et al. Leukemia inhibitory factor blocks early differentiation of skeletal muscle cells by activating ERK. Biochimica et biophysica acta 1743, 187-197, doi:10.1016/j.bbamcr.2004.11.002 (2005). 
Loss of stemness in satellite cells during subculturing is distinct from loss of stemness by differentiation

110 Miyake, T. et al. Cardiotrophin-1 Maintains the Undifferentiated State in Skeletal Myoblasts. J Biol Chem 284, 19679-19693, doi:10.1074/jbc.M109.017319 (2009).

111 Xiao, F. et al. Oncostatin M inhibits myoblast differentiation and regulates muscle regeneration. Cell Res 21, 350-364, doi:10.1038/cr.2010.144 (2011).

112 Ito, N., Shimizu, N., Tanaka, H. \& Takeda, S. Enhancement of Satellite Cell Transplantation Efficiency by Leukemia Inhibitory Factor. Journal of neuromuscular diseases 3, 201-207, doi:10.3233/JND-160156 (2016).

113 Ding, S. et al. Characterization and isolation of highly purified porcine satellite cells. Cell Death Discov 3, 17003, doi:10.1038/cddiscovery.2017.3 (2017). 



\section{Chapter 6}

\section{Proteomics of bovine muscle stem cell aging}

Shijie Ding, Ronny Mohren, Lea Melzener, Daniel G.M. Molin, Nynke van den Akker, Mitic Rada, Guanghong Zhou, Mark J. Post 


\begin{abstract}
Muscle stem cells (MuSCs; also known as satellite cells) are an ideal cell source to produce cultured meat. However, upon long-term culturing, bovine satellite cells eventually show proliferation and differentiation defects, referred to as loss of stemness. The defects caused by serial subculture has parallels with cell senescence and might therefore serve as an in vitro aging model. MuSCs have a specific aging phenotype defined by biomarkers that are also found in aged (murine) donors. We used label-free high-throughput proteomics to identify the protein changes in early and late passages to characterize the aging process and to identify potential candidates to prevent aging and with it the proliferation and differentiation defects. Further gene ontology (GO) and Kyoto Encyclopedia of Genes and Genomes (KEGG) pathways analysis showed that the proteins up-regulated in the late passages are involved in cell-cell adhesion, muscle contraction, mitochondrial electron transport NADH to ubiquinone, cell redox homeostasis, Fatty acid degradation, PI3K-Akt signaling pathway and Insulin signaling pathway. Early passages showed high expression of proteins involved in DNA replication, protein folding, translational initiation, DNA repair, fibroblast growth factor receptor signaling pathway, p53 regulation, proteasome-ubiquitin-dependent proteolysis, telomere maintenance via recombination and somatic stem cell population maintenance. These proteomic profiles correlate with the aging signal of MuSCs in vivo and relicative senescence signals in vitro. The proteomics data indicate that the dysfunction of satellite cells during long-term passage resembles aging.
\end{abstract}




\section{Introduction}

Aging is defined as the time-dependent persistent change of cellular (and also systemic) functionality and reproducibility, which affects most living organisms ${ }^{1,2}$. Aging research is becoming more and more popular and has experienced an unprecedented advance over recent years ${ }^{1-3}$. There are two cellular aging models ${ }^{2}$. Cells isolated from an old donor are called in vivo aged cells, which can be directly used for aging studies. On the other hand, in vitro aged cells can be obtained by prolonged subculturing or by stressing the cells with noxious substances such as oxidants, AGEs or lipofuscin ${ }^{2}$. Both models provide insight into the aging process.

Satellite cells are the stem cells in muscle tissue which are responsible for muscle regeneration upon injury ${ }^{4,5}$. They are located in a stem cell niche between the sarcolemma and the basement membrane of adult skeletal muscle cells. Aged MuSCs are decreased in cell number, and show impaired self-renewal and loss of regenerative ability upon implantation in in vivo muscle injury models ${ }^{6-8}$. The changes in extracellular niche function and intrinsic cell properties lead to MuSC dysfunction ${ }^{7-9}$. Several intracellular processes and signaling pathways have been described as being dysregulated in association with aging of satellite cells in vivo such as mitochondrial dysfunction ${ }^{10,11}$, FGF2 and FGF receptor 1 function ${ }^{12}$, protein homeostasis (proteostasis) ${ }^{13}$, p38 $8^{12,14}$, STAT3 ${ }^{15,16}, \mathrm{p}^{16}{ }^{17}$, canonical Wnt ${ }^{18}$, Notch signaling ${ }^{19}$, and epigenetic status ${ }^{8,20}$.

The limited replicative life-span of human fibroblast upon prolonged culturing was first described in 1961 and was further described as replicative senescence ${ }^{21-23}$. It is also referred to as in vitro aging of cells since replicative senescence showed similarities with in vivo aging ${ }^{2}$. Long-term cultured myoblast cells not only show proliferation arrest ${ }^{24-27}$, but are also impaired with respect to their ability to differentiate ${ }^{28}$. One of the features of cells subject to extensive subculturing is gradual impairment of glucose and lipid metabolism ${ }^{26,27}$. Long-term cultured myoblast cells in vitro also quickly and dramatically downregulate telomerase activity ${ }^{29}$. However, more information on ageing satellite cells in vitro is still needed ${ }^{26,27}$.

Quantitative proteomics, which is based on mass spectrometry, is a powerful approach used to understand global changes in protein expression in a cell, tissue or organism ${ }^{30}$. It can identify the protein expression and modifications underlying the molecular mechanisms of biological processes and disease states. Several studies used two-dimensional differential in-gel electrophoresis (2D-DIGE) in myoblast aging in vitro as a method to separate proteins by size and charge $27,31.2 \mathrm{D}-\mathrm{GE}$, however, has a number of inherent drawbacks, the major being that it is fairly insensitive to low copy proteins and thus cannot be used for the entire proteome ${ }^{32,33}$. In recent years, gel-free proteomics have become more popular due to their simpler experimental designs and sample-preparation methods $\mathrm{s}^{30,33}$. The developed quantitative proteomics has matured and is capable of delivering accurate, reproducible and comprehensive data at high throughput ${ }^{30}$. 
Understanding the molecular process controlling muscle stem cell proliferative expansion and commitment to differentiated cell lineages during long-term culture is crucial to obtain large amounts of functional cells for regenerative medicine and cultured meat research. Using the proteomics method, we identified some pathways that are increased and decreased during long-term passage. The proteomics data indicate that the dysfunction of satellite cells during long-term passage resembles the effect of aging.

\section{Results}

Subculture of bovine myoblast cells induce defects in proliferation and differentiation Satellite cells gradually lose their stemness when cultured in vitro ${ }^{24-26,34}$. During longterm passaging, the cells showed increased cell size (Figure 1a). Subculturing of myoblast cells also resulted in decreased proliferation as indicated by the cell doubling rate per day (Figure $1 \mathrm{~b}$ ). We also checked the differentiation ability of an early passage (P3) and late passage (P9). After undergoing a differentiation protocol, P3 cells were $80 \% \mathrm{MyHC}^{+}$cells whereas only $15 \%$ of cells from P9 were MyHC positive (Figure 1c, $1 d)$. These results indicate that long-term passaging leads to a gradual loss function of myoblast cells in proliferation as well as differentiation.

\section{Quantitative proteomics showed good quality data}

To understand the reason for loss of stemness during passaging, we collected the cells from P3, P6, P9 and applied an MS-based lable-free proteomics quantitative method. After filtering with master and high FDR confidence protein, 1874 reliable quantitative proteins were obtained across all passages in at least 3 of 4 replicates. The sample abundance of the proteins were similar for the groups and replicates suggesting sufficient quality of sample preparation and protein identification (Figure 2a). To assess the variability and reproducibility between replicates and passages, we next generated a principle component analysis (PCA). The PCA plot showed that the P3, P6, P9 were nicely separated by principle component 1 (34.6\%). The quantitative proteomics data from the four biological replicates correlated very well, while showing distinct differences between the passages (Figure $2 b$ ). Finally, we checked the expression of several housekeeping proteins. GAPDH, $\beta$-tubulin isotypes TUBB2A and TUBB2B were constant in different passages (Figure $2 \mathrm{c}$ ). Taking together, these results indicate sufficient quality of proteomics data. 
Figure 1. Bovine myoblast cells lose the ability to proliferate and to differentiate after long-term culture

a
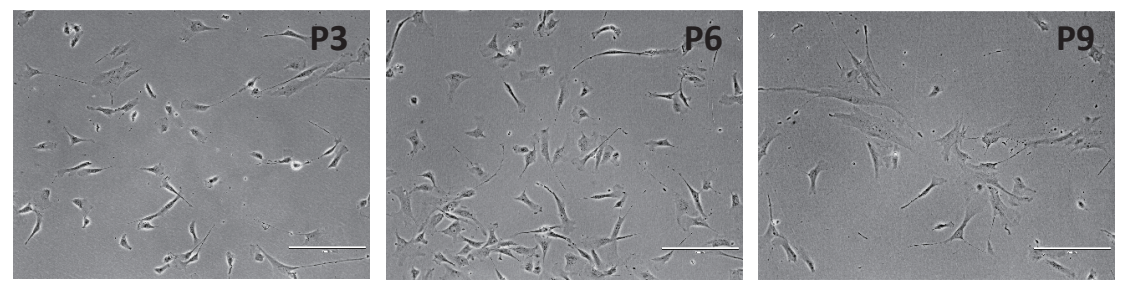

b

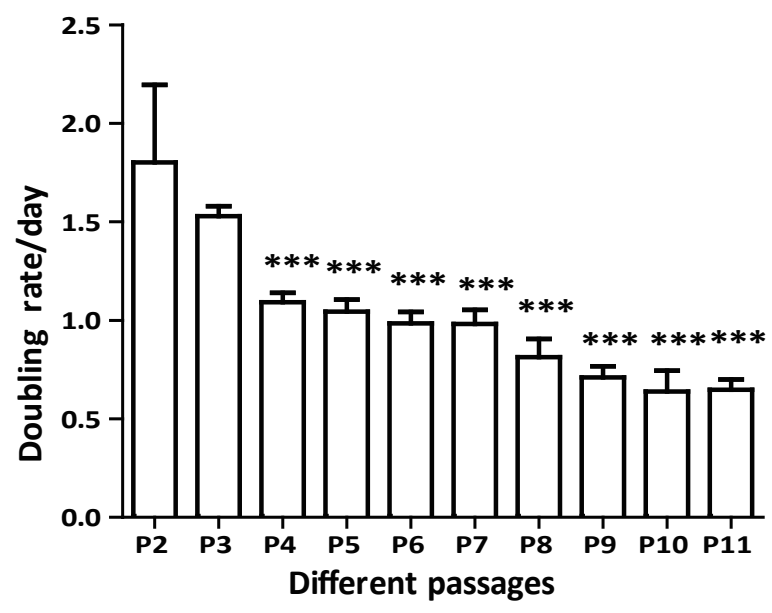

C

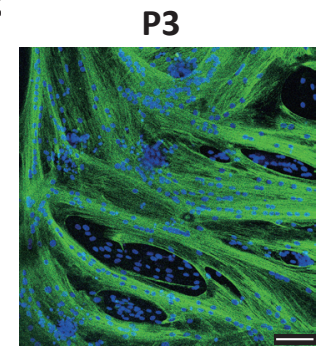

P9

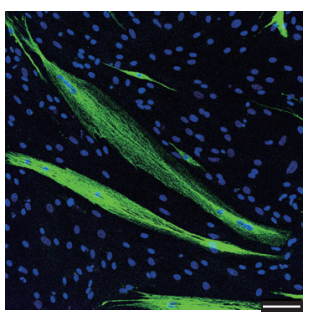

d

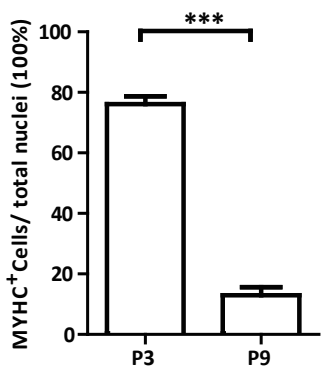

(a) Representative phase contrast images of bovine myoblast cells cultured in F-10 medium at passage 3, 6, 9. Scale bars: $200 \mu \mathrm{m}$. (b) Bovine myoblast cell division times in $24 \mathrm{hrs}$ at different passages. Data are represented as mean \pm S.E.M. ( $n=3-8)$. (c) Representative immunofluorescent staining images of Myosin Heavy Chain staining of myotubes differentiated from P3 and P9 myoblast cells after differentiation. Green indicates MYHC; blue indicates DAPI (nuclei). Scale bars: $200 \mu \mathrm{m}$. Significance was analyzed by Student's $\mathrm{t}$ test or one-way ANOVA followed by Dunnett's Multiple Comparison Test. Asterisks: *** indicates $p<0.001$. 
Chapter 6

Figure 2. Quantitative proteomics shows good quality data

a

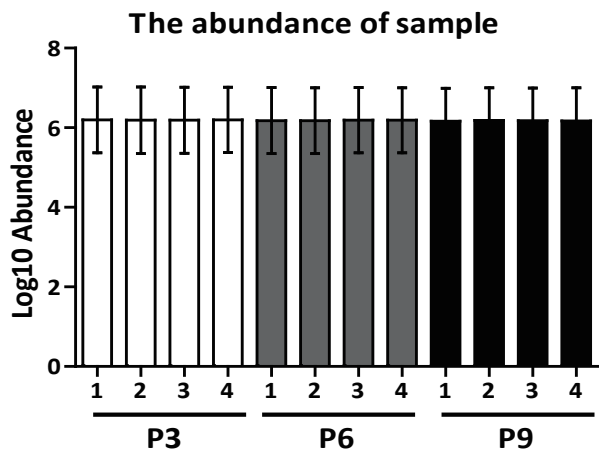

b

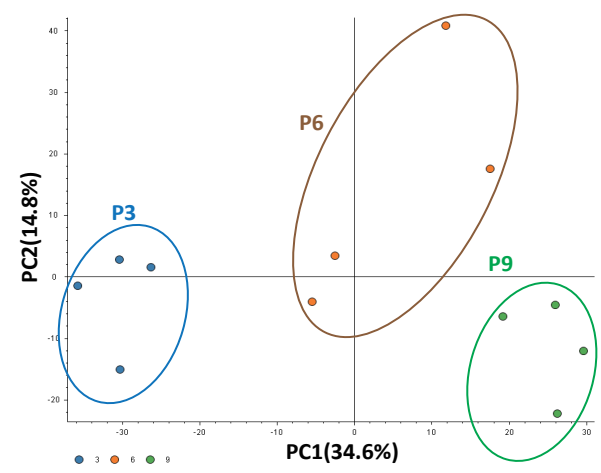

C Some housekeeping genes

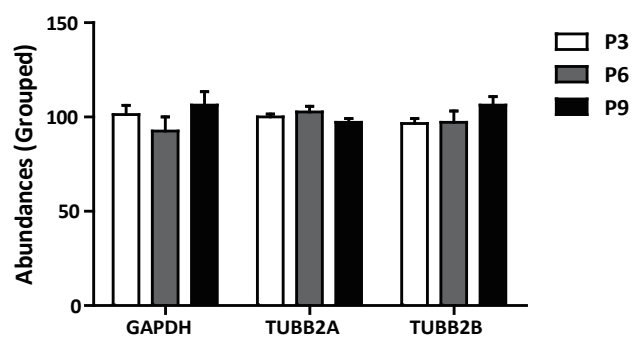

(a) The abundance of the peptides within the proteins in the samples are shown. Sample abundance was generated by PD 2.2 according for the quantitative peptides. Data are represented as mean \pm SD. (b) Principal component analysis (PCA) of all 1874 quantified proteins. Using principal components 1 and 2, 4 biology replicates in passage $3,6,9$. Blue indicates 4 biological replicates of P3. Orange indicates 4 biological replicates of P6. Green indicates 4 biological replicates of P9. (c) Pooled housekeeping proteins GAPDH, $\beta$-tubulin isotypes TUBB2A and TUBB2B abundances in passage 3, 6, 9. Data are represented as mean \pm SD. None of the differences were significant (one-way ANOVA) 


\section{The quantitative proteins can be divided in $\mathbf{3}$ different clusters}

We generated a heatmap using the 4 replicates for different passages. The dendrogram showed results similar to the PCA plot (Figure 3a). The heatmap of pooled proteins show different profiles for each passage (Figure $3 \mathrm{~b}$ ), which is especially obvious if one clusters the proteins according to magnitude of difference between the passages (Figure 3c). Cluster 1 contained protein ratios were 1.2 or more in passage 9 compared with passage 3 . Proteins that had an abundance ratio of 0.8 or less in P9 compared with P3 comprised cluster 2 , whereas cluster 3 represented the proteins stably expressed in P3 and P9. The P9 to P3 abundance ratios were between 0.8-1.2 (Figure 3c). Since we were interested in the changes during longterm passage, we focussed on clusters 1 and 2.

\section{DAVID analysis of enriched proteins in Cluster 1}

In cluster 1, with proteins that were up-regulated upon passaging, 328 proteins were enriched. Gene ontology (GO) was performed to identify any potential functional biological role of those proteins using the online Database for Annotation, Visualization and Integrated Discovery (DAVID) Bioinformatics Resources. Gene Ontology Biological Process annotation (GO_BP) showed that cell-cell adhesion, muscle contraction, mitochondrial electron transport, NADH to ubiquinone and cell redox homeostasis were up-regulated during passaging (Figure 4a). The KEGG PATHWAY analysis was also performed and some new pathways like Phagosome, Fatty acid degradation, PI3K-Akt signaling pathway and Insulin signaling pathway were found (Figure $4 \mathrm{~b}$ ). Those proteins were also related to aging diseases such as Parkinson's disease, Alzheimer's disease and Huntington's disease according to KEGG PATHWAY. These results indicate that longterm passaging increased mitochondrial and redox stress, imbalanced cell homeostasis and aging related defects. 
Figure 3. Clustering of quantitative proteins
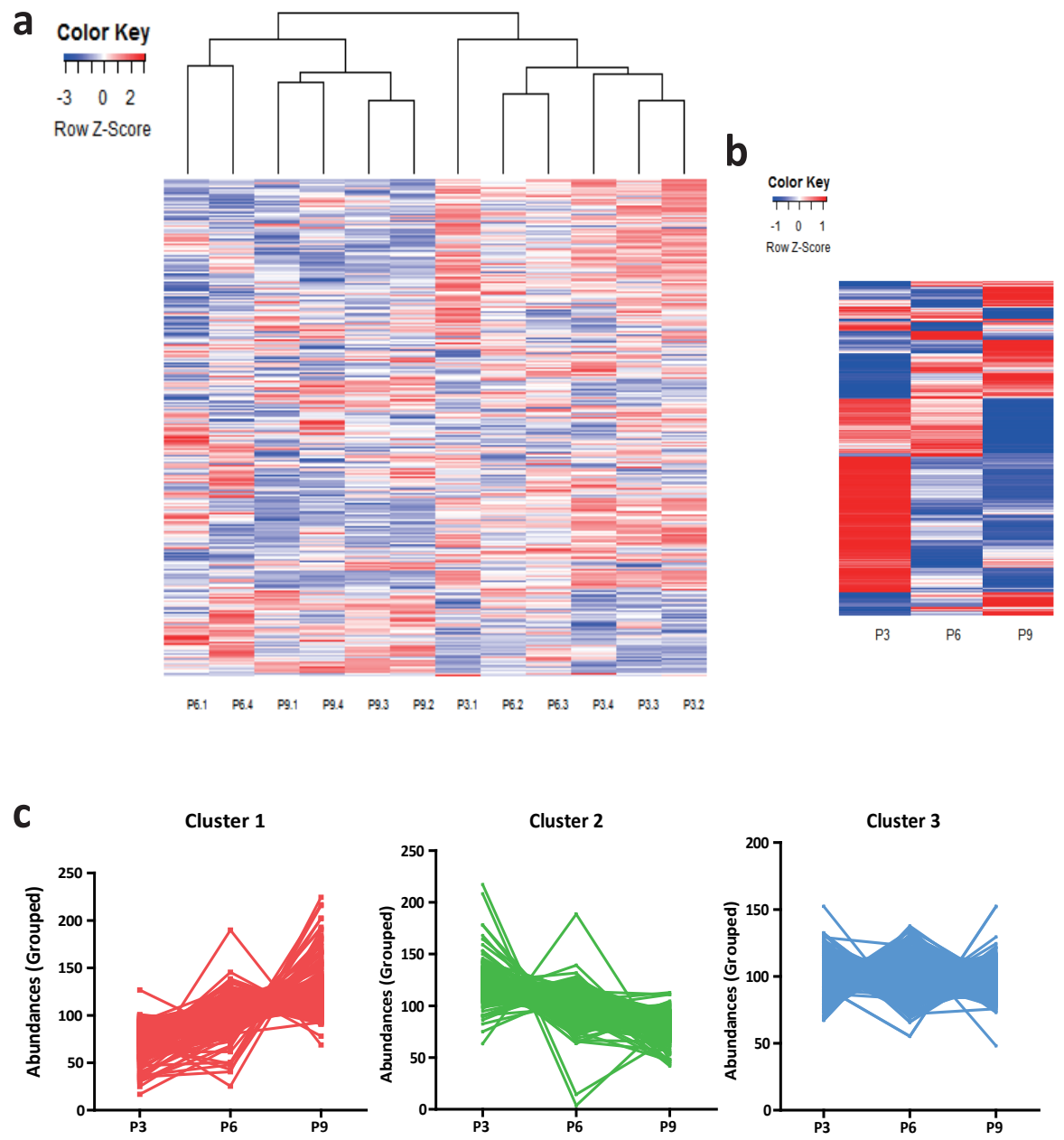

(a) Heatmap of all quantified proteins expression profile in 4 biology replicates from passage 3, 6, 9. The dendrogram showed the variety and unity between replicates and passages. (b) Heatmap of pooled all quantified proteins expression profile from passage $3,6,9$. (c) The quantitative proteins are divided into 3 clusters of according to protein expression between passage 3 and 9. Pooled proteins abundance ratios are 1.2 or more (left), 0.8 or less (middle), between 0.8 and 1.2 (right) from passage 9, as compared with passage 3 . 
Figure 4. Signaling pathways enriched in Cluster 1

a

Cluster 1

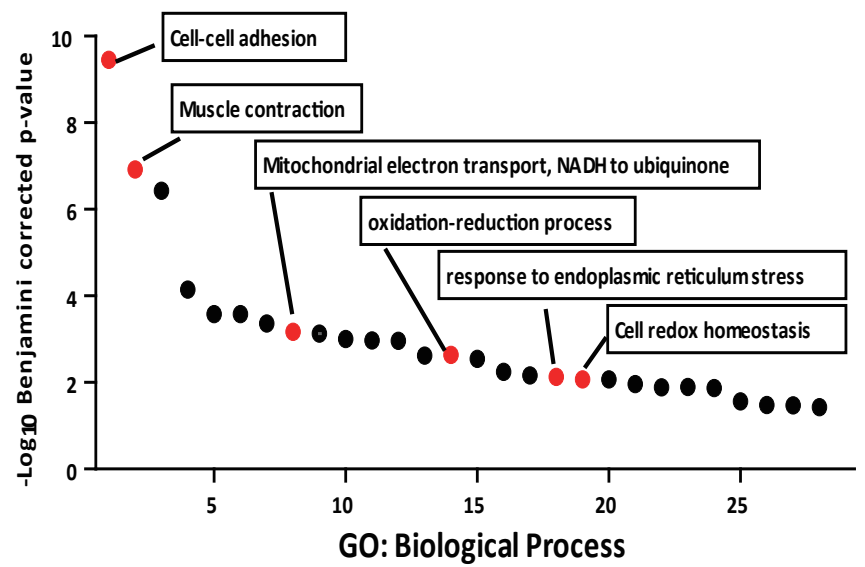

b

Cluster 1

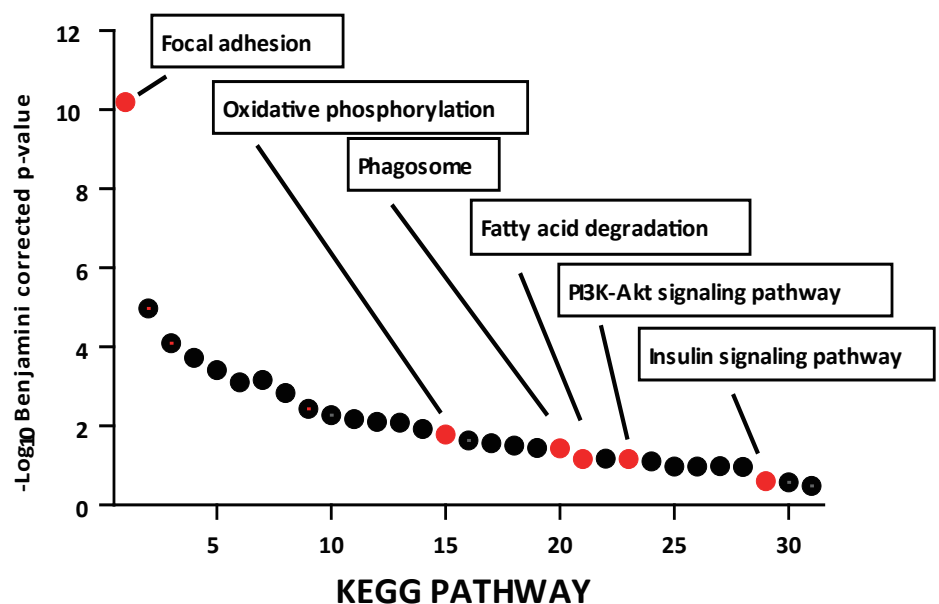

DAVID Analysis demonstrated up-regulated signaling pathways in bovine myoblast cells from passage 9, as compared with passage 3 using Gene Ontology Biological Process annotation (GO_BP) enrichment and KEGG pathway enrichment. (a) GO_BP analysis of 328 enriched proteins in cluster 1. (b) KEGG pathway analysis of 328 enriched proteins in cluster 1 . Signaling pathways were ranked on the basis of Benjamini-Hochberg corrected p-value. Each dot represents a signal pathway. Specific pathways related to satellite cell function are highlighted in red. 


\section{DAVID Analysis of enriched proteins in Cluster 2}

In total 443 proteins were highly expressed in passage 3 in cluster 2, GO_BP analysis showed that DNA replication, protein folding, translational initiation, DNA repair, fibroblast growth factor receptor signaling pathway, regulation of signal transduction by p53 class mediator, proteasome-mediated ubiquitin-dependent protein catabolic process, telomere maintenance via recombination and somatic stem cell population maintenance were enriched in P3 cells (Figure 5a). In addition, KEGG pathway analysis also showed that mismatch repair and ubiquitin mediated proteolysis pathways were highly expressed in p3. These results indicate that higher expression of proteostasis, fibroblast growth factor receptor, p53 signal and telomere maintenance could help maintain the proliferation and differentiation abilities of myoblast cells in P3 (Figure $5 b)$.

Long-term cultured bovine myoblasts showed alert mitochondrial proteins expression Proteins that were commonly up-regulated during passaging showed a substantial overlap (48 genes) with mitochondrial proteins from human mitochondrial proteins MitoCarta2.0 (Figure 6a, 6b) ${ }^{35}$. The up-regulated mitochondrial proteins in late passage myoblasts were annotated according to GO_BP and designated as mitochondrial (dys) function and oxidative stress in P9 cells rather than in P3 (Figure 6c).

\section{Long-term cultured bovine myoblasts showed loss of proteostasis}

Loss of proteostasis and entry into senescence is a reason for a decline in muscle stemcell regenerative function ${ }^{13}$. Our data showed that the proteasome-mediated ubiquitindependent protein catabolic process (by GO_BP and by KEGG) was enriched in p3 cells (Figure $5 \mathrm{a}, 5 \mathrm{~b}$ ). The proteostasis genes ${ }^{13}$ showed overlap (39 genes) with cluster 2 proteins (Figure 7a). The heatmap showed a down-regulation of those proteostasis proteins with increasing passage (Figure 7a, 7b). The down-regulation of proteostasis may cause defective autophagy, which disrupts satellite cell homeostasis during aging ${ }^{13}$. 
Figure 5. Signaling pathways enriched in Cluster 2

a

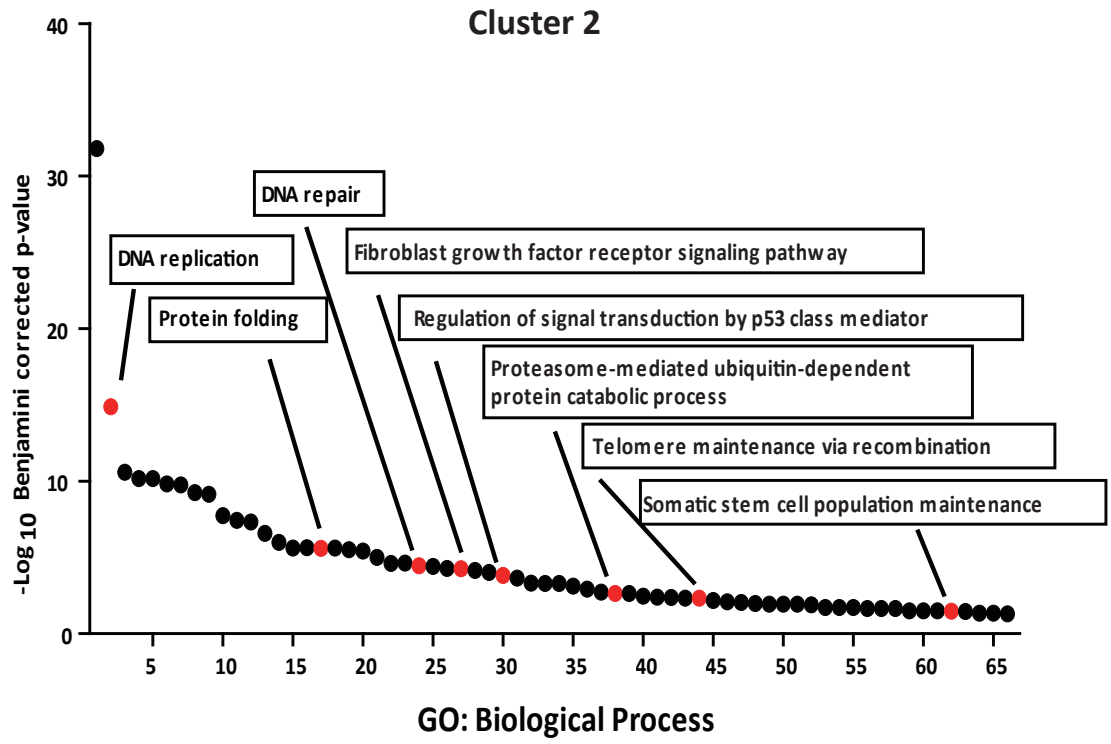

b

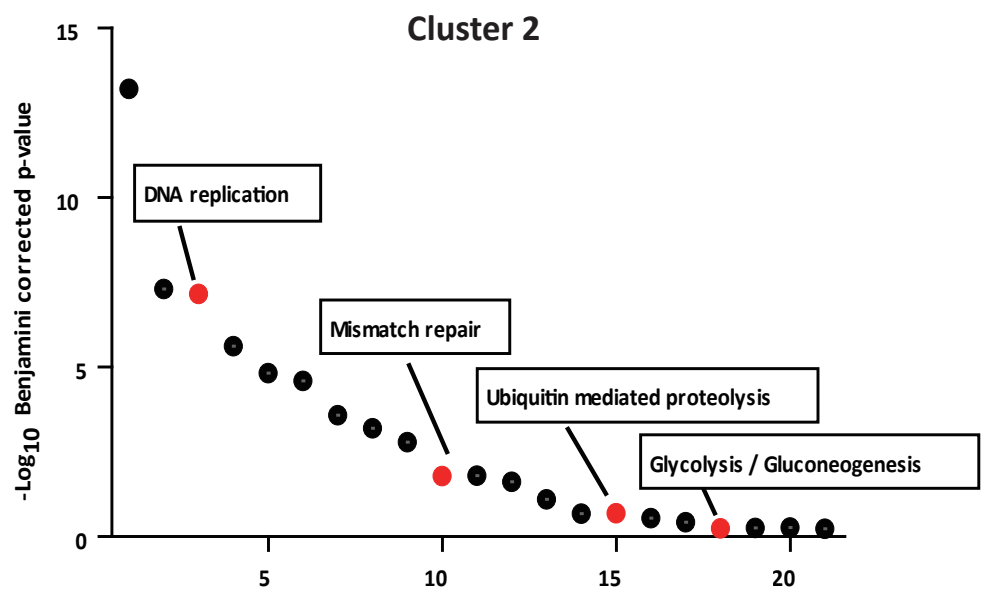

KEGG PATHWAY

DAVID Analysis demonstrates down-regulated signaling pathways in bovine myoblast cells from passage 9 , as compared with passage 3 using gene ontology biological process annotation (GO_BP) enrichment and KEGG pathway enrichment. (a) GO_BP analysis of 443 enriched proteins in cluster 2. (b) KEGG pathway analysis of 443 enriched proteins in cluster 2. Signaling pathways were ranked on the basis of Benjamini-Hochberg corrected p-value. Each dot represents a signal pathway. Specific pathways related to satellite cell function are highlighted in red. 
Figure 6. Long-term cultured bovine myoblasts showed alert mitochondrial proteins expression

a

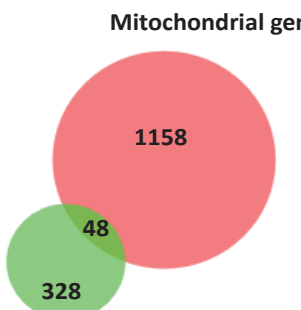

Up-regulated proteins in P9 b

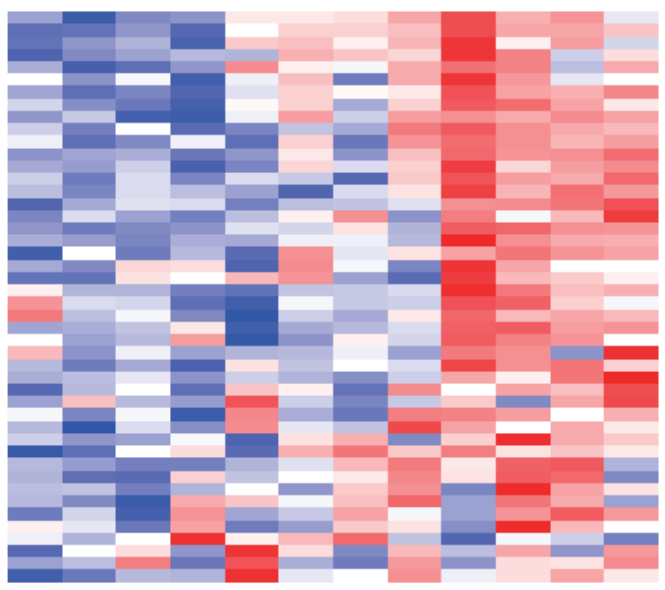

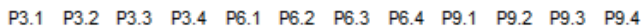

Color Key

Tा। IT

$\begin{array}{lll}-2 & 0 & 2\end{array}$

\section{C}

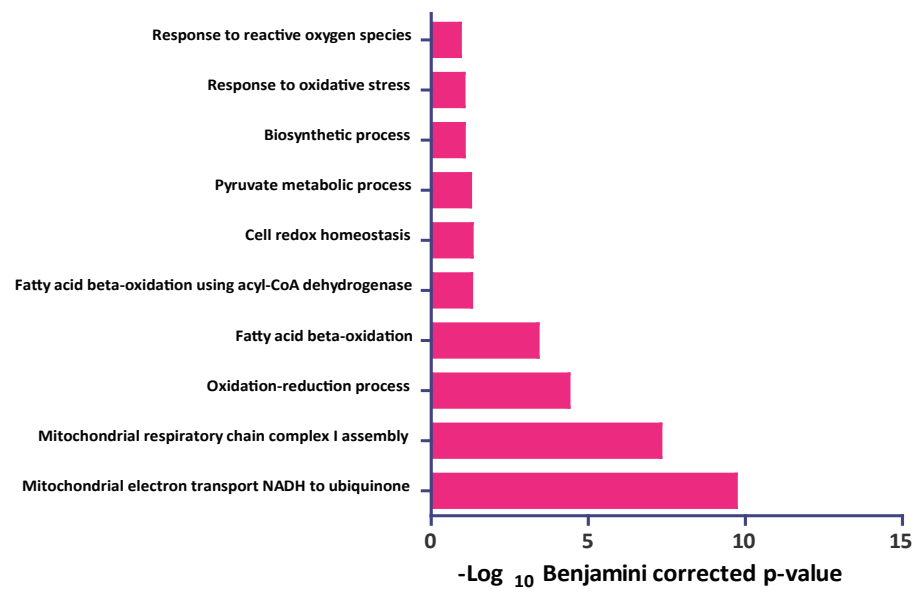

(a) Area proportional Venn diagram representing 48 common genes between the up-regulated proteins in $p 9$ and genes from the human mitochondrial transcriptome. (b) Heatmap of 48 quantified proteins expression profile in 4 biology replicates from (a). (c)DAVID analysis demonstrated signaling pathways in proteins from (a) using GO_BP enrichment. The top 10 signaling pathways were ranked on the basis of Benjamini-Hochberg corrected p-value. 
Figure 7. Long-term cultured bovine myoblasts showed loss of proteostasis

a

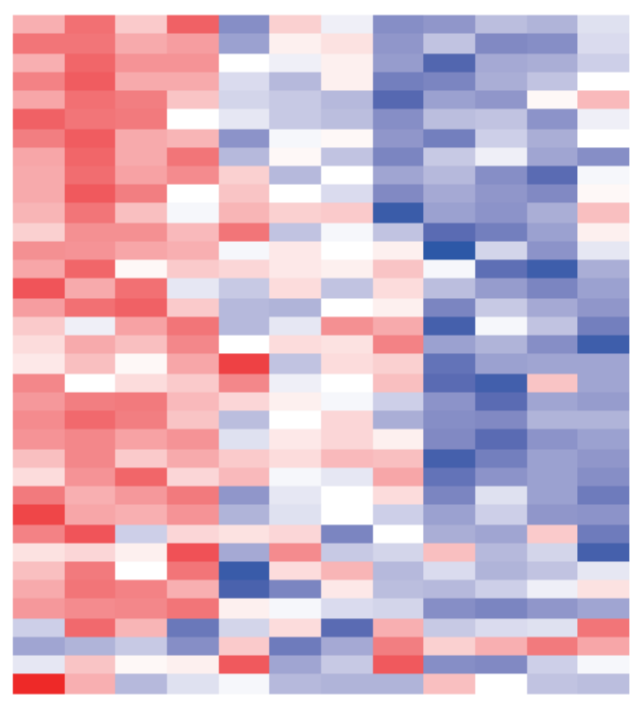

$\begin{array}{llllllllllll}\text { P3.1 } & \text { P3.2 } & \text { P3.3 } & \text { P3.4 } & \text { P6.1 } & \text { P6.2 } & \text { P6.3 } & \text { P6.4 } & \text { P9.1 } & \text { P9.2 } & \text { P9.3 } & \text { P9.4 }\end{array}$
Color Key

TIIT

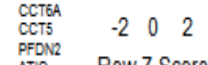

Row Z-Score

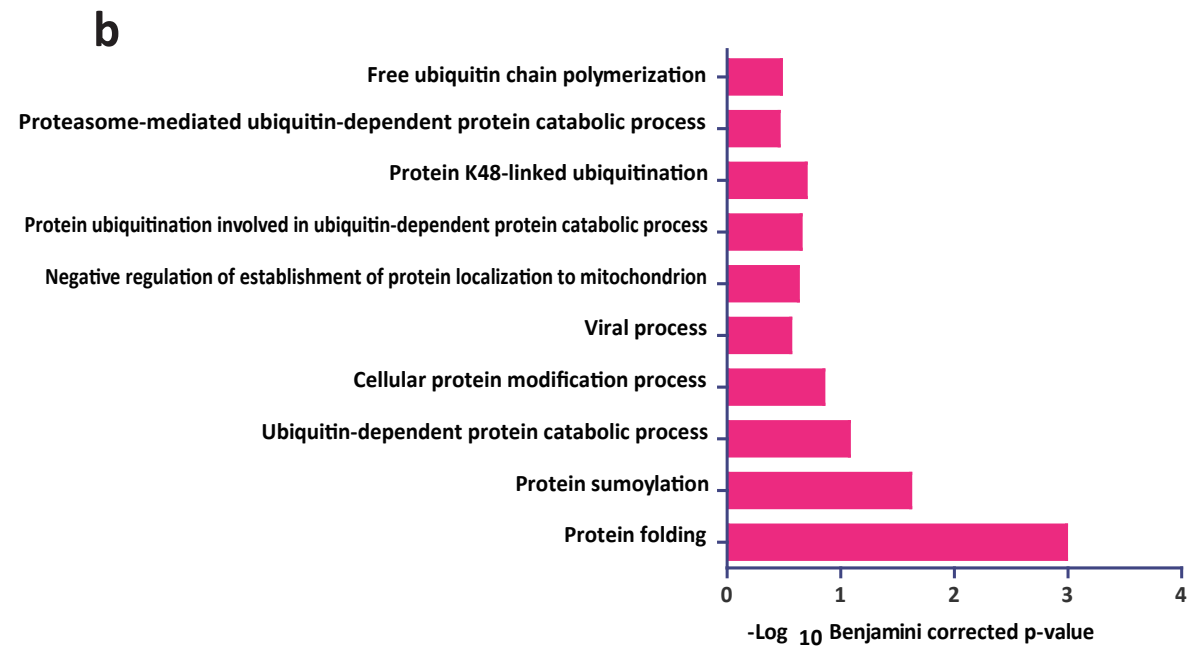

(a) Heatmap of 39 quantified proteins expression profile from overlap (39 genes) between the proteistasis genes $^{13}$ and claster 2 proteins in 4 biology replicates. (b) DAVID analysis demonstrates signaling pathways in proteins from (a) using gene ontology biological process annotation (GO_BP) enrichment. Top 10 signaling pathways were ranked on the basis of Benjamini-Hochberg corrected p-value. 


\section{Discussion}

Large scale culture of muscle stem cells is required to gain enough cells for clinical applications as well as for culturing meat. However, in muscle stem cells or myoblasts, growth arrest was shown in long-term culture ${ }^{27,28,36,37}$. In addition, the differentiation ability is diminished after culturing, even after a 3 days culture ${ }^{24,28,34,38,39}$. In accordance, we observed phenotypic changes in bovine myoblasts such as increased cell size as a function of passage (Figure 1 ) and reduced proliferation and differentiation ability (Figure 1).

Using proteomic analysis, we identified pathways that increased or decreased during long-term passage. Many of these signalings such as mitochondrial electron transport, $\mathrm{NADH}$ to ubiquinone ${ }^{40,41}$, response to endoplasmic reticulum stress ${ }^{42,43}$, cell redox homeostasis, oxidative phosphorylation, PI3K-Akt signaling pathway ${ }^{44}$ and insulin signaling pathway ${ }^{45}$ were up-regulated in the late passage indicating that induced oxidative stress by for instance increased reactive oxygen species (ROS) is increased with long-term passaging. The decreased expressions of DNA repair, proteostasis, fibroblast growth factor receptor ${ }^{12}, \mathrm{p} 53$ regulation $^{6}$ and telomere maintenance ${ }^{29,46}$ suggest that these signals may play a role in the loss of stemness. Those results indicate that primary bovine myoblast cells in vitro undergo a process resembling, if not being identical to, cell aging.

During aging, stem cells accumulate toxic metabolites (ROS), DNA damage, epigenetic alterations, aggregates of damaged proteins and dysfunctional mitochondria, all of which contribute to cell senescence ${ }^{2,8,47}$. In our results, "mitochondrial electron transport NADH to ubiquinone", "occurrence of an oxidation-reduction process", "a response to endoplasmic reticulum stress", "cell redox homeostasis", "mitochondrial respiratory chain complex I assembly" and "oxidative phosphorylation" pathways were accrued in the late passage suggesting an excess of reactive oxygen species ${ }^{42,43}$. Increased levels of ROS and stress signaling disrupt the genome and epigenetic status ${ }^{1,8}$.

Increased "DNA repair", "DNA damage response", "DNA recombination", "DNA replication" and "Mismatch repair" in the early passage indicate that these cells have a better functioning DNA repair system to insure genomic stability. Up-regulated "nucleosome assembly" and "histone exchange" may stabilize the epigenetic status in the early passage ${ }^{48}$.

Aged stem cells also gradually lose hallmarks such as telomere length ${ }^{29,49}$. In satellite cells, passaging of cells in vitro quickly and dramatically downregulates telomerase activity while aging in vivo showed a much slower rate 29,46 . In our results, the "telomere maintenance via recombination" as a biological process, is highly expressed in early passage, suggesting that there is disproportional telomere shortening during in vitro culture after this initial proliferation stage has passed. The observation that in late passage there is reduced telomere maintenance via recombination confirms that 
long-term cell culture is in essence a replicative senescence in bovine myoblast cells. We found that the muscle stem cells aging signal "fibroblast growth factor receptor signaling pathway" was highly expressed in the early passage. FGF receptor signaling is aberrant in aging satellite cells and constitutive FGFR1 signaling rescues self-renewal in SCs from aged mice ${ }^{14}$. Furthermore, augmented "Extracellular matrix organization", "Cell-matrix adhesion" "Collagen fibril organization" in the late passage condition suggests that long-term culture is associated with fibrosis, which is similar in for instance WNT-induced aging of muscle stem cell ${ }^{18}$.

A recent study identified that impaired Notch signaling leads to a decrease in p53 activity, whereas Notch stimulation by recombinant Delta-like ligand 1 and subsequent enhancement of $\mathrm{p} 53$ promoted the survival of aged MuSCs${ }^{6}$. In replicative senescence, the DNA damage signaling cascade in response to telomere erosion induces p53 activation, which in turn leads to p21 and Akt signaling ${ }^{50,51}$. In our results, "regulation of signal transduction by p53 class mediator" signal was up-regulated in the early passage, whereas telomere shortening was still protected. Therefore, further studies on p53 and aging in vivo and in vitro are needed to clarify this relationship.

Our proteomics data shows systematic biological changes during long-term passage. The dysfunction of myoblast cells during long-term passage resembles the effect of aging. Understanding the molecular pathways involved in this long-term passage deterioration of muscle stem cell function will be critical for extending the replicative capacity of muscle stem cells and developing new cultivation method for clinical and food usage.

\section{Materials and Methods}

\section{Bovine muscle tissues}

The bovine satellite cells in this study were derived from fresh muscle samples obtained at a local slaughterhouse. The transport time is about $30 \mathrm{~min}$.

\section{Bovine satellite cells isolation}

Bovine satellite cells were isolated from 4-6 year old male cattle as previously described and adapted to bovine tissues ${ }^{25,52,53}$. The detailed method for isolation mononuclear cells from muscle tissue was described in Chapter 2.

The frozen cells were first recovered in growth medium (F10 $+20 \%$ fetal calf serum + $5 \mathrm{ng} / \mathrm{ml}$ bFGF) for 2 days. The floting debris were washed away and the adherent cells were collected by trypsin dissociation. These cells were resuspended in FACS buffer and stained with APC anti-human CD29 Antibody (1:10, BioLegend, Cat\# 303008), PE-Cy ${ }^{\mathrm{TM}} 7$ anti-human CD56 (1:10, BD, Cat\# 335826), FITC anti-sheep CD31 (1:10, BIO- 
RAD, Cat\# MCA1097F), FITC anti-sheep CD45 (1:10, BIO-RAD, Cat\# MCA2220F) for 30 $45 \mathrm{~min}$ on ice. After antibody incubation, the cells were washed twice with cold PBS and reconstituted in growth medium. The viable $\mathrm{CD} 311^{-} \mathrm{CD} 45 \mathrm{CD} 56^{+} \mathrm{CD} 29^{+}$cells were isolated by cell sorting. Cell sorting was performed with a BD FACSAriall cell sorter using 405, 488nm and 640nm lasers. Unstained cells were routinely used to define FACS gating parameters.

\section{Satellite cell culture and differentiation}

Dishes (Corning) were coated with 0.05\% bovine collagen type I (Sigma, Cat\# C4243). FACS isolated bovine satellite cells and unsorted cells were cultured on collagen-coated dishes in F10 medium (Gibco, Cat\# 31550-023) containing 20\% fetal bovine serum (FBS, Gibco, Cat\# 10500-06), 5 ng/mL bFGF (R\&D, Cat\# 233-FB-025) and 1\% P.S.. For serial expansion, cells were passaged to maintain a density of $<60 \%$ confluence and counted at each passage. Bovine satellite cells differentiation was induced at $95 \%$ confluency with DMEM (Invitrogen, Cat\# 41966-29) with 2\% FBS. The differentiated cells were fixed with $4 \%$ PFA for immunofluorescent staining. The bright field images were acquired by AMG-EVOS microscope.

\section{Immunofluorescent analysis of cultured myotubes.}

Cultured satellite cells were fixed with ice-cold 4\% PFA (in PBS) for 20 min, rinsed with PBS, and permeabilized in 0.5\% Triton X-100 (in PBS) for 15 min. Permeabilized cells were blocked and incubated with primary antibodies in 1\% BSA (in PBS) overnight at $4^{\circ} \mathrm{C}$. Primary antibodies recognizing MyHC (1:500, Millipore, CAT\# 05-716). After washing with PBS, cells were incubated with Alexa 488 labeled anti-rabbit (1:600, Invitrogen, Cat \# A-11034), antibodies for $1 \mathrm{~h}$ at room temperature and mounted with VECTASHIELD mounting medium with DAPI (Vector Laboratories Cat\# H-1500).

\section{Differentiation efficiency percentage measurement}

The percentage of $\mathrm{MyHC}^{+}$nuclei per condition was expressed as $\mathrm{MyHC}^{+}$nuclei divided by total nuclei in the same field. More than 1000 nuclei from 4 or more randomly chosen fields were analysed.

\section{General, protein digestion for LC-MS analysis}

Proteins from passage 3, 6, 9 were collected and digested for Liquid Chromatography - Mass Spectrometry according to the standard protocol. Protein samples were reduced with $20 \mathrm{mM}$ Dithiothreitol (DTT) for 45 minutes and alkylated with $40 \mathrm{mM}$ lodoacetamide (IAM) for 45 minutes in the darkness. The alkylation was terminated by $20 \mathrm{mM}$ DDT to consume any excess IAM. Digestion was performed with a mixture of LysC and Trypsin, which was added at a ratio of 1:25 (enzyme to protein). After two hours of digestion at $37^{\circ} \mathrm{C}$ in a water bath, the lysate was diluted with $50 \mathrm{mM} \mathrm{ABC}$ to $1 \mathrm{M}$ 
Urea and further digested at $37^{\circ} \mathrm{C}$ overnight. The digestion was terminated by addition of formic acid (FA) to a total of $1 \%$.

\section{Liquid Chromatography - Mass Spectrometry}

Peptide separation was performed on a Thermo Scientific (Dionex) Ultimate 3000 Rapid Separation UHPLC system equipped with an Acclaim PepMap C18 analytical column ( 2 um, $100 \AA$, 75 um x $150 \mathrm{~mm}$ ). Peptide samples were first desalted on an online installed C18 trapping column. After desalting peptides were separated on the analytical column with a 90 minute linear gradient from $5 \%$ to $35 \%$ Acetonitrile (ACN) with $0.1 \%$ FA at $300 \mathrm{~nL} / \mathrm{min}$ flow rate. The UHPLC system was coupled to a $Q$ Exactive HF mass spectrometer (Thermo Scientific). DDA settings were as follows. Full MS scan between $375-1,500 \mathrm{~m} / \mathrm{z}$ at resolution of 120,000 followed by MS/MS scans of the top 15 most intense ions at a resolution of 30,000 .

\section{Mass Spectrometric Raw Data Analysis}

For protein identification and quantitation, the data dependent acquisition (DDA) spectra were analyzed with Proteome Discoverer (PD) version 2.2. Within the PD software, the search engine Sequest was used with the SwissProt [Homo sapiens] database (Homo sapiens (SwissProt TaxID=9606). The database search was performed with the following settings. Enzyme was trypsin, a maximum of 2 missed cleavages, minimum peptide length of 6 , precursor mass tolerance of $10 \mathrm{ppm}$, fragment mass tolerance of $0.02 \mathrm{Da}$, dynamic modifications of methionine oxidation and protein $\mathrm{N}$-terminus acetylation, static modification of cysteine carbamidomethylation.

\section{Mass spectrometry data processing, statistical analysis and bioinformatic analyses}

The identified proteins were filtered with "Master is equal to Master", "Protein FDR Confidence has level high in Protein FDR Confidence Combined", "Abundances (Grouped) Counts is greater than or equal to 3 in sample group 3, 6, 9" to get all 1874 quantified proteins. For proteins up-regulated in passage 9 compared with passage 3, The total proteins were further filtered with "Abundance ratios is greater than 1.2 in ratio passage 9/ passage 3 ". For proteins down-regulated in passage 9 compared with passage 3, The total proteins were further filtered with "Abundance ratios is less than 0.8 in ratio passage 9/ passage 3".Gene ontology (GO) and KEGG pathway was performed by the Database for Annotation, Visualization and Integrated Discovery (DAVID) Bioinformatics Resources online tool ${ }^{54,55}$. Heatmaps were drawn with $\mathrm{R}$ software according to the results from PD 2.2. Area proportional Venn diagram was drawn according to online tool ${ }^{56}$. 


\section{Statistics}

Statistical analyses were performed using GraphPad Prism 5 (GraphPad Software). For comparisons of two treatment groups, a Student's t-test was used. For more than two groups, One-way ANOVA with Dunnett's Multiple Comparison Test. Results were means \pm S.E.M. unless otherwise stated. $P<0.05$ was considered significant.

\section{Acknowledgements}

This work was supported by the Core Facility Flow Cytometry, a core facility of the Interdisciplinary Center for Clinical Research (IZKF) Aachen within the Faculty of Medicine at RWTH Aachen University. We thank the proteomics services in Maastricht Multimodal Molecular Imaging Institute (M4I), Maastricht University. This work was sponsored by Royal Netherlands Academy of Arts and Sciences and China Scholarship Council. 


\section{References}

1 Lopez-Otin, C., Blasco, M. A., Partridge, L., Serrano, M. \& Kroemer, G. The hallmarks of aging. Cell 153, 1194-1217, doi:10.1016/j.cell.2013.05.039 (2013).

2 Hohn, A. et al. Happily (n)ever after: Aging in the context of oxidative stress, proteostasis loss and cellular senescence. Redox Biol 11, 482-501, doi:10.1016/j.redox.2016.12.001 (2017).

3 Song, R., Sarnoski, E. A. \& Acar, M. The Systems Biology of Single-Cell Aging. iScience 7, 154-169, doi:10.1016/j.isci.2018.08.023 (2018).

4 Doles, J. D. \& Olwin, B. B. Muscle stem cells on the edge. Curr Opin Genet Dev 34, 24-28, doi:10.1016/j. gde.2015.06.006 (2015).

5 Dumont, N. A., Wang, Y. X. \& Rudnicki, M. A. Intrinsic and extrinsic mechanisms regulating satellite cell function. Development 142, 1572-1581, doi:10.1242/dev.114223 (2015).

6 Liu, L. et al. Impaired Notch Signaling Leads to a Decrease in p53 Activity and Mitotic Catastrophe in Aged Muscle Stem Cells. Cell stem cell, doi:10.1016/j.stem.2018.08.019 (2018).

7 Blau, H. M., Cosgrove, B. D. \& Ho, A. T. V. The central role of muscle stem cells in regenerative failure with aging. Nat Med 21, 854-862 (2015).

8 Ermolaeva, M., Neri, F., Ori, A. \& Rudolph, K. L. Cellular and epigenetic drivers of stem cell ageing Nature reviews. Molecular cell biology, doi:10.1038/s41580-018-0020-3 (2018).

9 Dumon, N. A., Wang, Y. X. \& Rudnicki, M. A. Intrinsic and extrinsic mechanisms regulating satellite cell function. Development 142, 1572-1581, doi:10.1242/dev.114223 (2015).

10 Zhang, H. et al. NAD(+) repletion improves mitochondrial and stem cell function and enhances life span in mice. Science 352, 1436-1443, doi:10.1126/science.aaf2693 (2016).

11 Baumann, K. Ageing: The yin and yang of mitochondrial dysfunction. Nature reviews. Molecular cell biology 17, 331, doi:10.1038/nrm.2016.71 (2016).

12 Bernet, J. D. et al. p38 MAPK signaling underlies a cell-autonomous loss of stem cell self-renewal in skeletal muscle of aged mice. Nat Med 20, 265-271, doi:10.1038/nm.3465 (2014).

13 Garcia-Prat, L. et al. Autophagy maintains stemness by preventing senescence. Nature 529, 37-42, doi:10.1038/nature16187 (2016).

14 Cosgrove, B. D. et al. Rejuvenation of the muscle stem cell population restores strength to injured aged muscles. Nat Med 20, 255-264, doi:10.1038/nm.3464 (2014).

15 Price, F. D. et al. Inhibition of JAK-STAT signaling stimulates adult satellite cell function. Nat Med 20, 1174-1181, doi:10.1038/nm.3655 (2014).

16 Tierney, M. T. et al. STAT3 signaling controls satellite cell expansion and skeletal muscle repair. Nat Med 20, 1182-1186 (2014).

17 Sousa-Victor, P. et al. Geriatric muscle stem cells switch reversible quiescence into senescence. Nature 506, 316-+, doi:10.1038/nature13013 (2014).

18 Brack, A. S. et al. Increased Wnt signaling during aging alters muscle stem cell fate and increases fibrosis. Science 317, 807-810 (2007).

19 Conboy, I. M., Conboy, M. J., Smythe, G. M. \& Rando, T. A. Notch-mediated restoration of regenerative potential to aged muscle. Science 302, 1575-1577, doi:DOI 10.1126/science.1087573 (2003).

20 Liu, L. et al. Chromatin Modifications as Determinants of Muscle Stem Cell Quiescence and Chronological Aging. Cell Rep 4, 189-204, doi:10.1016/j.celrep.2013.05.043 (2013).

21 Goldstein, S. Replicative senescence: the human fibroblast comes of age. Science 249, 1129-1133 (1990). 
22 Hayflick, L. \& Moorhead, P. S. The serial cultivation of human diploid cell strains. Exp Cell Res 25, 585621 (1961).

23 DiLoreto, R. \& Murphy, C. T. The cell biology of aging. Mol Biol Cell 26, 4524-4531, doi:10.1091/mbc. E14-06-1084 (2015).

$24 \mathrm{Fu}, \mathrm{X}$. et al. Combination of inflammation-related cytokines promotes long-term muscle stem cell expansion. Cell Res 25, 655-673, doi:10.1038/cr.2015.58 (2015).

25 Charville, G. W. et al. Ex Vivo Expansion and In Vivo Self-Renewal of Human Muscle Stem Cells. Stem Cell Rep 5, 621-632, doi:10.1016/j.stemcr.2015.08.004 (2015).

26 Nehlin, J. O., Just, M., Rustan, A. C. \& Gaster, M. Human myotubes from myoblast cultures undergoing senescence exhibit defects in glucose and lipid metabolism. Biogerontology 12, 349-365, doi:10.1007/ s10522-011-9336-5 (2011).

27 Baraibar, M. A. et al. Impaired energy metabolism of senescent muscle satellite cells is associated with oxidative modifications of glycolytic enzymes. Aging 8, 3375-3389, doi:10.18632/aging.101126 (2016).

28 Bigot, A. et al. Replicative aging down-regulates the myogenic regulatory factors in human myoblasts. Biol Cell 100, 189-199, doi:10.1042/Bc20070085 (2008).

29 O'Connor, M. S., Carlson, M. E. \& Conboy, I. M. Differentiation Rather Than Aging of Muscle Stem Cells Abolishes Their Telomerase Activity. Biotechnol Progr 25, 1130-1137, doi:10.1002/btpr.223 (2009).

30 Schubert, O. T., Rost, H. L., Collins, B. C., Rosenberger, G. \& Aebersold, R. Quantitative proteomics: challenges and opportunities in basic and applied research. Nat Protoc 12, 1289-1294, doi:10.1038/ nprot.2017.040 (2017).

31 Baraibar, M. A. et al. Oxidative stress-induced proteome alterations target different cellular pathways in human myoblasts. Free radical biology \& medicine 51, 1522-1532, doi:10.1016/j. freeradbiomed.2011.06.032 (2011).

32 Baggerman, G., Vierstraete, E., De Loof, A. \& Schoofs, L. Gel-based versus gel-free proteomics: a review. Combinatorial chemistry \& high throughput screening 8, 669-677 (2005).

33 Wong, J. W. \& Cagney, G. An overview of label-free quantitation methods in proteomics by mass spectrometry. Methods in molecular biology 604, 273-283, doi:10.1007/978-1-60761-444-9_18 (2010).

34 Montarras, D. et al. Direct isolation of satellite cells for skeletal muscle regeneration. Science 309, 2064-2067, doi:10.1126/science.1114758 (2005).

35 Calvo, S. E., Clauser, K. R. \& Mootha, V. K. MitoCarta2.0: an updated inventory of mammalian mitochondrial proteins. Nucleic Acids Res 44, D1251-1257, doi:10.1093/nar/gkv1003 (2016).

36 Decary, S. et al. Replicative potential and telomere length in human skeletal muscle: implications for satellite cell-mediated gene therapy. Hum Gene Ther 8, 1429-1438, doi:10.1089/hum.1997.8.12-1429 (1997).

37 Di Donna, S. et al. Regenerative capacity of human satellite cells: the mitotic clock in cell transplantation. Neurol Sci 21, S943-951 (2000).

38 Quarta, M. et al. An artificial niche preserves the quiescence of muscle stem cells and enhances their therapeutic efficacy. Nat Biotechnol 34, 752-759, doi:10.1038/nbt.3576 (2016).

39 Sharples, A. P., Al-Shanti, N., Lewis, M. P. \& Stewart, C. E. Reduction of Myoblast Differentiation Following Multiple Population Doublings in Mouse C2C12 Cells: A Model to Investigate Ageing? J Cell Biochem 112, 3773-3785, doi:10.1002/jcb.23308 (2011).

40 Esterhazy, D., King, M. S., Yakovlev, G. \& Hirst, J. Production of reactive oxygen species by complex I (NADH:ubiquinone oxidoreductase) from Escherichia coli and comparison to the enzyme from mitochondria. Biochemistry-Us 47, 3964-3971, doi:10.1021/bi702243b (2008). 
41 Mimaki, M., Wang, X., McKenzie, M., Thorburn, D. R. \& Ryan, M. T. Understanding mitochondrial complex I assembly in health and disease. Biochimica et biophysica acta 1817, 851-862, doi:10.1016/j. bbabio.2011.08.010 (2012).

42 Gu, S., Chen, C., Jiang, X. \& Zhang, Z. ROS-mediated endoplasmic reticulum stress and mitochondrial dysfunction underlie apoptosis induced by resveratrol and arsenic trioxide in A549 cells. Chemicobiological interactions 245, 100-109, doi:10.1016/j.cbi.2016.01.005 (2016).

43 Zeeshan, H. M., Lee, G. H., Kim, H. R. \& Chae, H. J. Endoplasmic Reticulum Stress and Associated ROS. Int J Mol Sci 17, 327, doi:10.3390/ijms17030327 (2016).

44 Le Belle, J. E. et al. Proliferative Neural Stem Cells Have High Endogenous ROS Levels that Regulate Self-Renewal and Neurogenesis in a PI3K/Akt-Dependant Manner. Cell stem cell 8, 59-71, doi:10.1016/j. stem.2010.11.028 (2011).

45 Barquissau, V. et al. Reactive oxygen species enhance mitochondrial function, insulin sensitivity and glucose uptake in skeletal muscle of senescence accelerated prone mice SAMP8. Free Radical Bio Med 113, 267-279, doi:10.1016/j.freeradbiomed.2017.10.012 (2017).

46 Magi, F. et al. Telomere length is independently associated with age, oxidative biomarkers, and sport training in skeletal muscle of healthy adult males. Free Radical Res 52, 639-647, doi:10.1080/10715762 2018.1459043 (2018).

47 Oh, J., Lee, Y. D. \& Wagers, A. J. Stem cell aging: mechanisms, regulators and therapeutic opportunities. Nat Med 20, 870-880, doi:10.1038/nm.3651 (2014).

$48 \mathrm{Xu}$, M. \& Zhu, B. Nucleosome assembly and epigenetic inheritance. Protein Cell 1, 820-829, doi:10.1007/s13238-010-0104-0 (2010).

49 Blasco, M. A. Telomere length, stem cells and aging. Nature chemical biology 3, 640-649, doi:10.1038/ nchembio.2007.38 (2007).

$50 \mathrm{Kim}, \mathrm{Y}$. Y. et al. Cooperation between p21 and Akt is required for p53-dependent cellular senescence. Aging Cell 16, 1094-1103, doi:10.1111/acel.12639 (2017).

51 Kuilman, T., Michaloglou, C., Mooi, W. J. \& Peeper, D. S. The essence of senescence. Genes Dev 24, 2463-2479, doi:10.1101/gad.1971610 (2010).

$52 \mathrm{Xu}, \mathrm{X}$. et al. Human Satellite Cell Transplantation and Regeneration from Diverse Skeletal Muscles. Stem Cell Rep 5, 419-434, doi:10.1016/j.stemcr.2015.07.016 (2015).

53 Ding, S. et al. Characterization and isolation of highly purified porcine satellite cells. Cell Death Discov 3, 17003, doi:10.1038/cddiscovery.2017.3 (2017).

54 Huang, D. W., Sherman, B. T. \& Lempicki, R. A. Systematic and integrative analysis of large gene lists using DAVID bioinformatics resources. Nat Protoc 4, 44-57, doi:10.1038/nprot.2008.211 (2009).

55 Huang, D. W., Sherman, B. T. \& Lempicki, R. A. Bioinformatics enrichment tools: paths toward the comprehensive functional analysis of large gene lists. Nucleic Acids Res 37, 1-13, doi:10.1093/nar/ gkn923 (2009).

56 Hulsen, T., de Vlieg, J. \& Alkema, W. BioVenn - a web application for the comparison and visualization of biological lists using area-proportional Venn diagrams. Bmc Genomics 9, doi:Artn 488 10.1186/14712164-9-488 (2008). 



\section{Chapter 7}

General discussion, future perspectives and conclusion 



\section{General discussion}

\section{Characterize and isolate high purity satellite cells in livestock animals}

Maintenance of stemness in a stem cell population is of considerable scientific and societal importance. A prerequisite for maintaining stemness is to start with a highly purified stem cell population, since most other cells in culture grow faster than the stem cells, so that the latter will eventually be outnumbere ${ }^{1-4}$. Satellite cells are a population of small mononucleated muscle stem cells in muscle tissue ${ }^{5,6}$. They are the most ideal cell source for cultured meat. In mouse muscle tissue, murine skeletal muscle-derived stem cells (MDSCs) contain fibroblast-like, myogenic, endothelial, myoendothelial, pericytes and other cell populations ${ }^{7,8}$. The multilineage differentiation capacity was also found in pig and human muscle derived stem cells ${ }^{9-11}$. The pre-plating method used for pig and bovine obtains a various purity of satellite cells $s^{12-15}$. Thus, it is necessary to develop a more efficient method to obtain highly purified satellite cells in livestock for cultured meat.

Here, we performed immunofluorescent staining assays and found that both CD56 and CD29 co-localized in the same cell with Pax7 in porcine skeletal muscles. Similar results were found in bovine muscle fibers. We improved the purity of pig and bovine satellite cells by FACS and established that a combination of negative selection for CD31 and CD45 with a positive selection for CD29 and CD56 results in a high purity satellite cells population as judged by their degree of PAX7 positivity. These purified satellite cells showed high myotube formation abilities in vitro and porcine satellite cells participated in the muscle regeneration in recipient mice (Chapter 2 and 3 ).

Previous studies in mouse have suggested that highly purified satellite cells can be obtained by FACS sorting $3,16,17$. The cell surface markers for FACS sorting have been well characterized in murine muscle tissues. The most commonly used cell surface markers in murine are CD34 and $\alpha 7$-integrin ${ }^{1,16,17}$. Recently, the CD56, CD29, epidermal growth factor receptor (EGFR) are identified as human satellite are cell surface markers ${ }^{2,18}$. Expression of these markers is species specific. For instance, mouse satellite cells express CD34, whereas human satellite cells do not ${ }^{2,11,16}$. Our results showed that CD56 and CD29 are satellite cell surface markers for large animals (pig and bovine), which indicates satellite cells in large animals are similar with human. However, Further characterization of CD34 expression in pig and bovine satellite cells are needed.

Next generation of cell sorting can be developed from specific cell metabolism. It has been reported that glucose-depleted culture medium supplemented with lactate can facilitate purification of human pluripotent stem cells (hPSCs)-derived cardiomyocytes $^{19}$. Further study found that use fatty acid fatty acid as a lactate replacement together with 3,3',5-Triiodo-L-thyronine $\left(T_{3}\right)$ can facilitate purification and show better function of hPSC-derived cardiomyocytes ${ }^{20}$. A recent report in cancer field found that monosaccharide mannose causes growth retardation in several tumor types in vitro. Mannose also inhibited tumor growth in mice without affect the weight of the 
mice, nor did it visibly affect their health ${ }^{21}$. These results indicate that the metabolic pathways can be used for specific cell purification or depletion. Further studies can focus on the satellite cell specific cell metabolic pathway to develop a faster, easier and safer sorting strategy for cultured meat production.

\section{Mediator pathways during differentiation and long-term culture}

Satellite cells are about $2-10 \%$ of total myonuclei ${ }^{17,22}$. For regenerative medicine and cultured meat purpose, it is a challenge to culture large amount of functional myoblast cells. After isolation from muscle tissue, satellite cells easily start to proliferate and differentiate to Myog $^{+}$myoblasts ${ }^{2,18,23,24}$. This differentiation is associated with less proliferative potential and lower engraftment efficiency ${ }^{23,25-28}$. Several signaling pathways have been confirmed to relate to the automatic myoblast differentiation process such as p38-MAPK ${ }^{26}$, JAK2-STAT3 ${ }^{25}$, canonical-Wnt ${ }^{27}$ and extracellular laminin ${ }^{29}$. By inhibiting these signals or recapitulating laminin, satellite cell function can be restored or maintained for a longer time ${ }^{25-27,29}$. We studied p38-MAPK and JAK2-STAT3 function in the differentiation process. These two signaling pathways were up-regulated during differentiation. Pharmacological inhibition of p38-MAPK and JAK2-STAT3 signals inhibited the fusion process (Chapter 3 and 4).

Subculture of stem cells decreases the proliferation and differentiation abilities, especially in mesenchymal stem cells ${ }^{30-33}$. The defects of serial cultivation were also observed in myoblast cells ${ }^{34-36}$. We also investigated the p38-MAPK and JAK2-STAT3 signaling pathways in long-term cultured myoblast cells and they showed different effects. Inhibition of p38-MAPK maintained stemness of long-term cultured myoblast cells (Chapter 3). Pharmacological inhibition of JAK2 and STAT3 however failed to affect proliferation or differentiation of the bovine myoblast cells in long-term culture (Chapter 4). We also pharmacologically inhibited Setd7 by PFI-2, which inhibits canonical-WNT signaling ${ }^{27}$ and this did not result in maintaining proliferation of bovine myoblast cells during long-term culture either (Chapter 5). These results indicate that long-term culturing of myoblast cells can be associated with either preserved or diminished differentiation capacity.

We then checked ERK and Akt signal pathways changes in differentiation and long-term culture process by Western Blot. Both ERK and Akt signals were down-regulated when the cells are confluent and then increased during differentiation. But ERK signal kept decreasing while Akt signal increased during long-term culture (Chapter 5 ). Those data again suggest that long-term culture may lead to different pathways and outcomes with respect to proliferation and differentiation. The expression profiles of p38-MARK, ERK and AKT signal indicate long-term culture defects that may due to in vitro aging or replicate senescence. 


\section{Long-term culture of bovine myoblast cells resembles the effect of aging}

The long-term culture-induced limited replicative life-span of human fibroblast was firstly described in 1961 and further developed as the replicative senescence ${ }^{37-39}$. It has also been called in vitro aging of cells since replicative senescence showed similarities with in vivo aging ${ }^{40}$. Long-term culture of myoblast cells not only showed proliferation arrest $^{2,17,36,41}$, but also impaired differentiation ability ${ }^{34}$.

Aged satellite cells show decreased cell number, impaired self-renewal and loss of

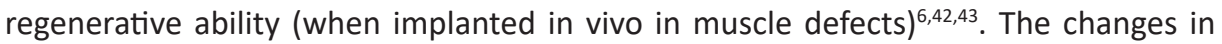
muscle extrinsic tissue microenvironment function and intrinsic alterations lead to dysfunction of $\mathrm{SCs}^{6,22,43}$. Several intracellular processes and signaling pathways have been described as being dysregulated in association with aging of satellite cells in vivo such as mitochondrial dysfunction ${ }^{44,45}$, FGF2 and FGF receptor 1 (FGFr1) function ${ }^{46}$, protein homeostasis (proteostasis) ${ }^{47}$, p38 ${ }^{26,46}$, STAT3 ${ }^{25,48}$, p $16^{49}$, canonical Wnt ${ }^{50}$, Notch signaling ${ }^{51}$, and epigenetic status ${ }^{43,52}$.

We used label-free high-throughput proteomics to identify the proteins changes in early and late passages. Further gene ontology (GO) and Kyoto Encyclopedia of Genes and Genomes (KEGG) pathways analysis helped us understand the long-term culture process systematically. These signaling changes correlate with the reported aging signal of MuSCs in vivo and relicative senescence signals in vitro.

In the early passage, myoblast cells showed enriched in DNA replication, protein folding, translational initiation, DNA repair, fibroblast growth factor receptor signaling pathway, p53 regulation, proteasome-ubiquitin-dependent proteolysis, telomere maintenance via recombination and somatic stem cell population maintenance (Chapter 6 ). Targeting these signals may help improve the myoblast cell function during long-term culture. In aged satellite cells, FGFR1 signaling is reduced compared to those from young mice ${ }^{46}$. Constitutive FGFR1 signaling partially rescues self-renewal in SCs from aged mice ${ }^{46}$. However, aberrant increased FGFR signaling is also found in solid tumor types ${ }^{53}$. Future studies may focus on rescuing these signals in a proper level to maintain the function of long-term cultured myoblast cells.

In the late passage, redox related signals like mitochondrial electron transport, $\mathrm{NADH}$ to ubiquinone ${ }^{54,55}$, response to endoplasmic reticulum stress ${ }^{56,57}$, Cell redox homeostasis, Oxidative phosphorylation, PI3K-Akt signaling pathway ${ }^{58}$, Insulin signaling pathway ${ }^{59}$ were up-regulated. This indicated that the oxidative stress might be one of the reasons for the defects during long-term passage. Indeed, slowing down or removing this oxidative stress may help in maintain geriatric satellite cell proliferation and regenerative abilities ${ }^{47}$. p38-MAPK signaling is a stress-induced signal ${ }^{43,60}$. Genetic or pharmacological inhibition of p38-MAPK signaling ameliorates age-associated satellite cell defects ${ }^{46}$. Inhibition of p38 inhibition also helped long-term culture of human satellite cells ${ }^{2}$. We investigated bovine satellite cells and showed up-regulated p38-MAPK signaling accompanied by a loss of differentiation ability during long-term 
culturing in vitro. Long-term cultivation with p38i helped maintained the stemness and differentiation abilities (chapter 3 ). Future studies may focus on inhibiting those signals in late passages to maintain the function of long-term cultured myoblast cells.

\section{Future perspectives for cultured meat}

Meat is one of the most important dietary components for humans. However, traditional animal agriculture has a substantial contribution to climate change and air pollution, to land, soil and water degradation and to the reduction of biodiversity ${ }^{61}$. The predicted increase in demand for meat and other animal products makes the traditional animal agriculture especially become a big issue for the environment ${ }^{62,63}$. Cultured meat is a technology, which potentially can solve part of the major upcoming problems with traditional livestock ${ }^{64-66}$. In this thesis, we have aimed to develop basic research to promote the development of cultured meat technology.

\section{Purification of muscle stem cells}

Muscle tissue is about $50-60 \%$ of the carcass and this is the most important part for raw meat and meat processing ${ }^{67}$. Skeletal muscle tissue consists of approximately $90 \%$ muscle fibers and $10 \%$ connective and fat ${ }^{68}$. The most important work for cultured meat is to rebuild muscle fibers. Satellite cells are an ideal cell source to produce cultured meat ${ }^{63,69}$. Here, we isolated high purified pig and bovine satellite cells (Chapter 2 and Chapter 3 ). The $\mathrm{MyHC}^{+}$myotube formation ability is more than $80 \%$ in early passages.

The purified livestock satellite cell is fundamental for cultured meat research. On the one hand, cultured meat is based on in vitro culture of satellite cells becoming myoblasts. However, there are more than 10 different cell types in muscle tissue ${ }^{7,8}$. The purified livestock satellite cells can be used to study bona fide satellite cell features during in vitro culture. On the other hand, the purification of satellite cells can also help to adapt the strategy for isolation other cell types in muscle tissue ${ }^{70}$, which may be needed to reconstruct muscle tissue with multipole cell types ${ }^{71}$. These will likely require modifications of the purification protocol.

\section{Exploration of signaling pathways during myoblast cell culture}

We studied several signaling pathways during satellite cell activation, proliferation and differentiation. By utilizing these signaling pathway, we can specifically control the satellite cell fate ${ }^{24}$ to efficiently produce cultured meat. Upon muscle insult, quiescent satellite cells are exposed to extrinsic, pro-myogenic stimuli which activate intrinsic pathways that stimulate activation, proliferation and differentiation ${ }^{5,24}$. Our data show that bovine satellite cells up-regulated p38-MAP and JAK2-STAT3 signaling during activation. ERK signal was important for subculture of myoblast cells. During 
differentiation, both p38-MAPK and JAK2-STAT3 signals were essential for the myoblast differentiation. The ERK and AKT signal down-regulated at the early differentiation stage and were important for late differentiation stage (chapter $3,4,5$ ).

Several growth factors can stimulate these signal pathways for myoblast cells ${ }^{24}$. For example, basic fibroblast growth factor (bFGF) can stimulate p38-MAPK, ERK-MAPK, PI3-kinase/Akt, activation of STAT and stimulation of phospholipase $\mathrm{C}$ gamma/protein kinase $C$ signaling ${ }^{72}$. Insulin-like growth factor-1 (IGF-1) stimulates ERK, Akt, STAT3 signaling ${ }^{73-75}$. There are several inhibitors that can inhibited unique signal pathways. The SB203580, SB 202190 are inhibitors for p38-MAPK signals ${ }^{26,46}$. Due to the harmful effects, there are also some peptide inhibitors such as STAT3 inhibitor peptide aptamers $^{76}$. Future studies should focus on two issues. Firstly, the function of signal pathways during satellite cell activation, proliferation and differentiation, should be further explored. Secondly, interventions in these pathways should be evaluated, keeping in mind at stimuli or inhibitors are compatible with eventually products that are sold in the food industry.

\section{Act on proteomic profiles}

For the $85 \mathrm{~g}$ of the world first cultured hamburger, we used 10,000 muscle strips. For one muscle fiber/strip about 1.5 million myoblast cells were differentiated, which amounts to 15 billion myoblast cells to form a hamburger ${ }^{63}$. Thus, the production scale of myoblasts much be very large, requiring long-term culture. The induced proliferation and differentiation defects during long-term culture of myoblast cells therefore presents an obstacle. Our proteomics data showed systematic changes in myoblast cells between early and late passage. Inhibiting or rescuing these signals may help maintaining the function of long-term cultured myoblast cells.

As an example, in our results, we have found that long-term cultivation with $\mathrm{p} 38 \mathrm{i}$ helped myoblast cells maintaining the stemness and differentiation abilities (chapter 3). Before knowing the proteomics data, we surmised that p38 inhibition would function to maintain PAX7 expression leading to short term inhibition of differentiation. The proteomics data highlighted oxidative stress as one of the potential defects during long-term passage and indeed p38-MAPK signal is a stress-induced signal ${ }^{43,77}$. This suggests that the inhibition of oxidative stress signal by p38-MAPK signaling may also be a reason for maintaince of stemness during subculture of myoblast cells ${ }^{43,77}$. Future studies may focus on inhibiting or rescuing aging signals in late passage to manage large scale myoblast cells for cultured meat, for instance by additional measures to reduce oxidative stress. 


\section{Conclusion}

FACS purification of bovine and pig satellite cells using CD29 and CD56 as positive markers increase the stem cell population. After long-term in vitro culturing, the satellite cells lose their stem cell identities and differentiation potentials. The defects of subculture satellite cells are not due to myoblast differentiation into myotubes as several main signaling pathways are differently expressed in the two different biological processes. Preventing the cell to differentiate in early stage myocytes/myoblasts is not sufficient to maintain the stemness of satellite cells during long-term passaging. Longterm culture of myoblast cells resembles the effect of aging. Inhibiting or rescuing aging signals may help to bring large scale bovine muscle cell culture for cultured beef applications closer to reality. 


\section{References}

1 Pasut, A., Oleynik, P. \& Rudnicki, M. A. Isolation of muscle stem cells by fluorescence activated cell sorting cytometry. Methods in molecular biology 798, 53-64, doi:10.1007/978-1-61779-343-1_3 (2012).

2 Charville, G. W. et al. Ex Vivo Expansion and In Vivo Self-Renewal of Human Muscle Stem Cells. Stem Cell Rep 5, 621-632, doi:10.1016/j.stemcr.2015.08.004 (2015).

3 Liu, L., Cheung, T. H., Charville, G. W. \& Rando, T. A. Isolation of skeletal muscle stem cells by fluorescenceactivated cell sorting. Nat Protoc 10, 1612-1624, doi:10.1038/nprot.2015.110 (2015).

4 Ding, S. et al. Characterization and isolation of highly purified porcine satellite cells. Cell Death Discov 3, 17003, doi:10.1038/cddiscovery.2017.3 (2017).

5 Dumont, N. A., Wang, Y. X. \& Rudnicki, M. A. Intrinsic and extrinsic mechanisms regulating satellite cell function. Development 142, 1572-1581, doi:10.1242/dev.114223 (2015).

6 Blau, H. M., Cosgrove, B. D. \& Ho, A. T. V. The central role of muscle stem cells in regenerative failure with aging. Nat Med 21, 854-862 (2015).

7 Gharaibeh, B. et al. Isolation of a slowly adhering cell fraction containing stem cells from murine skeletal muscle by the preplate technique. Nat Protoc 3, 1501-1509, doi:10.1038/nprot.2008.142 (2008).

8 Sherwood, R. I. et al. Isolation of adult mouse myogenic progenitors: Functional heterogeneity of cells within and engrafting skeletal muscle. Cell 119, 543-554, doi:DOI 10.1016/j.cell.2004.10.021 (2004).

9 Wilschut, K. J., Jaksani, S., Van Den Dolder, J., Haagsman, H. P. \& Roelen, B. A. J. Isolation and Characterization of Porcine Adult Muscle-Derived Progenitor Cells. J Cell Biochem 105, 1228-1239, doi:Doi 10.1002/Jcb.21921 (2008).

10 Pisani, D. F. et al. Hierarchization of myogenic and adipogenic progenitors within human skeletal muscle. Stem Cells 28, 2182-2194, doi:10.1002/stem.537 (2010).

11 Pisani, D. F. et al. Isolation of a Highly Myogenic CD34-Negative Subset of Human Skeletal Muscle Cells Free of Adipogenic Potential. Stem Cells 28, 753-764, doi:10.1002/stem.317 (2010).

12 Wilschut, K. J., Haagsman, H. P. \& Roelen, B. A. J. Extracellular matrix components direct porcine muscle stem cell behavior. Exp Cell Res 316, 341-352, doi:DOI 10.1016/j.yexcr.2009.10.014 (2010).

13 Patruno, M., Caliaro, F., Martinello, T. \& Mascarello, F. Expression of the paired box domain Pax7 protein in myogenic cells isolated from the porcine semitendinosus muscle after birth. Tissue Cell 40, 1-6, doi:DOI 10.1016/j.tice.2007.08.006 (2008).

14 Coles, C. A. et al. Proliferation Rates of Bovine Primary Muscle Cells Relate to Liveweight and Carcase Weight in Cattle. Plos One 10 (2015).

15 Will, K., Schering, L., Albrecht, E., Kalbe, C. \& Maak, S. Differentiation of bovine satellite cell-derived myoblasts under different culture conditions. In vitro cellular \& developmental biology. Animal 51, 885889, doi:10.1007/s11626-015-9916-9 (2015).

16 Sacco, A., Doyonnas, R., Kraft, P., Vitorovic, S. \& Blau, H. M. Self-renewal and expansion of single transplanted muscle stem cells. Nature 456, 502-506, doi:10.1038/nature07384 (2008).

$17 \mathrm{Fu}, \mathrm{X}$. et al. Combination of inflammation-related cytokines promotes long-term muscle stem cell expansion. Cell Res 25, 655-673, doi:10.1038/cr.2015.58 (2015).

$18 \mathrm{Xu}, \mathrm{X}$. et al. Human Satellite Cell Transplantation and Regeneration from Diverse Skeletal Muscles. Stem Cell Rep 5, 419-434, doi:10.1016/j.stemcr.2015.07.016 (2015).

19 Tohyama, S. et al. Distinct Metabolic Flow Enables Large-Scale Purification of Mouse and Human Pluripotent Stem Cell-Derived Cardiomyocytes. Cell stem cell 12, 127-137 (2013). 
20 Lin, B. et al. Culture in Glucose-Depleted Medium Supplemented with Fatty Acid and 3,3',5-TriiodoI-Thyronine Facilitates Purification and Maturation of Human Pluripotent Stem Cell-Derived Cardiomyocytes. Frontiers in endocrinology 8, 253, doi:10.3389/fendo.2017.00253 (2017).

21 Gonzalez, P. S. et al. Mannose impairs tumour growth and enhances chemotherapy. Nature 563, 719723, doi:10.1038/s41586-018-0729-3 (2018).

22 Dumon, N. A., Wang, Y. X. \& Rudnicki, M. A. Intrinsic and extrinsic mechanisms regulating satellite cell function. Development 142, 1572-1581, doi:10.1242/dev.114223 (2015).

23 Quarta, M. et al. An artificial niche preserves the quiescence of muscle stem cells and enhances their therapeutic efficacy. Nat Biotechnol 34, 752-759, doi:10.1038/nbt.3576 (2016).

24 Almada, A. E. \& Wagers, A. J. Molecular circuitry of stem cell fate in skeletal muscle regeneration, ageing and disease. Nature reviews. Molecular cell biology 17, 267-279, doi:10.1038/nrm.2016.7 (2016).

25 Tierney, M. T. et al. STAT3 signaling controls satellite cell expansion and skeletal muscle repair. Nat Med 20, 1182-1186 (2014).

26 Cosgrove, B. D. et al. Rejuvenation of the muscle stem cell population restores strength to injured aged muscles. Nat Med 20, 255-264, doi:10.1038/nm.3464 (2014).

27 Judson, R. N. et al. Inhibition of Methyltransferase Setd7 Allows the In Vitro Expansion of Myogenic Stem Cells with Improved Therapeutic Potential. Cell stem cell 22, 177-190 e177, doi:10.1016/j. stem.2017.12.010 (2018).

28 Rayagiri, S. S. et al. Basal lamina remodeling at the skeletal muscle stem cell niche mediates stem cell self-renewal. Nat Commun 9, doi:Artn 1075 10.1038/S41467-018-03425-3 (2018).

29 Ishii, K. et al. Recapitulation of Extracellular LAMININ Environment Maintains Stemness of Satellite Cells In Vitro. Stem Cell Rep 10, 568-582, doi:10.1016/j.stemcr.2017.12.013 (2018).

30 Sun, H. J. et al. A proteomic analysis during serial subculture and osteogenic differentiation of human mesenchymal stem cell. Journal of orthopaedic research : official publication of the Orthopaedic Research Society 24, 2059-2071, doi:10.1002/jor.20273 (2006).

31 Bae, S. H. et al. L-ascorbic acid 2-phosphate and fibroblast growth factor-2 treatment maintains differentiation potential in bone marrow-derived mesenchymal stem cells through expression of hepatocyte growth factor. Growth Factors 33, 71-78, doi:10.3109/08977194.2015.1013628 (2015).

32 Yang, Y. K., Ogando, C. R., Wang See, C., Chang, T. Y. \& Barabino, G. A. Changes in phenotype and differentiation potential of human mesenchymal stem cells aging in vitro. Stem Cell Res Ther 9, 131, doi:10.1186/s13287-018-0876-3 (2018).

33 Pradel, W., Mai, R., Gedrange, T. \& Lauer, G. Cell Passage and Composition of Culture Medium Effects Proliferation and Differentiation of Human Osteoblast-Like Cells from Facial Bone. J Physiol Pharmacol 59, 47-58 (2008).

34 Bigot, A. et al. Replicative aging down-regulates the myogenic regulatory factors in human myoblasts. Biol Cell 100, 189-199, doi:10.1042/Bc20070085 (2008).

35 Sharples, A. P., Al-Shanti, N., Lewis, M. P. \& Stewart, C. E. Reduction of Myoblast Differentiation Following Multiple Population Doublings in Mouse C2C12 Cells: A Model to Investigate Ageing? J Cell Biochem 112, 3773-3785, doi:10.1002/jcb.23308 (2011).

36 Nehlin, J. O., Just, M., Rustan, A. C. \& Gaster, M. Human myotubes from myoblast cultures undergoing senescence exhibit defects in glucose and lipid metabolism. Biogerontology 12, 349-365, doi:10.1007/ s10522-011-9336-5 (2011).

37 Goldstein, S. Replicative senescence: the human fibroblast comes of age. Science 249, 1129-1133 (1990) 
38 Hayflick, L. \& Moorhead, P. S. The serial cultivation of human diploid cell strains. Exp Cell Res 25, 585-621 (1961).

39 DiLoreto, R. \& Murphy, C. T. The cell biology of aging. Mol Biol Cell 26, 4524-4531, doi:10.1091/mbc.E1406-1084 (2015).

40 Hohn, A. et al. Happily ( $n$ )ever after: Aging in the context of oxidative stress, proteostasis loss and cellular senescence. Redox Biol 11, 482-501, doi:10.1016/j.redox.2016.12.001 (2017).

41 Baraibar, M. A. et al. Impaired energy metabolism of senescent muscle satellite cells is associated with oxidative modifications of glycolytic enzymes. Aging 8, 3375-3389, doi:10.18632/aging.101126 (2016).

42 Liu, L. et al. Impaired Notch Signaling Leads to a Decrease in p53 Activity and Mitotic Catastrophe in Aged Muscle Stem Cells. Cell stem cell, doi:10.1016/j.stem.2018.08.019 (2018).

43 Ermolaeva, M., Neri, F., Ori, A. \& Rudolph, K. L. Cellular and epigenetic drivers of stem cell ageing. Nature reviews. Molecular cell biology, doi:10.1038/s41580-018-0020-3 (2018).

44 Zhang, H. et al. $\mathrm{NAD}(+)$ repletion improves mitochondrial and stem cell function and enhances life span in mice. Science 352, 1436-1443, doi:10.1126/science.aaf2693 (2016).

45 Baumann, K. Ageing: The yin and yang of mitochondrial dysfunction. Nature reviews. Molecular cell biology 17, 331, doi:10.1038/nrm.2016.71 (2016).

46 Bernet, J. D. et al. p38 MAPK signaling underlies a cell-autonomous loss of stem cell self-renewal in skeletal muscle of aged mice. Nat Med 20, 265-271, doi:10.1038/nm.3465 (2014).

47 Garcia-Prat, L. et al. Autophagy maintains stemness by preventing senescence. Nature 529, 37-42, doi:10.1038/nature16187 (2016).

48 Price, F. D. et al. Inhibition of JAK-STAT signaling stimulates adult satellite cell function. Nat Med 20, 1174-1181, doi:10.1038/nm.3655 (2014).

49 Sousa-Victor, P. et al. Geriatric muscle stem cells switch reversible quiescence into senescence. Nature 506, 316-+, doi:10.1038/nature13013 (2014).

50 Brack, A. S. et al. Increased Wnt signaling during aging alters muscle stem cell fate and increases fibrosis. Science 317, 807-810 (2007).

51 Conboy, I. M., Conboy, M. J., Smythe, G. M. \& Rando, T. A. Notch-mediated restoration of regenerative potential to aged muscle. Science 302, 1575-1577, doi:DOI 10.1126/science.1087573 (2003).

52 Liu, L. et al. Chromatin Modifications as Determinants of Muscle Stem Cell Quiescence and Chronological Aging. Cell Rep 4, 189-204, doi:10.1016/j.celrep.2013.05.043 (2013).

53 Touat, M., Ileana, E., Postel-Vinay, S., Andre, F. \& Soria, J. C. Targeting FGFR Signaling in Cancer. Clin Cancer Res 21, 2684-2694, doi:10.1158/1078-0432.CCR-14-2329 (2015).

54 Esterhazy, D., King, M. S., Yakovlev, G. \& Hirst, J. Production of reactive oxygen species by complex I (NADH:ubiquinone oxidoreductase) from Escherichia coli and comparison to the enzyme from mitochondria. Biochemistry-Us 47, 3964-3971, doi:10.1021/bi702243b (2008).

55 Mimaki, M., Wang, X., McKenzie, M., Thorburn, D. R. \& Ryan, M. T. Understanding mitochondrial complex I assembly in health and disease. Biochimica et biophysica acta 1817, 851-862, doi:10.1016/j. bbabio.2011.08.010 (2012).

56 Gu, S., Chen, C., Jiang, X. \& Zhang, Z. ROS-mediated endoplasmic reticulum stress and mitochondrial dysfunction underlie apoptosis induced by resveratrol and arsenic trioxide in A549 cells. Chemicobiological interactions 245, 100-109, doi:10.1016/j.cbi.2016.01.005 (2016).

57 Zeeshan, H. M., Lee, G. H., Kim, H. R. \& Chae, H. J. Endoplasmic Reticulum Stress and Associated ROS. Int J Mol Sci 17, 327, doi:10.3390/ijms17030327 (2016). 
58 Le Belle, J. E. et al. Proliferative Neural Stem Cells Have High Endogenous ROS Levels that Regulate Self-Renewal and Neurogenesis in a PI3K/Akt-Dependant Manner. Cell stem cell 8, 59-71, doi:10.1016/j. stem.2010.11.028 (2011).

59 Barquissau, V. et al. Reactive oxygen species enhance mitochondrial function, insulin sensitivity and glucose uptake in skeletal muscle of senescence accelerated prone mice SAMP8. Free Radical Bio Med 113, 267-279, doi:10.1016/j.freeradbiomed.2017.10.012 (2017).

60 Ono, K. \& Han, J. The p38 signal transduction pathway: activation and function. Cell Signal 12, 1-13 (2000).

61 Steinfeld, H., Gerber, P., Wassenaar, T., Castel, V. \& De Haan, C. Livestock's long shadow: environmental issues and options. (Food \& Agriculture Org., 2006).

62 Thornton, P. K. Livestock production: recent trends, future prospects. Philosophical transactions of the Royal Society of London. Series B, Biological sciences 365, 2853-2867, doi:10.1098/rstb.2010.0134 (2010).

63 Post, M. J. Cultured beef: medical technology to produce food. J Sci Food Agric 94, 1039-1041, doi:10.1002/jsfa.6474 (2014).

64 Hocquette, J. F. Is in vitro meat the solution for the future? Meat science 120, 167-176, doi:10.1016/j. meatsci.2016.04.036 (2016).

65 Post, M. J. \& Hocquette, J. F. in New Aspects of Meat Quality (ed Peter P. Purslow) 425-441 (Woodhead Publishing, 2017).

66 Post, M. J. Cultured meat from stem cells: challenges and prospects. Meat science 92, 297-301, doi:10.1016/j.meatsci.2012.04.008 (2012).

67 Purslow, P. P. in Lawrie's Meat Science (Eighth Edition) (ed Fidel Toldra') 49-97 (Woodhead Publishing, 2017).

68 Listrat, A. et al. How Muscle Structure and Composition Influence Meat and Flesh Quality. TheScientificWorldJournal 2016, 3182746, doi:10.1155/2016/3182746 (2016).

69 Kadim, I. T., Mahgoub, O., Baqir, S., Faye, B. \& Purchas, R. Cultured meat from muscle stem cells: A review of challenges and prospects. J Integr Agr 14, 222-233, doi:Doi 10.1016/S2095-3119(14)60881-9 (2015).

70 Majka, S. M. et al. Analysis and isolation of adipocytes by flow cytometry. Methods in enzymology 537, 281-296, doi:10.1016/B978-0-12-411619-1.00015-X (2014).

71 Ostrovidov, S. et al. Skeletal muscle tissue engineering: methods to form skeletal myotubes and their applications. Tissue engineering. Part B, Reviews 20, 403-436, doi:10.1089/ten.TEB.2013.0534 (2014).

72 Pawlikowski, B., Vogler, T. O., Gadek, K. \& Olwin, B. B. Regulation of skeletal muscle stem cells by fibroblast growth factors. Developmental dynamics : an official publication of the American Association of Anatomists 246, 359-367, doi:10.1002/dvdy.24495 (2017).

$73 \mathrm{Ge}, \mathrm{X}$., Zhang, Y. \& Jiang, H. Signaling pathways mediating the effects of insulin-like growth factor-I in bovine muscle satellite cells. Mol Cell Endocrinol 372, 23-29, doi:10.1016/j.mce.2013.03.017 (2013).

74 Lawlor, M. A. et al. Dual control of muscle cell survival by distinct growth factor-regulated signaling pathways. Mol Cell Biol 20, 3256-3265 (2000).

75 Zong, C. S. et al. Mechanism of STAT3 activation by insulin-like growth factor I receptor. J Biol Chem 275, 15099-15105, doi:10.1074/jbc.M000089200 (2000).

76 Yue, P. \& Turkson, J. Targeting STAT3 in cancer: how successful are we? Expert Opin Investig Drugs 18, 45-56, doi:10.1517/13543780802565791 (2009). 
77 Tivey, H. S. et al. Small molecule inhibition of p38 MAP kinase extends the replicative life span of human ATR-Seckel syndrome fibroblasts. The journals of gerontology. Series A, Biological sciences and medical sciences 68, 1001-1009, doi:10.1093/gerona/gls336 (2013). 



\section{Summary}

how $12 \pi+5$ 

Meat is important for a balanced human food system. It provides the macronutrients, micronutrients and lots of key elements in the diet of man, which is essential for good health. Meat demand is predicted to substantially increase due to the global population growth and meat consumption increase in many developing countries. However, the traditional animal agriculture is not sustainable. The expansion of livestock production puts pressure on natural resources, animal welfare, human and livestock health. Cultured meat is produced by obtaining stem cells from the donor animals to culture muscle tissue in vitro for meat consumption. It is a technology, which potentially can solve major upcoming problems by traditional livestock.

Satellite cells (muscle stem cells) are one of the promising cell sources for cultured meat production. However, the major focus of satellite cell research to date has been on human and mouse cells for regenerative medicine. The lack of high purity livestock satellite cells from farm animals limit the research on cultured meat. In this thesis, we characterized and isolated highly purified satellite cells from pigs and cows. In these highly purified cells, we found that long-term in vitro cultivation induced defects in proliferation and differentiation. To understand the phenomenon, we checked several important mediator pathways during differentiation and in vitro aging. Results indicate that long-term culture of satellite cells shares features with in vitro cell aging. To systematically investigate the reasons for loss of function of long-term cultured myoblast cells, we performed high throughput label-free quantitative proteomics. Bioinformatics analysis confirmed that the subculture of myoblast cells resembles the effect of aging.

In chapter 2, we characterized pig muscle satellite cells and provided basic information for further utilization of these cells. We cloned the full-length cDNA sequence of porcine PAX7 and characterized the numbers of satellite cells located in various pieces of skeletal muscle. A fluorescence-activated cell sorting (FACS) based method was established to isolate highly purified pig satellite cells. Using this method, we isolated pig satellite cells and found that they lost their stem cell morphology, differentiation potential, and ability to repair muscle injury in vivo after prolonged in vitro culturing.

Chapter 3, reports on a study where we set up a FACS strategy to enrich bovine satellite cells. We found that p38-MAPK signaling is activated and PAX7 expression is gradually lost during satellite cell proliferation. The p38 inhibitor (SB203580) treatment maintained PAX7 expression but inhibited the fusion of satellite cells in a concentrationdependent way in short-term incubation. The mechanism of p38 inhibition was confirmed by inhibiting canonical p38 signaling, i.e. HSP27. Long-term culture with an appropriate concentration of p38i enhanced the proliferation and PAX7 expression, while the differentiation capacity recovered and was enhanced compared to vehicle control. These studies indicate that bovine satellite (stem) cell maintenance depends on cell purity and p38 MAPK signaling. Inhibition of p38 MAPK signaling is a promising strategy to facilitate large scale cell expansion of primary cells for tissue engineering and cultured meat purposes. 
In chapter 4, we showed that STAT3 signal was activated in cultured bovine satellite cells. Inhibition of JAK2 (JAK2i) or STAT3 (STAT3i) treatment inhibited instead of promoted myoblast cells proliferation. In accordance, JAK2 $i$ and STAT3i did not affect the expression of the stemness gene PAX7 in bovine myoblast cells and inhibited the differentiation process. In long-term culture of bovine satellite cells, pharmacological inhibition of JAK2 and STAT3 at optimal concentrations also did not affect proliferation, stemness or differentiation. Further western blotting indicated that the JAK2-STAT3 signal is not the reason for the long-term culture defects in bovine satellite cells.

We showed several signal pathways changes in long-term culturing (as a model for aging) and in differentiation by Western blot in chapter $\mathbf{5}$. The two processes showed similar expression profiles in p38-MAPK signaling. The JAK2-STAT3 signal pathway was up-regulated during differentiation but remained stable in long-term culture. Both ERK and Akt signal were down-regulated when the cells were confluent and then increased during differentiation. However, ERK signal kept decreasing whereas Akt signal remained increased during long-term culture.

In chapter 6, we used label-free high-throughput proteomics to identify the proteins changes in early and late passages. Further gene ontology (GO) and Kyoto Encyclopedia of Genes and Genomes (KEGG) pathways analyses showed that proteins up-regulated in late passage are involved in cell-cell adhesion, muscle contraction, mitochondrial electron transport, NADH to ubiquinone and cell redox homeostasis. Early passages showed high expression of proteins involved in DNA replication, protein folding, translational initiation, DNA repair, fibroblast growth factor receptor signaling pathway, p53 regulation, proteasome- ubiquitin-dependent proteolysis, telomere maintenance via recombination and somatic stem cell population maintenance. These signals corelate with the aging signal of MuSCs in vivo and with relicative senescence signals in vitro. The proteomics data indicate that the dysfunction of satellite cells during longterm passage resembles the effect of aging.

In conclusion, FACS purification of bovine and pig satellite cells using CD29 and CD56 as positive markers increase the stem cell population. After long-term in vitro culturing, the satellite cells lose their stem cell identities and potential to differentiate. The defects of subculture satellite cells are not due to myoblast differentiation into myotubes as several main signaling pathways are differently expressed in the two biological processes. Preventing the cell to differentiate in early stage myocytes/myoblasts is not sufficient to maintain the stemness of satellite cells during long-term passaging. Long-term culture of myoblast cells resembles the effect of aging. Inhibiting or rescuing aging signals may help to bring large scale bovine muscle cell culture for cultured beef applications closer to reality. 


\section{Samenvatting}

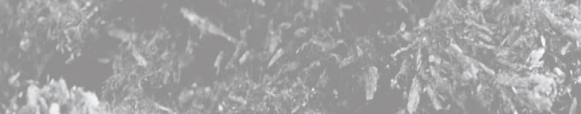

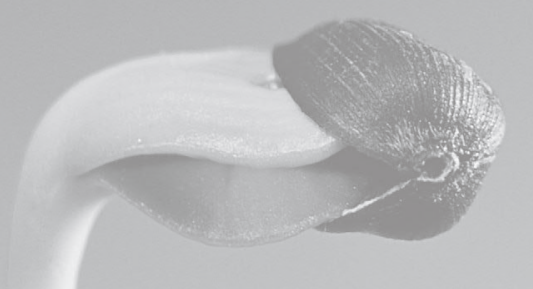



Vlees is belangrijk in het dieet van een mens, het biedt de macronutriënten, micronutriënten en veel belangrijke elementen, die essentieel zijn voor een goede gezondheid. Er wordt voorspeld dat de vraag naar vlees zal toenemen als gevolg van de wereldwijde bevolkingsgroei en de toename van de vleesconsumptie in veel ontwikkelingslanden. De traditionele veeteelt is echter niet duurzaam. De uitbreiding van de veeteelt zorgt voor druk op natuurlijke hulpbronnen, dierenwelzijn, gezondheid van mens en dier enzovoort. Gekweekt vlees wordt geproduceerd door stamcellen van de donordieren in vitro te kweken voor spierweefsel voor vleesconsumptie. Het is een technologie die de potentie heeft om belangrijke aankomende problemen van traditionele veeteelt gedeeltelijk op te lossen.

Satellietcellen (spierstamcellen) zijn een veelbelovende cellulaire bron voor gekweekte vleesproductie. Het onderzoek van satellietcellen is tot nu toe echter vooral gericht op mens en muis ten behoeve van regeneratieve geneeskunde. Het gebrek aan varkens- of koeien-satellietcellen met een hoge zuiverheid, beperkte het onderzoek naar gekweekt vlees. In dit proefschrift hebben we sterk gezuiverde satellietcellen in varken en koe geïsoleerd en gekarakteriseerd. In deze sterk gezuiverde celpopulaties van varkensen rundermyoblasten zagen we dat in vitro kweken leidde tot vermindering van proliferatie en differentiatie. Om te begrijpen hoe dit gebeurt, hebben we verschillende belangrijke signaaltransductie kanalen gecontroleerd tijdens differentiatie en in vitro veroudering. De resultaten toonden dat de lange termijn kweek van satellietcellen sterke overeenkomst vertoont met in vitro cel veroudering. Om dit meer systematisch te onderzoeken, hebben we ongelabelde kwantitatieve proteomics met hoge doorvoercapaciteit uitgevoerd.

In hoofdstuk 2 hebben we satellietcellen uit varkensspier gekarakteriseerd en basisinformatie verstrekt voor verder gebruik van deze cellen. We hebben de volledige cDNA-sequentie van varkens PAX7 gekloneerd en de hoeveelheid satellietcellen die zich in verschillende skeletspieren bevinden, gekwantificeerd. Een op fluorescentiegeactiveerde cel sortering (FACS) gebaseerde methode werd gebruikt om varkenssatellietcellen van hoge zuiverheid te isoleren. We zagen dat satellietcells, die op deze manier geisoleerd werden, na langdurig in vitro kweken, hun morfologieen vermogen om te differentiëren in spier en spierletsel in vivo te herstellen, verloren.

Hoofdstuk 3, beschrijft een onderzoek waarin we een FACS-strategie hebben opgesteld om de satellietcellen van runderen op te zuiveren. We hebben gevonden dat tijdens de proliferatie van satellietcellen, p38-MAPK-signalering wordt geactiveerd en PAX7expressie geleidelijk verdwijnt. Tijdens de vroege groei van satellietcellen, werd dmv een p38-remmer (P38i, SB203580), concentratieonafhankelijk de expressie van PAX7 gehandhaafd, maar werd de fusie (differentiatie) geremd Het mechanisme van p38-remming werd bevestigd door het remmen van klassieke p38-signalering, d.w.z. fosforylering van HSP27. Langdurige kweek met een optimale concentratie van p38i verhoogde de proliferatie en PAX7-expressie, terwijl de differentiatiecapaciteit herstelde en verbeterd was in vergelijking met vehikel controle. Deze studies geven aan 
dat optimalisatie van runder satellietcel kweek afhankelijk is van celzuiverheid en o.a. van p38 MAPK-signalering. Remming van p38 MAPK-signalering is een veelbelovende strategie om grootschalige cel-expansie van primaire cellen voor tissue-engineering en kweekvlees doeleinden te bevorderen.

In hoofdstuk 4 toonden we aan dat STAT3-signaal geactiveerd was in gekweekte runder satellietcellen. Remming van JAK2 (JAK2i) of STAT3 (STAT3i) in vroege stadia van celkweekhad een remmend i.p.v. stimulerend effect op de proliferatie van myoblastcellen, het vervolg stadium van satelliet cellen. JAK2i en STAT3i hadden ook geen invloed op de PAX7-expressie van runder myoblastcellen, en remde het differentiatieproces. Ook in langdurige kweek had ge-optimaliseerde farmacologische remming van JAK2 en STAT3 geen invloed op de proliferatie, de stamcel identiteit, of differentiatie van de runder-satellietcellen. Ook Western blot geeft aan dat het JAK2-STAT3-signaal niet de reden is voor de lange termijn kweekdefecten in rundersatellietcellen.

Met behulp van Western Blot analyse toonden we verschillende veranderingen in signaaltransductie paden gedurende lange termijn kweek (als een model voor veroudering) en in differentiatie van satellietcellen hoofdstuk 5. De twee processen vertoonden vergelijkbare expressie profielen in p38-MAPK-signalering. De JAK2-STAT3signaalroute was tijdens differentiatie opwaarts gereguleerd, maar bleef stabiel in een lange termijn kweek. Zowel ERK-als Akt-activatie nam af bij het bereiken van confluentie om vervolgens tijdens differentiatie toe te nemen. Tijdens langdurige kweek, bleef het ERK-signaal echter dalen, terwijl het Akt-signaal bleef stijgen.

In hoofdstuk 6 gebruikten we ongelabelde high-throughput proteomics om de veranderingen in eiwitten in vroege en late passages van runder satellietcellen te identificeren. Verdere genontologie (GO) en Kyoto Encyclopedia of Genes en Genomes (KEGG) -pathway-analyses lieten zien dat eiwitten die in late passage omhoog gereguleerd zijn, betrokken zijn bij cel-celadhesie, spiercontractie, mitochondriaal elektronentransport, NADH naar ubiquinon en cel-redox-homeostase. Vroege passages vertoonden hoge expressie van eiwitten die betrokken zijn bij DNA-replicatie, eiwitvouwing, translationele initiatie, DNA-reparatie, fibroblast groeifactorreceptor signaleringsroute, p53-regulering, proteasoom-ubiquitine-afhankelijke proteolyse, telomere handhaving via recombinatie en populatie onderhoud van somatische stamcellen. Deze signalen correleren met het verouderingssignaal van muizen satellietcellen in vivo en met verouderingssignalen in vitro. De proteomics-gegevens wijzen erop dat de disfunctie van satellietcellen tijdens langdurige kweek vergelijkbaar is met de veroudering van cellen.

Concluderend, FACS-zuivering van runder- en varkens-satellietcellen met behulp van CD29 en CD56 als positieve markers verhoogt de stamcelpopulatie door verhoogde zuiverheid. Na langdurig in vitro kweken verliezen de satellietcellen hun stamcelidentiteit en differentiatiepotentieel. De defecten van satellietcellen 
tijdens kweek zijn niet het gevolg van myoblasten differentiatie in myotubes omdat verschillende transductie paden worden geactiveerd in de twee verschillende biologische processen. Voorkomen van vroegtijdige differentiatie van satellietcellen in myocyten / myoblasten is niet voldoende om de stamcel identiteit van satellietcellen te behouden tijdens lange termijn kweek. Langdurige kweek van myoblastcellen lijkt op het effect van veroudering. Het remmen van verouderingssignalen kan helpen om een grootschalige runder-spiercelcultuur voor kweekvlees toepassingen te realiseren. 



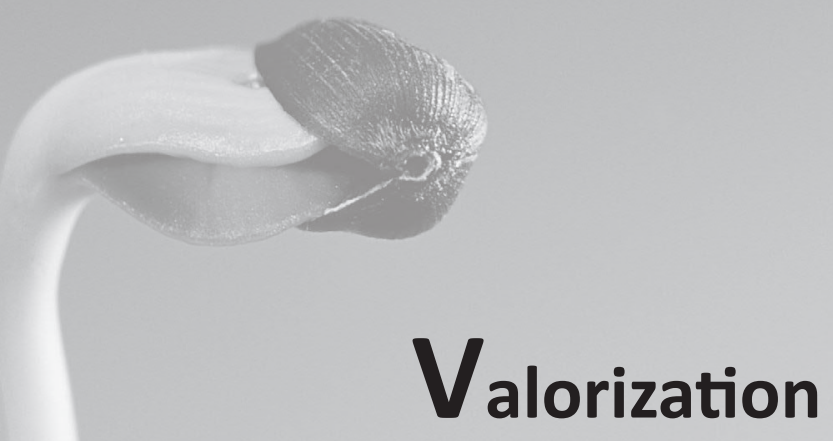

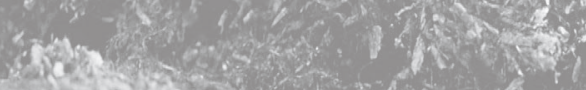



Humans are omnivores, eating plants and animals. Meat remains important in the human diet for many consumers in both developed and developing countries. However, meat demand is predicted to increase substantially due to global population growth and meat consumption increase in many developing countries, including China, India and Brazil and South Africa.

If that prediction turns into reality, the production of meat will become an important concern as the environmental impact of meat production is high. Cultured meat is produced by obtaining stem cells from donor animals to culture muscle and fat tissue in vitro for meat consumption. It is a technology, which has the potential to partially solve major upcoming problems with traditional livestock. My thesis mainly focuses on characterization and isolation of highly purified porcine and bovine satellite cells as cell sources for cultured meat. Since satellite cells lose proliferation and differentiation ability during in vitro culture, the reasons and solutions for this loss were also assessed. In this chapter, I will discuss the social, economic, scientific relevance of the thesis.

\section{Social and economic relevance}

Expansion of livestock meat production causes problems such as deforestation and land degradation, greenhouse gas emission, fresh water use and loss of biodiversity. Animal welfare and public health are also societal concerns associated with traditional livestock. By 2020, the global market for protein meat analogues such plant-based substitutes and cultured meat, is estimated to $\$ 46$ billion (GBPf33 billion), with significant growth potential. The global cultured meat market for the normal scenario is expected to be valued at USD 15.5 Million in 2021 and is projected to grow at a CAGR of $4.0 \%$, to reach USD 20.0 Million by 2027 . The North American region is projected to account for the largest share in the global cultured meat market because of a large meat-eating population, growing investment and research on cultured meat, and the presence of cultured meat manufacturers. The markets in Europe, Middle East \& Africa, South America and Asia Pacific region are also expected to grow at fastest growth rate. The growth in cultured meat market is also influenced by the presence of major players such as Mosameat (the Netherlands), Memphis Meat (United States), Just, Inc. (United States), Supermeat (Israel) Integriculture Inc. (Japan), etc. The numbers of these companies are also growing faster.

Cultured meat has social and economic benefits. Several life cycle analysis studies have estimated that cultured meat requires smaller quantities of agricultural inputs and land. Greenhouse gas emission (GHG) would be less in cultured meat compared with traditional livestock. However, the energy use would be more or less in cultured meat depending on different calculating methods. Those estimates are sometimes contradictory because industrialization of cultured meat has not occurred yet and assumptions need to be made. It is clear however that further technological development is still needed to realise the full benefits of cultured meat for society and environment. 
It is prerequisite to characterize and isolate highly purified porcine and bovine satellite cells as cell sources for cultured meat. Muscle tissue has dozens of cell types. The satellite cell is the most important cell type for cultured meat since it can differentiate into muscle with high efficiency in vitro. By isolation of highly purified satellite cells, one avoids inefficient (co)culture of cells that do not have muscle formation abilities. Loss of stemness of satellite cells in culture was also investigated and we have established some solutions for maintaining stemness during culture. Maintaining stemness results in a higher yield of cells from a single biopsy and therefore reduces the number of biopsies from live animals needed. Increasing the number of cell doublings per batch also reduces the number of transfers from small culture systems to larger systems, making the whole process more resource efficient and cost-effective.

\section{Scientific relevance}

The work presented in this thesis was primarily focused on scientific understanding of pig and bovine satellite cells. We unveiled the full-length cDNA sequence of porcine Paired box 7 (PAX7), the most important satellite cell marker. We developed fluorescence-activated cell sorting (FACS) strategy for isolating highly purified satellite cells from farm animals (like pig and cow), thus promoting satellite cell research in farm animals. The cultured meat technology will also greatly benefit from the presence of highly purified satellite cells as the cell source.

Satellite cells from mouse, dog and human lose their stemness after culturing in vitro. We observed similar results in pig and bovine satellite cells. We found that interfering with the p38-MAPK signal supports long-term culture of bovine muscle stem cells. This example brings the future of culturing functional satellite in large scale closer. Western blots and especially proteomics results indicated that the subculture of myoblast cells resembles the effect of aging. The proteomics data increase understanding of the protein expression in satellite cells leading to aging upon long-term culture. This may lead to hitherto not explored intervention in this aging process.

The aging effects of long-term culture are similarly occurring in other mammalian cells, such as fibroblast cells, endothelial cells, vascular smooth muscle cells and mesenchymal stem cells. In the future, we can also draw lessons from those cell types to fully understand the aging process during long-term culture in vitro. Likewise, our results may in part be translated to aging in those cells.

Large animals (like pigs) have many advantages in modeling human diseases due to their similar anatomic and physiological features to human beings. The work in this thesis will facilitate the production of large animal muscle organoids for drug testing and for non-food tissue engineering, for instance to repair large muscle defects for medical applications. Careful characterization of the large animal skeletal muscle stem cells (satellite cells) will also facilitate the generation of large animal models of skeletal muscle disease. For example, the swine Duchenne muscular dystrophy (DMD) model 
recapitulates human symptoms better than the mouse model.

\section{Beyond the thesis}

In this work we characterized and isolated highly purified satellite cells from livestock (pig and bovine) as cell sources for cultured meat. We also investigated the reasons for loss of stemness during long-term culture and solutions to prevent these defects. Future work may focus on aging pathways. Preventing aging will facilitate large scale production of satellite cells, thus allowing the development of a cultured meat product with a higher percentage of muscle proteins. These studies on satellite cells can also be translated to other cell types in meat such as adipocytes, which in turn will eventually lead to successful development of a "real steak". 



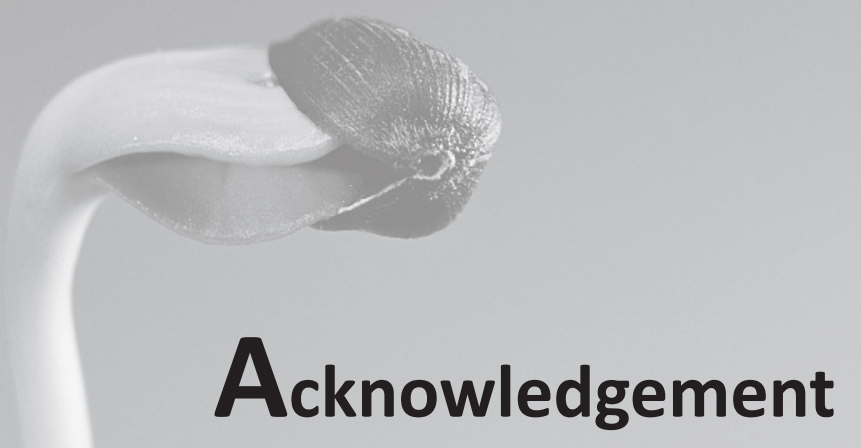

han $14 x+2$

Acknowledgement

an
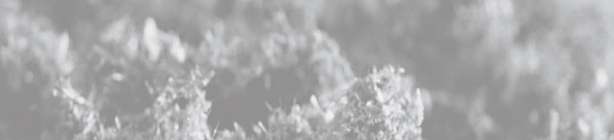

I want to extend my heartfelt gratitude to my supervisor, Professor Mark Post. His conscientious academic spirit and modest, open-minded personality inspire me both in academic study and daily life. I was quite grateful to him for working on the thesis over the Christmas holidays. I appreciate his contributions of time and ideas to make my work productive and stimulating. I would like to thank him for encouraging my research and for allowing me to grow as a research scholar.

I would also like to express my deepest appreciation to my co-supervisor, Professor Guanghong Zhou. His deep insights helped me at various stages of my research during the last 7 years. He sent me to learn new technologies for the interdisciplinary project and encouraged me to study abroad for a long time, which make me understand the discipline theory system and learned a lot of useful skills. He also encouraged and helped me to promote the cultured meat research in China.

I'm also extremely grateful to my supervisor, professor Ping $\mathrm{Hu}$, for guiding me as a joint $\mathrm{PhD}$ student in her lab. Her valuable suggestions, comments and guidance encourage me to learn more day by day. She gives me much help and advice during the whole process of my first paper. The discussion, ideas, and feedback have been absolutely invaluable. I am also indebted towards her for her generosity, selfless support for the three years in Shanghai.

I cannot express enough thanks to my committee for their continued support and encouragement: M.C. Harmsen, E.C.M. Mariman, C. Reutelingsperger, C. Neuhoff and R. Langen. Thanks for generously offering their time and guidance throughout the preparation and review of this document. They have each provided helpful feedback. This project would not be nearly as good without their help.

I'd like to thank my fellow graduate students, research technicians, collaborators, and the multitude of undergraduates who contributed to this research In Mark's lab. Thanks to Geertje for helping me familiarize the lab and look for the equipment all over the university and hospital. I would also like to thank the secretary office Bianca and Vivian. They help me handle lots of routine business. Thanks also to Daniel, Nynke and Mick for suggestions and performance to improve the thesis. I also thank Ruud, Chantal, Anon, Frea, Günther, Jonathan, Choi, Lea, Tobias, Jeroen, Rada, Vincent, Sophie, Franco, Natalie, Stan and Carolina for sharing their ideas and helpful suggestions for my work. Special thanks to Ronny from M4I Institute for his help in proteomics. In the end, I would also like to thank my best Chinese friends Ying Gong and many others in Maastricht. I really had a good time with all of them.

I also had great pleasure of working with Ping's lab members in Shanghai. I very much appreciate Julieta for teaching me the experiment skills and scientific rules. I really appreciate Yan Liu, Sheng Li and Wenjun Yang. Their willingness to help and useful experiment skills always made my experiment easier to move on. l'd like to thank my fellow graduate students, Fu Xin, Jie Yin, Hengjiang Guo, Lele Yang, Bo Xu, Fei Wang, 
Hongye Wang, Di Pan. They have so many valuable suggestions and we shared ideas and experiments tips together.

Also, I would like to express my sincere gratitude to all the professors and teachers in Nanjing. I am grateful to professor Xinglian Xu. She is amiable and gives a lot of important suggestions and advice. I'd also like to extend my gratitude to professor Chunbao Li. He was always willing to help me both academically and officially. Many thanks to professors and teachers who have taught me, like Xiaohong Chen, Mingsheng Dong, Wei Li, Juqing Wu, Wangang Zhang, Minyi Han, Keping Ye and many other teachers. Their instructions have helped broaden my horizon and their enlightening teaching has provided me with a solid foundation to accomplish this thesis. Special thanks to professor Huhu Wang for guiding me to start my scientific career. I also had great pleasure of working with all my friends like Tong Xing, Wang Guangyu, Lin Chen, Rui Liu, Chong Xie and many others in Meat Center and Nanjing agricultural university. I also thank all the departmental staff like Yun Bai, Xiaobo Yu and many others for helping me during these years of my study both academically and officially.

Finally, I would especially like to thank my parents and parents-in-law for their love and encouragement. They helped a lot in taking care of our family during these 7 years of my PhD. In particular, I would like to thank my wife, Meichao has been extremely supportive of me throughout this entire process and has made countless sacrifices to help me get to this point. Without such a team behind me, I doubt that I would be in this place today. 





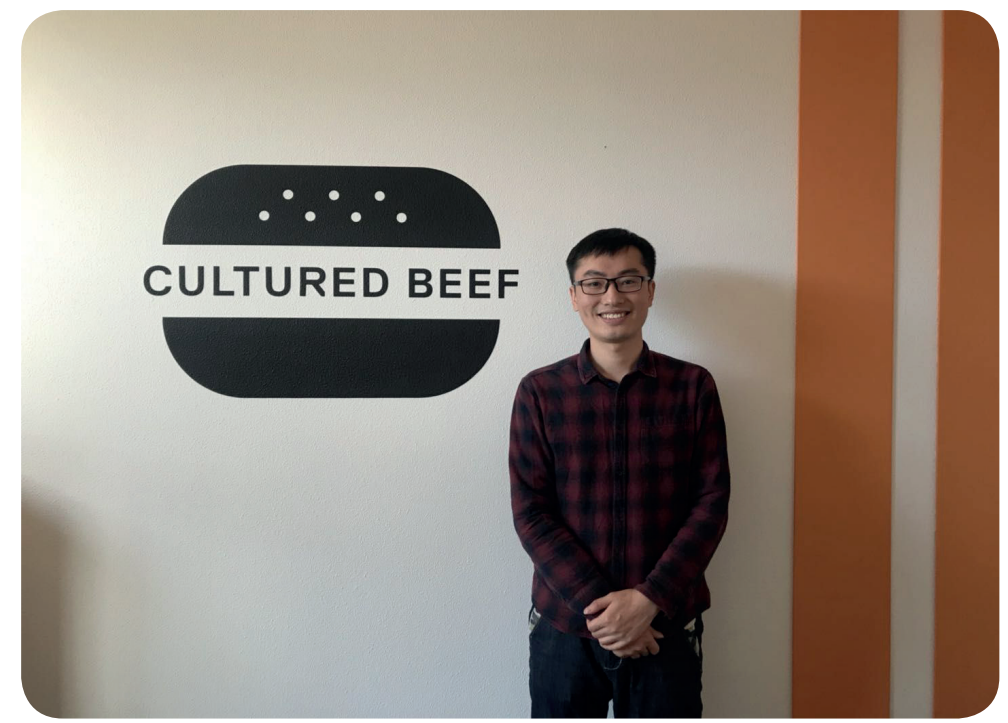

\section{About the author:}

Shijie Ding was born on February $24^{\text {th }} 1990$ in Dafeng, China. In 2008, he completed his secondary school in Jiangsu Yancheng Middle School. He studied Food Science and Technology at Nanjing Agricultural University and obtained his bachelor degree in 2012. He became a master student right after completing his bachelor degree. In 2014, he became a PhD candidate. He studied spoilage organisms in sliced hams in Prof. Zhou's lab at Nanjing Agricultural University from Sep.2012- Nov.2013. Then he, under the advice of Guanghong Zhou, changed his research topic to cultured meat. He moved to Shanghai to study the cell biology as the Visiting Ph.D student under the supervision of Prof. Ping Hu at Institute of Biochemistry and Cell Biology, Shanghai Institutes for Biological Sciences, Chinese Academy of Sciences. He learned stem cell related techniques and started to isolate and culture pig muscle stem cells for cultured meat purpose during the 3 years in Shanghai. After that, he applied for the Individual Visits grants (from Royal Netherlands Academy of Arts and Sciences) and joint PhD student scholarship (from China Scholarship Council) to study cultured meat at Maastricht University under the supervision of Prof. Mark Post. In 2017, he got the opportunity to apply a PhD-position at the lab of Prof. Mark Post. His project is about maintaining the stemness of satellite cells during long-term culture for cultured meat purpose. 



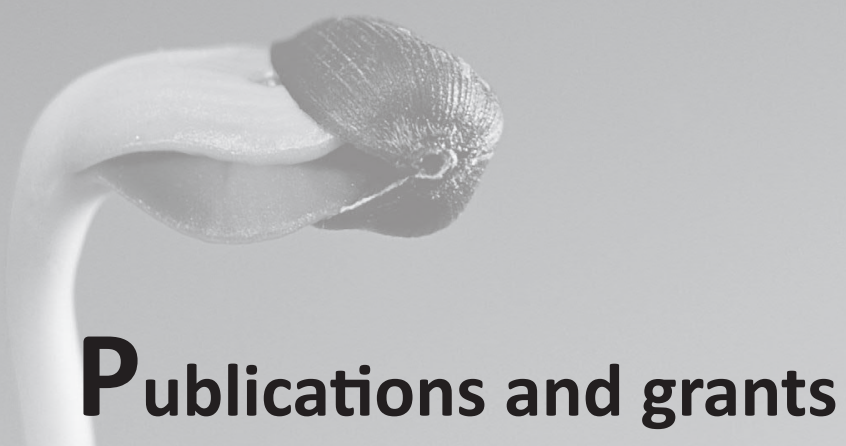

ha 



\section{Papers:}

1. Ding, S. J., Swennen, G. N. M., Messmer, T., Gagliardi, M., Molin, D. G. M., Li, C. B., Zhou, G. H., and Post, M. J. (2018) Maintaining bovine satellite cells stemness through p38 pathway. Sci Rep-Uk 8 (IF 2018: 4.122)

2. Ding, S., Wang, F., Liu, Y., Li, S., Zhou, G., and Hu, P. (2017) Characterization and isolation of highly purified porcine satellite cells. Cell Death Discov 3, 17003 (IF: NA)

3. Ding, S., Li, C., Cheng, N., Cui, X., Xu, X., and Zhou, G. (2015) Redox Regulation in Cancer Stem Cells. Oxid Med Cell Longev 2015, 750798 (IF 2015: 3.516)

4. Wang, H. H., Ding, S. J., Wang, G. Y., Xu, X. L., and Zhou, G. H. (2013) In situ characterization and analysis of Salmonella biofilm formation under meat processing environments using a combined microscopic and spectroscopic approach. Int J Food Microbiol 167, 293-302 (IF 2013: 3.155)

5. Wang, H. H., Ding, S. J., Dong, Y., Ye, K. P., Xu, X. L., and Zhou, G. H. (2013) Biofilm Formation of Salmonella Serotypes in Simulated Meat Processing Environments and Its Relationship to Cell Characteristics. J Food Protect 76, 1784-1789 (IF 2013: 1.797)

\section{Abstracts:}

1. Shijie Ding. Ex Vivo Expansion of Bovine Satellite Cells. The Third International Conference on Cultured Meat, Maastricht, The Netherlands, 2017

2. Shijie Ding. p38 mediates differentiation of satellite cells into myoblasts. The Dutch Physiology Society meeting- 33rd Dutch Physiology Days, Landgoed ISVW, The Netherlands, 2017.

3. Shijie Ding. Proteomics of bovine muscle stem cells aging. The Fourth International Conference on Cultured Meat, Maastricht, The Netherlands, 2018

\section{Oral presentations:}

Shijie Ding. p38 mediates differentiation of satellite cells into myoblasts. The Dutch Physiology Society meeting- 33rd Dutch Physiology Days, Landgoed ISVW, The Netherlands, 2017. 


\section{Poster Presentation:}

1. Shijie Ding. Ex Vivo Expansion of Bovine Satellite Cells. The Third International Conference on Cultured Meat, Maastricht, The Netherlands, 2017

2. Shijie Ding. Proteomics of bovine muscle stem cells aging. The Fourth International Conference on Cultured Meat, Maastricht, The Netherlands, 2018

\section{Scholarship and funding:}

The Individual Visits grants from China Exchange Programme offered by Royal Netherlands Academy of Arts and Sciences (KNAW). 2017

The joint PhD student scholarship under the State Scholarship Fund offered by China Scholarship Council (CSC). 2017-2018 